\title{
Evaluation of heavy duty diesel engines regulated emissions based on variation of fuel properties by use of additives
}

Robert Ray Tincher

West Virginia University

Follow this and additional works at: https://researchrepository.wvu.edu/etd

\section{Recommended Citation}

Tincher, Robert Ray, "Evaluation of heavy duty diesel engines regulated emissions based on variation of fuel properties by use of additives" (2007). Graduate Theses, Dissertations, and Problem Reports. 4343. https://researchrepository.wvu.edu/etd/4343

This Thesis is protected by copyright and/or related rights. It has been brought to you by the The Research Repository @ WVU with permission from the rights-holder(s). You are free to use this Thesis in any way that is permitted by the copyright and related rights legislation that applies to your use. For other uses you must obtain permission from the rights-holder(s) directly, unless additional rights are indicated by a Creative Commons license in the record and/ or on the work itself. This Thesis has been accepted for inclusion in WVU Graduate Theses, Dissertations, and Problem Reports collection by an authorized administrator of The Research Repository @ WVU. For more information, please contact researchrepository@mail.wvu.edu. 
Evaluation of Heavy Duty Diesel Engines Regulated Emissions Based on Variation of Fuel Properties by Use of Additives

\author{
Robert Ray Tincher \\ Thesis submitted to the \\ College of Engineering and Mineral Resources \\ at West Virginia University \\ in partial fulfillment of the requirements \\ for the degree of \\ Master of Science \\ in \\ Mechanical Engineering \\ Gregory J. Thompson, Ph.D., Chair \\ Nigel N. Clark, Ph.D. \\ Mridul Gautam, Ph.D. \\ Department of Mechanical Engineering
}

Morgantown, West Virginia
2007

Keywords: Diesel Engines, Fuel Properties, Biodiesel, Additives

Copyright 2007 Robert Ray Tincher 


\title{
ABSTRACT \\ Evaluation of Heavy Duty Diesel Engines Regulated Emissions Based on Variation of Fuel Properties by Use of Additives
}

\author{
Robert Ray Tincher
}

Heavy-duty diesel engines exhaust emissions contribute to the ambient air quality; therefore, the United States Environmental Protection Agency (EPA) and California Air Resources Board (CARB) have created stringent emissions standards. Since the implementation of these standards in the early 1970s, overall engine and fuel technology improvement have created a significant reduction in emissions. Many different factors, such as fuel composition, properties, additives, and engine technology, influence regulated emissions constituents.

This study was completed in order to evaluate engine emissions from several different diesel fuels with and without cetane improving additives on recent and early production electronically controlled heavy duty diesel engines (HDDE). Both petroleum-based diesel and biodiesel were tested to compare the advantages and disadvantages of each fuel type. Five engines - 1991 Detroit Diesel Corporation S60, 1992 Detroit Diesel Corporation S60, 1992 rebuilt Detroit Diesel S60, 1999 Cummins ISM 370, and 2004 Cummins ISM 370 were used to represent a wide spectrum of engine technologies. The chosen engines were tested using the Federal Test Procedure (FTP) and Supplemental Emissions Test (SET) dynamometer cycles. In order to determine the effectiveness of each fuel additive, it was necessary to investigate the NOx production as a function of the brake specific power for each engine since NOx emissions are the primary concern from HDDE.

It was found that the additives had the most impact on reducing emissions in the early production Detroit Diesel Corporation engines, and there was a negative effect on the recent production Cummins engines. It was also found that the additives reduced NOx up to about 250 brake horsepower, but increased NOx production above this point. The older technology DDC S60 engines showed an average reduction of $6.5 \%$ for $\mathrm{NOx}$ and $\mathrm{NO}_{2}$ during low power operation, but showed an average increase of $2 \%$ while in high power operation. The other emissions constituents of THC, TPM, and CO have an average reduction of $10 \%, 3 \%$ and $15 \%$, respectively. The Cummins engines showed an average $\mathrm{NOx}$ and $\mathrm{NO}_{2}$ reduction of $5 \%$ for low power operation, but quickly increased NOx production up to $6 \%$ during high power operation. The emissions constituents of THC, TPM and CO show an average reduction of 20\%, 25\% and $20 \%$, respectively for the newer technology engines. 


\section{ACKNOWLEDGEMENTS}

I would like to take this opportunity to thank everyone who has helped me become a successful young engineer. First and foremost, I would like to thank Dr. Gregory Thompson for giving me the option to complete my Masters degree in one year. The help and guidance I received from Dr. Thompson is something that has helped me to build my young professional career, and for this I will be forever grateful. I would also like to thank my committee members, Dr. Nigel Clark and Dr. Mridul Gautam, for imparting invaluable knowledge that helped me complete my Masters.

A special acknowledgement goes to Bradley Ralston for educating me about the WVU CAFEE and emissions testing, and also helping me to start my young graduate career on the right foot. I would also like to thank Tom Spencer, David Estep, and Byron Rapp for all the help they provided during my thesis work. The time and energy John Nuszkowski has spent reviewing my data and the advice he has given me has proven to be invaluable to my work. I am very grateful to Wesley Hardin, Michael Ursic, and Kevin Flaim for helping me through all the long hours in the test cell. Without these three friends, graduate school would not have been nearly as enjoyable.

Without the love and support of my parents none of this would have been possible in the first place, and for this I would like to dedicate my Masters work to them. Last but not least, I would like to thank my wonderful girlfriend, Rachel, for continually believing in me and supporting me through all the hours of thesis work I had to endure. 


\section{Table of Contents}

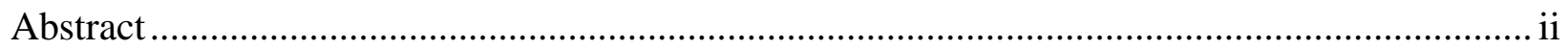

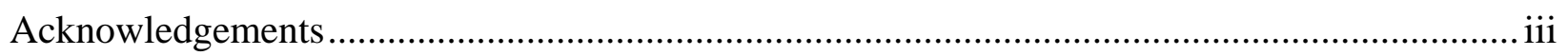

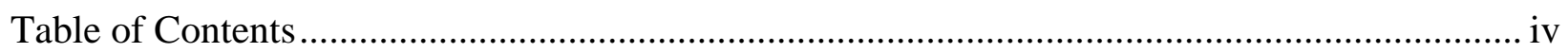

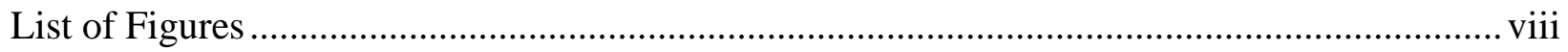

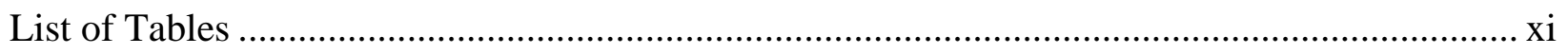

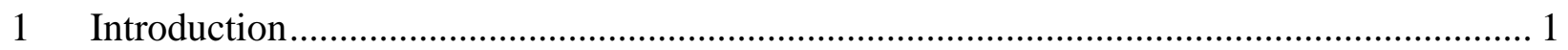

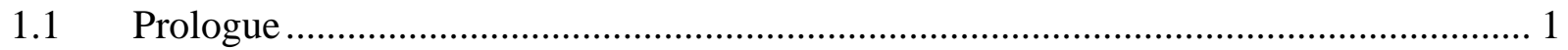

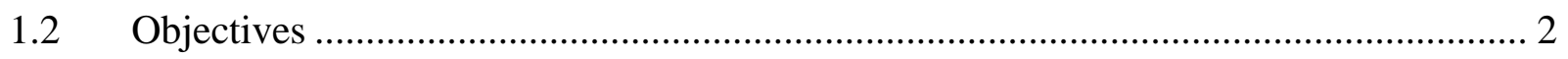

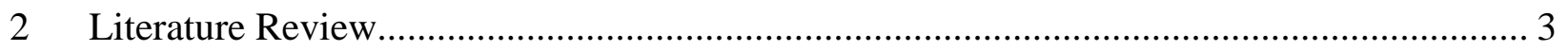

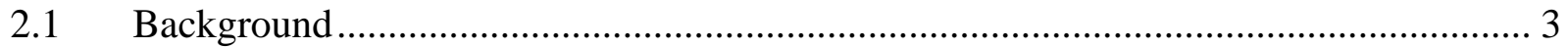

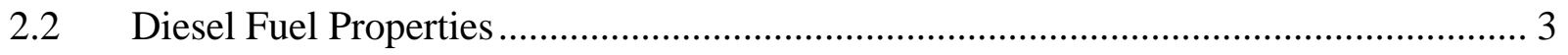

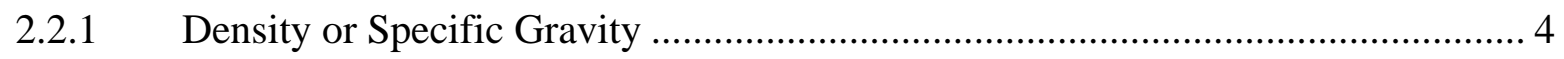

2.2.2 Cetane Number .................................................................................... 5

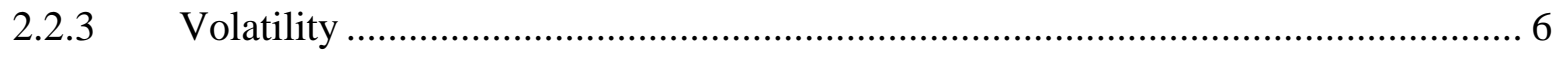

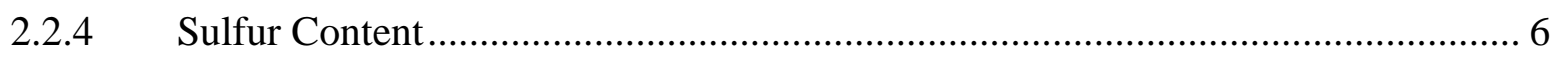

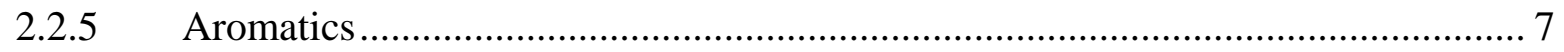

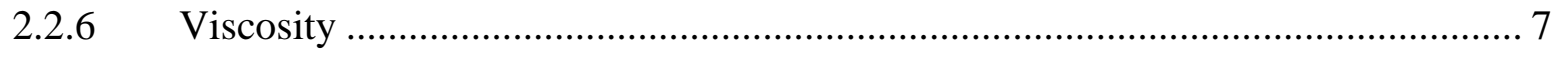

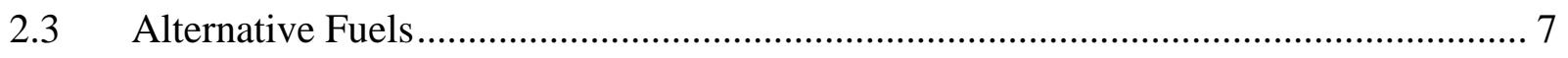

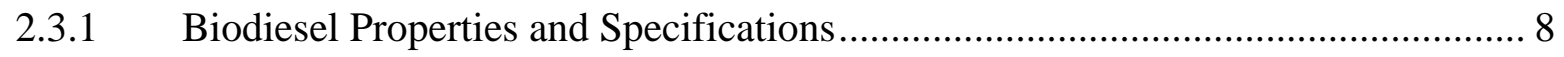

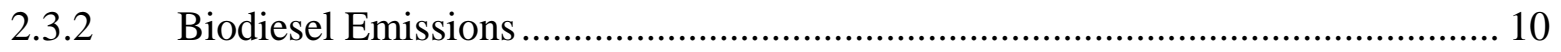

2.3.3 Ethanol-Diesel Blends .............................................................................. 12

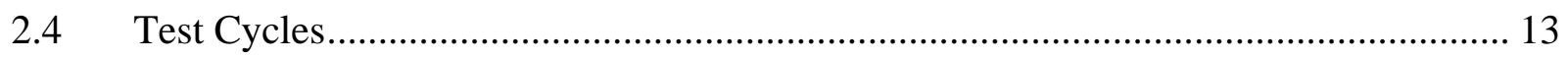

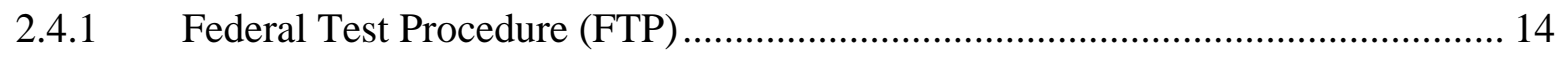

2.4.2 Supplemental Emissions Test (SET) ........................................................... 15

2.5 Previous Studies on Heavy-Duty Diesel Engine Regulated Emissions...................... 17

2.5.1 Petroleum Diesel Fuel Properties............................................................... 17

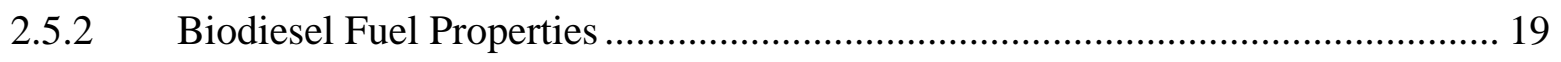

2.5.3 Emissions Due to Combustion................................................................... 20 
2.5.4 Emissions Due to Engine Control Unit (ECU) Changes ...................................... 21

2.5.5 Diesel Fuel Additives.......................................................................................... 22

2.5.6 Diesel Engine Design..................................................................................... 23

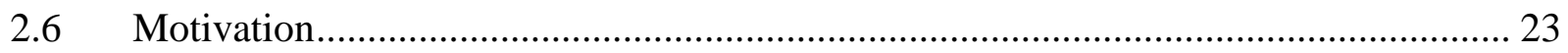

3 Experimental Procedures and Equipment .......................................................................... 25

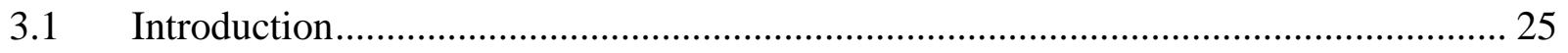

3.2 Test Engines......................................................................................................... 25

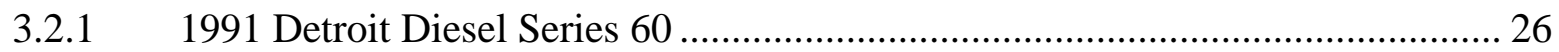

3.2.2 1992 Detroit Diesel Series 60 ………………............................................. 26

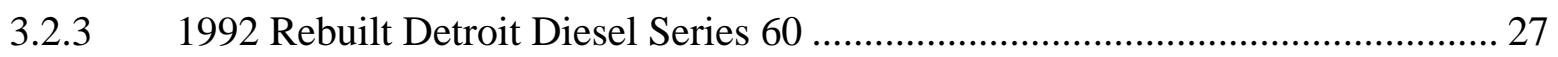

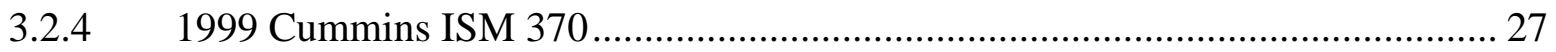

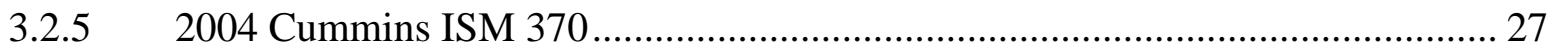

3.3 Engine Parameters ………………………………................................................. 34

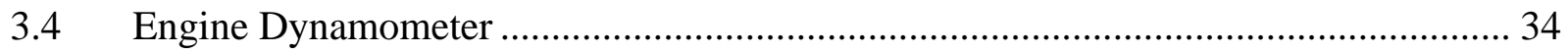

3.5 Full-Scale Dilution Tunnel and Sampling System ....................................................... 35

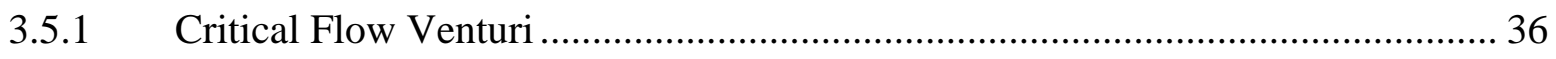

3.5.2 Gaseous Sampling System........................................................................... 37

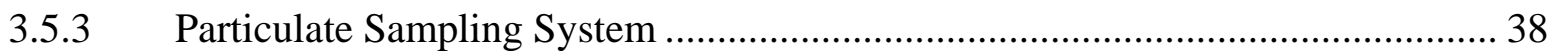

3.6 Exhaust Gas Analyzers ..................................................................................... 38

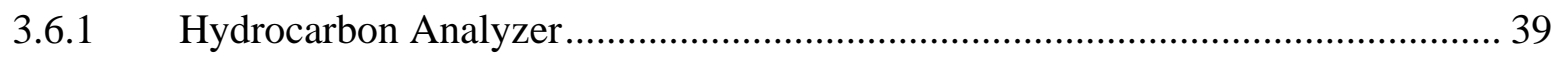

3.6.2 Oxides of Nitrogen Analyzers ....................................................................... 39

3.6.3 Carbon Monoxide and Carbon Dioxide Analyzers.................................................. 40

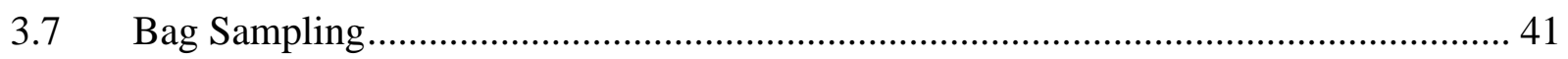

3.8 Intake Air Flow Measurement ............................................................................... 42

3.9 Intake Temperature and Humidity Measurement Devices ............................................ 42

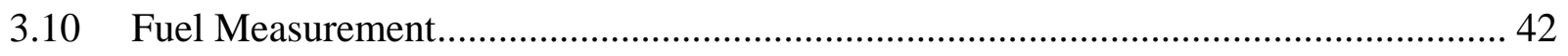

3.11 Instrumentation Control and Data Acquisition .............................................................. 43

3.12 Emissions Testing Procedures ..................................................................................... 44

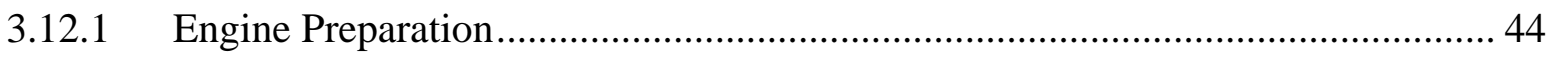

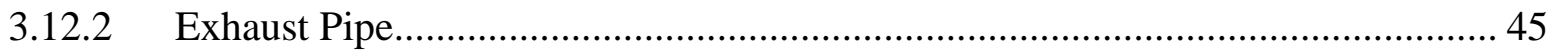

3.12.3 Analyzer Calibration and Calibration Gases......................................................... 45 


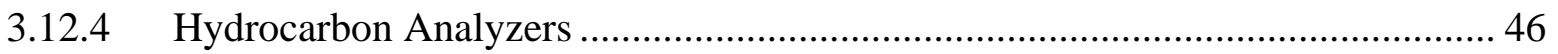

3.12.5 Oxides of Nitrogen Analyzers ........................................................................ 46

3.12.6 Carbon Monoxide and Carbon Dioxide Analyzers................................................... 47

3.12.7 Heated Lines and Probes....................................................................................... 47

3.12.8 Particulate and Filter Weighing ....................................................................... 48

3.12.9 Propane Injections......................................................................................... 49

3.12.10 Torque Cell Calibration ...................................................................................... 50

$4 \quad$ Test Fuels and Additives.................................................................................................... 51

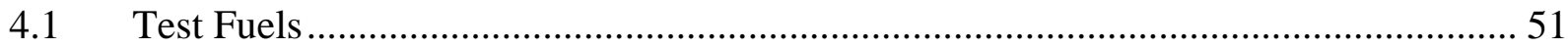

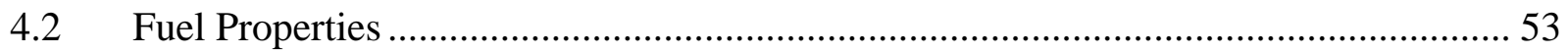

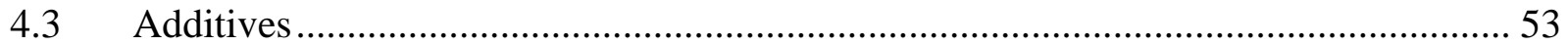

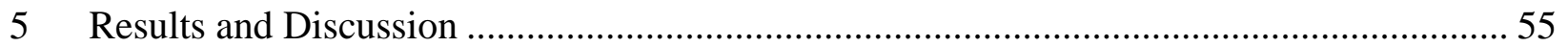

$5.1 \quad$ Test Engines and Examined Fuels ............................................................................... 55

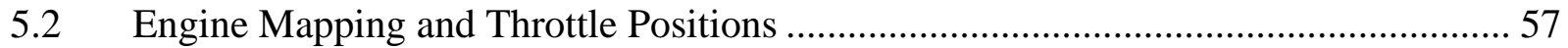

5.3 Useful Life of Older Technology Engines................................................................... 57

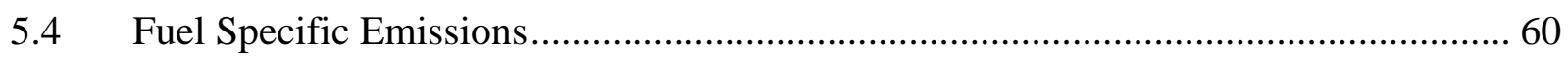

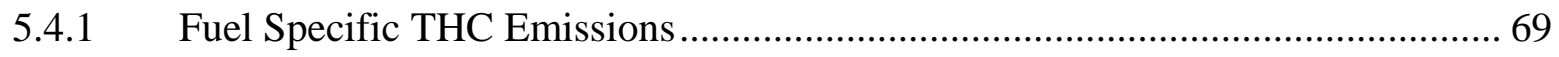

5.4.2 Fuel Specific CO Emissions ………………....................................................... 71

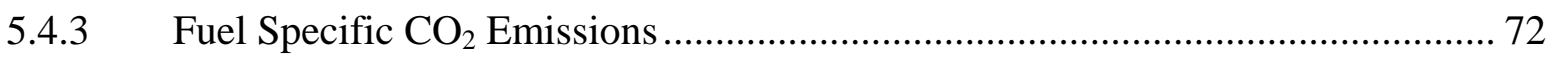

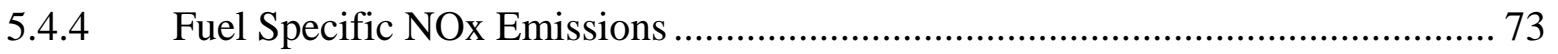

5.4.5 Fuel Specific $\mathrm{NO}_{2}$ Emissions........................................................................ 74

5.4.6 Fuel Specific TPM Emissions........................................................................... 75

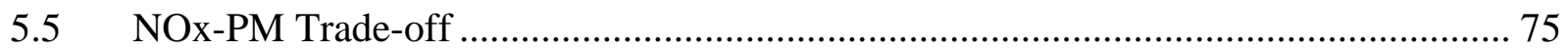

$5.6 \quad$ Work and Fuel Economy …………………….......................................................... 77

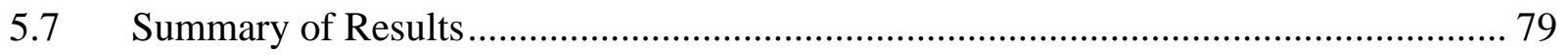

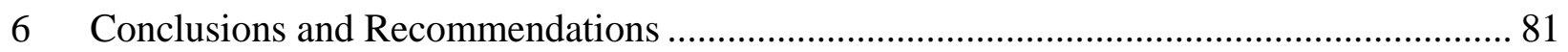

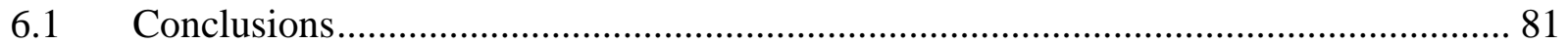

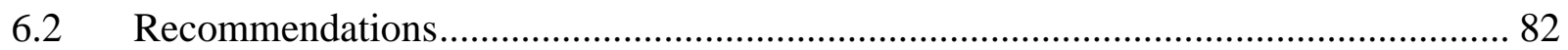

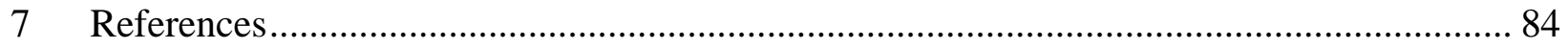

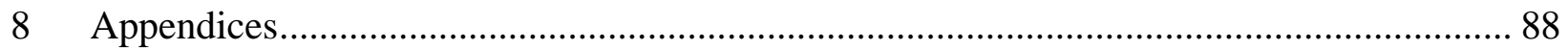

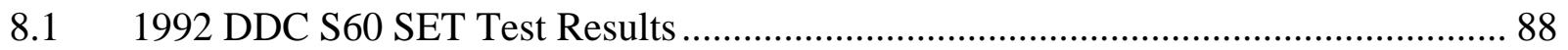




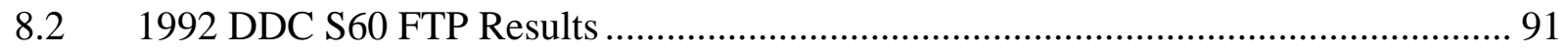

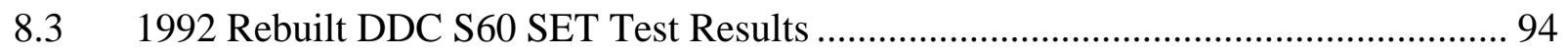

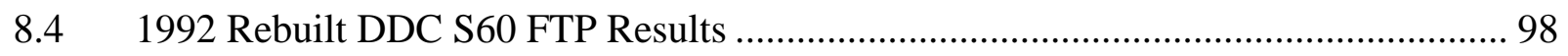

8.5 1999 Cummins ISM 370 SET Test Results .......................................................... 101

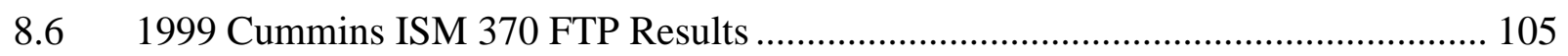

8.7 2004 Cummins ISM 370 SET Test Results ........................................................ 108

8.8 2004 Cummins ISM 370 FTP Results .............................................................. 112

8.9 Summary of FTP Emissions Data for 1991 DDC S60 ......................................... 115

8.10 Summary of FTP Emissions Data for 1992 DDC S60 ......................................... 119

8.11 Summary of FTP Emissions Data for 1992 Rebuilt DDC S60............................... 123

8.12 Summary of FTP Emissions Data for 1999 Cummins ISM 370 ............................ 129

8.13 Summary of FTP Emissions Data for 2004 Cummins ISM 370 ............................ 136

8.14 Summary of Multiple SET Test Emissions Data for 1992 DDC S60 ...................... 145 


\section{List of Figures}

Figure 2-1 Effect of Cetane Number on Heavy-Duty Diesel Emissions .................................... 5

Figure 2-2 Cetane Variability in Biodiesel and Petrodiesel Fuels ........................................... 9

Figure 2-3 Average Impact of Biodiesel on Emissions from Heavy-Duty Engines Subjected to

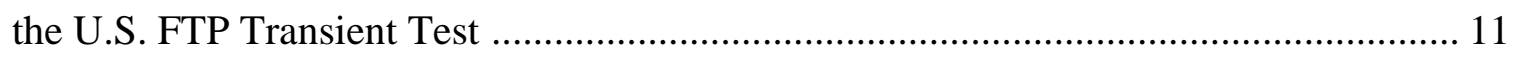

Figure 2-4 Engine Speed versus Time for a 1992 DDC S60 Engine Over FTP Cycle ................ 14

Figure 2-5 Engine Torque versus Time for a 1992 DDC S60 Engine Over FTP Cycle.............. 15

Figure 2-6 13-Mode SET Cycle Weight Factors .................................................................. 16

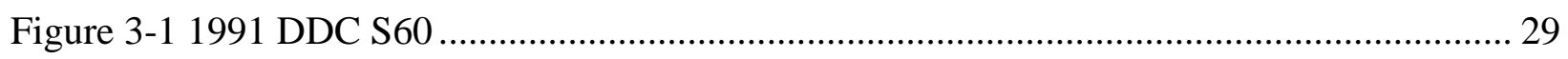

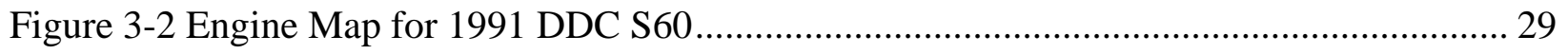

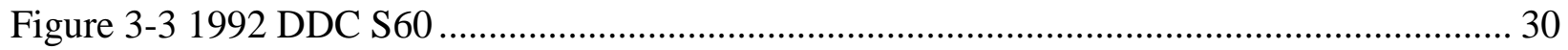

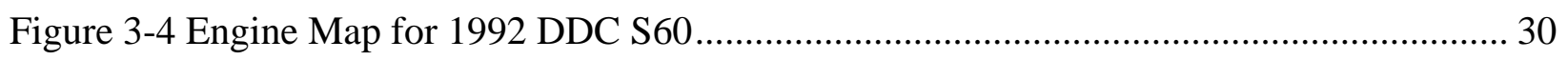

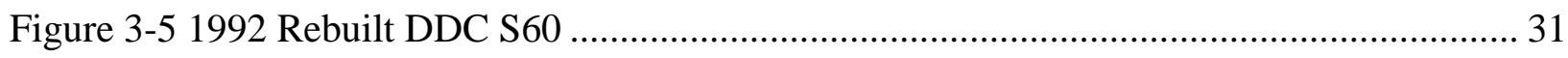

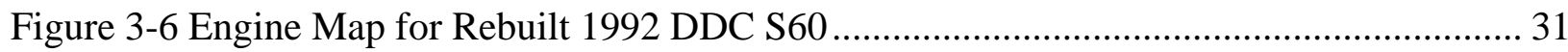

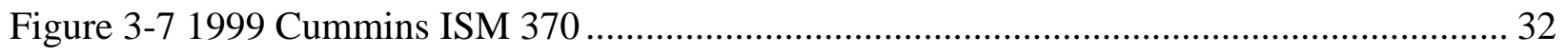

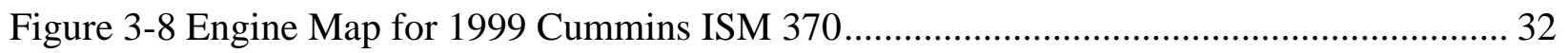

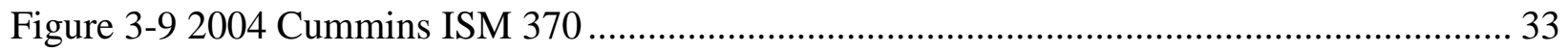

Figure 3-10 Engine Map for 2004 Cummins ISM 370 ........................................................ 33

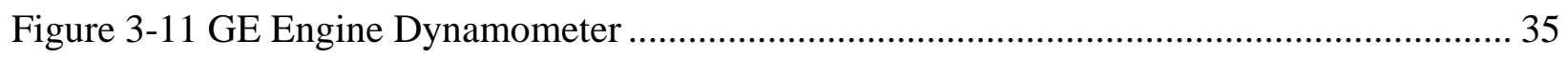

Figure 3-12 Stainless Steel Dilution Tunnel with Mixing Orifice............................................ 36

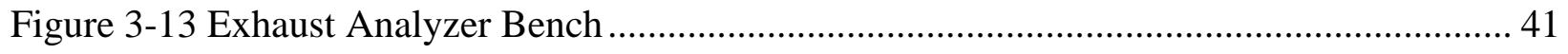

Figure 3-14 Sampling Plane and PM Sampling System ...................................................... 41

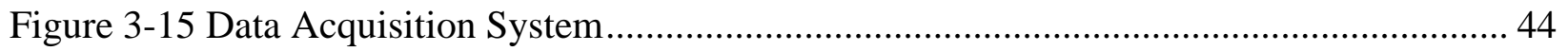

Figure 3-16 Clean Room Weighing Area and Ultra-Microbalance........................................ 49

Figure 3-17 Propane Injection Setup …........................................................................... 50

Figure 4-1 Biodiesel Fuel Used During the Study ............................................................... 51

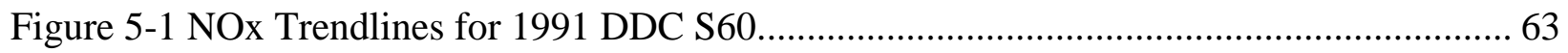

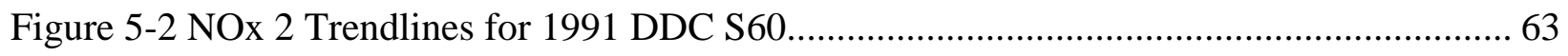

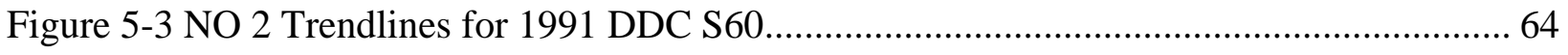

Figure 5-4 NOx and $\mathrm{NO}_{2}$ Percent Difference from Neat Fuels for 1991 DDC S60................... 64 
Figure 5-5 CO Percent Difference from Neat Fuels for 1991 DDC S60 ......................................... 66

Figure 5-6 THC Percent Difference from Neat Fuels for 1991 DDC S60 ……………….............. 67

Figure 5-7 THC Percent Difference from Neat Fuels for 1991 DDC S60 …………………….... 70

Figure 5-8 CO Percent Difference from Neat Fuels for 1991 DDC S60 ....................................... 71

Figure 5-9 CO2 Percent Difference from Neat Fuels for 1991 DDC S60 ....................................... 72

Figure 5-10 NOx Percent Difference from Neat Fuels for 1991 DDC S60.................................... 73

Figure 5-11 $\mathrm{NO}_{2}$ Percent Difference from Neat Fuels for 1991 DDC S60 …………………........ 74

Figure 5-12 TPM Percent Difference from Neat Fuels for 1991 DDC S60 …………................... 75

Figure 5-13 NOx-PM Trade-off for SET tests................................................................................ 76

Figure 5-14 NOx-PM Trade-off for FTP tests ........................................................................... 77

Figure 5-15 Brake Specific Work for FTP Cycle ……………………....................................... 78

Figure 5-16 Brake Specific Fuel Consumption for FTP Cycle...................................................... 78

Figure 8-1 THC Percent Difference from Neat Fuel for 1992 DDC S60 ………………................ 88

Figure 8-2 CO Percent Difference from Neat Fuel for 1992 DDC S60 …………......................... 89

Figure 8-3 $\mathrm{CO}_{2}$ Percent Difference from Neat Fuel for 1992 DDC S60 …………….................... 89

Figure 8-4 NOx Percent Difference from Neat Fuel for 1992 DDC S60 …………...................... 90

Figure 8-5 $\mathrm{NO}_{2}$ Percent Difference from Neat Fuel for 1992 DDC S60 ....................................... 90

Figure 8-6 TPM Percent Difference from Neat Fuel for 1992 DDC S60...................................... 91

Figure 8-7 NOx and $\mathrm{NO}_{2}$ Percent Difference from Neat Fuels versus Power for 1992 DDC S60 92

Figure 8-8 CO Percent Difference from Neat Fuels versus Power for 1992 DDC S60 ................ 93

Figure 8-9 THC Percent Difference from Neat Fuels versus Power for 1992 DDC S60 .............. 93

Figure 8-10 THC Percent Difference from Neat Fuels for 1992 Rebuilt DDC S60...................... 94

Figure 8-11 CO Percent Difference from Neat Fuels for 1992 Rebuilt DDC S60 ……………...... 95

Figure 8-12 CO 2 Percent Difference from Neat Fuels for 1992 Rebuilt DDC S60...................... 95

Figure 8-13 NOx Percent Difference from Neat Fuels for 1992 Rebuilt DDC S60 ...................... 96

Figure 8-14 $\mathrm{NO}_{2}$ Percent Difference from Neat Fuels for 1992 Rebuilt DDC S60 ...................... 96

Figure 8-15 TPM Percent Difference from Neat Fuels for 1992 Rebuilt DDC S60 ..................... 97

Figure 8-16 NOx and $\mathrm{NO}_{2}$ Percent Difference from Neat Fuels versus Power for 1992 Rebuilt

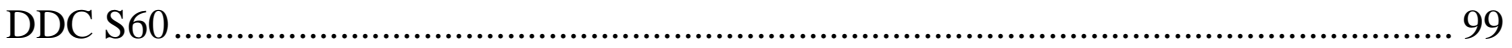

Figure 8-17 CO Percent Difference from Neat Fuels versus Power for 1992 Rebuilt DDC S60. 99 
Figure 8-18 THC Percent Difference from Neat Fuels versus Power for 1992 Rebuilt DDC S60 100

Figure 8-19 THC Percent Difference from Neat Fuels for 1999 Cummins ISM 370 ............... 102

Figure 8-20 CO Percent Difference from Neat Fuels for 1999 Cummins ISM 370 ................. 102

Figure 8-21 CO 2 Percent Difference from Neat Fuels for 1999 Cummins ISM 370 ................ 103

Figure 8-22 NOx Percent Difference from Neat Fuels for 1999 Cummins ISM 370................ 103

Figure 8-23 $\mathrm{NO}_{2}$ Percent Difference from Neat Fuels for 1999 Cummins ISM 370 ............... 104

Figure 8-24 TPM Percent Difference from Neat Fuels for 1999 Cummins ISM 370 ............... 104

Figure 8-25 NOx and $\mathrm{NO}_{2}$ Percent Difference from Neat Fuels versus Power for 1999 Cummins ISM 370 106

Figure 8-26 CO Percent Difference from Neat Fuels versus Power for 1999 Cummins ISM 370 107

Figure 8-27 THC Percent Difference from Neat Fuels versus Power for 1999 Cummins ISM 370 107

Figure 8-28 THC Percent Difference from Neat Fuel for 2004 Cummins ISM 370 ................. 109

Figure 8-29 CO Percent Difference from Neat Fuel for 2004 Cummins ISM 370 .................. 109

Figure 8-30 $\mathrm{CO}_{2}$ Percent Difference from Neat Fuel for 2004 Cummins ISM 370 ................. 110

Figure 8-31 NOx Percent Difference from Neat Fuel for 2004 Cummins ISM 370 ................ 110

Figure 8-32 $\mathrm{NO}_{2}$ Percent Difference from Neat Fuel for 2004 Cummins ISM 370 ................. 111

Figure 8-33 TPM Percent Difference from Neat Fuel for 2004 Cummins ISM 370................ 111

Figure 8-34 NOx and $\mathrm{NO}_{2}$ Percent Difference from Neat Fuels versus Power for 2004 Cummins ISM 370 113

Figure 8-35 CO Percent Difference from Neat Fuels versus Power for 2004 Cummins ISM 370 114

Figure 8-36 THC Percent Difference from Neat Fuels versus Power for 2004 Cummins ISM 370 114 


\section{List of Tables}

Table 1-1 EPA Heavy-Duty Diesel Engine Emissions Standards (g/bhp-hr)................................. 1

Table 2-1 Comparison between Biodiesel and Petrodiesel Properties .......................................... 8

Table 2-2 Effect of Biodiesel Fuel on Tailpipe Emissions ........................................................... 11

Table 2-3 Summary of E-Diesel on Regulated Emissions Constituents......................................... 13

Table 2-4 13-Mode SET Cycle Set Points................................................................................... 16

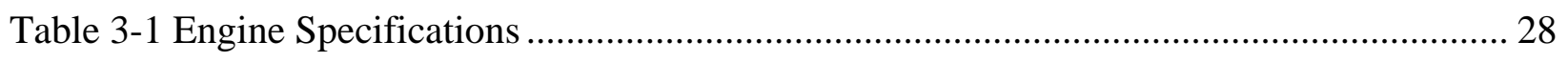

Table 3-2 Calibration Gases Used for Testing............................................................................. 45

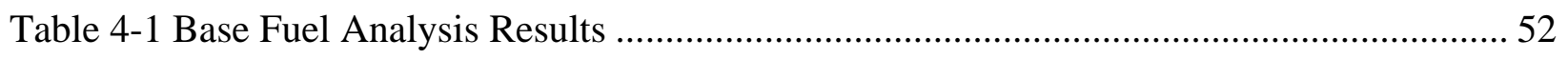

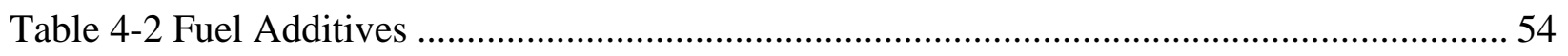

Table 5-1 Examined Fuels for each Test Engine ........................................................................ 56

Table 5-2 Useful Life Data for Older Technology Engines ......................................................... 59

Table 5-3 Useful Life Variation Analysis for Older Technology Engines ..................................... 59

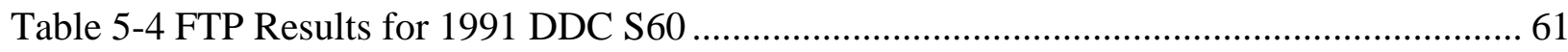

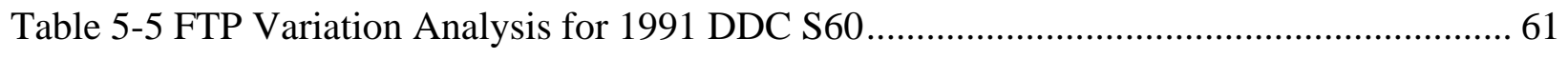

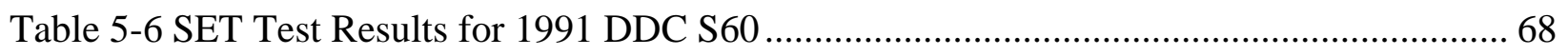

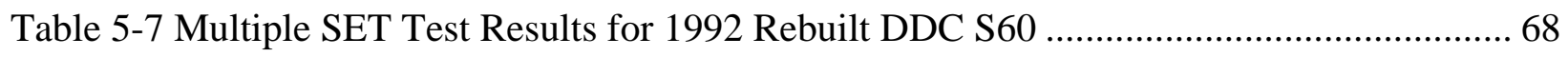

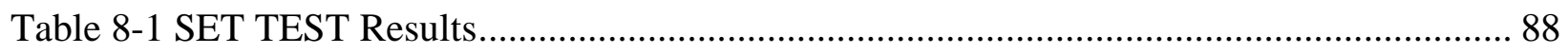

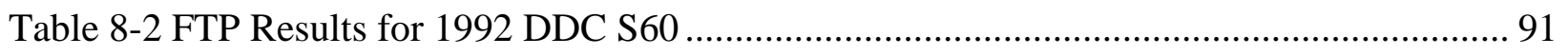

Table 8-3 Variation Analysis for 1992 DDC S60................................................................... 92

Table 8-4 SET Test Results for 1992 Rebuilt DDC S60 ………………………………................. 94

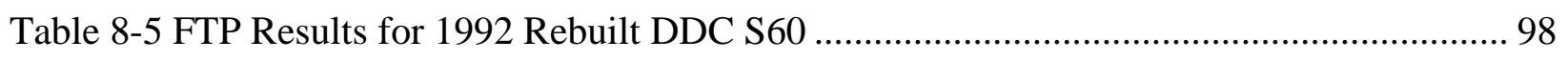

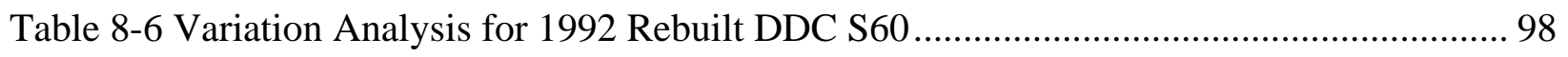

Table 8-7 SET Test Results for 1999 Cummins ISM 370 ........................................................... 101

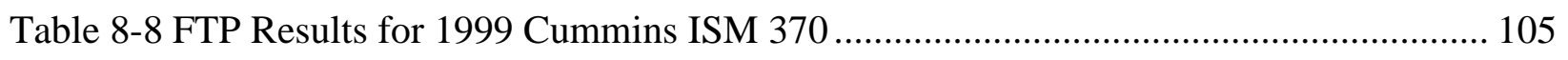

Table 8-9 Variation Analysis for 1999 Cummins ISM 370 ........................................................ 106

Table 8-10 SET Test Results for 2004 Cummins ISM 370 ........................................................ 108

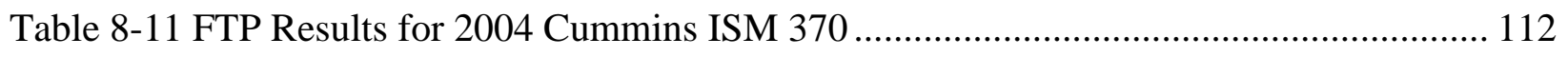

Table 8-12 Variation Analysis for 2004 Cummins ISM 370..................................................... 113

Table 8-13 Summary of CP 0.05 Cert Neat 1 Fuel for 1991 DDC S60 ..................................... 115 
Table 8-14 Summary of CP 0.05 Cert 12-ml ODA Fuel for 1991 DDC S60 ............................... 115

Table 8-15 Summary of Grad REF Neat Fuel for 1991 DDC S60 .............................................. 116

Table 8-16 Summary of Grad CAND Neat Fuel for 1991 DDC S60 ………………………......... 116

Table 8-17 Summary of Grad CAND 12-ml ODA Fuel for 1991 DDC S60 ……..................... 117

Table 8-18 Summary of Grad CAND 16-ml ODA 2x Fuel for 1991 DDC S60 ......................... 117

Table 8-19 Summary of Grad CAND 8-ml 2-EHN Fuel for 1991 DDC S60 ………….............. 118

Table 8-20 Summary of Grad CAND 10-ml DTBP Fuel for 1991 DDC S60............................... 118

Table 8-21 Summary of CP 0.05 Cert Neat 2 Fuel for 1991 DDC S60 ……….......................... 119

Table 8-22 Summary of CP 0.05 Cert Neat Fuel for 1992 DDC S60 .......................................... 119

Table 8-23 Summary of CP 0.05 Cert 12-ml ODA Fuel for 1992 DDC S60 …………............... 120

Table 8-24 Summary of Grad REF Neat Fuel for 1992 DDC S60 …......................................... 120

Table 8-25 Summary of Grad CAND Neat Fuel for 1992 DDC S60 ......................................... 121

Table 8-26 Summary of Grad CAND 12-ml ODA Fuel for 1992 DDC S60 …………............... 121

Table 8-27 Summary of Grad CAND 6-ml 2-EHN Fuel for 1992 DDC S60 ……...................... 122

Table 8-28 Summary of Grad REF 10-ml DTBP Fuel for 1992 DDC S60.................................. 122

Table 8-29 Summary of CP 0.05 Cert Neat Fuel for 1992 Rebuilt DDC S60.............................. 123

Table 8-30 Summary of CP 0.05 Cert 12-ml ODA Fuel for 1992 Rebuilt DDC S60 ................. 123

Table 8-31 Summary of Grad REF Neat Fuel for 1992 Rebuilt DDC S60 ................................. 124

Table 8-32 Summary of Grad REF 16-ml ODA Fuel for 1992 Rebuilt DDC S60 …………...... 124

Table 8-33 Summary of Grad CAND Neat 1 Fuel for 1992 Rebuilt DDC S60 ……................... 125

Table 8-34 Summary of Grad CAND 8-ml 2-EHN Fuel for 1992 Rebuilt DDC S60................. 125

Table 8-35 Summary of Grad CAND 16-ml ODA Fuel for 1992 Rebuilt DDC S60 ………...... 126

Table 8-36 Summary of Grad CAND 16-ml ODA 2x Fuel for 1992 Rebuilt DDC S60 ............ 126

Table 8-37 Summary of Grad CAND Neat 2 Fuel for 1992 Rebuilt DDC S60 .......................... 127

Table 8-38 Summary of Grad CAND 10-ml DTBP Fuel for 1992 Rebuilt DDC S60 …............. 127

Table 8-39 Summary of Grad CAND 6-ml ODA Fuel for 1992 Rebuilt DDC S60 ……............ 128

Table 8-40 Summary of Grad CAND 12-ml ODA Fuel for 1992 Rebuilt DDC S60 ................. 128

Table 8-41 Summary of CP 0.05 Cert Neat 1 Fuel for 1999 Cummins ISM 370 ....................... 129

Table 8-42 Summary of CP 0.05 Cert 12-ml ODA Fuel for 1999 Cummins ISM 370............... 129

Table 8-43 Summary of Grad REF Neat Fuel for 1999 Cummins ISM 370 ............................... 130

Table 8-44 Summary of Grad CAND Neat Fuel for 1999 Cummins ISM 370 ………................ 130 
Table 8-45 Summary of Grad CAND 12-ml ODA Fuel for 1999 Cummins ISM 370 ............. 131

Table 8-46 Summary of Grad CAND 6-ml ODA Fuel for 1999 Cummins ISM 370 ............... 131

Table 8-47 Summary of Grad CAND 6-ml 2-EHN Fuel for 1999 Cummins ISM 370 ............ 132

Table 8-48 Summary of Grad CAND 10-ml DTBP Fuel for 1999 Cummins ISM 370............ 132

Table 8-49 Summary of Grad CAND 16-ml ODA Fuel for 1999 Cummins ISM 370 ............. 133

Table 8-50 Summary of Grad REF Neat Fuel for 1999 Cummins ISM 370 ........................... 133

Table 8-51 Summary of CP 0.05 Cert Neat 2 Fuel for 1999 Cummins ISM 370 .................... 134

Table 8-52 Summary of CP 0.05 Cert B20 A Neat Fuel for 1999 Cummins ISM 370 ............. 134

Table 8-53 Summary of CP 0.05 Cert B20 B Neat Fuel for 1999 Cummins ISM 370 .............. 135

Table 8-54 Summary of CP 0.05 Cert B20 B 6-ml 2-EHN Fuel for 1999 Cummins ISM $370 . .135$

Table 8-55 Summary of CP 0.05 Cert B20 10-ml DTBP Fuel for 1999 Cummins ISM $370 . . . .136$

Table 8-56 Summary of Grad REF Neat Fuel for 2004 Cummins ISM 370 ........................... 136

Table 8-57 Summary of CP 0.05 Cert Neat 1 Fuel for 2004 Cummins ISM 370 .................... 137

Table 8-58 Summary of CP 0.05 Cert 12-ml ODA Fuel for 2004 Cummins ISM 370............. 137

Table 8-59 Summary of CP 0.05 Cert 6-ml 2-EHN Fuel for 2004 Cummins ISM 370............ 138

Table 8-60 Summary of CP 0.05 Cert 12-ml 2-EHN Fuel for 2004 Cummins ISM 370........... 138

Table 8-61 Summary of CP 0.05 Cert 24-ml ODA Fuel for 2004 Cummins ISM 370............. 139

Table 8-62 Summary of CP 0.05 Cert 15-ml DTBP Fuel for 2004 Cummins ISM 370 ........... 139

Table 8-63 Summary of Grad CAND Neat Fuel for 2004 Cummins ISM 370 ....................... 140

Table 8-64 Summary of Grad CAND 6-ml ODA Fuel for 2004 Cummins ISM 370 ............... 140

Table 8-65 Summary of CP 0.05 Cert B20 B Neat Fuel for 2004 Cummins ISM 370 ............. 141

Table 8-66 Summary of CP 0.05 Cert B20 A Neat Fuel for 2004 Cummins ISM 370 ............. 141

Table 8-67 Summary of CP 0.05 Cert B20 C Neat Fuel for 2004 Cummins ISM 370 ............. 142

Table 8-68 Summary of CP 0.05 Cert B20 B 10-ml DTBP Fuel for 2004 Cummins ISM 370. 142

Table 8-69 Summary of CP 0.05 Cert Neat 2 Fuel for 2004 Cummins ISM 370 .................... 143

Table 8-70 Summary of CP 0.05 Cert Neat 3 Fuel for 2004 Cummins ISM 370 .................... 143

Table 8-71 Summary of Grad REF Neat 2 Fuel for 2004 Cummins ISM 370 ........................ 144

Table 8-72 Summary of Multiple SET Test Data for 1992 Rebuilt DDC S60........................ 145 


\section{Introduction}

\subsection{Prologue}

With an ever increasing concern of the contribution of heavy-duty diesel engine exhaust constituents, the EPA has created a strict set of emissions regulations from these engines. The regulated diesel emissions include: hydrocarbons (HC), carbon monoxide (CO), oxides of nitrogen (NOx), which include nitrogen monoxide (NO) and nitrogen dioxide $\left(\mathrm{NO}_{2}\right)$, particulate matter (PM), and non-methane hydrocarbons (NMHC). EPA heavy-duty diesel engine emission standards for model year 1988 to 2010 are listed in Table 1-1 for engines being tested over the transient Federal Test Procedure (FTP) engine dynamometer cycle [1]. The years 2007 to 2010 are a phase in period for NOx. In October 1998, a court settlement between the EPA, CARB, Department of Justice, and the major diesel engine manufacturers was reached on the issue of high NOx emissions during certain driving modes. As a result, the 2004 emissions standards were moved to October 2002.

Table 1-1 EPA Heavy-Duty Diesel Engine Emissions Standards (g/bhp-hr) [1]

\begin{tabular}{|l|c|c|c|c|c|c|}
\hline \multicolumn{1}{|c|}{ Year } & HC & CO & NOx & PM & NMHC + NOx & NMHC \\
\hline 1988 & 1.3 & 15.5 & 10.7 & 0.6 & n/a & n/a \\
\hline 1990 & 1.3 & 15.5 & 6.0 & 0.6 & n/a & n/a \\
\hline 1991 & 1.3 & 15.5 & 5.0 & 0.25 & n/a & n/a \\
\hline 1994 & 1.3 & 15.5 & 5.0 & 0.1 & n/a & n/a \\
\hline 1998 & 1.3 & 15.5 & 4.0 & 0.1 & n/a & n/a \\
\hline $2004 *$ option 1$)$ & 1.3 & 15.5 & n/a & 0.1 & 2.4 & n/a \\
\hline $2004 *($ option 2$)$ & 1.3 & 15.5 & n/a & 0.1 & 2.5 & 0.5 \\
\hline $2007-2010$ & 1.3 & 15.5 & 0.2 & 0.01 & n/a & 0.14 \\
\hline
\end{tabular}

* 2004 was moved to October 2002

Through combined technology improvements in both engine design and fuel processing, a significant reduction in exhaust emissions has been possible. In order for future engines to reach the near zero emissions mark, external engine technologies will need more development. 
These external technologies include: aftertreatment systems, turbochargers, exhaust gas recirculation (EGR), and diesel particulate traps. Although engine technologies have a greater affect on emissions levels than fuel quality and properties, the fuel does have an influence on the emissions level generated by the engine.

Despite having a multitude of experimental data, fuel property influence on regulated emissions is still not clear [2]. The properties of diesel fuels that influence emissions are usually intercorrelated, which means care must be taken to separate the fuel property changes in the test fuel. If multiple fuel properties are changed simultaneously, then it is difficult to pinpoint an exact fuel property to an emission change. Techniques such as non-linear regression and neural network modeling can be used to help find the affect of changing fuel properties on engine emissions.

\subsection{Objectives}

The main objective of this study was to evaluate engine emissions from several diesel fuels with and without cetane improving additives on recent and early electronically controlled heavy duty diesel engines (HDDE). The chosen engines were tested using the FTP and Supplemental Emissions Test (SET) dynamometer cycles. The study examined how the changes in fuel properties due to different fuel additives made an impact on the emissions from older and newer electronically-controlled engines.

The second objective was to test the advantages and disadvantages of using different types of biodiesel for emissions reduction when compared to petroleum diesel with fuel additives. B20 blends of soy, mineral, and cottonseed were used to evaluate the influence fuel properties of each type of biodiesel had on engine emissions. A B20 blend consists of $20 \%$ biodiesel fuel and $80 \%$ petroleum diesel fuel, by volume. 


\section{Literature Review}

\subsection{Background}

Diesel fuels, which have historically been obtained from the distillation of crude oil, consist of a mixture of many hydrocarbons with boiling points in the wide range of 150 to $380^{\circ} \mathrm{C}$. In order to meet the market demands at any given time, refineries blend conversion products into the primary distillation streams [2].

The hydrotreating and hydrocracking processes that breaks rings, chains, and saturate the molecules of the crude oil has a major role in determining the quality and quantity of the streams drawn off. There are three main types of hydrocarbons, including: paraffinic, naphthenic, and aromatic hydrocarbons. These different hydrocarbon types produce different diesel fuels with different cetane number, energy content, cloud point and sulfur content [3]. Aromatics have a high boiling point and specific gravity but a fairly low cetane number when compared to a paraffinic hydrocarbon. Paraffinic hydrocarbons have the highest cetane number and the lowest specific gravity. Napthenes have the highest specific gravity and boiling point, but the lowest cetane number [3].

\subsection{Diesel Fuel Properties}

Environmental considerations and emissions legislation have both highly influenced current formulation and properties of fuels. In order to have a low-emission diesel engine, the interaction between engine technologies, fuel quality, and emissions need to be well understood [2]. Many studies have been completed to study the influence of fuel properties and additives on emission levels. 
Standards specify the requirements placed on diesel fuels, such as the ASTM D975 in the United States, EN 590 in the European Union, and JIS K2204 in Japan [3]. The most important parameters specified within these standards that also influence emissions include:

- Density or Specific Gravity

- Cetane Number

- Volatility

- Sulfur Content

- Aromatics

\subsubsection{Density or Specific Gravity}

Density is an important fuel property concerning maximum power output, volumetric fuel economy, and regulated diesel emissions [2]. The effect of density on emissions is related to complex physical interactions with the fuel injection system that can lead to changes in the dynamic timing and mass injection flow rate [4]. A lower density fuel will create a lower maximum power and also lower some of the emission constituents. Normally a reduction in NOx is seen with in increase in PM, and CO always follows the same trend as PM. Although a reduction of both PM and NOx along with an increase in CO conflicts with emissions results, some researchers have found this to be true [2,5]. A large HC increase is more pronounced in older technology engines that initially have a high HC emission level.

Specific gravity is a ratio of the density of the material being tested to the density of water as measured with the ASTM 287 method [3]. The United States uses API gravity which is an arbitrary scale representing the density or gravity of liquid petroleum products [3]. A high API gravity means the material is light-weight. ASTM1298 is used in measuring API gravity and can be calculated using the following formula:

$$
{ }^{\circ} \text { APIGravity }=\frac{141.5}{S G}-131.5 \text {. }
$$




\subsubsection{Cetane Number}

The cetane number is the measure of the ignition quality of a given diesel fuel based on ignition delay in a diesel engine. When the cetane number is high, the ignition delay is short and the ignition quality is improved [3]. The ASTM D613 method, along with a Cooperative Fuels Research (CFR) engine, are used to establish the cetane number of a fuel by comparing its ignition delay with that of two reference fuels under standard operating conditions [3]. The two reference fuels are: cetane (n-hexadecane or $n-\mathrm{C}_{16} \mathrm{H}_{34}$ ) which is assigned a cetane number of 100 , and heptamethylnonane $\left(\mathrm{C}_{12} \mathrm{H}_{34}\right)$, which is given a cetane number of 15 [2]. The formula used to calculate this diesel fuel property is given as:

$$
C N=\left(\% n-C_{16} H_{34}\right)+0.15\left(\% C_{12} H_{34}\right) . \quad \text { Equation 2-2 }
$$

Figure 2-1 shows the effect of cetane number on emission levels of NOx, CO, and HC from three different heavy-duty diesel truck engines [3]. The Japanese 6-mode test cycle was used to complete this study. When a test fuel with a high cetane number is used, the emissions of NOx, CO and HC were lower. A sharp increase in emissions is seen as the cetane number approaches 30 .

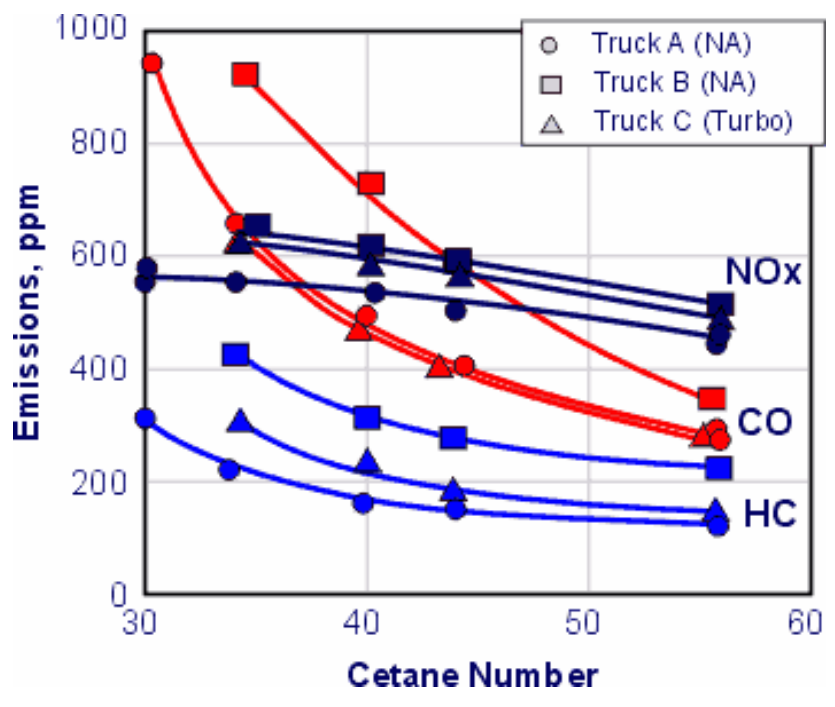

Figure 2-1 Effect of Cetane Number on Heavy-Duty Diesel Emissions [3] 


\subsubsection{Volatility}

Volatility defines the evaporation characteristics of a liquid. A highly volatile liquid will boil at a low temperature and evaporate quickly [2, 3]. ASTM D86 is the accepted method for controlled heating of a sample of fuel in a standard apparatus [2]. The distillation range of the fuel is determined by placing a sample in a distillation apparatus and heating. Several factors are recorded during the process, which include: initial boiling point, final boiling point, percent of condensate removed, and percent of nonvolatile residue [3]. The volatility of a given diesel fuel influences many fuel properties, such as autoignition temperature, cetane number, and viscosity because it is dependent upon the chemical composition.

\subsubsection{Sulfur Content}

Diesel fuels naturally contain a large amount of chemically bound sulfur and this quantity is relative to the quality of the crude oil. Sulfur content can be reduced at the refinery with the treatment of hydrogen; however, this adds cost to the refinery process [2]. The negative effects of having large quantities of sulfur in diesel fuels are seen in three categories: emissions, corrosion and wear, and exhaust aftertreatment [6]. Sulfur dioxide $\left(\mathrm{SO}_{2}\right)$, which has a negative environmental effect, is what most of the sulfur in the exhaust is converted into during the combustion process. Sulfate particulate occurs when the sulfur oxidizes to sulfur trioxide $\left(\mathrm{SO}_{3}\right)$, which bonds with water molecules to form sulfuric acid [6]. In the United States, on-road diesel fuels are limited to $15 \mathrm{ppm}$. This concentration enables the use of aftertreatment controls so the 2007 PM emission limits can be met. 


\subsubsection{Aromatics}

The effect of total aromatics on emissions formation has been highly debated for many years [2]. Some of the most recent work has shown that aromatics have little to no effect on HC, CO, or PM, but some studies showed mixed results. If the aromatics are decreased by $20 \%$ or more, there is a slight decrease in the amount of NOx formation. Since there is a reduction in aromatics, the flame temperature also decreases, which decreases the amount of NOx emissions production. Some studies have also reduced the amount of just the polycyclic aromatics, which seems to have a benefit for reducing both $\mathrm{HC}$ and NOx, but has no effect on CO emissions [2]. The PM emissions also show a reduction, but only in the older model high-emitting engines.

\subsubsection{Viscosity}

Although viscosity may not be directly influence emissions formation, it does affect several properties that directly influence formation of emissions constituents. This fuel property is the measure of the resistance to flow of a liquid, which means a higher viscosity fuel [2]. The viscosity of a diesel fuel plays a major role in the operation of fuel injection equipment, which must be accurately measured in very small quantities to be injected during the compression stroke. It also has a major impact on the atomization and lubricity of diesel fuels [7]. The tolerance band between the minimum and maximum viscosity values for a diesel fuel is kept small so that no problems occur in either the fuel system or engine [2].

\subsection{Alternative Fuels}

There have been many suggestions for diesel fuel alternatives, such as vegetable oils and animal fats. The common sources of oil include soybean, rape, sunflower, coconut, palm, and used frying oil, but methods have also been developed to make biodiesel from such exotic 
materials as oils produced by certain species of algae [8]. All of these oils are converted to methyl esters before they can be used as a diesel fuel. The ASTM Biodiesel Task Force describe biodiesel as [9]: Biodiesel is defined as the mono alkyl esters of long-chain fatty acids derived from renewable lipid feedstocks, such as vegetable oils and animal fats, for use in compression ignition (diesel) engines.

Since biodiesel is renewable and a potential greenhouse gas emissions reducing fuel, it is one of the most attractive alternative fuels available. High prices present a barrier for a widespread use of biodiesel use [2]. Since pure biodiesel can be up to twice the price of petrodiesel, it can be blended with petroleum diesel. The most common blend is $20 \%$ biodiesel and $80 \%$ petroleum diesel by volume, which is usually referred to as B20 [3].

\subsubsection{Biodiesel Properties and Specifications}

In the United States ATSM D6751 was adopted as the standard for biodiesel (B100) as a blend component with petroleum diesel fuels [2, 3]. Table 2-1 shows the average properties of neat biodiesel fuel compared to those of petroleum diesel fuel [10]. The biodiesel fuels considered were soybean and rapeseed oil-based fuels, as well as animal based biodiesels. The petroleum based fuels taken into consideration were market fuels sold within the U.S., excluding California fuels.

Table 2-1 Comparison between Biodiesel and Petrodiesel Properties [10]

\begin{tabular}{|l|c|c|}
\hline Property & Biodiesel & Petrodiesel \\
\hline Natural Cetane Number & 55 & 44 \\
\hline Sulfur (ppm) & 54 & 333 \\
\hline Nitrogen (ppm) & 18 & 114 \\
\hline Aromatics (vol.\%) & 0 & 34 \\
\hline T10 $\left({ }^{\circ} \mathrm{C}\right)$ & 331 & 217 \\
\hline T50 $\left({ }^{\circ} \mathrm{C}\right)$ & 343 & 263 \\
\hline T90 $\left({ }^{\circ} \mathrm{C}\right)$ & 352 & 317 \\
\hline Specific Gravity & 0.88 & 0.85 \\
\hline Kinematic Viscosity @ $40{ }^{\circ} \mathrm{C}\left(\mathrm{mm}^{2} / \mathrm{s}\right)$ & 6.0 & 2.6 \\
\hline
\end{tabular}


Some of the characteristics of biodiesel, such as high cetane numbers and low sulfur levels, are advantages, low heating value and high pour point temperature but are some of the drawbacks [3]. A practically sulfur-free biodiesel is attainable through vegetable oils, whereas animal based biodiesel can contain small amounts of sulfur. Biodiesel is also biodegradable, which is advantageous from an environmental standpoint (fuel spills), but can be a drawback for engine use. A high concentration of biodiesel means the fuel is more susceptible to degradation and water absorption [2].

Cetane is the only fuel property for biodiesel that does not have a tight spectrum, as can be seen in literature. Figure 2-2 compares the cetane numbers from several neat biodiesel fuels with that of petroleum diesel [10]. The single data point for virgin oil fuel shows that it is considerably different from the ester based diesel fuels.

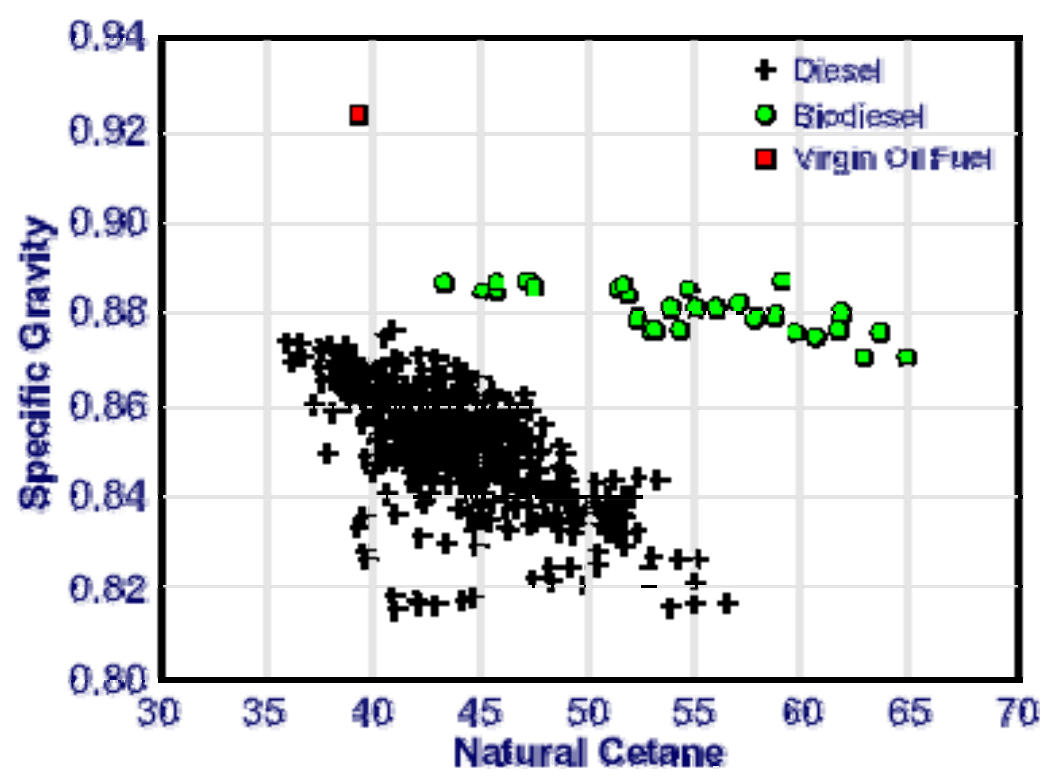

Figure 2-2 Cetane Variability in Biodiesel and Petrodiesel Fuels [10] 


\subsubsection{Biodiesel Emissions}

After numerous studies have been performed on exhaust emissions from biodiesel fuels and their blends, the results are usually contradictory and inconclusive. Several reasons can attribute to the observed data scatter, which include the following $[2,10]$ :

- The properties of various biodiesel fuels, such as cetane, have too much variability to be properly examined and summarized.

- Studies are consistently conducted on different types of engines, which will show different emission trends.

- Different test cycles have been used, which include steady-state and transient cycles, and this will result in emissions differences

- Since the engines being tested using biodiesel are never calibrated back to their original power output to account for the lower heating value, then the emission levels are affected.

- In order to get the absolute best data, the combustion process of the engine would need to be tuned for the specific biodiesel being used. If these test engines were calibrated correctly, even lower emission values would likely be possible.

There is wide agreement in the literature that both biodiesel and blends of biodiesel have a decreased amount of $\mathrm{CO}$ and HC [2]. This is mostly due to the high oxygen content, which allows for more complete oxidation in the combustion chamber. NOx emissions are typically higher with a biodiesel due to the high oxygen content as well. Figure 2-3 shows that as the percentage of biodiesel increases, all of the emissions constituents decrease except NOx which increases by about $10 \%[10]$. 


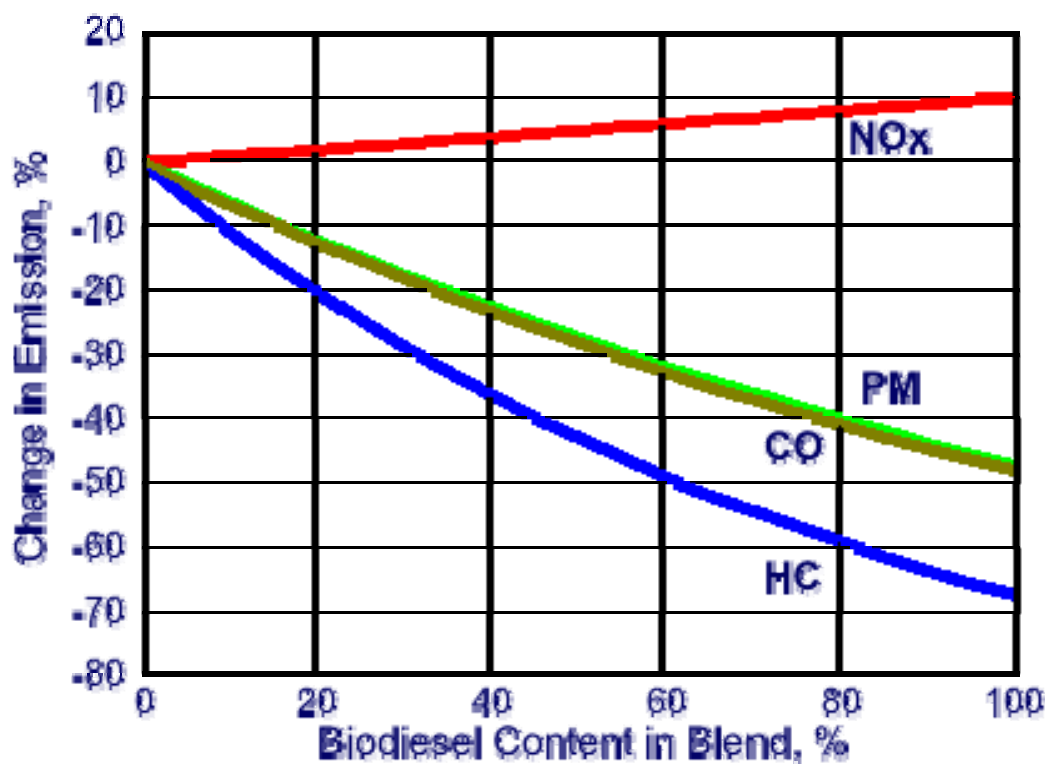

Figure 2-3 Average Impact of Biodiesel on Emissions from Heavy-Duty Engines Subjected to the U.S. FTP Transient Test [10]

Table 2-2 summarizes the influence biodiesel has on emissions relative to petroleum based diesel fuels [2]. An increase in the emissions level shows that biodiesel creates a higher level of emissions than petrodiesel, and decreased emissions is just the opposite.

Table 2-2 Effect of Biodiesel Fuel on Tailpipe Emissions [2]

\begin{tabular}{|l|l|}
\hline Emission & Effect of Biodiesel \\
\hline Regulated Emissions & Decrease \\
\hline Carbon Monoxide & Decrease \\
\hline Hydrocarbons & Increase \\
\hline Nitrogen Oxides & Decrease \\
\hline Total Particulate Matter (TPM) & \\
\hline Unregulated Emissions & Decrease \\
\hline Carbon Particulates & Increase \\
\hline Organic Particulates (SOF) & Decrease \\
\hline Sulfate Particulates & Decrease \\
\hline Visible Smoke & Decrease \\
\hline PAH, nitro-PAH & Inconclusive \\
\hline Aldehydes &
\end{tabular}




\subsubsection{Ethanol-Diesel Blends}

Ethanol has gained popularity as a gasoline blend in order to satisfy octane requirements and some reformulated gasoline requirements. Ethanol is also being examined for diesel substitution. The concurrent use of ethanol and diesel in compression ignition engines has been recently studied, and it was found that alcohol-diesel emulsions and blends were the only approaches most compatible with commercial diesel engines [11]. The most promising method was to blend diesel and ethanol (up to $15 \%$ by volume) because this was stable and could be done with little to no engine modifications. When ethanol was blended with diesel fuel (typically US No. 2 diesel), it was used with an additive which helped to maintain fuel stability and improved cetane number and lubricity. The additive package was needed because the ethanol lowers the natural cetane number of the diesel fuel, which creates a long ignition delay and an unacceptable deterioration in combustion quality [11].

Ethanol-diesel blends were able to reduce some regulated emissions, especially particulate matter which has shown a reduction of up to $30 \%$. When the cetane number of an ethanol-diesel blend was increased to match the original diesel fuel, an improvement was seen in the emissions level when compared to an ethanol-diesel blend without a cetane improving additive [12]. An increase in $\mathrm{HC}$ and $\mathrm{CO}$ emissions was almost always seen, and NOx usually had no change. The summary ethanol-diesel blends had on regulated emissions in shown in Table 2-3, where negative percentages indicate a reduction in emissions and a positive percentage indicates an increase in emissions [12]. 
Table 2-3 Summary of E-Diesel on Regulated Emissions Constituents [12]

\begin{tabular}{|l|c|c|c|c|}
\hline & HC & CO & NOx & PM \\
\hline \multicolumn{5}{|c|}{ All Data } \\
\hline Average & $41 \%$ & $16 \%$ & $1 \%$ & $-13 \%$ \\
\hline Minimum & $-16 \%$ & $-30 \%$ & $-20 \%$ & $-72 \%$ \\
\hline Maximum & $164 \%$ & $93 \%$ & $25 \%$ & $65 \%$ \\
\hline \multicolumn{5}{|c|}{ Equal Cetane Number Data } \\
\hline Average & $6 \%$ & $-9 \%$ & $-2 \%$ & $-25 \%$ \\
\hline Minimum & $-16 \%$ & $-30 \%$ & $-20 \%$ & $-31 \%$ \\
\hline Maximum & $22 \%$ & $5 \%$ & $25 \%$ & $-20 \%$ \\
\hline
\end{tabular}

\subsection{Test Cycles}

Heavy-duty diesel engines used in on road vehicles are tested and certified in the United States using the FTP and SET engine test cycles. Engine manufacturers are also required to perform in-use emissions testing. Along with these well-known dynamometer test cycles, many other test cycles have been developed to study emissions formation.

In addition to the ESC, which was essentially the same as the SET cycle, Europe also uses the European Transient Cycle (ETC). The ETC, also called the FIGE cycle, had three parts: city driving, rural driving, and motorway driving. Japan used the 13-mode Japanese test cycle as the steady state test, and the JE05 is the transient test cycle. A worldwide harmonized engine test cycle was also recently developed for the emissions certification procedure of HDDE. Transient and steady-state test cycles were developed for the possibility of worldwide engine certification.

Many other test cycles have been used for light-duty and off-road engines. Light-duty engines (engines used in vehicles less than 19,500 pounds GVWR) were normally tested using a chassis dynamometer transient test cycle. Off-road diesel engines were evaluated using an engine test stand and steady-state test cycles. 


\subsubsection{Federal Test Procedure (FTP)}

The FTP is the prominent transient test cycles used to test HDDE and analyze the emissions formed that closely simulated on-road driving conditions in the United States. The transient test was developed to take into account the truck and bus traffic in and around city roads and expressways. This test cycle included motoring segments where the dynamometer was forced to drive the engine.

The test cycle includes four main segments: New York non-freeway (NYNF), Los Angeles non-freeway (LANF), Los Angeles freeway (LAFY), and a repeat of the NYNF. The first and fourth segments represented light urban traffic with frequent stops and starts. The second segment represented crowded urban traffic with very few stops, and the third segment represented crowded freeway traffic [1, 2]. Figure 2-4 shows a typical target engine speed versus time plot for the FTP cycle adapted to a 1992 DDC S60 engine. Figure 2-5 shows a typical target engine torque versus time plot for the FTP cycle adapted to a 1992 DDC S60 engine. Both plots were based on the engine map used to test the engine which can be seen in Figure 3-4.

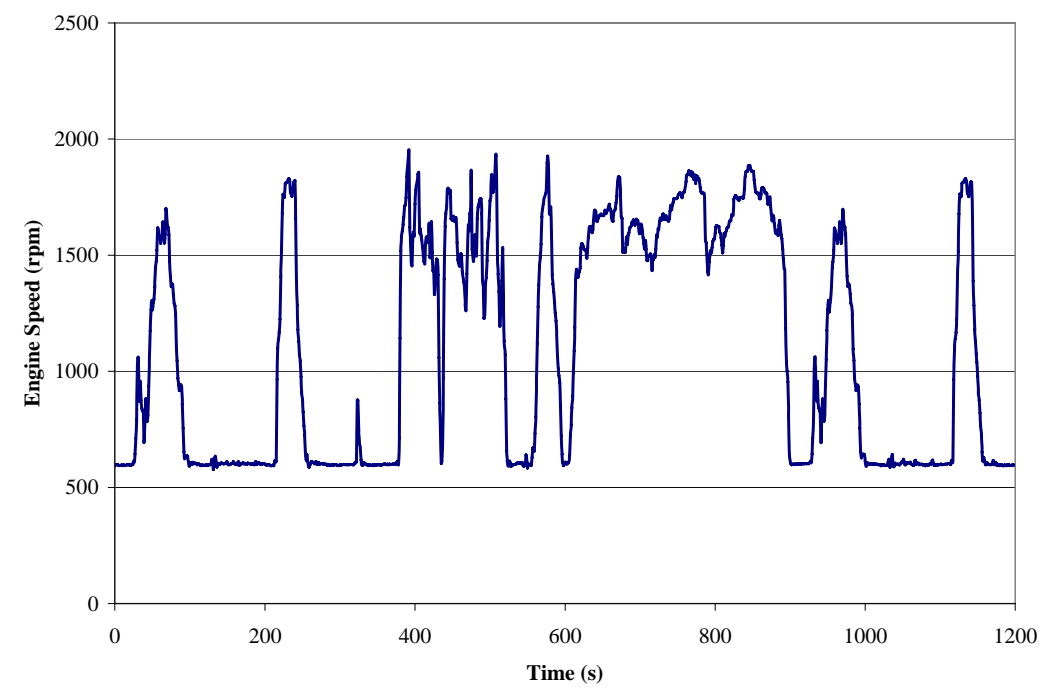

Figure 2-4 Engine Speed versus Time for a 1992 DDC S60 Engine Over FTP Cycle 


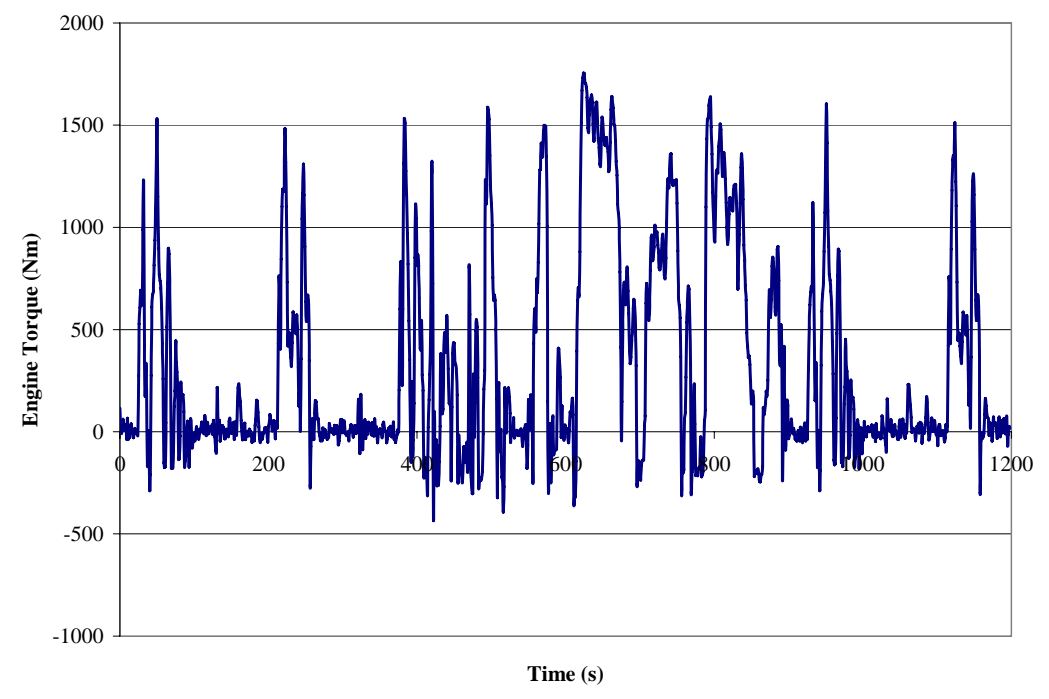

Figure 2-5 Engine Torque versus Time for a 1992 DDC S60 Engine Over FTP Cycle

\subsubsection{Supplemental Emissions Test (SET)}

The SET is a 13-mode steady-state test procedure that has been used in the United States since October 1998 for testing HDDE along with the FTP. This test cycle is also known as the ESC and the OICA/ACEA cycle. The engine is tested over a sequence of steady-state modes on an engine dynamometer. The specified engine speed must be held to within $\pm 50 \mathrm{rpm}$ and the specified torque be held to within $\pm 2 \%$ of the maximum torque at the test speed [2]. The regulated emissions are measured during each mode and an average is found using the weighting factor specific to each mode. Table 2-4 shows the example set points for each engine used during this study, and Figure 2-6 shows the set points and weighting factors of each mode. 
Table 2-4 13-Mode SET Cycle Set Points

\begin{tabular}{|c|c|c|c|c|c|c|c|}
\hline Mode & $\begin{array}{c}\text { Engine Speed } \\
(\mathrm{rpm})\end{array}$ & $\begin{array}{c}\text { Load } \\
(\%)\end{array}$ & $\begin{array}{c}\text { Max Torque } \\
(\mathrm{ft}-\mathrm{lb})\end{array}$ & $\begin{array}{c}\text { Set Point } \\
(\mathrm{ft}-\mathrm{lb})\end{array}$ & $\begin{array}{c}\text { Power } \\
(\mathrm{hp})\end{array}$ & $\begin{array}{c}\text { Weight Factor } \\
(\%)\end{array}$ & $\begin{array}{c}\text { Duration } \\
(\mathrm{min})\end{array}$ \\
\hline 1 & 600 & $0 \%$ & 668 & 0 & 0 & 15 & 4 \\
\hline 2 & 1199 & $100 \%$ & 1419 & 1418 & 55 & 8 & 2 \\
\hline 3 & 1422 & $50 \%$ & 1336 & 668 & 76 & 10 & 2 \\
\hline 4 & 1422 & $75 \%$ & 1336 & 1002 & 133 & 10 & 2 \\
\hline 5 & 1199 & $50 \%$ & 1419 & 709 & 68 & 5 & 2 \\
\hline 6 & 1199 & $75 \%$ & 1419 & 1064 & 119 & 5 & 2 \\
\hline 7 & 1199 & $25 \%$ & 1419 & 355 & 170 & 5 & 2 \\
\hline 8 & 1422 & $100 \%$ & 1336 & 1336 & 74 & 9 & 2 \\
\hline 9 & 1422 & $25 \%$ & 1336 & 334 & 129 & 10 & 2 \\
\hline 10 & 1644 & $100 \%$ & 1176 & 1179 & 73 & 8 & 2 \\
\hline 11 & 1644 & $25 \%$ & 1176 & 295 & 182 & 5 & 2 \\
\hline 12 & 1644 & $75 \%$ & 1176 & 884 & 364 & 5 & 2 \\
\hline 13 & 1644 & $50 \%$ & 1176 & 590 & 90 & 5 & 2 \\
\hline
\end{tabular}

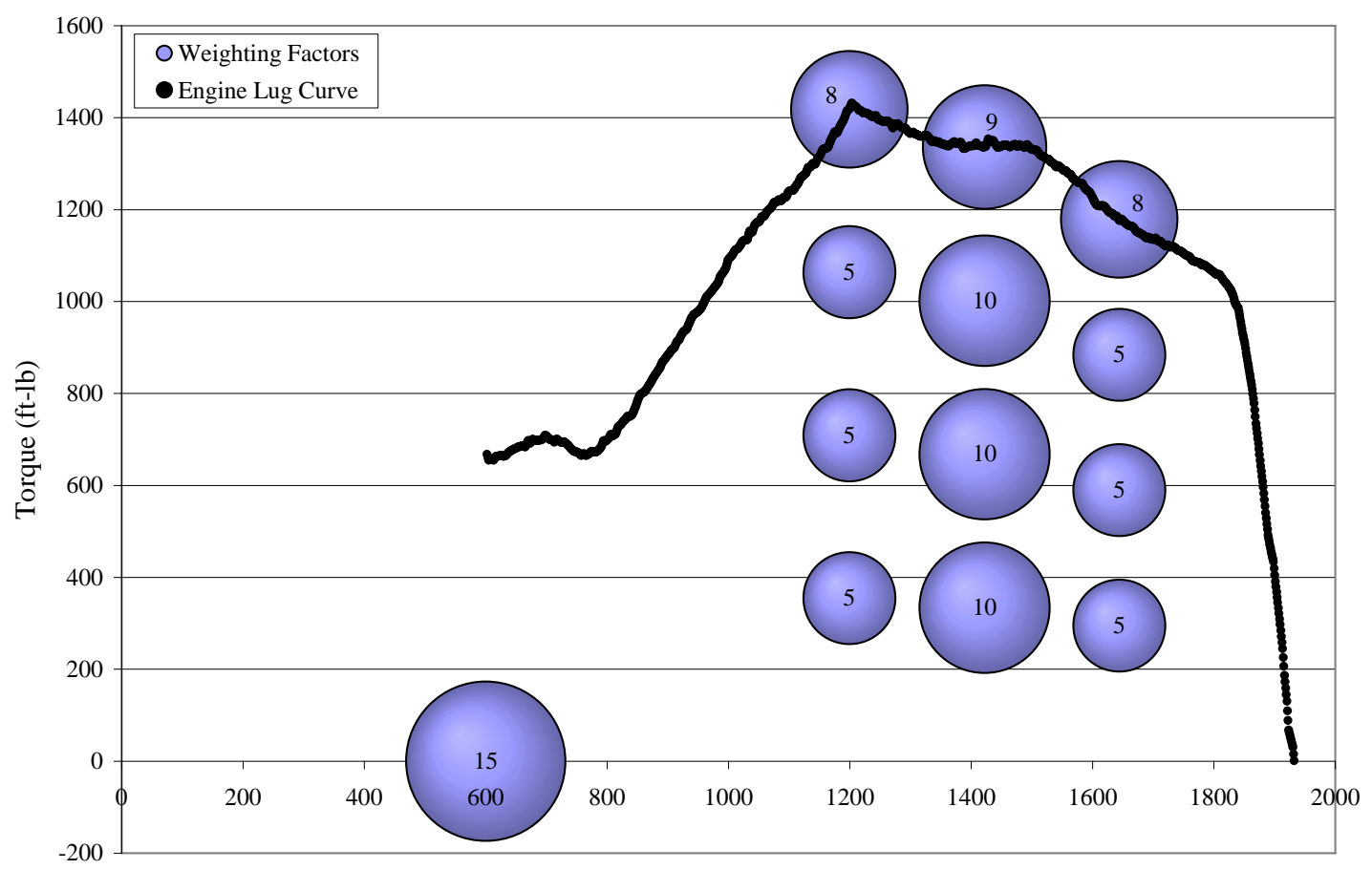

Engine Speed (rpm)

Figure 2-6 13-Mode SET Cycle Weight Factors 


\subsection{Previous Studies on Heavy-Duty Diesel Engine Regulated Emissions}

\subsubsection{Petroleum Diesel Fuel Properties}

In a study by the Petroleum Energy Center, tests were conducted to examine the effects of engine technology and fuel properties on diesel exhaust emissions [13]. Four heavy-duty diesel engines were selected, and they include: a DDC series 60 that was equipped with high pressure direct injection, a Cummins B 5.9 that was equipped with high pressure direct injection and an oxidation catalyst, and two Japanese engines, one with turbocharging and the other with natural aspiration. The U.S. made engines complied with 1994 emissions standards, while the two Japanese-made engines complied with 1991 Japanese emissions standards.

This study found that the use of an oxidation catalyst enabled THC, CO, and PM levels to be reduced, which holds true regardless of the test fuel used. Fuel modification was not as effective at reducing THC, CO, and PM as the oxidation catalyst. The high pressure injection effectively reduced PM emissions. The effects of fuel properties on exhaust emissions tended to remain unchanged regardless of the emissions test used, but the composition of PM emissions did change. It is fairly evident that improvements in engine technology have a greater impact on reducing emissions than fuel modification.

In a study performed by Southwest Research Institute, three test engines were initially chosen, but a 1991 DDC Series 60 was of most interest for continuing the study since it best reflected the future trends in engine development needed to meet 1991 emissions limits [14]. Three fuels were chosen from an original field of eight, and each had a sulfur level less than or equal to 500 parts per million. The sulfur level of each fuel was adjusted as needed using ditertiary butyl disulfate. In order to study the effects of fuel cetane number and aromatic content, these three fuels had a wide variation in both properties. 
It was found that NOx and TPM emissions responded to changes in both aromatic content and cetane number [14]. When the aromatics were reduced and the base cetane number was increased, NOx decreases. TPM was reduced when aromatic content was reduced. The greatest reduction of $\mathrm{HC}$ emissions was expected when the cetane number was increased from a low base cetane number. $\mathrm{CO}$ emissions responded the best with low cetane number fuels, and reduced when this base number was incrementally increased.

During a study conducted by Esso Research Centre, Statoil PKS Fuels Technology, and Rover Group, tests were performed on a recent technology light-duty engine to find the effect of fuel properties on emissions [15]. Seven test fuels were used during this study, which included four fuels varying in poly-aromatics and density. Two separate stages were performed during this study, where in the first stage the engine was run normal production configuration of its controls and in the second stage the engine EGR rate and injection timing were maintained at the manufacturer's setting using a modified control system.

During the first stage, it was found that fuel effects on regulated emissions constituents were consistent with previous studies, but changes in the engine calibration settings were occurring. The primary changes were occurring in the EGR rate and injection timing. With the use of the modified control system in the second stage, it was found that the emissions were substantially different. The differing results of the two stages confirmed that effects of fuel properties on engine calibration were major contributors to emissions effects. It was also found that fuel effects on in-cylinder processes can only be studied when the EGR rate and injection timing variables are held constant. If these variables of EGR rate and injection timing cold be held constant, an improvement in emissions and fuel economy would be seen, but this technology would be costly. 


\subsubsection{Biodiesel Fuel Properties}

In a study by Southwest Research Institute, MARC IV, and National Biodiesel Board, the use of biodiesel fuels derived from vegetable oils or animal fats as a substitute for conventional petroleum fuel in diesel engines is gaining attention because it is a renewable resource, is biodegradable, and reduces exhaust emissions [16]. Three modern diesel engines with and without oxidation catalysts were used to measure transient emissions. Neat biodiesel, blended biodiesel, and petroleum diesel were used, and the regulated emission constituents from each engine were measured.

It was found that the biodiesel created lower emission levels for HC, CO, and PM when compared to a conventional diesel fuel. This is most likely due to ten percent oxygen content by weight of the neat biodiesel. There was an increase in the NOx emissions by approximately 12 percent, and it was thought that this was due to the large amount of oxygen found in the fuel. Both the neat biodiesel and biodiesel blend reduced the engine power output, but the blend fuel had a much lower reduction of power.

During a study conducted by Colorado Institute for Fuels and High-Altitude Engine Research, conventional and biodiesel fuel blends were created to test the emission levels of NOx, CO, THC, and PM during a heavy-duty transient test [17]. A 1991 DDC Series 60 engine was used for this study. The tested fuels were $20 \%, 35 \%, 65 \%$ and $100 \%$ biodiesel blends.

As the amount of biodiesel increased in the test fuels, the level of NOx emissions also increased, but the other regulated emissions constituents decreased. It was determined that the increase in NOx was due to an increasing amount of oxygen in the fuels. The engine efficiency did not change, but the power output of the engine decreased slightly as the percentage of biodiesel increased. 


\subsubsection{Emissions Due to Combustion}

In a study conducted by Pennsylvania State University and Conoco Philips, experiments were completed with a 2000 commercially available six-cylinder direct-injection diesel engine [18]. Four different fuels were used to look into the effect on emission levels and combustion characteristics. These fuels included: a low sulfur diesel (BP325 - 325 ppm), an ultra-low sulfur diesel (BP15 - 15 ppm), and two 20\% biodiesel blends of the base fuels. The AVL 8-Mode test protocol was used to complete an in-cylinder pressure trace analysis as well as determine the emissions constituents of CO, NOx, THC, and PM.

Pallflex 90-mm filters were used to collect the PM sample over the complete 8-Mode steady-state test. In addition to obtaining a brake specific PM mass ( $\mathrm{g} / \mathrm{kWh}$ ), the filters were also analyzed for soluble organic fraction (SOF) and soot. The gaseous emissions were collected through a heated sample line, and measured with an AVL CEB II emissions analyzer.

This study found that the start of injection varied with each fuel, where the higher the density the earlier the start of injection. Higher NOx emissions are partially caused by an early start of injection, which was seen with the denser biodiesel blends. The overall gaseous emissions were found to decrease with the ultra-low sulfur diesel when compared to the low sulfur diesel base fuel. The ultra-low sulfur diesel showed the lowest gaseous emissions level, except there was an increase in NOx emissions due to the early start on injection when compared to the base fuels. The brake-specific fuel consumption for the two base fuels was equivalent, and there was an observed increase with the two biodiesel blends.

During a study completed by Wuhan Transportation University, three different diesel engine combustion chamber shapes were selected and simulated using a multidimensional modeling technique [19]. The turbulence energy, the squish, and the turbulence of each shape 
were analyzed, and to validate the numerical modeling, a single cylinder DI diesel engine was used to complete a set of experimental tests. The three combustion chamber types were: central projection type (chamber A), shallow w type (chamber B), and pataloid type (chamber C).

The numerical analysis portion of the study found that the squish flow in chambers $\mathrm{A}$ and B was higher than chamber C, which was caused by the contracted throats in chambers A and C. Combustion chambers A and B also show a similar total turbulence kinetic energy distribution, where high turbulence energy spreads from the lower region to the upper and outer regions of the chamber. This was the desired distribution because improved engine performance by promoting air and fuel mixing. Chamber $\mathrm{C}$ had high turbulence energy intensity in the center of the chamber which was not favorable for air fuel mixing at heavy loads. Chamber A had the best intensity of swirl because the peak was reached at TDC and only reduced by $9 \%$ at $50^{\circ}$ ATDC. This long swirl period would be good for an active airflow later in the combustion period, which would be beneficial to an accelerated diffuse burn and less smoke formation.

For the experimental portion of the study, only chambers A and C were used. The two chambers were tested at $11 \mathrm{~kW} / 2400 \mathrm{rpm}$ and $8 \mathrm{~kW} / 1600 \mathrm{rpm}$. Chamber A showed lower smoke emission at both speeds, and the fuel consumption and smoke production were less sensitive to injection timing when compared to chamber C. NOx emission was found to be higher with chamber A at the $1600 \mathrm{rpm}$ speed, which is caused by the increased premixed burn from the strong air motion. With the retardation of injection timing, chamber A had a large reduction in NOx and a slight increase in both fuel consumption and smoke emission.

\subsubsection{Emissions Due to Engine Control Unit (ECU) Changes}

In a study completed by FEV Motorentechnik GmbH \& Co., KG and Carl Schenck AG, an automatic optimization system that controls the whole calibration process of programming the 
ECU was developed [20]. Since many engine functions that reduce exhaust emissions and fuel consumption were managed by the ECU, the need for a sophisticated test system to automatically search for the optimized engine calibration was observed.

Using speed and load points, beginning of injection, and basic pump position were the independent parameters used to start the optimization procedure. With the use of a mathematical method, factors for each optimization loop were defined based on the previous loop. This was completed to avoid oscillation behavior and also have a fast convergence rate. After the optimization procedure was complete, a set of basic pump position and beginning of injection parameters for each speed and load point was obtained. The combined sets of data were the base for the final ECU map generation. The optimized system decreased the NOx level around 40\%, but the fuel consumption increased 3\%. Total hydrocarbons and particulate matter both increased, but stayed well below the test limits. It was found that the system could be adapted to many different test cycles and newer legislative emission limits.

\subsubsection{Diesel Fuel Additives}

During a study conducted by National Yunlin University of Science and Technology, several different fuel additives were added to diesel fuel with two different dosages and regulated emission levels were recorded [21]. The fuel additives, EHN, DTBP, MTBE, DMC, Diglyme, Monoglyme, and Ethanol, were added to the base diesel fuel and were classified into four categories: cetane number improver, oxygenate, deposit cleaner, and combustion improver.

It was shown that these additives can have a large impact on the spray penetration of the fuel, air-fuel mixing process, ignition delay, chemical reaction rates, and heat release. Some of the additives have a positive effect on the reduction of regulated emissions, but not necessarily all the constituents. Certain testing results show that some of the additives did not have a 
positive effect on the emission level. It is known that there is an optimized dosage for each of these additives in order to reduce emissions.

\subsubsection{Diesel Engine Design}

Cummins Engine Company conducted a study of the constraints caused by the fuel oxidation chemistry limitations are key determinants of the engine's overall design, determining allowed intake conditions, air-fuel ratios, compression ratio requirements, and the use of ancillary devices for exhaust emissions aftertreatment [22]. Peak cycle temperatures within the

combustion chamber cause NOx generation. Certain thresholds of intake manifold temperature and compression ratio must be met to start combustion.

When the chemical limits are combined with the design of the engine, constraints to the engines overall power output and emissions are made. Fuel oxidation chemistry limits the requirement for additional aftertreatment devices. All of the chemical limits can only be changed by manipulating the basic chemistry of the fuel oxidation process.

\subsection{Motivation}

Due to years of research and development, many changes have been made to both internal and external engine technology as well as fuel refinery processes; therefore a great reduction in the emissions levels has been seen. In order for older diesel engines to have a major reduction in exhaust emissions, many diesel fuel additives have been developed. The motive of this research is to complete an in depth study as to how these diesel additives affect recent technology engines as compared to early technology diesel engines.

In a previous study completed by Gibble [23], commercially available fuels were tested on a 1999 Ford B250 engine using the FTP cycle, the steady-state cycle, and in-use testing. This 
study found emission level differences during in-use testing were attributed to differences in fuel properties. In a separate study completed by Reddy [24], commercially available fuels were tested on both a 1992 DDC Series 60 and a 2004 Cummins ISM 370 using the FTP and steadystate cycles. This study found the reduction in emission levels due to fuel property changes was small when compared to advancements in engine technologies. The current research takes the two previous studies into consideration, but with the addition of changing fuel properties by way of diesel fuel additives. 


\section{Experimental Procedures and Equipment}

\subsection{Introduction}

The experimental equipment and procedures used in performing this study were conducted at the Center for Alternative Fuels, Engines, and Emissions (CAFEE) at West Virginia University which operates in compliance with 40 CFR Part 86, Subpart $N$ and the standards set by ISO 8178 [1]. Five engines - 1991 Detroit Diesel Corporation S60, 1992 Detroit Diesel Corporation S60, 1992 rebuilt Detroit Diesel S60, 1999 Cummins ISM 370, and 2004 Cummins ISM 370 were chosen for this study in order to represent a wide spectrum of engine technologies from the CAFEE inventory. In addition, all of these engines produce approximately $370 \mathrm{hp}$, allowing a comparison between the engine technologies to be made while holding at least one variable constant. The following contains a detailed summery of all engines, equipment, and procedures used during this study.

\subsection{Test Engines}

In order for each of the engines listed below to be tested in a laboratory environment, some changes were made in order for the engines to be accommodated. The intercooler found in a typical on-road vehicle was replaced with a liquid-to-air intercooler, and the radiator was replaced with a liquid-to-liquid heat exchanger. All of the accessories such as the fan and air conditioning unit were either disengaged or removed. The CAFEE heating, ventilation, and air

conditioning system provided the intake restriction and the intake filter was replaced with a laboratory filter. An exhaust backpressure valve, located on the exhaust pipe, took the place of the exhaust muffler. 


\subsubsection{Detroit Diesel Series 60}

A turbocharged, direct-injection, inline six cylinder DDC Series 60 engine was used during part of this study to analyze the exhaust emissions in a laboratory setting. This engine met the EPA emissions standards for 1991, which was previously mentioned in Table 1-1. This engine was rebuilt to original DDC specifications and previously used by the Colorado School of Mines in order to complete fuel studies, but was later obtained by National Renewable Energy Laboratories (NREL). NREL loaned this engine to WVU. Since it has been rebuilt to original DDC specifications, this engine can be considered a pristine laboratory engine which is very suitable for HDDE emissions testing. A display of the engine specifications can be found in Table 3-1 and the engine can be seen in Figure 3-1. A representative map from the engine used for testing can be seen in Figure 3-2.

\subsubsection{Detroit Diesel Series 60}

A turbocharged, direct-injection, inline six cylinder DDC Series 60 engine was used during part of this study to analyze the exhaust emissions in a laboratory setting. This engine met the EPA emissions standards for 1991, which can be found in Table 1-1. The 1992 DDC S60 was a salvaged engine which had no known history prior to becoming part of the WVU CAFEE engine inventory. The cylinder head has been cleaned, and regular engine maintenance has been performed on this engine since becoming a part of the CAFEE inventory. A display of the engine specifications can be found in Table 3-1, and the engine can be seen in Figure 3-3. A representative map from the engine used for testing can be seen in Figure 3-4. 


\subsubsection{Rebuilt Detroit Diesel Series 60}

This engine was the same as the 1992 DDC S60, except it had been rebuilt in 2006. WVU also obtained this engine from a salvage yard without prior history of its use or care. The engine was aged on the engine dynamometer for 100 hours before testing began. This engine has been completely rebuilt to the original 1992 DDC specifications, and it also complies with the 1991 EPA emissions standards (found in Table 1-1). Like the 1991 DDC S60, can be considered a pristine laboratory engine which is suitable for emissions testing and in-cylinder pressure analysis. The specifications for this engine can be found in Table 3-1, and the engine can be seen in Figure 3-5. Figure 3-6 represents an engine map used for testing. This engine provided in-cylinder pressure data which is the dissertation topic of John Nuszkowski [25]. Incylinder pressure data will not be used in this work.

\subsubsection{Cummins ISM 370}

A turbocharged, direct-injection, inline six cylinder Cummins ISM 370 engine was used during part of this study to analyze the exhaust emissions in a laboratory setting. The engine complied with 1998 emissions standards, which were previously mentioned in Table 1-1. This engine was procured from Cummins Engine for a previous project and has been in the WVU CAFEE inventory since. This engine is considered a pristine laboratory engine. The engine specifications for this engine can be found in Table 3-1. The engine can be seen in Figure 3-7 and the representative engine map which was used for testing can be seen in Figure 3-8.

\subsubsection{Cummins ISM 370}

This engine was designed for providing good performance and fuel economy, as well as greatly reducing the overall NOx production. This engine was similar to the 1999 Cummins ISM 
370 with the exception of a variable geometry turbocharger and cooled EGR. The engine complied with 2004 Option 2 EPA emissions standards, which were previously mentioned in Table 1-1. This engine was procured from Cummins Engine for a previous project and has been in the WVU CAFEE inventory since. This engine is considered a pristine laboratory engine. The engine specifications for this engine can be found in Table 3-1. The engine can be seen in Figure 3-9 and the representative engine map which was used for testing can be seen in Figure 3-10.

Table 3-1 Engine Specifications

\begin{tabular}{|c|c|c|c|c|c|}
\hline Engine Manufacturer & $\begin{array}{l}\text { Detroit Diesel } \\
\text { Corporation }\end{array}$ & $\begin{array}{l}\text { Detroit Diesel } \\
\text { Corporation }\end{array}$ & $\begin{array}{l}\text { Detroit Diesel } \\
\text { Corporation }\end{array}$ & Cummins & Cummins \\
\hline Engine Model, Year & $\begin{array}{c}\text { DDC Series 60, } \\
1991\end{array}$ & $\begin{array}{c}\text { DDC Series 60, } \\
1992\end{array}$ & $\begin{array}{c}\text { Rebuilt DDC Series 60, } \\
1992\end{array}$ & $\begin{array}{c}\text { ISM } 370 \text { ESP, } \\
1999\end{array}$ & $\begin{array}{l}\text { ISM 370, } \\
\quad 2004\end{array}$ \\
\hline Configuration & Inline 6 cylinder & Inline 6 cylinder & Inline 6 cylinder & Inline 6 cylinder & Inline 6 cylinder \\
\hline Displacement (L) & 11.1 & 12.7 & 12.7 & 10.7 & 10.7 \\
\hline Power Rating (hp) & $345 @ 1800$ rpm & $360 @ 1810$ rpm & $360 @ 1810$ rpm & $370 @ 2100$ rpm & $370 @ 2100$ rpm \\
\hline Torque Rating (ft-lbs) & $1335 @ 1200$ rpm & $1450 @ 1200$ rpm & $1450 @ 1200$ rpm & $1450 @ 1200$ rpm & $1450 @ 1200$ rpm \\
\hline Compression Ratio & $16.5: 1$ & $15: 1$ & $15: 1$ & $16.5: 1$ & $16.5: 1$ \\
\hline Bore X Stroke (mm x mm) & $130 \times 139$ & $135 \times 165$ & $135 \times 165$ & $125 \times 147$ & $125 \times 147$ \\
\hline Air Handling & $\begin{array}{l}\text { Turbocharged, } \\
\text { Aftercooled }\end{array}$ & $\begin{array}{l}\text { Turbocharged, } \\
\text { Aftercooled }\end{array}$ & $\begin{array}{l}\text { Turbocharged, } \\
\text { Aftercooled }\end{array}$ & $\begin{array}{l}\text { Turbocharged, } \\
\text { Aftercooled }\end{array}$ & $\begin{array}{l}\text { Turbocharged, } \\
\text { Aftercooled }\end{array}$ \\
\hline Exhaust Gas Recirculation (EGR) & N/A & N/A & N/A & N/A & Cooled EGR \\
\hline
\end{tabular}




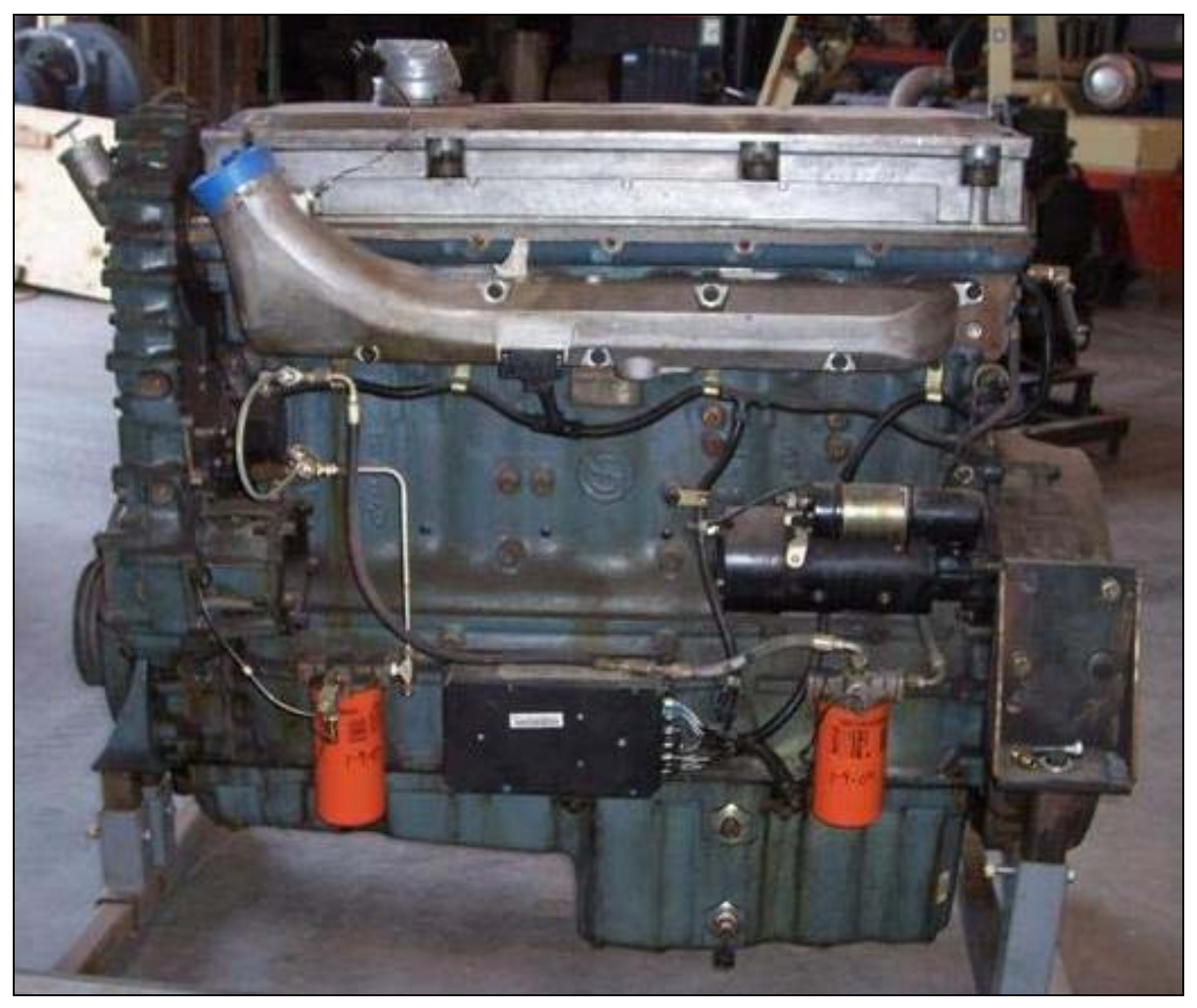

Figure 3-1 1991 DDC S60

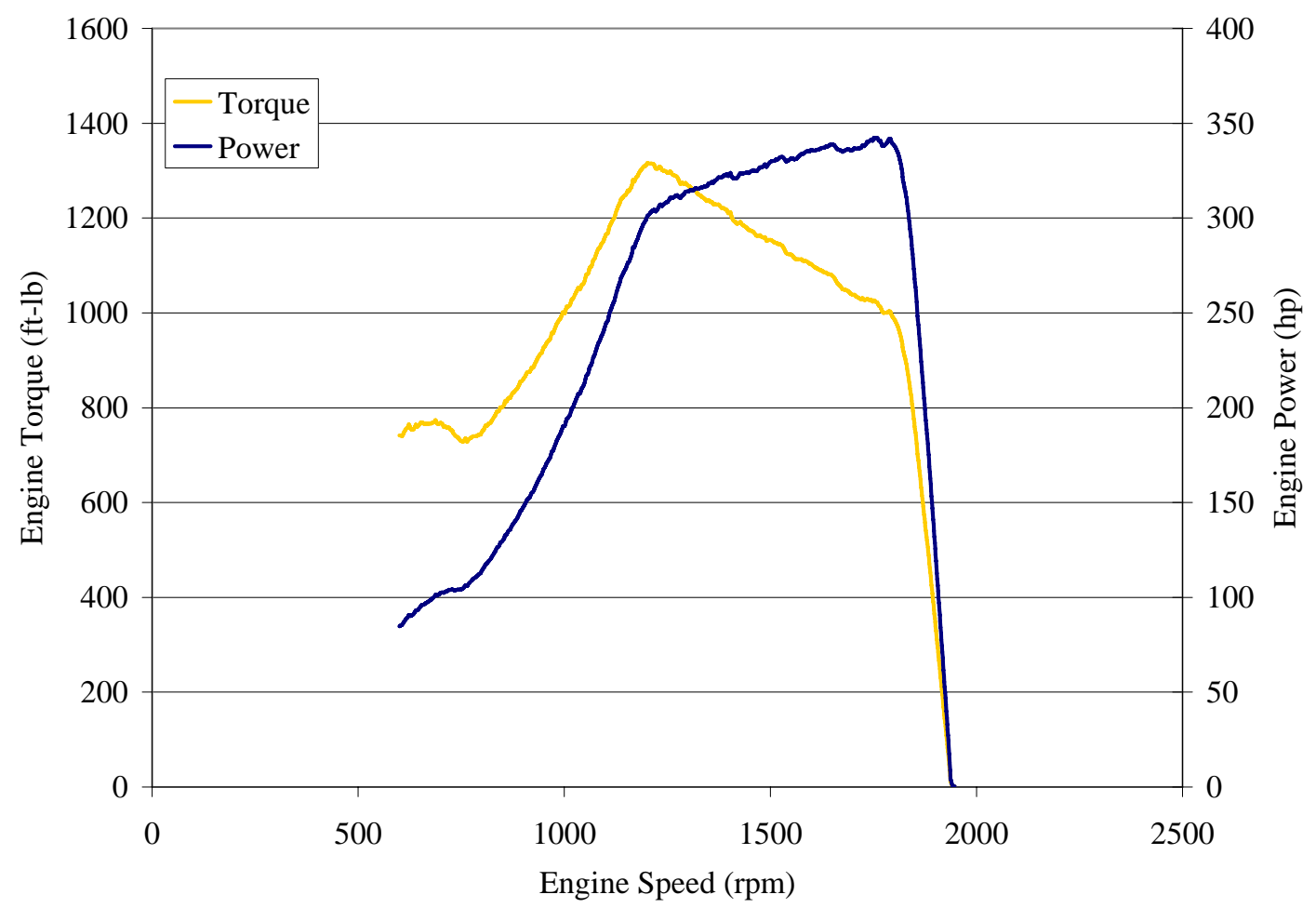

Figure 3-2 Engine Map for 1991 DDC S60 


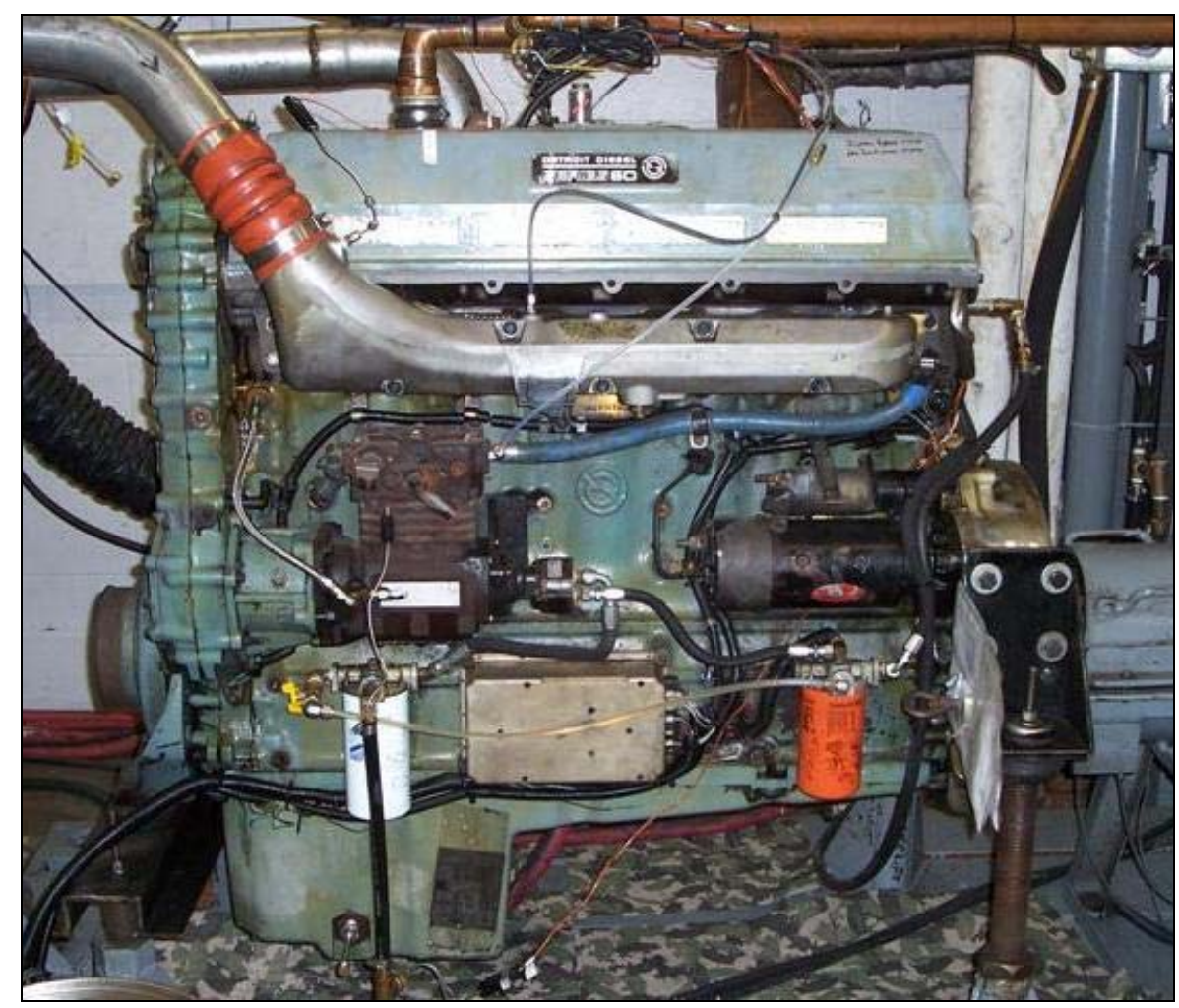

Figure 3-3 1992 DDC S60

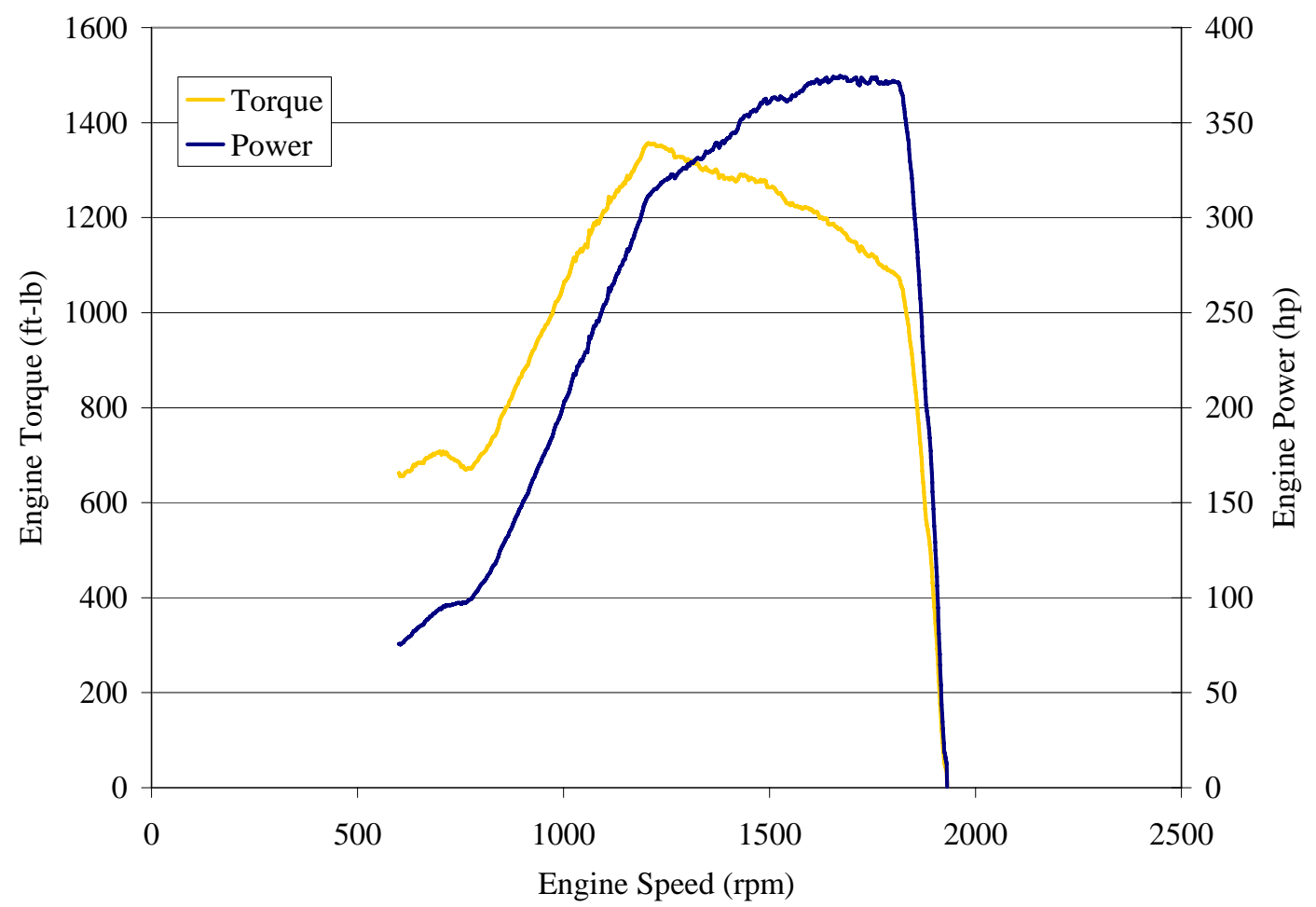

Figure 3-4 Engine Map for 1992 DDC S60 


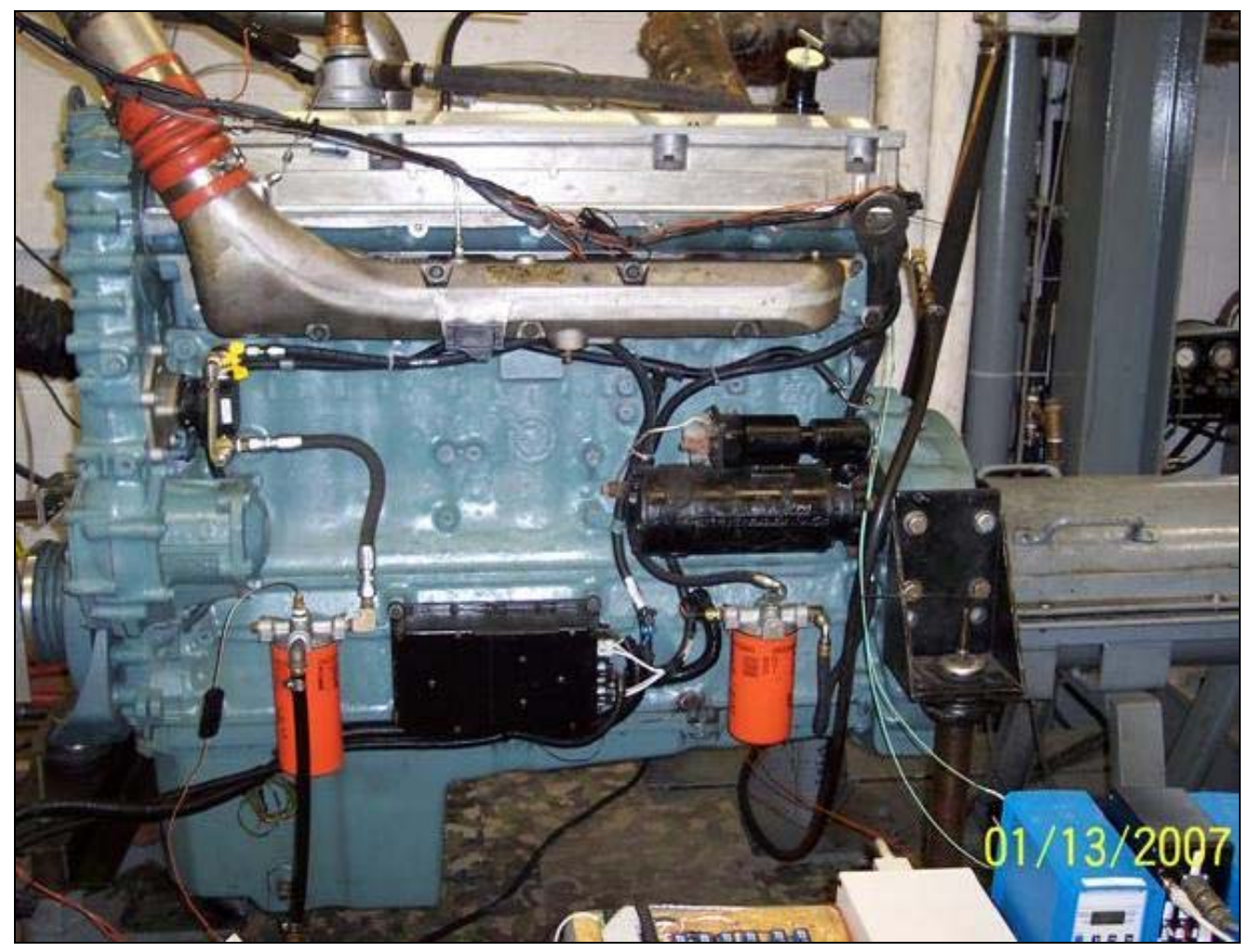

Figure 3-5 1992 Rebuilt DDC S60

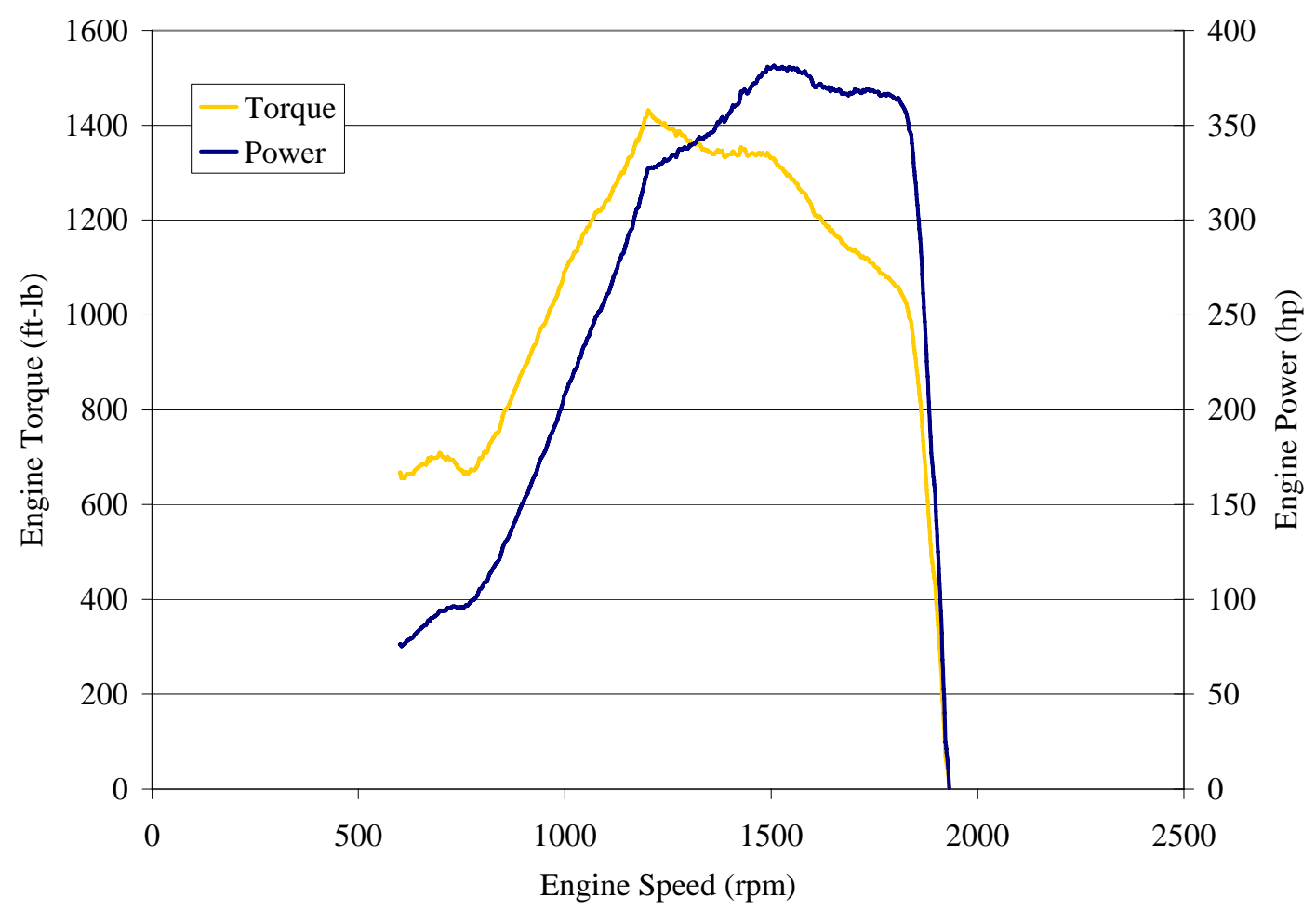

Figure 3-6 Engine Map for Rebuilt 1992 DDC S60 


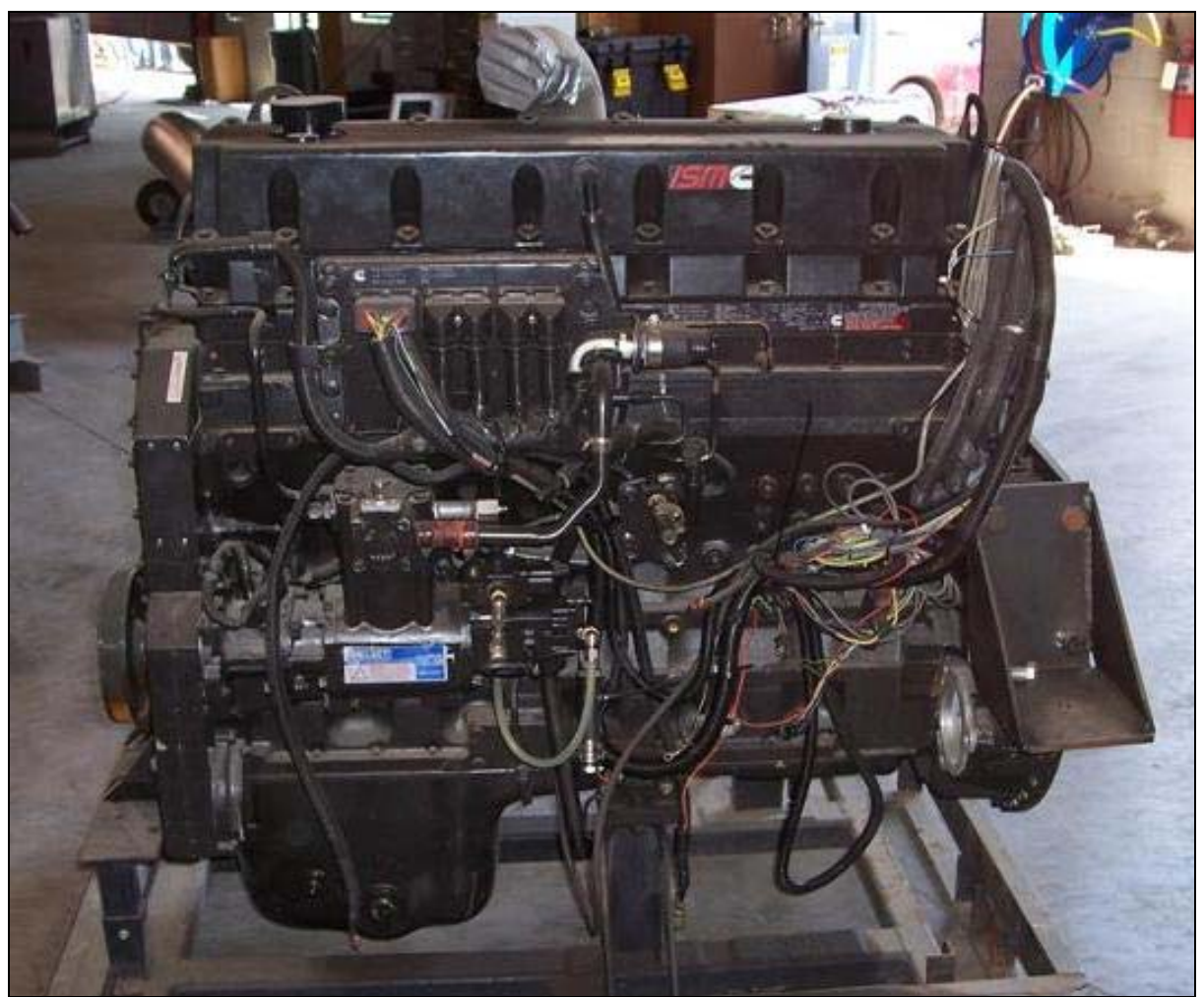

Figure 3-7 1999 Cummins ISM 370

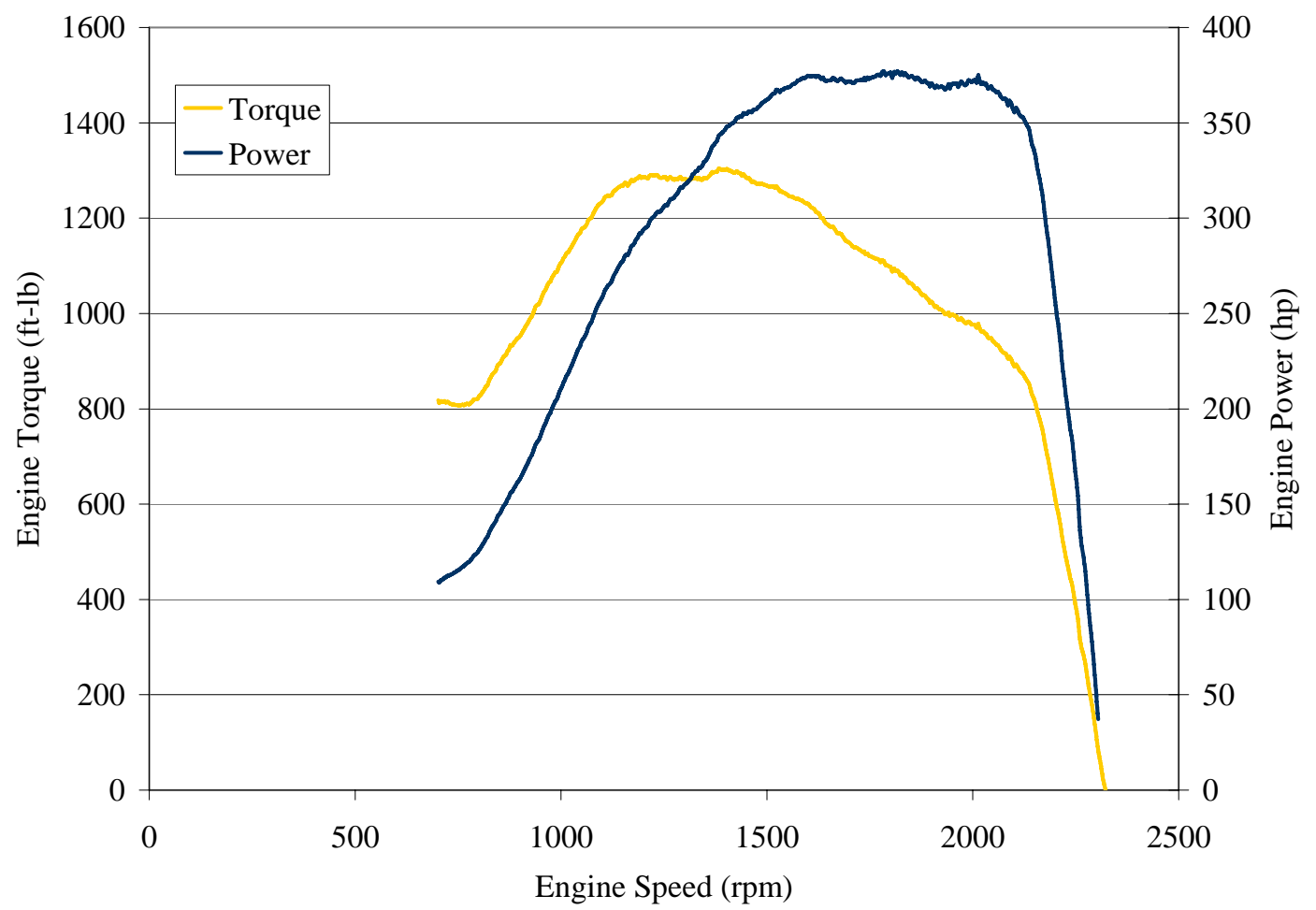

Figure 3-8 Engine Map for 1999 Cummins ISM 370 


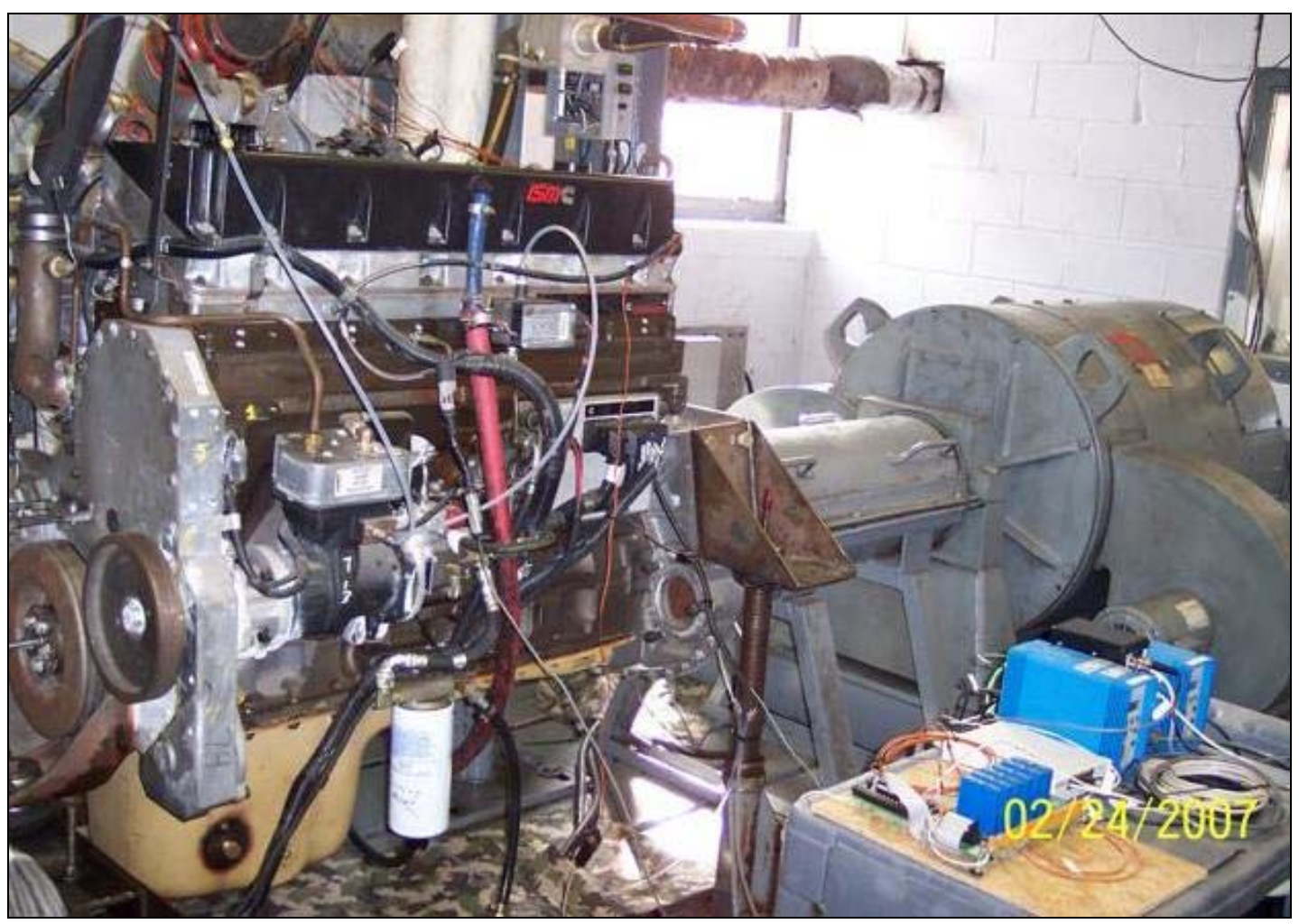

Figure 3-9 2004 Cummins ISM 370

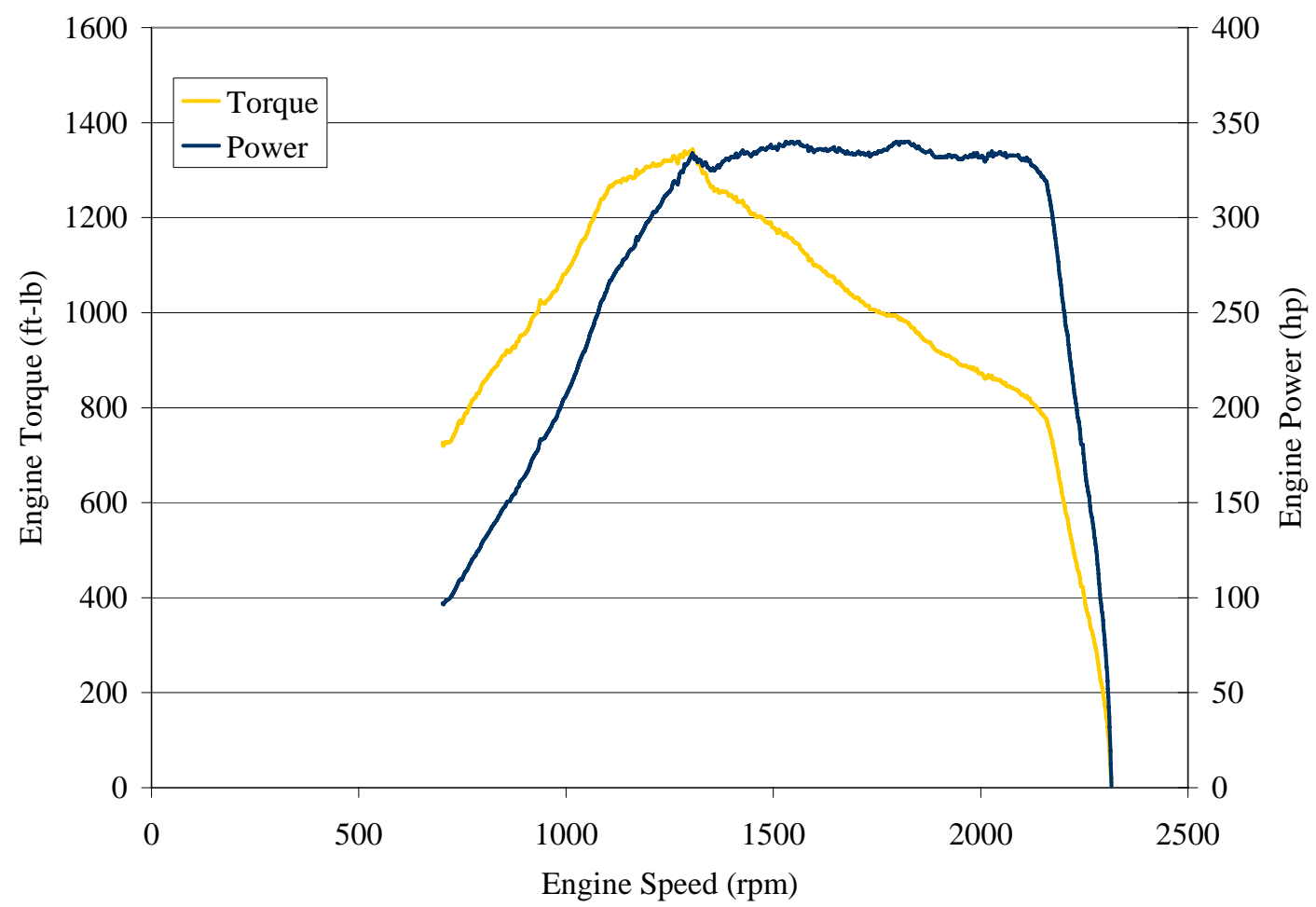

Figure 3-10 Engine Map for 2004 Cummins ISM 370 


\subsection{Engine Parameters}

During the engine testing procedure, several parameters were recorded in order to ensure proper engine function. These parameters included: manifold air temperature and pressure, intake depression, exhaust back pressure, exhaust temperature, coolant temperature, and oil temperature. Several other parameters were also recorded in order to insure the laboratory was functioning properly, and all of these parameters were checked at the end of each test cycle in order to validate the test. The other parameters recorded included: water inlet and outlet temperatures for each of the heat exchangers, fuel temperature, intake air temperature, and intake air humidity. The parameters listed above, along with several other measurements, were required for the calculation of the regulated emissions.

\subsection{Engine Dynamometer}

The CFR required the engine to be operated within a sufficiently close range to the set point over the entire test cycle [1]. The regression limits laid out in the CFR require the engine dynamometer speed and engine throttle be controlled. The engine speed is controlled by the dynamometer which is commanded to the set point speed. The dynamometer then forces the engine to rotate. A proportional-integral-derivative (PID) controller methodology was used to specify and adjust the throttle position, and these parameters are normally tuned for a specific engine to meet the regression requirements of the FTP.

The dynamometer used for testing during this study at the CAFEE was a General Electric direct current model DYC 243 and can be seen in Figure 3-11. The dynamometer is capable of absorbing 550hp and delivering up to 500hp. The engine is coupled to the dynamometer using a Vulkan coupling and drive shaft. The engine speed was determined by a digital encoder attached to the dynamometer, and a load cell mounted on the dynamometer measured the force, which 
was used to calculate the engine torque. In order to be in compliance with 40 CFR, Part 86, Subpart N, the dynamometer was calibrated in accordance with the procedures followed at CAFEE [26].

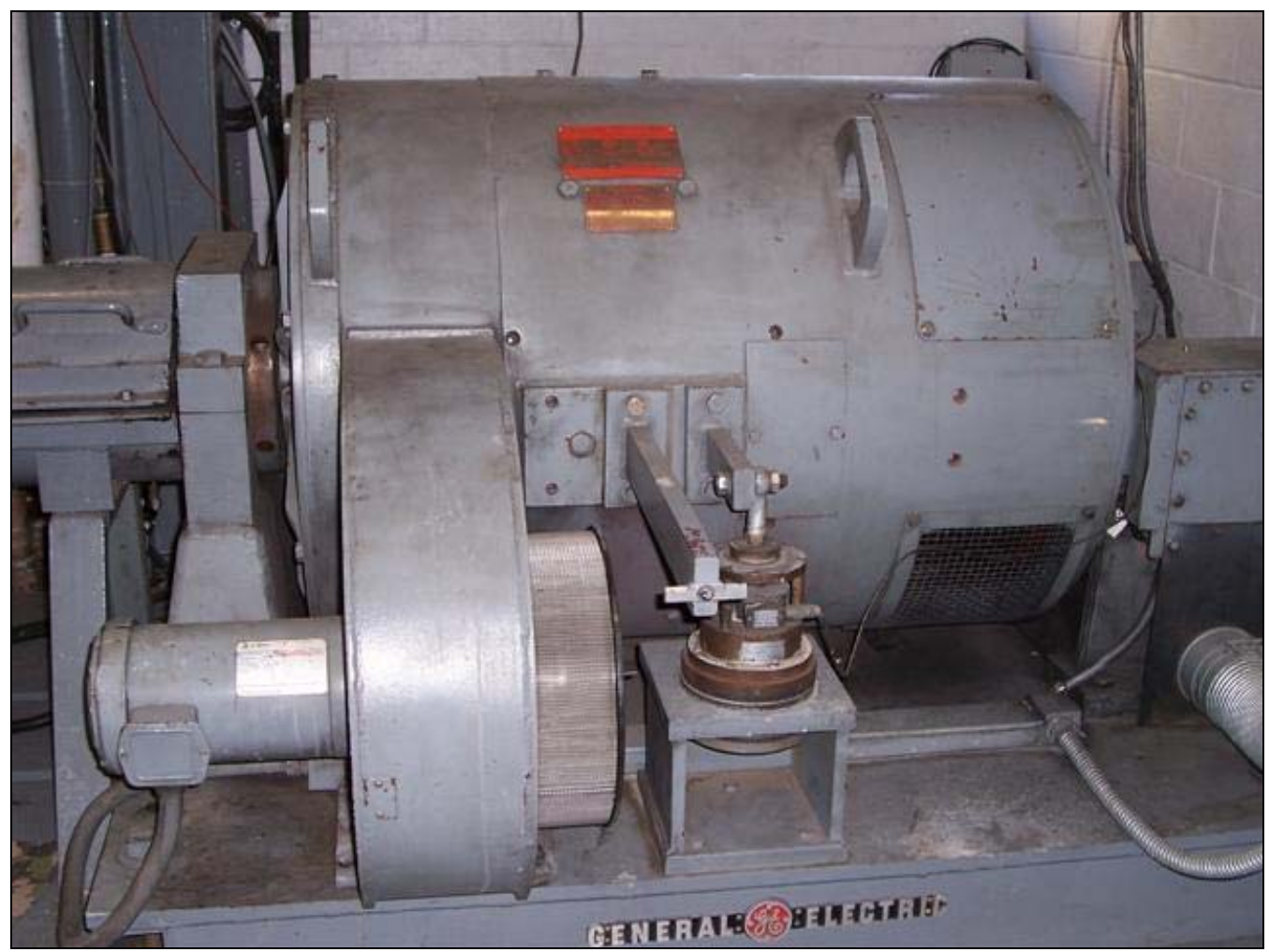

Figure 3-11 GE Engine Dynamometer

\subsection{Full-Scale Dilution Tunnel and Sampling System}

A full-scale dilution tunnel was used at WVU in order to measure the effects of exhaust emissions on a simulated real world environment. A full-scale dilution tunnel dilutes the entire amount of engine exhaust with ambient air. The dilution of the exhaust allows a multitude of reactions to occur and also lowers the exhaust temperature, which was necessary to remove any water droplets that could negatively affect the emissions measurement. The primary purpose of the dilution tunnel was to allow for the formation of particulate matter, but the measurement of gaseous emissions was also simplified with the full-scale dilution. 
A constant volume sampler system (CVS) was used on the full-scale dilution tunnel. The total volume of the mixture of exhaust and dilution air must be measured in order to satisfy the CVS method of measuring the emissions mass. A 75hp blower was used to pull the diluted exhaust through a set of four critical flow venturis (CFV) (three $1000 \mathrm{scfm}$ and one $400 \mathrm{scfm}$ ) in order to determine the mass flow rate of the dilution tunnel exhaust. A mixing orifice was placed at the end of the insulated engine exhaust pipe in order to facilitate proper mixing of raw engine exhaust and ambient air. Located 10 diameters downstream, the sampling plane of analyzer probes collected the diluted engine exhaust through heated sampling lines so no condensation would occur. The 18 inch stainless steel tunnel and mixing orifice are shown in Figure 3-12.

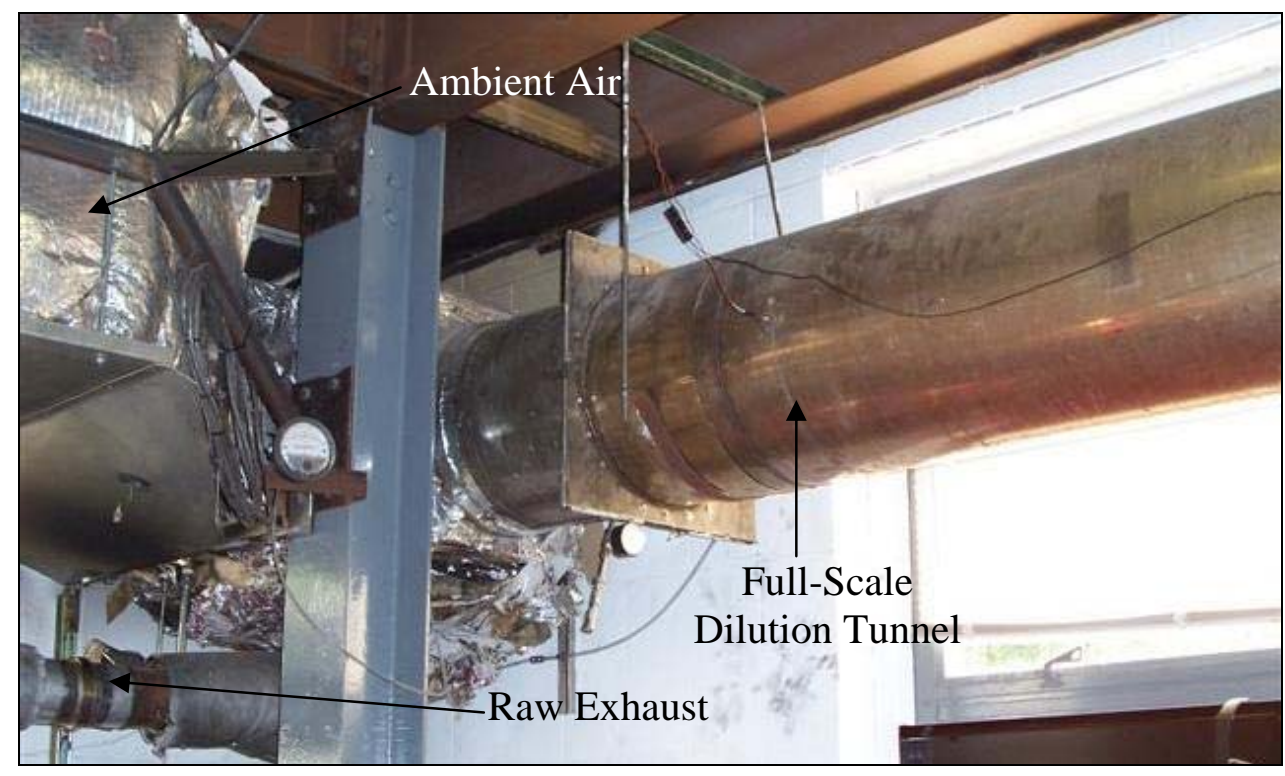

Figure 3-12 Stainless Steel Dilution Tunnel with Mixing Orifice

\subsubsection{Critical Flow Venturi}

The CFV-CVS system at the CAFEE had one $400 \mathrm{scfm}$ venturi and three $1000 \mathrm{scfm}$ venturis, but this study only utilized the single $400 \mathrm{scfm}$ venturi and two of the $1000 \mathrm{scfm}$ venturis for a total flow rate of $2400 \mathrm{scfm}$. The venturi flow rate was proportional to the 
pressure and temperature before the diluted exhaust entered the venture throat. The mass flow rate through the dilution tunnel with the use of a CFV was calculated by the following equation:

$$
Q(s c f m)=K_{v} \frac{P_{a b s}}{\sqrt{T_{a b s}}} . \quad \text { Equation 3-1 }
$$

Where, Q (scfm) was the standard volumetric flow rate at 29.92 in $\mathrm{Hg}$ and $68^{\circ} \mathrm{F}$.

$\mathrm{K}_{\mathrm{v}}$ was the calibration constant for the operating venturis.

$\mathrm{P}_{\mathrm{abs}}$ was the absolute pressure before the venturi entrance.

$\mathrm{T}_{\mathrm{abs}}$ was the absolute temperature of the diluted exhaust before the venturi entrance.

\subsubsection{Gaseous Sampling System}

The gaseous sampling system at the WVU CAFEE consisted of heated sampling probes and lines, heated pumps, heated filters, a chiller unit, exhaust gas analyzers and an exhaust system. The stainless steel sampling probes were placed in a radial fashion 10 diameters from the mixing orifice on the dilution tunnel. The sampling plane can be seen in Figure 3-14. Connected to the heated probes were heated sampling lines, which led to the rear of the emissions analyzer bench. The heated lines and probes were maintained at a temperature above the dew point to prevent condensation, and the individual temperatures were dependant on the emissions specie. NOx and $\mathrm{CO} / \mathrm{CO}_{2}$ heated lines were maintained at $235 \pm 20^{\circ} \mathrm{F}$ so as to prevent water condensation, whereas THC heated lines and probes were maintained at $375 \pm 20^{\circ} \mathrm{F}$ to prevent condensation of the heavier hydrocarbons.

The exhaust sample was then filtered with heated micro-fiber filters maintained at $235^{\circ} \mathrm{F}$, except the THC analyzer had an internal filter and pump. The sample was then pumped into the back of the emissions analyzers by heated pumps (Unique Products Model No. 1584). The $\mathrm{CO} / \mathrm{CO}_{2}$ sample was pumped through the chiller unit (Dominic Hunter Model No CD5-100), 
which removed the water in the sample before being pumped to the back of the analyzer. The gas analyzer bench consisted of several different exhaust emission analyzers, which are explained in more detail in Section 3.6.

\subsubsection{Particulate Sampling System}

In order to accurately measure TPM emission mass, a gravimetric-based approach was used at the WVU CAFEE. A small slipstream was taken from the main dilution tunnel for the TPM measurement, and a secondary dilution tunnel was used to allow for further dilution of the slipstream sample. The filter face temperature was maintained below $125^{\circ} \mathrm{F}$, before it entered the stainless steel filter holder through a small transfer tube. Primary and secondary filters were used, in series, in order to improve filter trapping efficiency. These filters were $70 \mathrm{~mm}$ fluorocarbon-coated glass fiber filters, model T60A20. The volumetric flow rate through the filter was controlled by a mass flow controller. The filters were pre-conditioned and weighed prior to and after testing in a controlled clean-room environment. The TPM sampling system can be seen in Figure 3-14.

\subsection{Exhaust Gas Analyzers}

The exhaust emissions analyzer bench at the WVU CAFEE consists of analyzers manufactured by Horiba, Rosemount Analytical, California Analytical and Eco Physics as shown in Figure 3-13. These analyzers are capable of analyzing THC, NOx, $\mathrm{CO}$ and $\mathrm{CO}_{2}$. A NOx efficiency tester is also located on the bench to test the converter efficiency in the NOx analyzer. This section discusses a brief principle of operation and specification for each analyzer type. 


\subsubsection{Hydrocarbon Analyzer}

A heated flame ionization detector (HFID) was used to measure the total hydrocarbon concentration in the gaseous exhaust sample (Rosemount Analytical - Model 402). An HFID has a heated oven which contains a burner with a heated pump. The small flame within the analyzer is sustained by a regulated flow of air and a $40 \%$ / $60 \%$ mixture of hydrogen and helium. A split ring detector within the analyzer has polarized electrodes to establish an electrostatic field and collect positive ions. When the regulated sample is introduced into the burner, it is ionized within the flame and the electrostatic field causes a small current between the electrodes. The measured current is directly proportional to the total hydrocarbon concentration in the sample. A secondary hydrocarbon analyzer (California Analytical - 600-HFID) was used as a quality control / quality assurance (QA/QC) device, and both analyzers have a linear response curve.

\subsubsection{Oxides of Nitrogen Analyzers}

Oxides of nitrogen were measured with two separate analyzers using two separate sampling systems. The primary NOx analyzer was the Rosemount Analytical Model 955, and the Eco Physics CLD $844 \mathrm{CM}$ h was the QA/QC device. The Eco Physics analyzer had two parallel reaction chambers to guarantee simultaneous measurement of NO and NOx so a precise $\mathrm{NO}_{2}$ value could be generated [27]. Both analyzers worked on the principle of chemiluminescence, which produced light photons by a chemical or electrochemical reaction. NO reacts with ozone $\left(\mathrm{O}_{3}\right)$ to form $\mathrm{NO}_{2}$, and approximately $10 \%$ of this formed $\mathrm{NO}_{2}$ is in an excited state. The excited $\mathrm{NO}_{2}$ immediately released a photon in order to reach a stable, nonexcited state. The released photons were then detected by a photon detector, and the number of detected photons was directly proportional to the number of NO molecules in the sample. NOx was detected by first passing the sample through a $\mathrm{NO}_{2}$ to $\mathrm{NO}$ converter before the 
chemiluminescence detector. The level of NOx in the sample was detected by the device that responded proportionally to the $\mathrm{NO}$ in the sample and the $\mathrm{NO}$ formed from $\mathrm{NO}_{2}$ dissociation. Both the Rosemount 955 and the Eco Physics analyzers have a linear response curve.

\subsubsection{Carbon Monoxide and Carbon Dioxide Analyzers}

A Horiba AIA-210 and a Horiba AIA-210 LE were used to measure $\mathrm{CO}$ and $\mathrm{CO}_{2}$ emissions, respectively. Both analyzers are non-dispersive infrared (NDIR) devices, which is based on the infrared absorption spectrum of gases. The absorbed energy was measured, and this information was used to determine the concentration of specific gases in the gaseous sample. A low CO analyzer was used for low ranges (up to 1000 ppm), and a high CO analyzer was used for high ranges (up to $5000 \mathrm{ppm}$ ). In having two $\mathrm{CO}$ analyzers, the wide range of $\mathrm{CO}$ emissions produced during an FTP or steady state test could be measured more accurately.

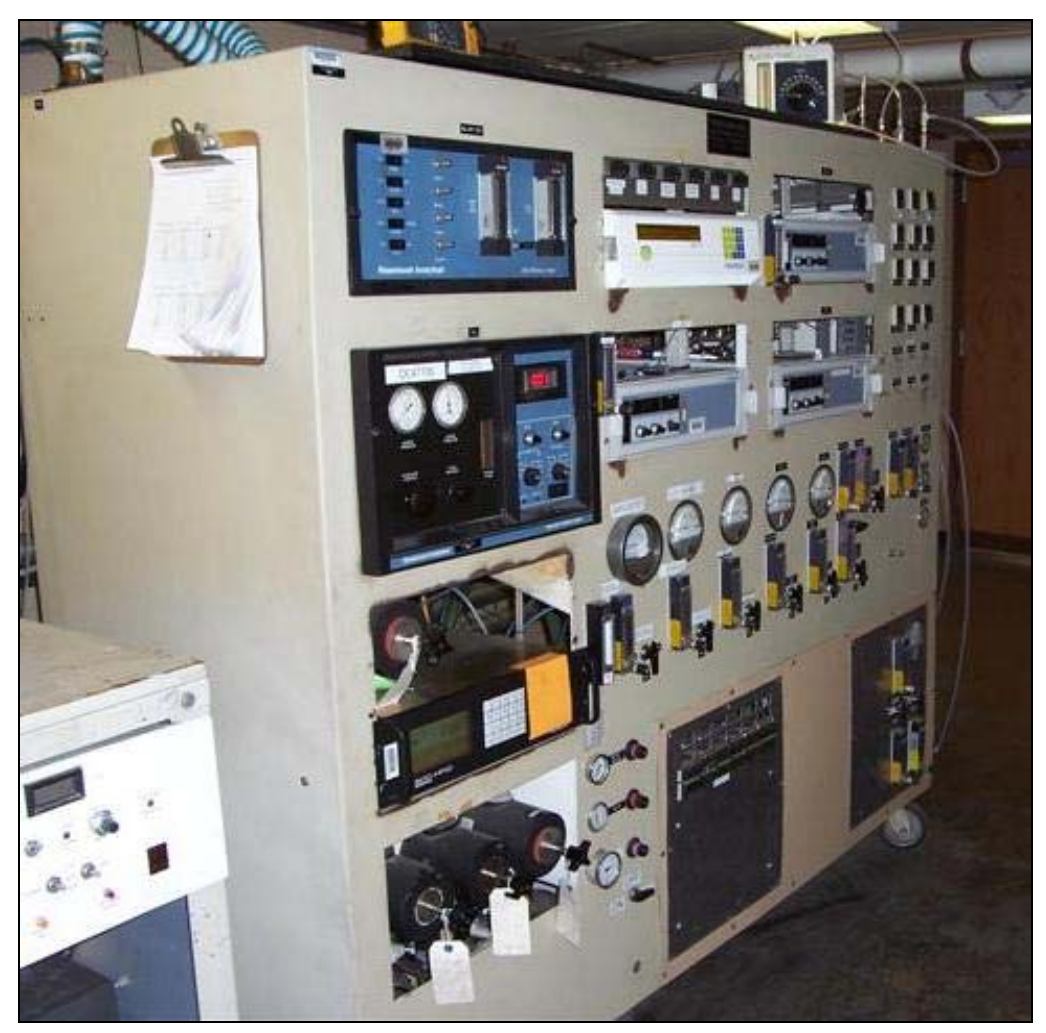




\section{Figure 3-13 Exhaust Analyzer Bench}

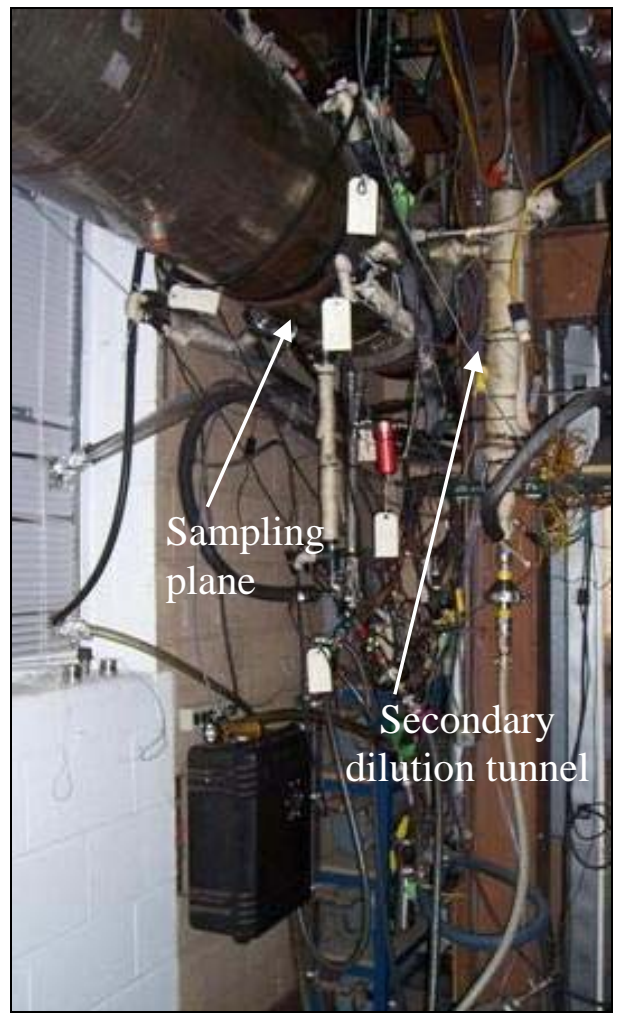

\section{Figure 3-14 Sampling Plane and PM Sampling System}

\subsection{Bag Sampling}

An integrated emissions analysis was completed with the use of the exhaust emissions analyzers previously mentioned and two 80-liter Tedlar bags. The background bag sample was taken upstream of the dilution tunnel before the exhaust gases were mixed into the ambient air. The dilute bag sample was taken from a probe located in the sampling plane.

The contents of each bag were analyzed separately using the emissions analyzers, and the values were recorded using a data acquisition system (section 3.11). Both bags were completely evacuated at the end of the analysis period so as to be ready for the next test. In order to account for the influence of ambient air pollutants, the background bag emissions values were subtracted from the continuous sample or dilute bag values. 


\subsection{Intake Air Flow Measurement}

The intake volumetric air flow rate for each engine was measured using a laminar flow element (LFE) manufactured by Meriam Instruments (Model No. 50MC2-6) as a QA/QC check. The differential pressure across the LFE was measured using an Omega differential pressure transmitter. The inlet temperature to the LFE was measured using a resistance temperature device. The inlet temperature and the pressure differential were then used to calculate the actual volumetric flow rate. The absolute pressure was also measure upstream of the LFE.

\subsection{Intake Temperature and Humidity Measurement Devices}

An HX52 temperature-humidity transmitter, located upstream of the LFE, was used to measure the intake temperature and relative humidity. The temperature and relative were also measured in the air handling system before the mixing orifice using a wet bulb / dry bulb system. Since the two systems were at different locations in the CAFEE, difference in the temperatures and relative humidity readings were different. A GE sensor hygrometer was located in the intake pipe after the LFE, and this device was used to measure the intake air humidity. The GE sensor was used to reduce the laboratory data for the NOx correction factor. A second hygrometer, the EdgeTech DewPrime II, was used to calibrate the GE sensor hygrometer and also as a QA/QC check to verify the intake air temperature and humidity.

\subsection{Fuel Measurement}

There were three methods used at the WVU CAFEE in order to calculate the amount of consumed fuel. The first method used the amount of carbon measured in the dilute exhaust which was proportional to the amount of combusted fuel. The fuel consumption equation 
required the specific gravity of the test fuel, the hydrogen-to-carbon and oxygen-to-carbon ratio of the test fuel, and the mass of $\mathrm{HC}, \mathrm{CO}$ and $\mathrm{CO}_{2}$.

The second method used was measuring the fuel flow with a Max Machinery (Model 710) fuel conditioning system. The fuel measurement system consisted of a fuel tank, fuel supply and return lines, fuel meter, fuel pump, and a heat exchanger. The heat exchanger allowed the fuel to be at or below $109^{\circ} \mathrm{F}$ before it entered the engine, so as to comply with 40 CFR Part 86, Subpart N. The fuel metering system had an output of counts, which was the digital signal recorded to measure the mass flow rate of the fuel into the engine.

The last method used was a fuel scale which measured the mass of the test fuel in a 16gallon fuel barrel. The fuel weight was measured prior to the start and the end of each test cycle in order to find the overall fuel consumption. This scale was accurate to approximately $0.5 \%$ of the FTP fuel consumption.

\subsection{Instrumentation Control and Data Acquisition}

Most of the laboratory measurements were recorded with a computer-controlled data acquisition (DAQ) system, which is shown in Figure 3-15. The transducers voltage output was proportional to some physical measurement. Some of the transducers transmit a current that was proportional to a physical measurement, and since the DAQ records voltage these signals must be converted to a voltage. Signal conditioning, such as a low pass filter or excitation for a strain gage was used to account for variations.

A “3B” module was used at the WVU CAFFEE for signal conditioning, isolation, signal linearization, and zero and span. The voltage output from the 3B module was recorded as an analog-to-digital (ADC) value, and these values were converted into engineering units through 
calibration files. If an error were to be found in the calibration, the data was able to be reprocessed.

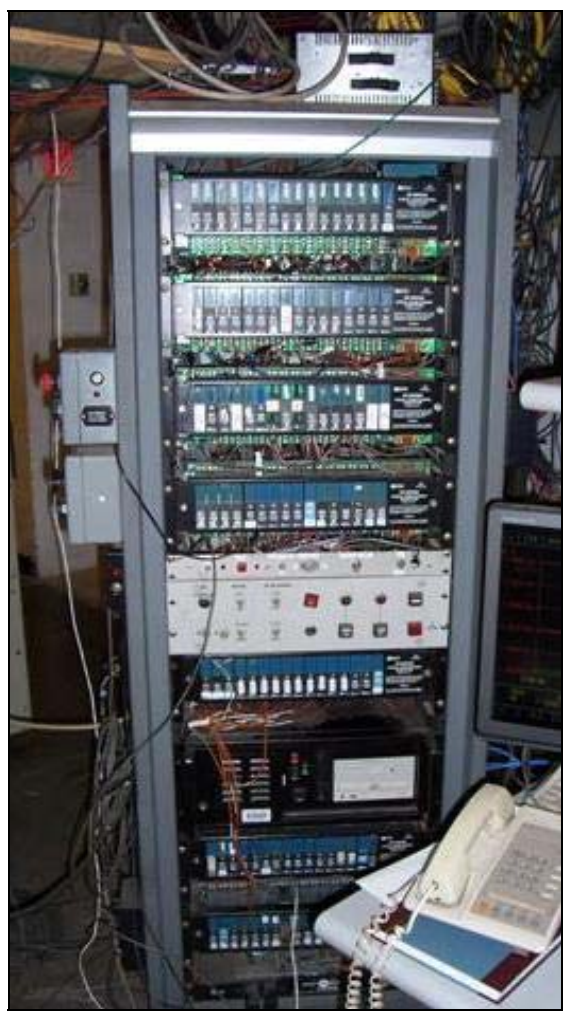

Figure 3-15 Data Acquisition System

\subsection{Emissions Testing Procedures}

Several QA/QC checks were performed in accordance with 40 CFR Part 86, Subpart N prior to the study. These laboratory checkouts include: NOx efficiency test, analyzer calibration and interference checks, pressure and temperature check for the heated lines, and propane injections. All of these checkouts insure the quality of the data presented.

\subsubsection{Engine Preparation}

For the purpose of this study, no hardware changes were made to any of the engines. However, the 1992 Rebuilt DDC S60 and the 2004 Cummins ISM 370 engines were fashioned 
with additional hardware in order to complete in-cylinder pressure analysis research by John Nuszkowski. Prior to actual testing procedures, engine oil and filters, engine coolant and filters, and fuel filters were replaced in order to ensure each engine had a similar starting condition.

\subsubsection{Exhaust Pipe}

The facility-type exhaust system specifications were in accordance with 40 CFR Part 86, Subpart N. The 5 inch diameter exhaust pipe was covered in a 1 inch layer of fiberglass insulation. A butterfly valve was fitted onto the pipe before the mixing orifice to adjust the exhaust back pressure as specified for each engine.

\subsubsection{Analyzer Calibration and Calibration Gases}

The calibration of each analyzer was in accordance with 40 CFR Part 86, Subpart N [1]. The calibration gases used to obtain the 10-point calibration curve were certified within an accuracy of $1 \%$, traceable to NIST. Each calibration gas was renamed using a Standard Reference Material (SRM) gas bottle. The analyzer calibrations were completed prior to the start of testing, and each calibration gas was chosen based on the emissions output of a specific engine. The calibration gases chosen for each engine in this study are shown in Table 3-2, with the second NOx row specifying the gas concentration chosen for the SET tests.

Table 3-2 Calibration Gases Used for Testing

\begin{tabular}{|l|c|c|c|c|c|}
\hline Calibration Gases & $\begin{array}{c}\text { 1991 DDC } \\
\text { S60 }\end{array}$ & $\begin{array}{c}\text { 1992 DDC } \\
\text { S60 }\end{array}$ & $\begin{array}{c}\text { 1992 Rebuilt } \\
\text { DDC S60 }\end{array}$ & $\begin{array}{c}\text { 1999 Cummins } \\
\text { ISM 370 }\end{array}$ & $\begin{array}{c}\text { 2004 Cummins } \\
\text { ISM 370 }\end{array}$ \\
\hline Propane $(\mathrm{ppm})$ & 10.19 & 10.19 & 10.0 & 10.19 & 10.1 \\
\hline Low CO $(\mathrm{ppm})$ & 99.90 & 99.90 & 500.3 & 99.90 & 98.9 \\
\hline High CO $(\mathrm{ppm})$ & 983.0 & 983.0 & 1001 & 983.0 & 985.5 \\
\hline $\mathrm{CO}_{2}(\mathrm{ppm})$ & 3.449 & 3.449 & 3.997 & 3.449 & 4.002 \\
\hline NOx $(\mathrm{ppm})$ - FTP & 221.4 & 221.4 & 223.1 & 221.4 & 249.1 \\
\hline NOx $(\mathrm{ppm})$ - SET & 502.9 & 502.9 & 502.9 & 502.9 & 502.9 \\
\hline
\end{tabular}




\subsubsection{Hydrocarbon Analyzers}

A FID peak was performed on the Rosemount Analytical 402 prior to the start of testing. This optimization is performed to ensure the fuel/air mixture supplied to the analyzer resulted in the maximum response. This maximum response was determined by an iterative process where a range of fuel and air mixtures were supplied to the analyzer while the response was monitored. This FID peak was set before the analyzer could be calibrated. The hydrocarbon analyzer was then calibrated on a specified propane concentration using a 10-point calibration curve. The heated probed was flooded with zero air and the calibration gases to ensure the zero and $100 \%$ ranges were being met, respectively. The specified calibration gas was then varied from $90 \%$ to 0\% using a Horiba SGD-710 gas divider. The DAQ system recorded the ADC value for each point, and plotted these points against the set point. A calibration curve and calibration coefficients were then obtained. Once a satisfactory calibration curve was obtained, the calibration file was saved and used by the reduction program to convert the ADC values into engineering units.

\subsubsection{Oxides of Nitrogen Analyzers}

The NOx analyzers were calibrated in a similar fashion to the HC analyzers using a 10point calibration method. Since both the Rosemount Analytical and the Eco Physics NOx analyzers converted $\mathrm{NO}_{2}$ to $\mathrm{NO}$ so that the chemiluminescent detector could property measure the amount of NOx in the exhaust sample, a monthly converter efficiency was completed. This test was performed on both analyzers to ensure the converter had an efficiency of at or above $90 \%$ since this meant the converter was working properly. If the test failed, maintenance would have been performed on the NOx analyzer to bring it up to the specification value. 
Since the NOx analyzer reacts differently when NOx was in the presence of $\mathrm{CO}_{2}$ or water vapor than it does when only NOx is present, a quench check was performed in order to quantify the differences in response. The sum of both water vapor and $\mathrm{CO}_{2}$ should not exceed $2 \%$. Although this was not required, it was an additional QA/QC step taken at the CAFEE laboratory. It is noted that these analyzers do not meet this requirement, but do meet the 2004 requirements.

\subsubsection{Carbon Monoxide and Carbon Dioxide Analyzers}

Unlike the linear calibration curve seen with the $\mathrm{HC}$ and NOx analyzers, the $\mathrm{CO}$ and $\mathrm{CO}_{2}$ analyzers had a non-linear curve-fit. The complete sample systems for these three analyzers were not calibrated like the THC and NOx systems. Only the sample system post-chiller was incorporated in these calibrations. The two $\mathrm{CO}$ analyzers were checked for $\mathrm{CO}_{2}$ and water interference. This procedure ensured the functionality of both the chiller unit and the analyzer, which is specified in 40 CFR Part 86, Subpart N [1].

\subsubsection{Heated Lines and Probes}

The heated lines and probes from the sampling plane were periodically taken out of service and QA / QC pressure (leak) and temperature checks were performed. The temperature check was performed by disconnecting the two ends of the heated line and running a thermocouple through the entire line to check the temperature every four inches. The leak check was performed by first flushing the lines with pressurized air to eliminate any particulate residue. Next, one end of the heated line was capped off and the opposite end was attached to a pressurized air system with Teflon line. Once the line was pressurized, the pressure drop over a five minute span was recorded. Any substantial change in either temperature or pressure resulted in further investigation and the possibility of replacing the malfunctioning part. 


\subsubsection{Particulate and Filter Weighing}

To ensure the secondary dilution tunnel was functioning properly, the mass flow ratio between the primary tunnel and secondary tunnel flow rate must be maintained $\pm 5 \%$. The accuracy and precision of the filter face temperature measurement must be within $\pm 1.9{ }^{\circ} \mathrm{C}$. The mass flow rate meter must be calibrated using the LFE on a yearly basis under standard conditions of $20{ }^{\circ} \mathrm{C}$ and $101.3 \mathrm{kPa}$. The details of these calibrations can be found in CAFEE Emissions Laboratory Standard Procedures [26].

Prior to testing, PM filters were pre-conditioned as specified in 40 CFR Part 86, Subpart N. This pre-conditioning period lasted for at least an hour, and the filters were housed in glass Petri dishes while inside the clean room so no contamination could occur. Once the filters were in equilibrium with the clean room environment of $22 \pm 3^{\circ} \mathrm{C}$ and a dew point of $9.5 \pm 1^{\circ} \mathrm{C}$, a set of three reference filters was created. These reference filters measured the amount of variation for the entire testing period, and these filters were able to be used for up to one month. After the reference filters were created, the specified amount of PM filters were weighed using a Sartorius SE2-F ultra-microbalance in accordance with 40 CFR Part 86, Subpart N. Figure 3-16 shows the clean room weighing area and the ultra-microbalance used for pre- and post-weighing filters.

After a test cycle was complete, the TPM filters were brought back into the clean room to be conditioned back to the clean room environment for at least an hour. After this hour, the filter post-weight was taken and recorded using the ultra-microbalance. During each testing period, a background filter was taken to record the amount of PM in the ambient air within the dilution tunnel. These test cycle post-weighed filters, along with a background filter were used to perform a PM analysis of each test run. 


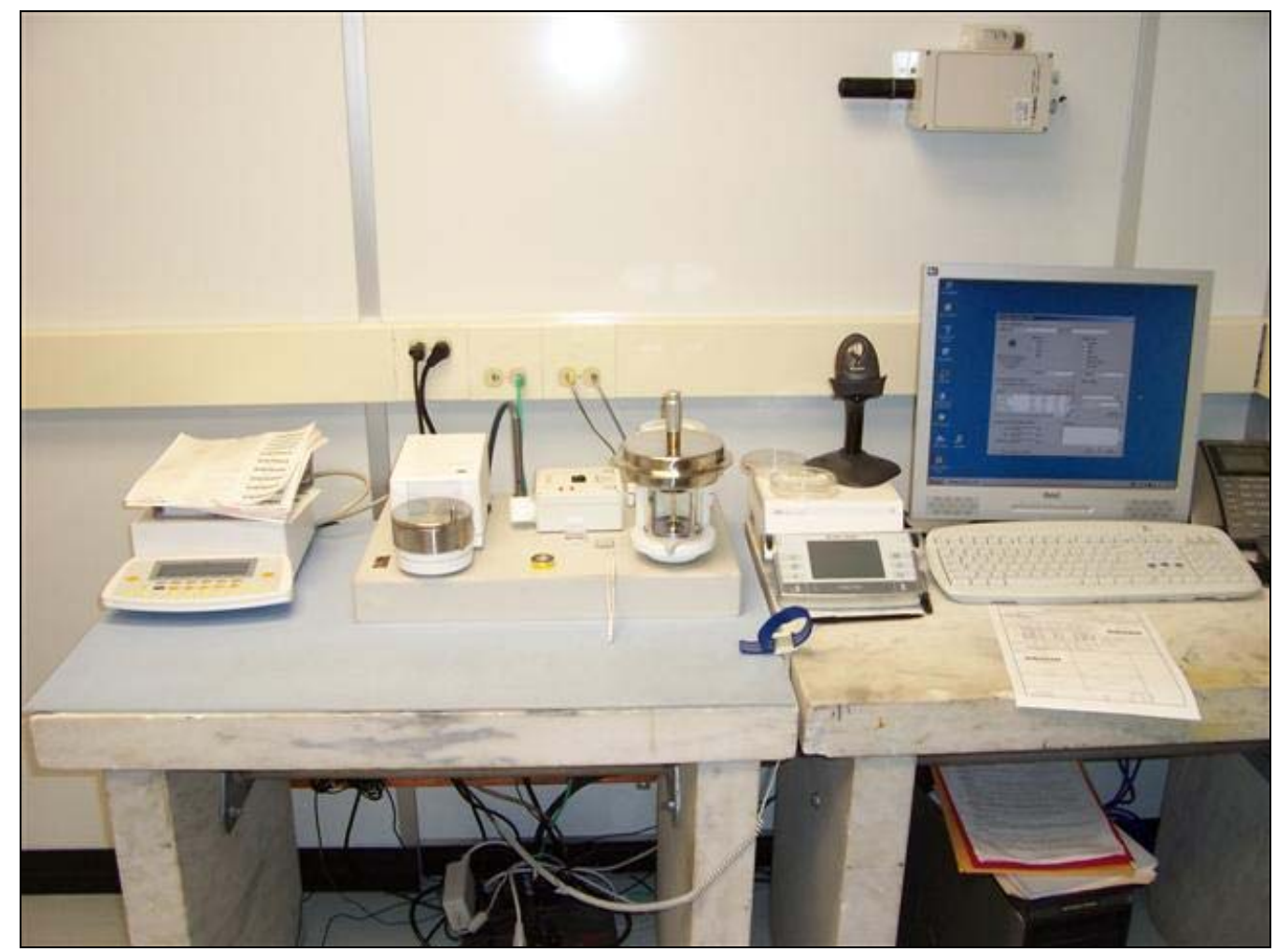

Figure 3-16 Clean Room Weighing Area and Ultra-Microbalance

\subsubsection{Propane Injections}

In order to verify the constant volume sampling system was working properly, and no leaks existed within the dilution tunnel, propane injections were performed in accordance with 40 CFR Part 86.1319-90. Propane was injected into the dilution tunnel at a known rate via a propane injection kit, which can be seen in Figure 3-17, and the HC analyzer measures the propane concentration in the tunnel. The difference between the amount injected and the amount recovered by the analyzer had to be lower than $\pm 2 \%$, and five consecutive injections had to fall within a $\pm 0.5 \%$ range. 


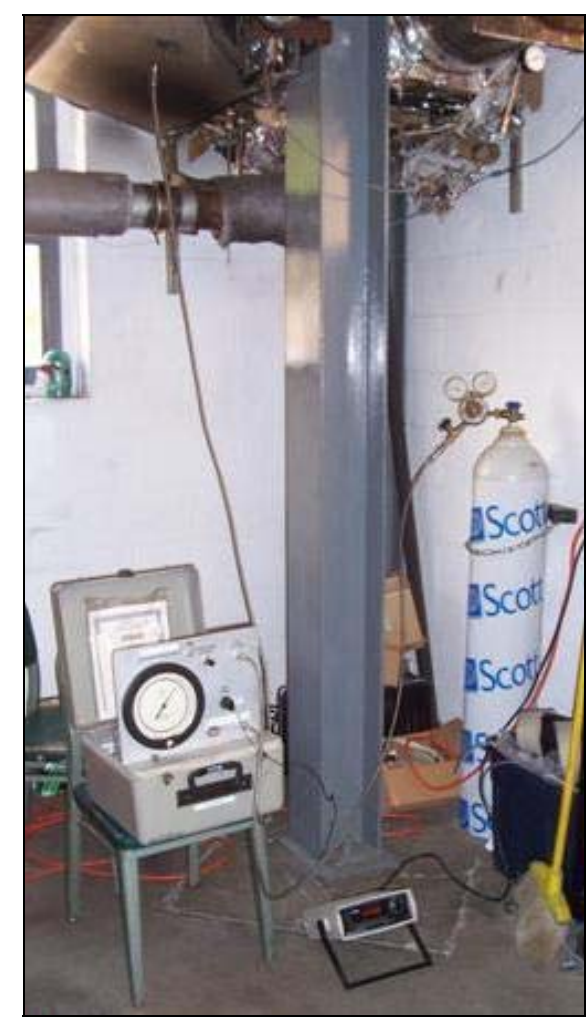

Figure 3-17 Propane Injection Setup

\subsubsection{Torque Cell Calibration}

The torque cell for the dynamometer was calibrated prior to the start of testing in accordance with 40 CFR Part 86.1318-84. This procedure started with hanging a series of weights from the calibration arm, and the cell response was recorded for each point. A curve fit relating the response to the torque was then created. 


\section{Test Fuels and Additives}

\subsection{Test Fuels}

Seven base fuels were used over the duration of this project, which included three No. 2 diesel fuels and three biodiesel blends (B20). Some of the fuels were obtained through a proprietary agreement, but all the fuels examined during this study have been used previously for engine testing at the WVU CAFEE.

The No. 2 diesel fuels included: Chevron Phillips 0.05 Certification fuel (CP 0.05 Cert), Graduate Candidate Fuel (Grad CAND), and Graduate Reference Fuel (Grad REF). The CP 0.05 Cert fuel is a low sulfur diesel used for federal certification testing. The biodiesel blends were prepared by blending 80\% CP 0.05 Cert and 20\% biodiesel. Three different types of biodiesel fuel were used for blending, including: soy, mineral (animal-based), and cotton seed as seen in Figure 4-1. The B20 blend names were: CP 0.05 Cert / soy biodiesel (CP 0.05 Cert A), CP Cert / mineral biodiesel (CP 0.05 Cert B), and CP Cert / cotton seed biodiesel (CP 0.05 Cert C).

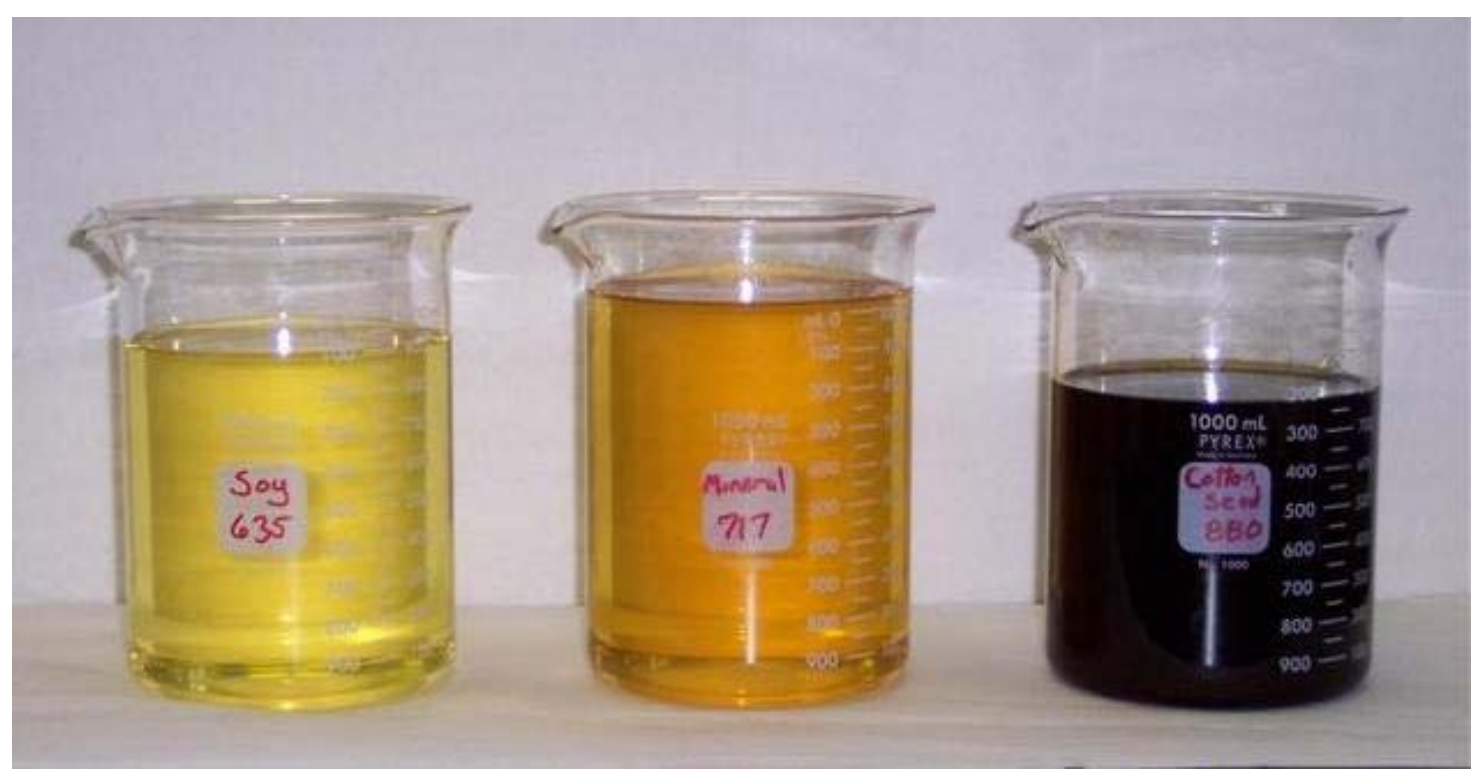

Figure 4-1 Biodiesel Fuel Used During the Study 
Fuel samples were collected for each base fuel and each treated fuel at the end of the testing period, and stored in one-gallon sample containers. Each sample container was named using a unique number for ease of identification. Each of the analyzed fuels was sent to Southwest Research Institute (SwRI), so the analysis results would be consistent. The available fuel properties colleted for each of the test fuels is located in Table 4-1 with the ASTM standards used to analyze each specific property. A complete analysis of the test fuels will be finished upon receipt of the fuel analyses. This addition will be provided to the WVU libraries website as soon as available.

Table 4-1 Base Fuel Analysis Results

\begin{tabular}{|c|c|c|c|c|c|}
\hline Fuel Property & Unit of Measurement & ASTM Test Method & CP 0.05 Cert & Grad CAND Fuel & Grad REF Fue \\
\hline Specific Gravity 60/60 & - & ASTM D 4052 & 0.8484 & & \\
\hline API Gravity & - & ASTM D 1250 & 35.3 & 38.13 & 38.55 \\
\hline Corrosion (3 hrs @ 50²) & - & ASTM D 130 & $1 \mathrm{~A}$ & & \\
\hline Particulate Matter & $\mathrm{mg} / \mathrm{l}$ & ASTM D 6217 & 1.0 & & \\
\hline Cloud Point & ${ }^{\circ} \mathrm{F}$ & ASTM D 2500 & 4.0 & & \\
\hline Flash Point, PM & ${ }^{\circ} \mathrm{F}$ & ASTM D 93 & 150.0 & & \\
\hline Pour Point & ${ }^{\circ} \mathrm{F}$ & ASTM D 97 & -10.0 & & \\
\hline Sulfur & $\mathrm{ppm}$ & ASTM D 5453 & 305.8 & & \\
\hline Viscosity @ 40 $\mathrm{C}$ & $\mathrm{cSt}$ & ASTM D 445 & 2.6 & & \\
\hline Hydrogen & $\mathrm{Wt} \%$ & ASTM D 3343 & 13.2 & & \\
\hline Carbon & $\mathrm{Wt} \%$ & Calculated & 86.8 & & \\
\hline Carbon Density & g/gal & Calculated & 2783 & & \\
\hline Net Heat of Combustion & $\mathrm{BTU} / \mathrm{lb}$ & ASTM D 3338 & 18444 & & \\
\hline Cetane Number & - & ASTM D 613 & 47.0 & 48.8 & 54.3 \\
\hline Cetane Index & - & ASTM D 976 & 47.6 & & \\
\hline Distillation - IBP & ${ }^{\circ} \mathrm{F}$ & \multirow{16}{*}{ ASTM D 86} & 356 & 351 & 383 \\
\hline Distillation - 5\% & ${ }^{\circ} \mathrm{F}$ & & 405 & 396 & 422 \\
\hline Distillation - $10 \%$ & ${ }^{\circ} \mathrm{F}$ & & 424 & 407 & 432 \\
\hline Distillation - 20\% & ${ }^{\circ} \mathrm{F}$ & & 453 & 436 & 450 \\
\hline Distillation - 30\% & ${ }^{\circ} \mathrm{F}$ & & 477 & 460 & 468 \\
\hline Distillation - 40\% & ${ }^{\circ} \mathrm{F}$ & & 497 & 482 & 483 \\
\hline Distillation - 50\% & ${ }^{\circ} \mathrm{F}$ & & 514 & 500 & 497 \\
\hline Distillation - 60\% & ${ }^{\circ} \mathrm{F}$ & & 532 & 517 & 512 \\
\hline Distillation - 70\% & ${ }^{\circ} \mathrm{F}$ & & 553 & 535 & 529 \\
\hline Distillation - 80\% & ${ }^{\circ} \mathrm{F}$ & & 579 & 558 & 550 \\
\hline Distillation - 90\% & ${ }^{\circ} \mathrm{F}$ & & 615 & 596 & 581 \\
\hline Distillation - 95\% & ${ }^{\circ} \mathrm{F}$ & & 647 & 636 & 612 \\
\hline Distillation - EP & ${ }^{\circ} \mathrm{F}$ & & 665 & 658 & 629 \\
\hline Distillation - Loss & ML & & 0.5 & 0.8 & 0.9 \\
\hline Distillation - Residue & ML & & 1.5 & 1.5 & 1.5 \\
\hline Distillation - Recovered & ML & & 98 & 97.7 & 97.6 \\
\hline Aromatics & Vol\% & \multirow{3}{*}{ ASTM D 1319} & 30.9 & 27.0 & 8.8 \\
\hline Olefins & Vol\% & & 3.4 & & \\
\hline Saturates & Vol\% & & 65.7 & & \\
\hline
\end{tabular}




\subsection{Fuel Properties}

The fuel properties which were found to have an impact on diesel engine emissions were previously mentioned and discussed in the literature review chapter. Since one of the additives used during this study was proprietary, the treated fuel samples were not analyzed. The following encompasses the fuel properties of the test fuels used for the study and their effect on emissions.

\subsection{Additives}

Three different diesel additives were used throughout the duration of the study in order to create different blended treats of each base fuel. Each of the additives was known as a cetane improver, which reduced the ignition delay time to provide proper starting, smooth operation, and efficient combustion [3]. Since the cetane number would be the only fuel property affected enough for another fuel analysis, it was decided the base fuel analysis would be enough for this study. The treated fuel blends were mixed at the CAFEE prior to the start of testing.

The chemical names of two of the additives were: 2-Ethlyhexyl Nitrate (2-EHN) and Ditertiary Butyl Peroxide (DTBP). The third additive was a proprietary organic derived additive (ODA), and the information for this additive was not available to the public. The available physical properties for each of the additives used are found in Table 4-2 [28, 29, 30]. 
Table 4-2 Fuel Additives [28, 29, 30]

\begin{tabular}{|c|c|c|c|c|}
\hline Physical Property & $\begin{array}{c}\text { Unit of } \\
\text { Measurement }\end{array}$ & $\begin{array}{c}\text { 2-Ethylhexyl } \\
\text { Nitrate } \\
(2-E H N)\end{array}$ & $\begin{array}{c}\text { Di-tertiary- } \\
\text { Butyl Peroxide } \\
\text { (DTBP) }\end{array}$ & $\begin{array}{c}\text { Organic } \\
\text { Derived } \\
\text { Additive } \\
\text { (ODA) }\end{array}$ \\
\hline Molecular Weight & - & 175.23 & 206.3 & \multirow{14}{*}{$\begin{array}{l}\text { Proprietary } \\
\text { Organic } \\
\text { Derived } \\
\text { Additive }\end{array}$} \\
\hline Flash Point & ${ }^{\circ} \mathrm{C}$ & 70 & 10 & \\
\hline Freezing Point & ${ }^{\circ} \mathrm{C}$ & -45 & -40 & \\
\hline Boiling Point & ${ }^{\circ} \mathrm{C}$ & 100 & 111 & \\
\hline Vapor Pressure @ 20ㄷ & $\mathrm{Pa}$ & 27 & 2600 & \\
\hline Vapor Pressure @ 40C & $\mathrm{Pa}$ & $40-53$ & $\mathrm{~N} / \mathrm{A}$ & \\
\hline Vapor Pressure @ 82 $\mathrm{C}$ & $\mathrm{kPa}$ & 1.33 & N/A & \\
\hline Density @ 20 $\mathrm{C}$ & $\mathrm{g} / \mathrm{mL}$ & 0.96 & N/A & \\
\hline Kinematic Viscosity @ 20ㄷ & $\mathrm{cSt}$ & 1.8 & N/A & \\
\hline Solubility in Water @ $20^{\circ} \mathrm{C}$ & $\mathrm{mg} / \mathrm{L}$ & 12.6 & insoluble & \\
\hline Heat of Vaporization & $\mathrm{kJ} / \mathrm{kg}$ & 368 & $\mathrm{~N} / \mathrm{A}$ & \\
\hline Heat of Decomposition & $\mathrm{J} / \mathrm{g}$ & 2100 & $\mathrm{~N} / \mathrm{A}$ & \\
\hline Auto / Self Ignition Temperature & ${ }^{\circ} \mathrm{C}$ & 130 & 80 & \\
\hline Decomposition Temperature & ${ }^{\circ} \mathrm{C}$ & 100 & 111 & \\
\hline
\end{tabular}




\section{Results and Discussion}

\subsection{Test Engines and Examined Fuels}

Each of the previously mentioned HDDE were tested with each of the No.2 base fuels, and the additives and concentrations mixed with these base fuels varied between the different engines. The B20 biodiesel blends were only tested on the two Cummins engines since there was a limited supply available. The test matrix for the tested fuels and engines is seen in Table $5-1$.

It is noted that not every fuel and additive combination were tested on each engine. There were a couple reasons why this occurred. First, there were limited quantities of fuel and test cell time. Secondly, additional additives or additive concentrations were added as the testing progressed based on knowledge gained throughout this campaign. As a result of these two reasons, the test matrix was filled in to provide the widest range of fuels and additives as possible. A future dissertation by John Nuszkowski will attempt to fill in some of the voids found in this table, and also further explain emissions trends with in-cylinder pressure analysis data. 
Table 5-1 Examined Fuels for each Test Engine

\begin{tabular}{|c|c|c|c|c|c|c|c|c|c|c|c|c|c|c|c|c|c|c|c|c|c|c|c|}
\hline & \multicolumn{7}{|c|}{ CP 0.05 Cert } & \multicolumn{8}{|c|}{ Grad CAND Fuel } & \multicolumn{3}{|c|}{ Grad REF Fuel } & \multirow{2}{*}{ 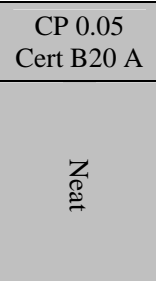 } & \multicolumn{3}{|c|}{$\begin{array}{c}\text { CP } 0.05 \text { Cert } \\
\text { B20 B }\end{array}$} & $\begin{array}{r}\text { CP } 0.05 \\
\text { Cert B20 }\end{array}$ \\
\hline & $\begin{array}{l}\not z \\
\stackrel{D}{\sim}\end{array}$ & $\begin{array}{l}\vec{N} \\
\stackrel{3}{\Xi} \\
O \\
O \\
\end{array}$ & 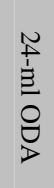 & $\begin{array}{l}\text { I } \\
\stackrel{1}{1} \\
N \\
\frac{1}{1} \\
\frac{1}{Z} \\
Z\end{array}$ & 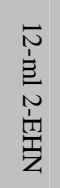 & 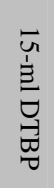 & 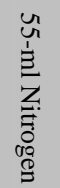 & 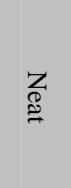 & $\begin{array}{l}\stackrel{\rho}{1} \\
\stackrel{1}{O} \\
\stackrel{D}{D}\end{array}$ & $\begin{array}{l}\vec{N} \\
\stackrel{J}{3} \\
O \\
O \\
\end{array}$ & $\begin{array}{l}\vec{p} \\
\stackrel{1}{O} \\
\stackrel{0}{0}\end{array}$ & 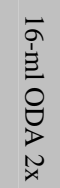 & 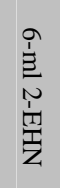 & 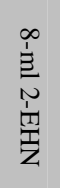 & 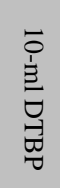 & $\begin{array}{l}Z \\
\stackrel{D}{0} \\
\stackrel{2}{2}\end{array}$ & $\begin{array}{l}\vec{D} \\
\stackrel{\Xi}{\Xi} \\
\stackrel{D}{D}\end{array}$ & 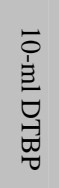 & & $\begin{array}{l}Z \\
2 \\
\stackrel{0}{*}\end{array}$ & 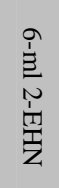 & 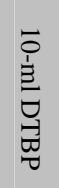 & $\begin{array}{l}Z \\
\stackrel{\mathbb{D}}{\approx}\end{array}$ \\
\hline 1991 DDC S60 & $3 / 1^{\mathrm{A}}$ & $3 / 1$ & - & - & - & - & - & $3 / 1$ & - & $3 / 1$ & - & $3 / 1$ & - & $3 / 1$ & $3 / 1$ & $3 / 1$ & - & - & - & - & - & - & - \\
\hline 1992 DDC S60 & $3 / 1$ & $3 / 1$ & - & - & - & - & - & $3 / 1$ & $3 / 1$ & $3 / 1$ & - & - & $3 / 1$ & - & - & $3 / 1$ & - & $3 / 1$ & - & - & - & - & - \\
\hline 1992 Rebuilt DDC S60 & $3 / 1$ & $3 / 1$ & - & - & - & - & - & $3 / 2^{A}$ & $3 / 2$ & $3 / 1$ & $3 / 2$ & $3 / 2$ & - & $3 / 2$ & $3 / 2$ & $3 / 3$ & $3 / 3$ & - & - & - & - & - & - \\
\hline 1999 Cummins ISM 370 & $3 / 1^{\mathrm{A}, \mathrm{B}}$ & $3 / 1$ & - & - & - & - & - & $3 / 1$ & $3 / 1$ & $3 / 1$ & - & - & $3 / 1$ & - & $3 / 1$ & $3 / 1^{\mathrm{A}, \mathrm{B}}$ & $3 / 1$ & - & $3 / 1$ & $3 / 1$ & $3 / 1$ & $3 / 1$ & - \\
\hline 2004 Cummins ISM 370 & $3 / 1^{\mathrm{A}, \mathrm{B}, \mathrm{C}}$ & $3 / 1$ & $3 / 1$ & $3 / 1$ & $3 / 1$ & $3 / 1$ & $3 / 1$ & $3 / 1$ & $3 / 1$ & - & - & - & - & - & - & $3 / 1^{\mathrm{A}, \mathrm{B}}$ & - & - & $3 / 1$ & $3 / 1$ & - & $3 / 1$ & $3 / 1$ \\
\hline
\end{tabular}

- $\quad$ : Indicates non-tested fuels

3/1 : Indicates number of hot start FTP tests / number of SET tests

A : Indicates an additional FTP test sequence was run to obtain day-to-day variation

$\mathrm{B}$ : Indicates an additional SET test was run to verify day-to-day variation

C : Indicates Grad REF engine map and CP 0.05 Cert engine map were used 


\subsection{Engine Mapping and Throttle Positions}

The GRAD REF engine map was used for the majority of the testing campaign for each engine. One test sequence for the 2004 Cummins ISM 370 used the CP 0.05 Cert map in order to study the effect of different engine maps on the emissions levels.

Three throttle position algorithms were used during this study. Throttle 3 was the throttle used during certification work at the WVU CAFFEE, and this was the throttle used for each of the Detroit Diesels. Throttle 1 and 2 were more aggressive than Throttle 3. After testing concluded for the first test engine (1992 rebuilt DDC S60), it was determined that Throttle 1 and 2 were similar enough that only Throttle 1 could be used for the rest of the testing campaign. For the purpose of this study, the test sequences run on Throttle 3 for the DDC S60 engines and Throttle 1 for the Cummins ISM engines were studied. Throttle 1 was used for the Cummins engines because Throttle 3 was not able to pass the regression analysis. A more in depth study of the throttle positions will be complete in a future thesis by Michael Ursic [31].

\subsection{Useful Life of Older Technology Engines}

Table 5-2 is a display of the useful life data for the five baseline and treated fuels used on the three Detroit Diesel Corporation engines. An average of the NOx, CO, and THC was calculated for each fuel based on the power output of the engine. The average of each emissions constituent for each fuel was then used to complete a variation analysis, which is seen in Table 5-3. It is interesting to note that the 1992 Rebuilt DDC S60 had a higher variation in both NOx and CO than the other two DDC engines. The 1992 DDC S60 had the highest variation in THC, which was upwards of $17 \%$. The 1991 DDC S60 had the lowest variation for all of the emissions constituents, where NOx had variability between $3.2 \%$ and $4.8 \%$. Based on the 
similarity of the 1992 and rebuilt 1992 DDC S60 engines, there does not appear to be a significant difference between these two engines. 
Table 5-2 Useful Life Data for Older Technology Engines

\begin{tabular}{|c|c|c|c|c|c|c|c|c|c|c|c|c|c|c|c|c|c|c|c|c|c|}
\hline \multirow{2}{*}{ Test Engine } & \multirow{2}{*}{$\begin{array}{l}\text { Emissions } \\
\text { Constituent }\end{array}$} & \multicolumn{4}{|c|}{ CP 0.05 Cert Neat 1} & \multicolumn{4}{|c|}{ CP 0.05 Cert 12-ml ODA } & \multicolumn{4}{|c|}{ Grad REF Neat } & \multicolumn{4}{|c|}{ Grad CAND Neat } & \multicolumn{4}{|c|}{ Grad CAND 12-ml ODA } \\
\hline & & $\begin{array}{c}0 \text { to } 100 \\
\text { hp }\end{array}$ & $\begin{array}{l}101 \text { to } \\
200 \mathrm{hp}\end{array}$ & $\begin{array}{l}201 \text { to } \\
300 \mathrm{hp}\end{array}$ & $\begin{array}{l}301 \text { to } \\
345 \mathrm{hp}\end{array}$ & $\begin{array}{c}0 \text { to } 100 \\
\text { hp }\end{array}$ & $\begin{array}{l}101 \text { to } \\
200 \mathrm{hp}\end{array}$ & $\begin{array}{l}201 \text { to } \\
300 \mathrm{hp}\end{array}$ & $\begin{array}{l}301 \text { to } \\
345 \text { hp }\end{array}$ & $\begin{array}{c}0 \text { to } 100 \\
\text { hp }\end{array}$ & $\begin{array}{l}101 \text { to } \\
200 \mathrm{hp}\end{array}$ & $\begin{array}{l}201 \text { to } \\
300 \mathrm{hp}\end{array}$ & $\begin{array}{l}301 \text { to } \\
345 \text { hp }\end{array}$ & $\begin{array}{c}0 \text { to } 100 \\
\text { hp }\end{array}$ & $\begin{array}{l}101 \text { to } \\
200 \mathrm{hp}\end{array}$ & $\begin{array}{l}201 \text { to } \\
300 \mathrm{hp}\end{array}$ & $\begin{array}{l}301 \text { to } \\
345 \mathrm{hp}\end{array}$ & $\left|\begin{array}{c}0 \text { to } 100 \\
\text { hp }\end{array}\right|$ & $\begin{array}{l}101 \text { to } \\
200 \mathrm{hp}\end{array}$ & $\begin{array}{l}201 \text { to } \\
300 \mathrm{hp}\end{array}$ & $\begin{array}{l}301 \text { to } \\
345 \mathrm{hp}\end{array}$ \\
\hline \multirow{3}{*}{$\begin{array}{c}1991 \text { DDC } \\
\text { S60 }\end{array}$} & NOx (g/s) & 0.0811 & 0.1717 & 0.2561 & 0.3237 & 0.0798 & 0.1716 & 0.2597 & 0.3303 & 0.0715 & 0.1582 & 0.2387 & 0.2996 & 0.0775 & 0.1674 & 0.2502 & 0.3149 & 0.0759 & 0.1662 & 0.2522 & 0.3183 \\
\hline & $\mathrm{CO}(\mathrm{g} / \mathrm{s})$ & 0.0441 & 0.1181 & 0.1586 & 0.0753 & 0.0418 & 0.1149 & 0.1568 & 0.0751 & 0.0414 & 0.1167 & 0.1660 & 0.0739 & 0.0404 & 0.1103 & 0.1584 & 0.0705 & 0.0393 & 0.1089 & 0.1543 & 0.0670 \\
\hline & THC (g/s) & 0.0012 & 0.0016 & 0.0016 & 0.0018 & 0.0011 & 0.0016 & 0.0016 & 0.0018 & 0.0011 & 0.0016 & 0.0016 & 0.0019 & 0.0012 & 0.0016 & 0.0016 & 0.0019 & 0.0011 & 0.0016 & 0.0016 & 0.0019 \\
\hline \multirow{3}{*}{$\begin{array}{c}1992 \text { DDC } \\
\text { S60 }\end{array}$} & NOx (g/s) & 0.1181 & 0.2354 & 0.2744 & 0.3183 & 0.1121 & 0.2262 & 0.2726 & 0.3204 & 0.1028 & 0.2078 & 0.2532 & 0.2988 & 0.1144 & 0.2262 & 0.2654 & 0.3103 & 0.1061 & 0.2163 & 0.2660 & 0.3141 \\
\hline & $\mathrm{CO}(\mathrm{g} / \mathrm{s})$ & 0.0413 & 0.1485 & 0.2436 & 0.2256 & 0.0365 & 0.1399 & 0.2320 & 0.2145 & 0.0379 & 0.1498 & 0.2452 & 0.2185 & 0.0399 & 0.1502 & 0.2397 & 0.2069 & 0.0371 & 0.1468 & 0.2321 & 0.1981 \\
\hline & THC (g/s) & 0.0027 & 0.0035 & 0.0036 & 0.0040 & 0.0020 & 0.0026 & 0.0029 & 0.0032 & 0.0021 & 0.0027 & 0.0028 & 0.0032 & 0.0029 & 0.0037 & 0.0036 & 0.0040 & 0.0024 & 0.0032 & 0.0035 & 0.0040 \\
\hline \multirow{3}{*}{$\begin{array}{c}1992 \\
\text { Rebuilt } \\
\text { DDC S60 }\end{array}$} & NOx (g/s) & 0.1163 & 0.2308 & 0.3369 & 0.2829 & 0.1063 & 0.2163 & 0.2808 & 0.3402 & 0.0986 & 0.2009 & 0.2601 & 0.3134 & 0.1120 & 0.2203 & 0.2763 & 0.3329 & 0.1040 & 0.2102 & 0.2740 & 0.3318 \\
\hline & $\mathrm{CO}(\mathrm{g} / \mathrm{s})$ & 0.0459 & 0.1480 & 0.2459 & 0.2714 & 0.0389 & 0.1416 & 0.2376 & 0.2509 & 0.0417 & 0.1494 & 0.2466 & 0.2581 & 0.0430 & 0.1421 & 0.2340 & 0.2493 & 0.0363 & 0.1310 & 0.2250 & 0.2420 \\
\hline & THC (g/s) & 0.0028 & 0.0038 & 0.0032 & 0.0036 & 0.0025 & 0.0038 & 0.0036 & 0.0043 & 0.0027 & 0.0041 & 0.0038 & 0.0046 & 0.0028 & 0.0038 & 0.0032 & 0.0037 & 0.0022 & 0.0031 & 0.0027 & 0.0031 \\
\hline
\end{tabular}

Table 5-3 Useful Life Variation Analysis for Older Technology Engines

\begin{tabular}{|c|c|c|c|c|c|c|c|c|c|c|c|c|c|}
\hline \multirow{2}{*}{ Test Engine } & \multirow{2}{*}{$\begin{array}{l}\text { Emissions } \\
\text { Constituent }\end{array}$} & \multicolumn{4}{|c|}{ Average } & \multicolumn{4}{|c|}{ Standard Deviation } & \multicolumn{4}{|c|}{ Coefficient of Variation (\%) } \\
\hline & & $\begin{array}{c}0 \text { to } 100 \\
\text { hp }\end{array}$ & $\begin{array}{l}101 \text { to } \\
200 \mathrm{hp}\end{array}$ & $\begin{array}{l}201 \text { to } \\
300 \mathrm{hp}\end{array}$ & $\begin{array}{l}301 \text { to } \\
345 \text { hp }\end{array}$ & $\begin{array}{c}0 \text { to } 100 \\
\text { hp }\end{array}$ & $\begin{array}{l}101 \text { to } \\
200 \mathrm{hp}\end{array}$ & $\begin{array}{l}201 \text { to } \\
300 \text { hp }\end{array}$ & $\begin{array}{l}301 \text { to } \\
345 \text { hp }\end{array}$ & $\begin{array}{c}0 \text { to } 100 \\
\text { hp }\end{array}$ & $\begin{array}{l}101 \text { to } \\
200 \text { hp }\end{array}$ & $\begin{array}{l}201 \text { to } \\
300 \text { hp }\end{array}$ & $\begin{array}{l}301 \text { to } \\
345 \text { hp }\end{array}$ \\
\hline \multirow{3}{*}{1991 DDC S60 } & $\mathrm{NOx}(\mathrm{g} / \mathrm{s})$ & 0.0772 & 0.1670 & 0.2514 & 0.3174 & 0.0037 & 0.0055 & 0.0080 & 0.0115 & 4.8 & 3.3 & 3.2 & 3.6 \\
\hline & $\mathrm{CO}(\mathrm{g} / \mathrm{s})$ & 0.0414 & 0.1138 & 0.1588 & 0.0724 & 0.0018 & 0.0040 & 0.0044 & 0.0036 & 4.3 & 3.5 & 2.7 & 4.9 \\
\hline & THC (g/s) & 0.0012 & 0.0016 & 0.0016 & 0.0018 & 0.0001 & 0.0000 & 0.0000 & 0.0000 & 4.5 & 2.0 & 1.9 & 2.2 \\
\hline \multirow{3}{*}{1992 DDC S60 } & NOx (g/s) & 0.1107 & 0.2224 & 0.2663 & 0.3124 & 0.0062 & 0.0106 & 0.0084 & 0.0085 & 5.6 & 4.8 & 3.1 & 2.7 \\
\hline & $\mathrm{CO}(\mathrm{g} / \mathrm{s})$ & 0.0386 & 0.1471 & 0.2385 & 0.2127 & 0.0020 & 0.0042 & 0.0062 & 0.0106 & 5.2 & 2.8 & 2.6 & 5.0 \\
\hline & THC (g/s) & 0.0024 & 0.0032 & 0.0033 & 0.0037 & 0.0004 & 0.0005 & 0.0004 & 0.0004 & 16.8 & 14.8 & 11.5 & 11.6 \\
\hline \multirow{3}{*}{$\begin{array}{l}1992 \text { Rebuilt DDC } \\
\text { S60 }\end{array}$} & $\mathrm{NOx}(\mathrm{g} / \mathrm{s})$ & 0.1074 & 0.2157 & 0.2856 & 0.3203 & 0.0069 & 0.0112 & 0.0297 & 0.0231 & 6.4 & 5.2 & 10.4 & 7.2 \\
\hline & $\mathrm{CO}(\mathrm{g} / \mathrm{s})$ & 0.0412 & 0.1424 & 0.2378 & 0.2543 & 0.0037 & 0.0073 & 0.0090 & 0.0111 & 9.0 & 5.1 & 3.8 & 4.4 \\
\hline & THC (g/s) & 0.0026 & 0.0037 & 0.0033 & 0.0038 & 0.0003 & 0.0004 & 0.0004 & 0.0006 & 9.9 & 9.8 & 12.4 & 15.0 \\
\hline
\end{tabular}




\subsection{Fuel Specific Emissions}

Complex physical and chemical reactions, such as ignition, combustion, vaporization and atomization, all occur during normal diesel combustion. Each new engine model year brought about changes in general engine design, control strategy and new operating conditions, and each of these changes determined how the engine would respond to fuel properties. A high pre-mix burn portion of combustion would in turn cause high in-cylinder temperatures and pressures, which are known to cause high NOx formation [32]. HC found in the gas phase of diesel exhaust was normally attributed to high or low air-to-fuel ratios, and also large droplets of fuel toward the end of injection. CO was a product of incomplete combustion, and was known to be a dissociation product of $\mathrm{CO}_{2}$. Both organic and inorganic substances found in the fuel and air make up the composition of PM.

The results for the FTP and SET tests for the 1991 DDC S60 engine with a variation analysis can be seen in Table 5-4 through Table 5-6. The FTP results for the other engines can be found in Table 8-2, Table 8-5, Table 8-8, and Table 8-11. The variation analyses for these FTP results are shown in Table 8-3, Table 8-6, Table 8-9, and Table 8-12. The results of the SET tests for the other four test engines is displayed in Table 8-1, Table 8-4, Table 8-7, and Table 8-10. These results include the regulated emissions levels along with an $\mathrm{NO}_{2}$ analysis, as well as the brake-specific fuel consumption (BSFC) and work. The FTP results tables were obtained by averaging the brake-specific emissions data for each hot start for each fuel which can be found in Table 8-13 through Table 8-72 in the appendices. The number of FTP tests and SET tests completed for each engine with respect to the test fuels used is displayed in Table 5-1. A further analysis of the effect each additive had on $\mathrm{NO}_{2}$ and $\mathrm{NOx}$ was also completed. 
Table 5-4 FTP Results for 1991 DDC S60

\begin{tabular}{|c|c|c|c|c|c|c|c|c|c|}
\hline & \multicolumn{3}{|c|}{ CP 0.05 Cert } & \multirow{2}{*}{$\frac{\text { Grad REF }}{\text { Neat }}$} & \multicolumn{5}{|c|}{ Grad CAND } \\
\hline & Neat 1 & Neat 2 & $\begin{array}{l}12-\mathrm{ml} \\
\text { ODA }\end{array}$ & & Neat & $\begin{array}{l}12-\mathrm{ml} \\
\text { ODA }\end{array}$ & $\begin{array}{c}16-\mathrm{ml} \\
\text { ODA 2x }\end{array}$ & $\begin{array}{c}\text { 8-ml } \\
\text { 2-EHN }\end{array}$ & 10-ml DTBP \\
\hline THC (g/bhp-hr) & 0.0620 & 0.0591 & 0.0564 & 0.0588 & 0.0607 & 0.0582 & 0.0604 & 0.0603 & 0.0589 \\
\hline Standard Deviation & 0.0026 & 0.0027 & 0.0006 & 0.0018 & 0.0014 & 0.0007 & 0.0020 & 0.0007 & 0.0013 \\
\hline CO (g/bhp-hr) & 2.453 & 2.565 & 2.351 & 2.453 & 2.370 & 2.282 & 2.233 & 2.252 & 2.270 \\
\hline Standard Deviation & 0.0552 & 0.0203 & 0.0167 & 0.0234 & 0.0129 & 0.0322 & 0.0153 & 0.0107 & 0.0165 \\
\hline CO2 (g/bhp-hr) & 538.1 & 533.7 & 535.2 & 528.8 & 536.7 & 539.9 & 532.8 & 531.7 & 533.9 \\
\hline Standard Deviation & 1.110 & 0.5723 & 0.5515 & 0.3916 & 1.947 & 5.894 & 0.9571 & 0.4986 & 1.306 \\
\hline NOx (g/bhp-hr) & 4.612 & 4.625 & 4.560 & 4.216 & 4.463 & 4.408 & 4.402 & 4.423 & 4.417 \\
\hline Standard Deviation & 0.0142 & 0.0197 & 0.0093 & 0.0072 & 0.0127 & 0.0161 & 0.0031 & 0.0101 & 0.0101 \\
\hline NOx 2 (g/bhp-hr) & 4.588 & 4.600 & 4.550 & 4.184 & 4.456 & 4.378 & 4.358 & 4.392 & 4.388 \\
\hline Standard Deviation & 0.0116 & 0.0227 & 0.0107 & 0.0047 & 0.0101 & 0.0141 & 0.0113 & 0.0172 & 0.0192 \\
\hline $\mathrm{NO}_{2}$ (g/bhp-hr) & 0.6869 & 0.6924 & 0.6886 & 0.7115 & 0.7195 & 0.6953 & 0.7531 & 0.7571 & 0.7711 \\
\hline Standard Deviation & 0.0190 & 0.0080 & 0.0283 & 0.0098 & 0.0155 & 0.0164 & 0.0055 & 0.0175 & 0.0110 \\
\hline TPM (g/bhp-hr) & 0.1332 & 0.1370 & 0.1302 & 0.1318 & 0.1277 & 0.1248 & 0.1236 & 0.0833 & 0.1213 \\
\hline Standard Deviation & 0.0027 & 0.0015 & 0.0010 & 0.0015 & 0.0010 & 0.0018 & 0.0015 & 0.0721 & 0.0015 \\
\hline BSFC (lb/bhp-hr) & 0.3786 & 0.3796 & 0.3791 & 0.3771 & 0.3803 & 0.3801 & 0.3799 & 0.3803 & 0.3814 \\
\hline Standard Deviation & 0.0007 & 0.0005 & 0.0007 & 0.0003 & 0.0002 & 0.0002 & 0.0003 & 0.0006 & 0.0025 \\
\hline FC (lb) & 8.635 & 8.653 & 8.644 & 8.514 & 8.580 & 8.576 & 8.577 & 8.582 & 8.607 \\
\hline Standard Deviation & 0.0026 & 0.0027 & 0.0006 & 0.0018 & 0.0014 & 0.0007 & 0.0020 & 0.0007 & 0.0013 \\
\hline
\end{tabular}

Table 5-5 FTP Variation Analysis for 1991 DDC S60

\begin{tabular}{|l|c|c|c|}
\hline & Average & $\begin{array}{c}\text { Standard } \\
\text { Deviation }\end{array}$ & $\begin{array}{c}\text { Coefficient of } \\
\text { Variation (\%) }\end{array}$ \\
\hline THC (g/bhp-hr) & 0.0594 & 0.0016 & 2.7 \\
\hline $\mathrm{CO}$ (g/bhp-hr) & 2.359 & 0.1127 & 4.8 \\
\hline $\mathrm{CO} 2$ (g/bhp-hr) & 534.5 & 3.370 & 0.6 \\
\hline NOx (g/bhp-hr) & 4.459 & 0.1271 & 2.9 \\
\hline NOx 2 (g/bhp-hr) & 4.433 & 0.1326 & 3.0 \\
\hline NO 2 (g/bhp-hr) & 0.7195 & 0.0328 & 4.6 \\
\hline TPM (g/bhp-hr) & 0.1237 & 0.0159 & 12.9 \\
\hline BSFC (lb/bhp-hr) & 0.3796 & 0.0012 & 0.3 \\
\hline FC (lb) & 8.596 & 0.0434 & 0.5 \\
\hline
\end{tabular}

The effectiveness of each fuel additive was studied by eventually creating a percent difference comparison, where each treated fuel percent difference is taken with respect to the respective neat fuel. This graph can be seen in Figure 5-4, and it was obtained by first comparing the reduced data of NOx, NOx 2, and NO 2 as a function of power, which can be seen 
in Figure 5-1 through Figure 5-3. It is noted that NOx 2 and NO 2 refer to NOx and NO emissions, respectively, from the second NOx analyzer. This reduced data was time-shifted to match the power curve, since the analyzers measure the emissions with a time delay. A $5^{\text {th }}$ order polynomial trendline was used to obtain an empirical relation between power and the emissions rate. The equation of each trendline was used to find the percent difference for each engine. The NO 2 polynomial trendline emissions data was subtracted from the NOx 2 polynomial trendline emissions data in order to get the total engine-out $\mathrm{NO}_{2}$ for each fuel. This difference was then used to calculate a percent difference in $\mathrm{NO}_{2}$ in the same manner as $\mathrm{NOx}$.

Figure 5-4 is a display of NOx and $\mathrm{NO}_{2}$ percent differences for each treated and multiple run neat fuel from the baseline fuel. The $\mathrm{NOx}$ and $\mathrm{NO}_{2}$ percent difference plots for the other four test engines are shown in Figure 8-7, Figure 8-16, Figure 8-25, and Figure 8-34. The negative percent difference is a reduction in both constituents, and a positive percent difference is an increase based on the neat fuel emissions levels. The figure shows that between 150 and 200 horsepower, the additives begin to increase NOx production by about $2 \%$. $\mathrm{NO}_{2}$ is increases by as much as 14\%, and this increase occurs between 25 and 75 horsepower for the majority of the treated fuels.

It is interesting to note that when the CP 0.05 Cert was run a second time (CP 0.05 Cert Neat 2), the $\mathrm{NOx}$ and $\mathrm{NO}_{2}$ increased by approximately $1 \%$ and $2.5 \%$, respectively. This is consistent with day-to-day variations. Based on this result and data to be presented below, differences less than $1 \%$ for $\mathrm{NOx}$ and $2.5 \%$ for $\mathrm{NO}_{2}$ would not be considered significant. Although the percent differences of the $\mathrm{NO}_{2}$ are somewhat high, this is only $10 \%$ to $15 \%$ of the total NOx; therefore, there is only a $2 \%$ to $3 \%$ change in $\mathrm{NO}_{2}$ compared to the total $\mathrm{NOx}$ production. That is, the NO and NOx ratio is only changing a few percent. 


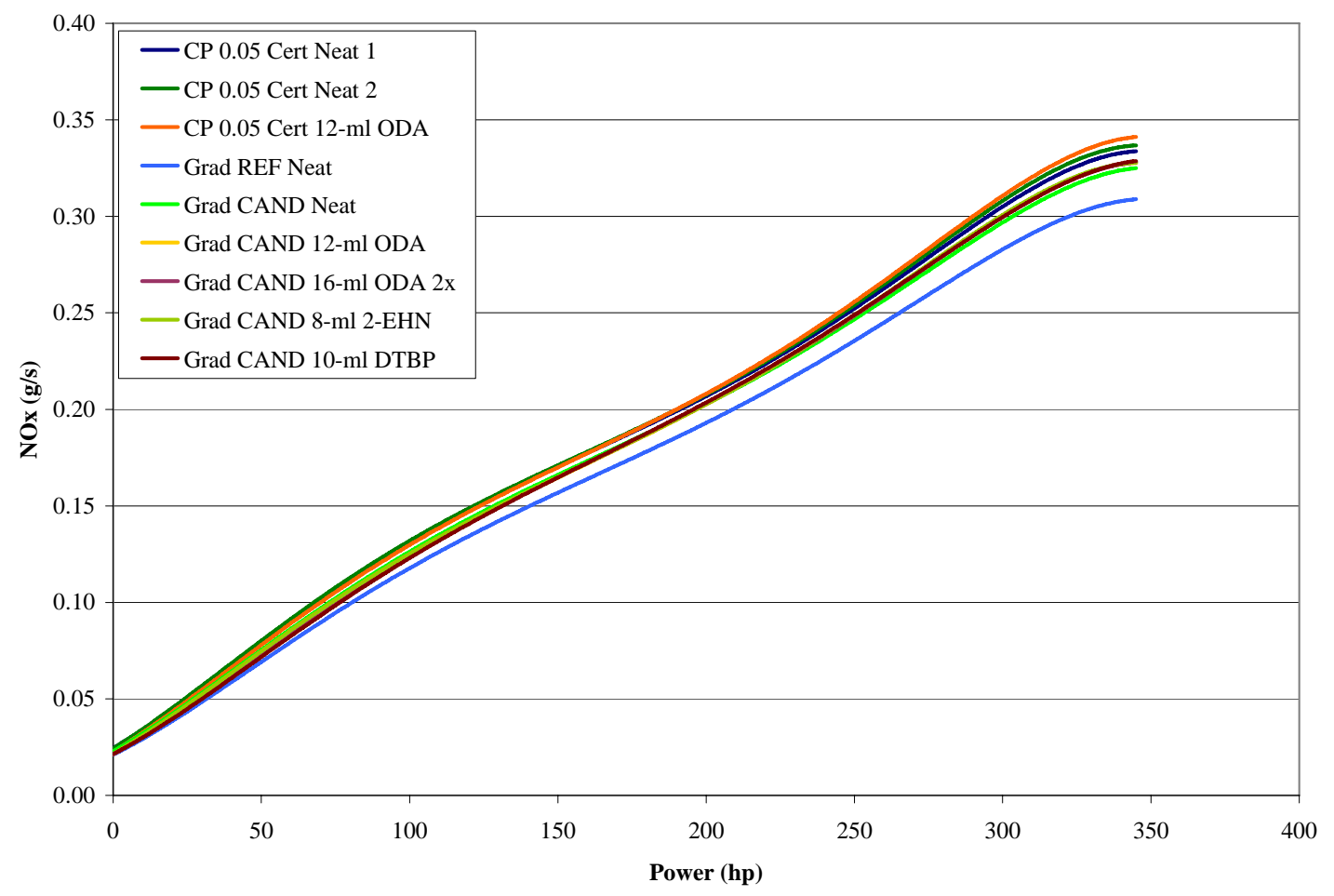

Figure 5-1 NOx Trendlines for 1991 DDC S60

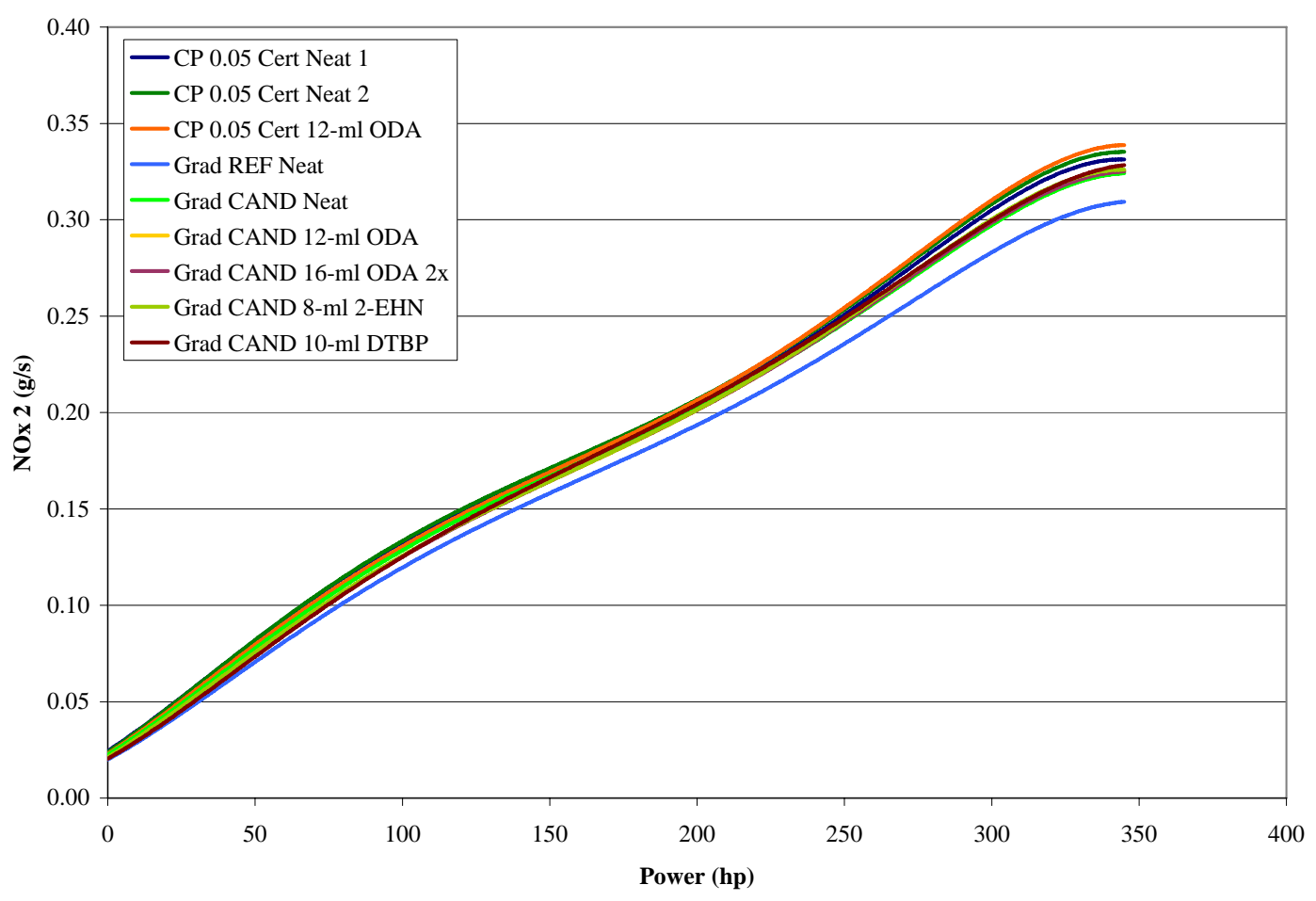

Figure 5-2 NOx 2 Trendlines for 1991 DDC S60 


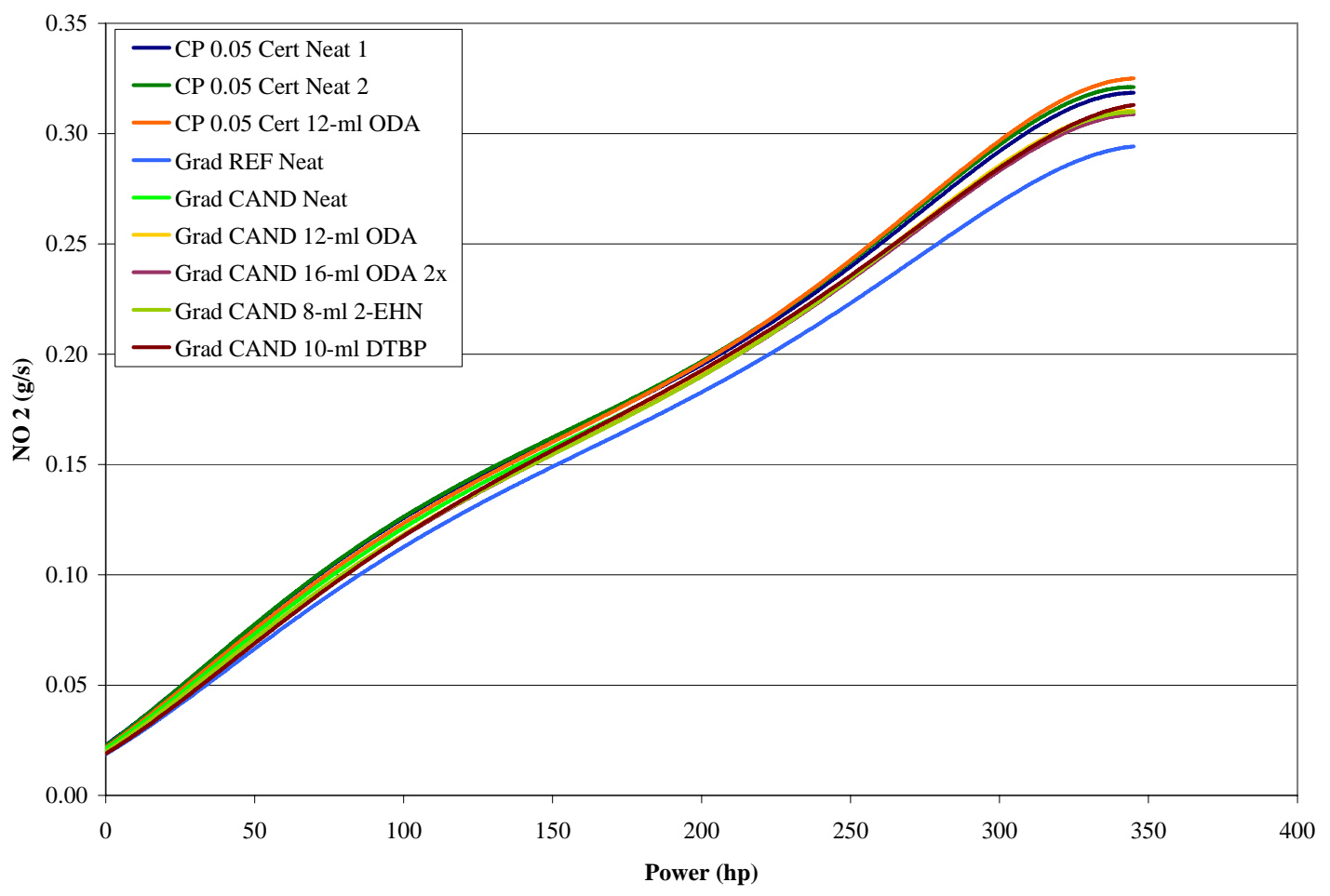

Figure 5-3 NO 2 Trendlines for 1991 DDC S60

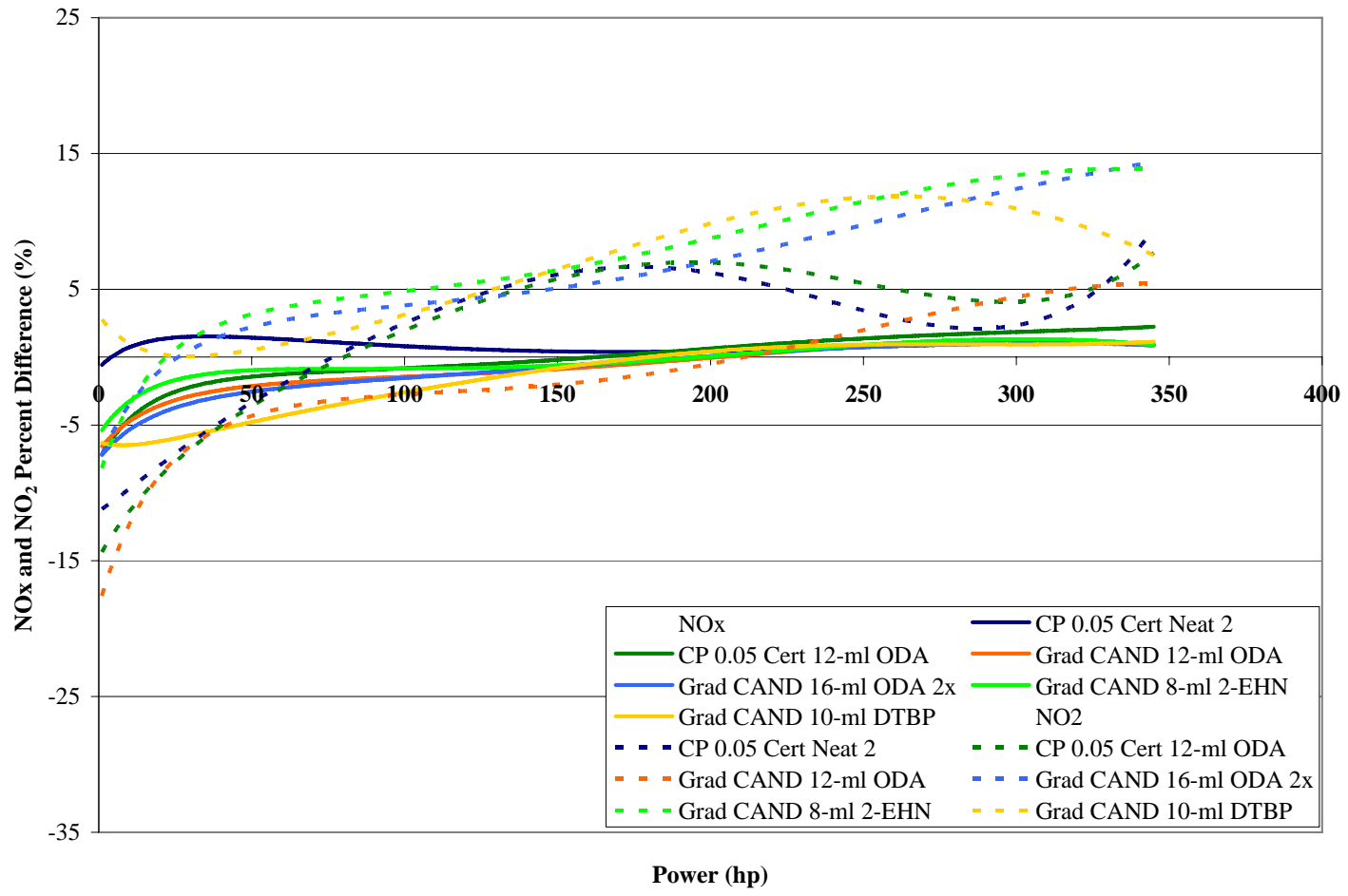

Figure 5-4 NOx and $\mathrm{NO}_{2}$ Percent Difference from Neat Fuels for 1991 DDC S60 
Figure 5-5 presents the CO percent differences for each treated and multiple run neat fuel from the baseline fuel. Figure 8-8, Figure 8-17, Figure 8-26, and Figure 8-35 display the CO percent difference plots for each of the remaining test engines. This data was taken from the high CO analyzer, since the low CO analyzer over-ranged for longer than the allowable time as written in the CFR. This is a similar figure to the $\mathrm{NOx}$ and $\mathrm{NO}_{2}$ percent difference figure in that a negative percent difference is a reduction in the emissions constituent, and a positive percent difference is an increase based on the neat fuel emissions levels. The figure shows that there is a reduction up to $15 \%$ in $\mathrm{CO}$ with most of the treated fuels.

It is interesting to note that when the CP 0.05 Cert was run a second time (CP 0.05 Cert Neat 2), the CO increased by approximately $4.5 \%$. If the data were re-reduced and compared to the CP 0.05 Cert Neat 2 fuel, the CO emissions would appear much lower. This is consistent with day-to-day variations. Based on this result and data to be presented below, differences less than $4.5 \%$ would not be considered significant. Although the percent differences are not as significant as the figure shows, the reduction in $\mathrm{CO}$ is consistent with historical data showing a reduction in $\mathrm{CO}$ with the additives used during this study. 


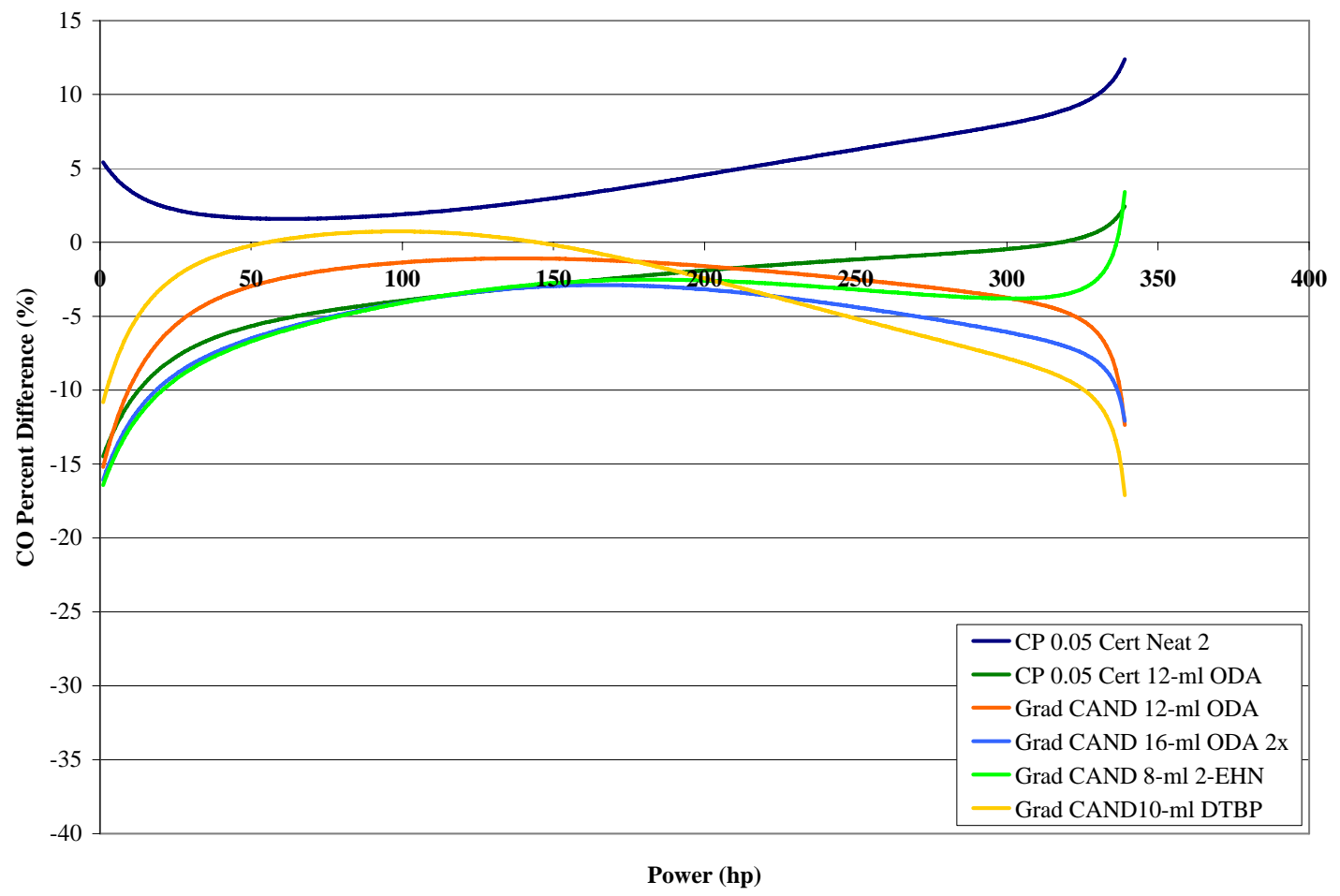

Figure 5-5 CO Percent Difference from Neat Fuels for 1991 DDC S60

Figure 5-6 presents the THC percent differences for each treated and multiple run neat fuel from the baseline fuel. This data was taken from the primary THC analyzer. The THC percent difference plots for the other test engines are shown in Figure 8-9, Figure 8-18, Figure 8-27, and Figure 8-36. This is a similar figure to the previous percent difference figures in that a negative percent difference is a reduction in emissions, and a positive percent difference is an increase based on the neat fuel emissions levels. The figure shows that there is a reduction up to approximately $17 \%$ in THC with most of the treated fuels.

It is interesting to note that when the CP 0.05 Cert was run a second time (CP 0.05 Cert Neat 2), the THC decreased by approximately 3.5\%. Based on this result and data to be presented below, differences less than $3.5 \%$ would not be considered significant. Although the percent differences are not as significant as the figure shows, the reduction in THC is also 
consistent with historical data showing a reduction in hydrocarbons with the additives used during this study.

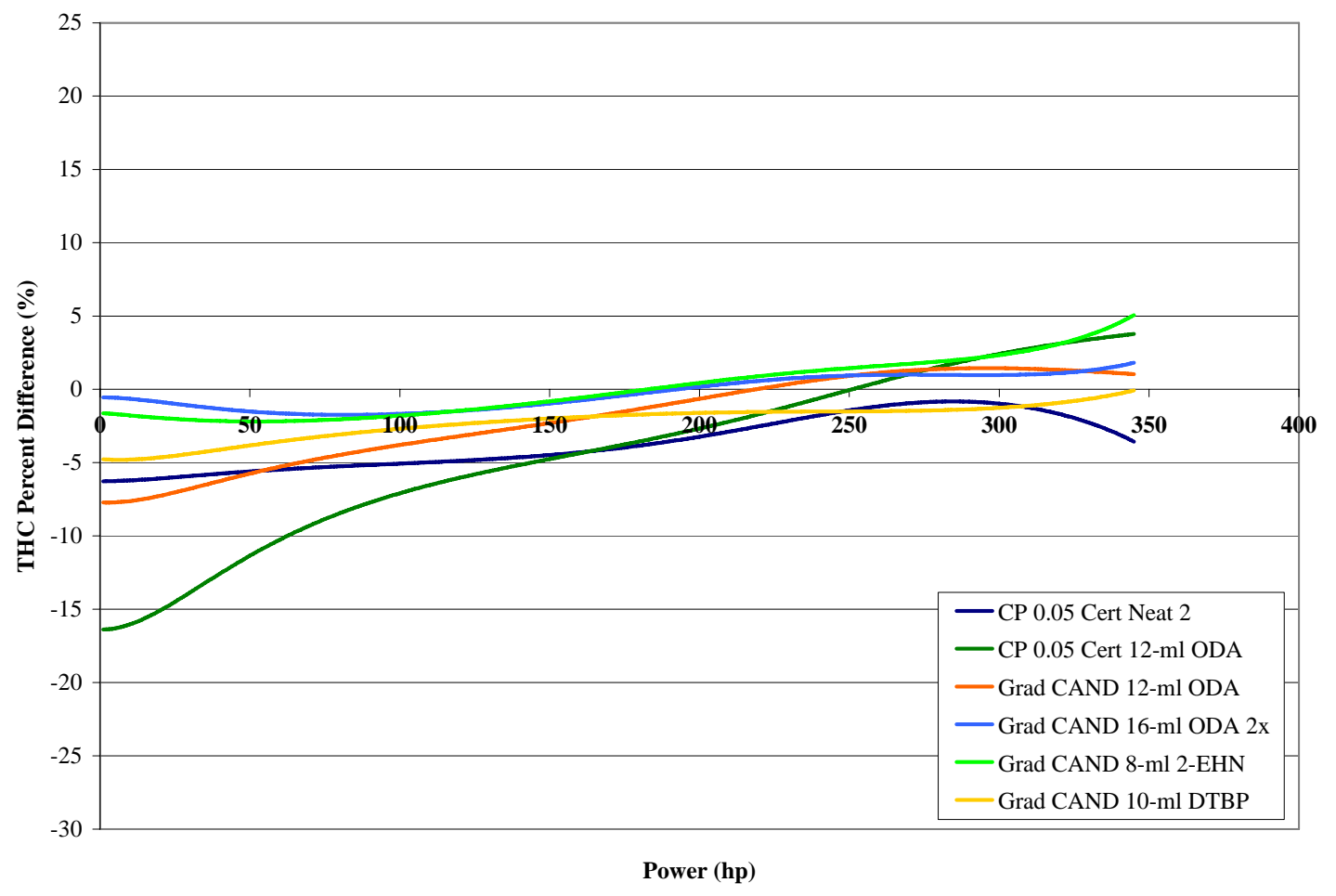

Figure 5-6 THC Percent Difference from Neat Fuels for 1991 DDC S60

For each SET test, the weighted emissions, BSFC, and work values were obtained by first calculating the mode specific values. Each mode specific value was an average of the respective data for the last 30 seconds of the mode. This allowed the engine to come into steady-state phase without large changes in the data. It is noted that the engine was at operating condition (oil and coolant approximately $180^{\circ} \mathrm{F}$ ) for mode 1 , idle, but that mode 2 (1199 rpm and $\left.1419 \mathrm{ft}-\mathrm{lb}\right)$ there were variations in the engine oil and coolant temperature throughout the mode for the two minute duration. The subsequent modes, 3 to 13, did not exhibit large oil and coolant temperature variations, and was assumed to be near steady-state operating condition for these modes. Although it is permissible to run the SET test with longer mode lengths, the idle mode 
was maintained at four minutes and the remaining modes were maintained at two minutes, the minimum specification listed in 40 CFR Part 86 [1]. This was done to minimize time and fuel usage, since only mode 2 was influenced.

Table 5-6 SET Test Results for 1991 DDC S60

\begin{tabular}{|l|c|c|c|c|c|c|c|c|}
\hline \multirow{2}{*}{ Weighted Values } & \multicolumn{2}{|c|}{ CP 0.05 Cert } & Grad REF & \multicolumn{4}{c|}{ Grad CAND } \\
\cline { 2 - 10 } & Neat & 12 -ml ODA & Neat & Neat & 12-ml ODA & $\begin{array}{c}\text { 16-ml ODA } \\
\text { 2x }\end{array}$ & 8-ml 2-EHN & 10 -ml DTBP \\
\hline THC (g/bhp-hr) & 0.0230 & 0.0236 & 0.0238 & 0.0254 & 0.0240 & 0.0260 & 0.0255 & 0.0252 \\
\hline CO (g/bhp-hr) & 0.7346 & 0.7253 & 0.7741 & 0.7543 & 0.7471 & 0.7054 & 0.7447 & 0.7431 \\
\hline CO2 (g/bhp-hr) & 456.5 & 459.7 & 450.9 & 458.0 & 455.7 & 453.1 & 453.2 & 454.1 \\
\hline NOx (g/bhp-hr) & 8.389 & 8.474 & 7.897 & 8.172 & 8.216 & 8.254 & 8.229 & 8.205 \\
\hline NO2 (g/bhp-hr) & 0.1761 & 0.1789 & 0.1873 & 0.1763 & 0.1750 & 0.2027 & 0.2028 & 0.1952 \\
\hline TPM (g/bhp-hr) & 0.0581 & 0.0587 & 0.0516 & 0.0529 & 0.0508 & 0.0508 & 0.0503 & 0.0484 \\
\hline BSFC (g/bhp-hr) & 147.0 & 139.2 & 147.1 & 147.2 & 148.1 & 147.2 & 146.9 & 147.2 \\
\hline Power (bhp) & 177.2 & 177.0 & 175.6 & 175.5 & 175.5 & 175.5 & 175.6 & 175.4 \\
\hline Work (bhp-hr) & 1.475 & 1.474 & 1.465 & 1.462 & 1.463 & 1.463 & 1.463 & 1.462 \\
\hline
\end{tabular}

For the 1992 rebuilt DDC S60, multiple SET tests were run in order to find the run-to-run variation between each fuel for the emissions constituents. The data obtained from this variation analysis will be used to infer the variation of the other engine's SET test data since only one SET test was run for these other engines for each fuel and additive combination. It was found that GRAD REF neat had a variation between $0 \%$ for power and $6.3 \%$ for $\mathrm{NO}_{2}$, whereas the GRAD REF treated with16-ml ODA had a variation of $0.1 \%$ for power and $6.7 \%$ for $\mathrm{NO}_{2}$. For the Grad CAND neat, a variation of $0 \%$ was found for power and $5.4 \%$ for $\mathrm{NO}_{2}$. The treat rate which had the highest variation for GRAD CAND was the 6-ml ODA, which was found to be between $0 \%$ for work and $8.4 \%$ for THC. The GRAD CAND 8-ml 2-EHN treat rate had the lowest amount of variability, which was found to be between $0 \%$ for work and $2.0 \%$ for NO2. All of the multiple SET test maximum coefficient of variation (COV) results can be seen in Table 5-7. The data in this table will be used to specify if changes in emissions were significant.

Table 5-7 Multiple SET Test Results for 1992 Rebuilt DDC S60 


\begin{tabular}{|c|c|c|c|c|c|c|c|c|c|}
\hline \multirow[b]{2}{*}{ COV Values } & \multicolumn{2}{|c|}{ Grad REF } & \multicolumn{6}{|c|}{ Grad CAND } & \multirow[b]{2}{*}{ Average } \\
\hline & Neat & $\begin{array}{l}16-\mathrm{ml} \\
\text { ODA }\end{array}$ & Neat 1 & $\begin{array}{l}6-\mathrm{ml} \\
\text { ODA }\end{array}$ & $\begin{array}{l}\text { 16-ml } \\
\text { ODA }\end{array}$ & $\begin{array}{c}16-\mathrm{ml} \\
\text { ODA } 2 x\end{array}$ & \begin{tabular}{|c|}
$8-\mathrm{ml}$ \\
$2-\mathrm{EHN}$
\end{tabular} & $\begin{array}{l}\text { 10-ml } \\
\text { DTBP }\end{array}$ & \\
\hline THC (\%) & 4.9 & 0.9 & 4.1 & 8.4 & 2.0 & 1.0 & \begin{tabular}{|l|}
0.0 \\
\end{tabular} & 0.6 & 2.7 \\
\hline $\mathrm{CO}(\%)$ & 1.2 & 1.8 & 0.9 & 0.1 & 0.1 & 0.6 & 0.7 & 1.5 & 0.8 \\
\hline $\mathrm{CO} 2(\%)$ & 1.0 & 0.2 & 0.2 & 3.7 & 0.3 & 0.1 & 0.0 & 0.3 & 0.7 \\
\hline NOx (\%) & 0.4 & 0.2 & 0.1 & 4.0 & 0.2 & 0.1 & 0.0 & 0.5 & 0.7 \\
\hline $\mathrm{NO}_{2}(\%)$ & 6.3 & 6.7 & 5.4 & 3.8 & 1.8 & 5.3 & 2.0 & 4.8 & 4.5 \\
\hline TPM (\%) & 2.2 & 2.6 & 4.0 & 2.3 & 1.3 & 3.1 & 0.0 & 8.2 & 3.0 \\
\hline$\overline{B S F C ~(\%)}$ & 0.6 & 1.3 & 1.7 & 1.8 & 1.6 & 1.5 & 0.8 & 1.6 & 1.4 \\
\hline Power (\%) & 0.0 & 0.1 & 0.0 & 0.1 & 0.1 & 0.0 & 0.1 & 0.0 & 0.1 \\
\hline Work (\%) & 0.1 & 0.0 & 0.0 & 0.0 & 0.0 & 0.0 & 0.0 & 0.0 & 0.0 \\
\hline
\end{tabular}

The emissions were calculated for each of the 13 modes for each SET test and for each fuel. The treated fuels were then compared to the respective neat fuels by using a percent difference. A negative percent difference shows a reduction in a particular emission constituent from the neat fuel and a positive percent difference shows an increase. Although mode one can show a reduction up to $60 \%$, this information must be taken lightly since all of the data for the first mode were very small values due to the selected tunnel flow rate and analyzer full-scale range selected to capture the highest concentration while testing. Any variation in small numbers would show up in the figures below as a large reduction, and some of the variation could be attributed to the selected laboratory or emissions analyzer ranges. Figure 5-7 through Figure 5-12 contain the data for each emissions constituent for the 1991 DDC S60, which was shown as an example to illustrate the effect of the additives used during this study.

\subsubsection{Fuel Specific THC Emissions}

Fuel specific THC emissions for the 1991 DDC S60 are displayed in Figure 5-7 for each of the 13 modes. The difference of each treated fuel is based upon the respective neat fuel. Referring back to Table 5-7, the Grad CAND treats of 16-ml ODA 2x, 8-ml 2-EHN and 10-ml 
DTBP are the most significant. Although the data included in the multiple SET test variation results in Table 5-7 is for the 1992 rebuilt DDC S60 engine, it is the best reference for this study to conclude whether the emissions change is significant. The other two treats were not run multiple times, so a conclusion can not be drawn as to whether the reductions are significant. Figure 8-1, Figure 8-10, Figure 8-19, and Figure 8-28 show similar plots for each of the other test engines. Since the magnitude of THC emissions is so low, it is difficult to conclude whether the increases or reductions are significant. Based on the repeat Neat fuel runs in Figure 8-10, Figure 8-19, and Figure 8-28, many of the treated fuel THC show variations within the repeat Neat fuel runs; however, the biodiesel THC does show a significant reduction which is consistent with the literature.

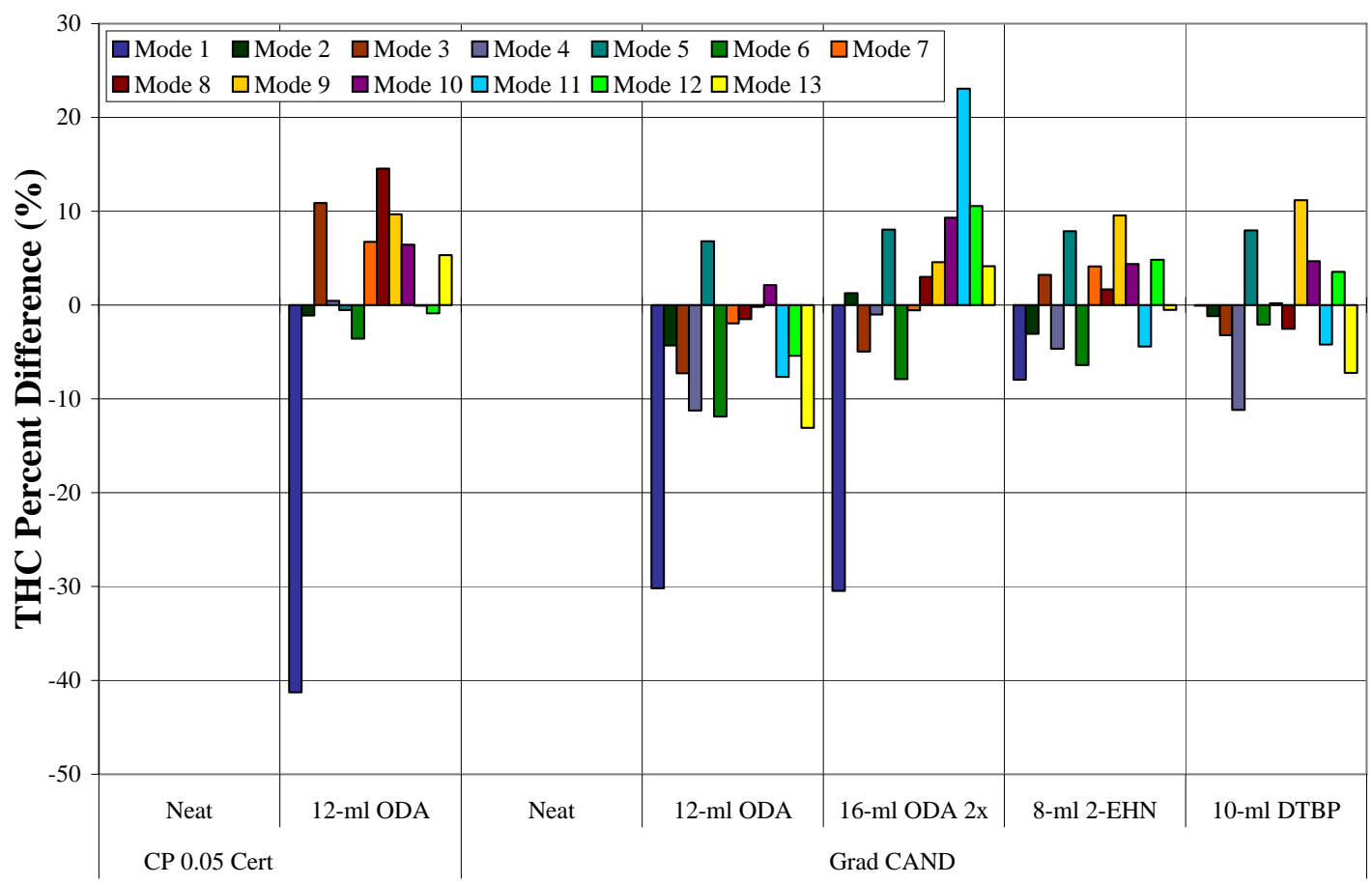

Fuel

Figure 5-7 THC Percent Difference from Neat Fuels for 1991 DDC S60 


\subsubsection{Fuel Specific CO Emissions}

Figure 5-8 illustrates the fuel specific CO emissions for the 1991 DDC S60 for each of the 13 modes. Looking ahead to Figure 5-12, which shows the percent difference of TPM versus the neat fuels, the CO follows the same reduction pattern for the Grad CAND fuel as PM. Figure 8-2, Figure 8-11, Figure 8-20, and Figure 8-29 are displays of similar plots for the other test engines, which can be viewed in the Appendix section. Each of these figures shows a similar trend with the $\mathrm{CO}$ emissions reduction following the PM emissions reduction. Based on the repeat SET test data in Figure 8-11, Figure 8-20, and Figure 8-29 any differences greater than $10 \%$ are seen as significant. The fuels treated with the ODA have modes with reductions greater than $10 \%$ and these additives do reduce the overall CO.

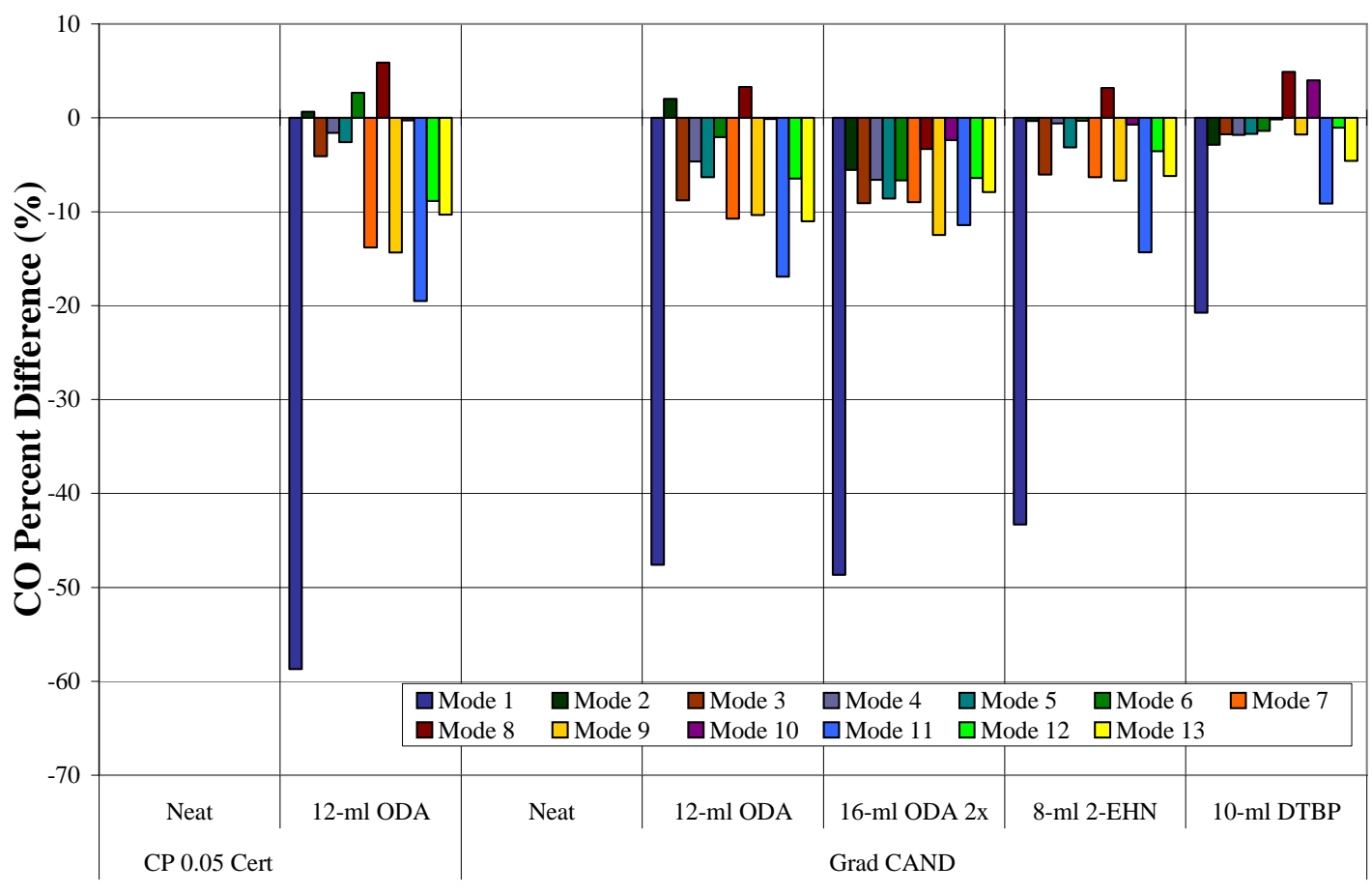

Fuel

Figure 5-8 CO Percent Difference from Neat Fuels for 1991 DDC S60 


\subsubsection{Fuel Specific $\mathrm{CO}_{2}$ Emissions}

Figure 5-9 illustrates the amount of fuel consumed based on a tunnel carbon balance, since it could be calculated using the $\mathrm{CO}_{2}$ mass. Based upon the multiple SET test data in Table 5-7, the reduction in $\mathrm{CO}_{2}$ is not significant. The weighted SET test brake-specific $\mathrm{CO}_{2}$ varies $\pm 1.85 \%$ between the neat and treated fuels. This variation is partially run-to-run variations as Table 5-7 indicates and also day-to-day variations, which cannot be shown. The $\mathrm{CO}_{2}$ SET test data can be viewed in the Appendix in Figure 8-3, Figure 8-12, Figure 8-21, and Figure 8-30 for the other test engines. It is observed that the $\mathrm{CO}_{2}$ data for the 1992 rebuilt DDC S60 in Figure 8-12 for the last three modes of Grad CAND 6-ml ODA is evidently an error and should be discarded.

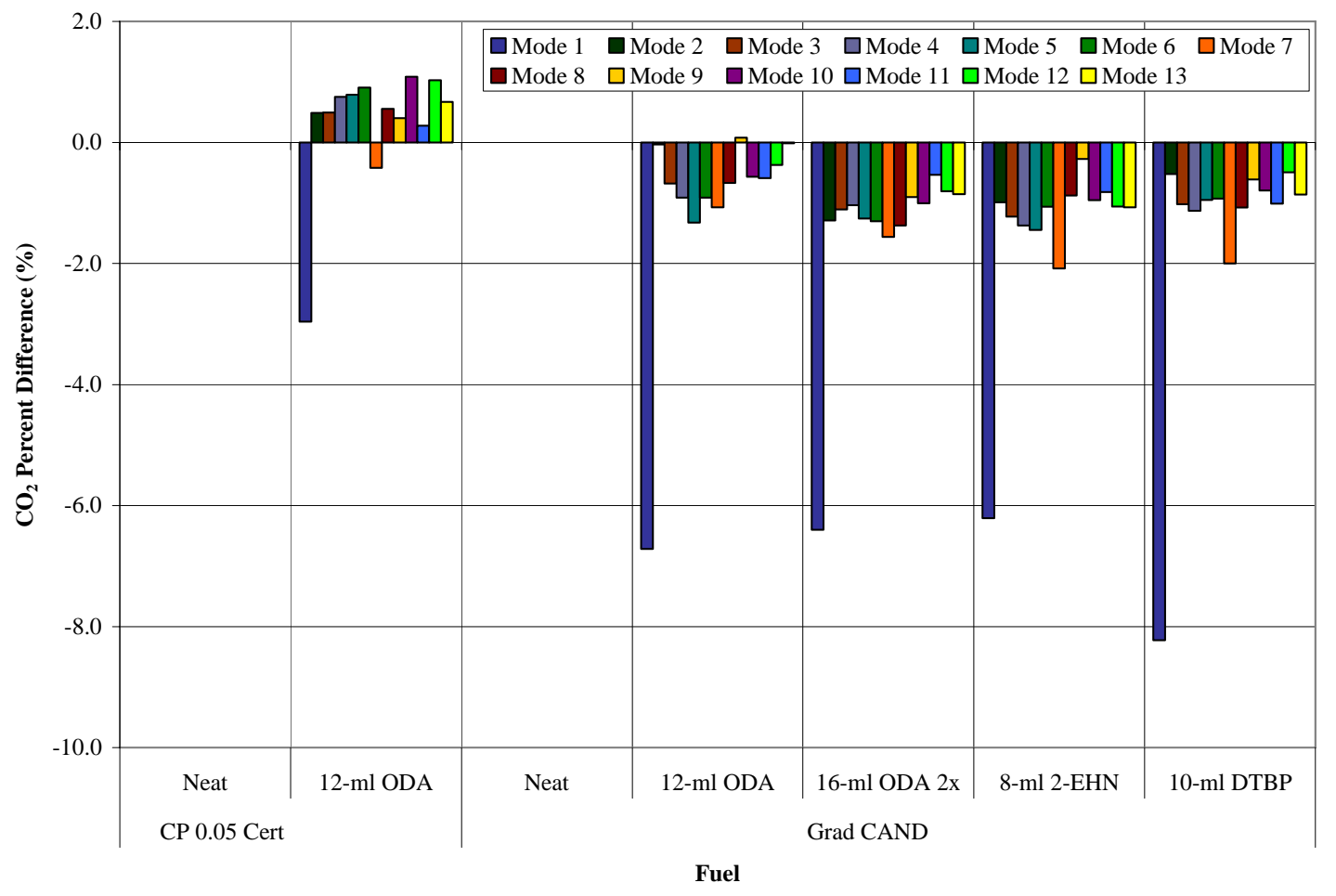

Figure 5-9 CO2 Percent Difference from Neat Fuels for 1991 DDC S60 


\subsubsection{Fuel Specific NOx Emissions}

The NOx percent difference based on the neat fuels can be seen in Figure 5-10. It is clearly shown that there is a NOx reduction in the low power modes of 7,9 , and 11 , but an increase in NOx in the high power modes. It is estimated that any differences greater than $1.5 \%$ are significant based on repeat SET tests and repeat neat fuel evaluations. This shows where the fuel additives are working, and also where the additives start to increase the NOx production. This was also clearly plotted for the FTP data in Figure 5-4. Figure 8-4, Figure 8-13, Figure 8-22, and Figure 8-31 can be seen in the Appendix for the other test engines. From the figures in the appendix, it is clear that the additives work on the older DDC engines, but can increase the NOx production by up to $5 \%$ in all modes in the newer Cummins engines. For the biodiesel blends, NOx seems to increase significantly for all non-idle modes, including the additized biodiesels.

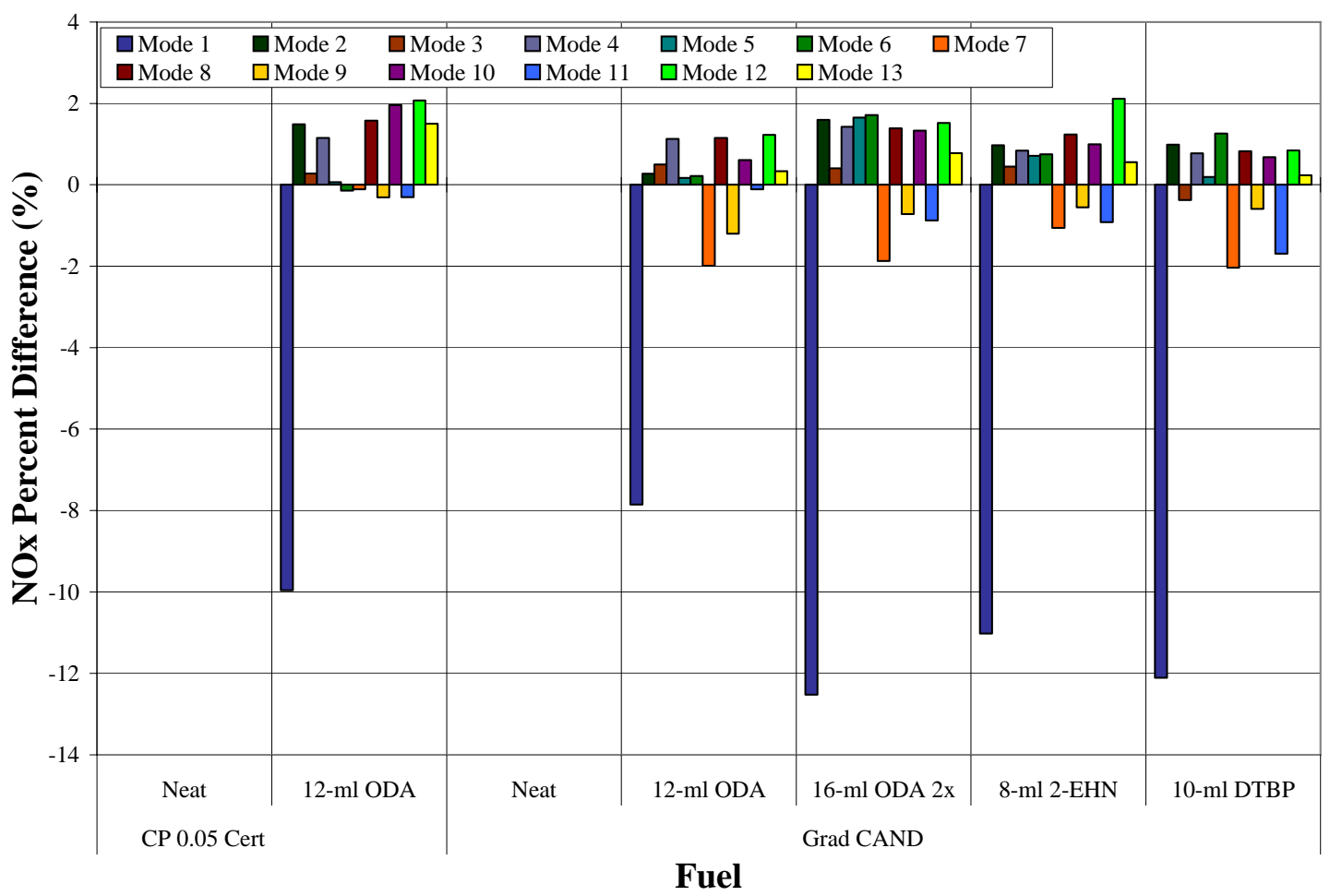

Figure 5-10 NOx Percent Difference from Neat Fuels for 1991 DDC S60 


\subsubsection{Fuel Specific $\mathrm{NO}_{2}$ Emissions}

Figure 5-11 presents the $\mathrm{NO}_{2}$ percent difference versus the baseline fuel for each of the 13 modes. Since Table 5-7 shows a fairly high variability for all of the fuels, it is difficult to discern if the $\mathrm{NO}_{2}$ is actually increasing as much as is shown. The other test engine data for $\mathrm{NO}_{2}$ can be viewed in Figure 8-5, Figure 8-14, Figure 8-23, and Figure 8-32 in the Appendix. Based on the limited data here, no conclusions can be drawn about the $\mathrm{NO}_{2}$ production. It appears as though day-to-day variations can have a large impact in determining $\mathrm{NO}_{2}$ production from subtraction of NO from NOx.

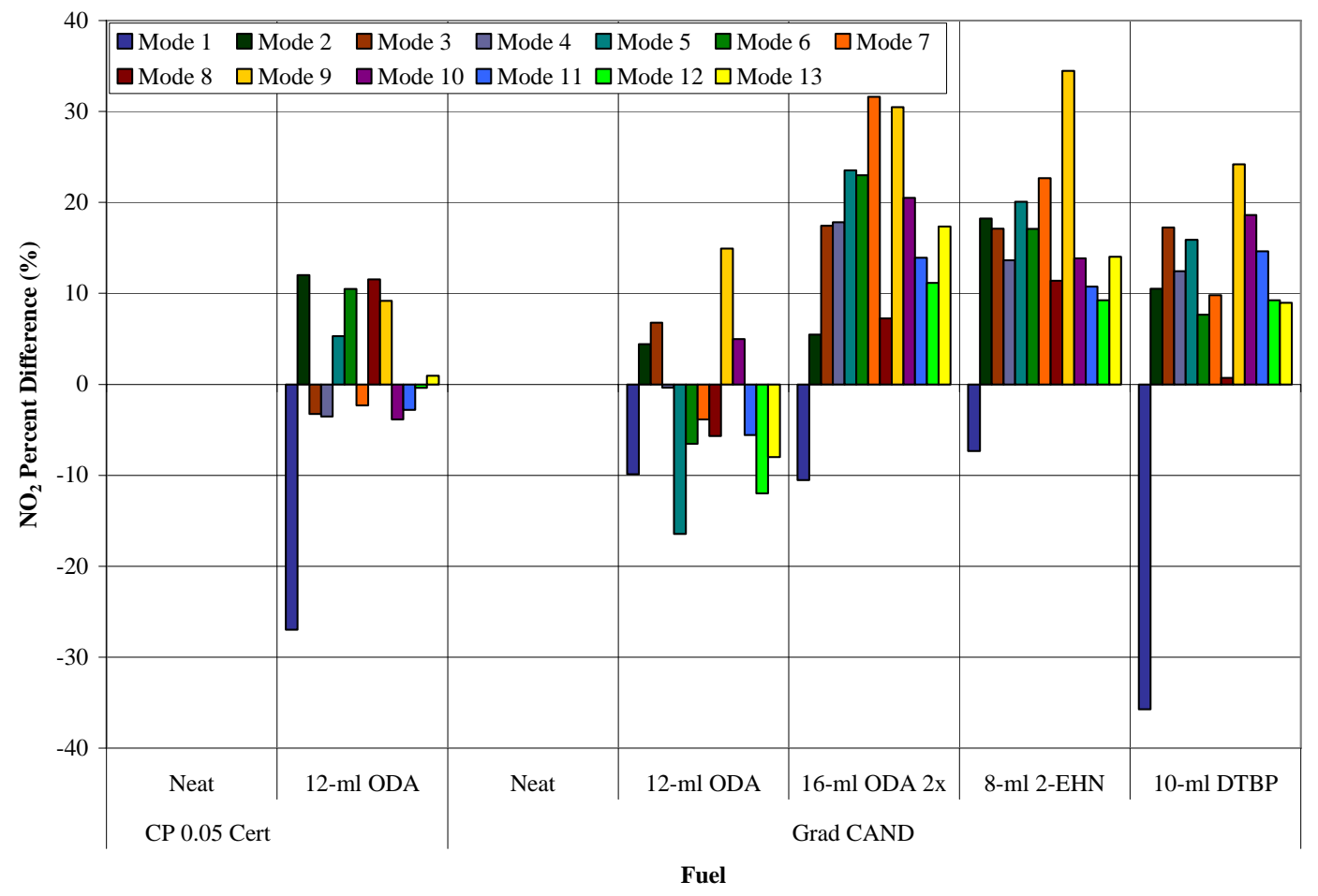

Figure 5-11 $\mathrm{NO}_{2}$ Percent Difference from Neat Fuels for 1991 DDC S60 


\subsubsection{Fuel Specific TPM Emissions}

The TPM emissions percent difference is shown for each of the 1991 DDC S60 test fuels in Figure 5-12. The PM reductions shown in this plot are not significant for the additized fuels due to the high variability, which can be seen in Table 5-7. Figure 8-6, Figure 8-15, Figure 8-24, and Figure 8-33 display the other test engine data for TPM. The TPM is reduced significantly for all the biodiesel blends, which is consistent with the literature.

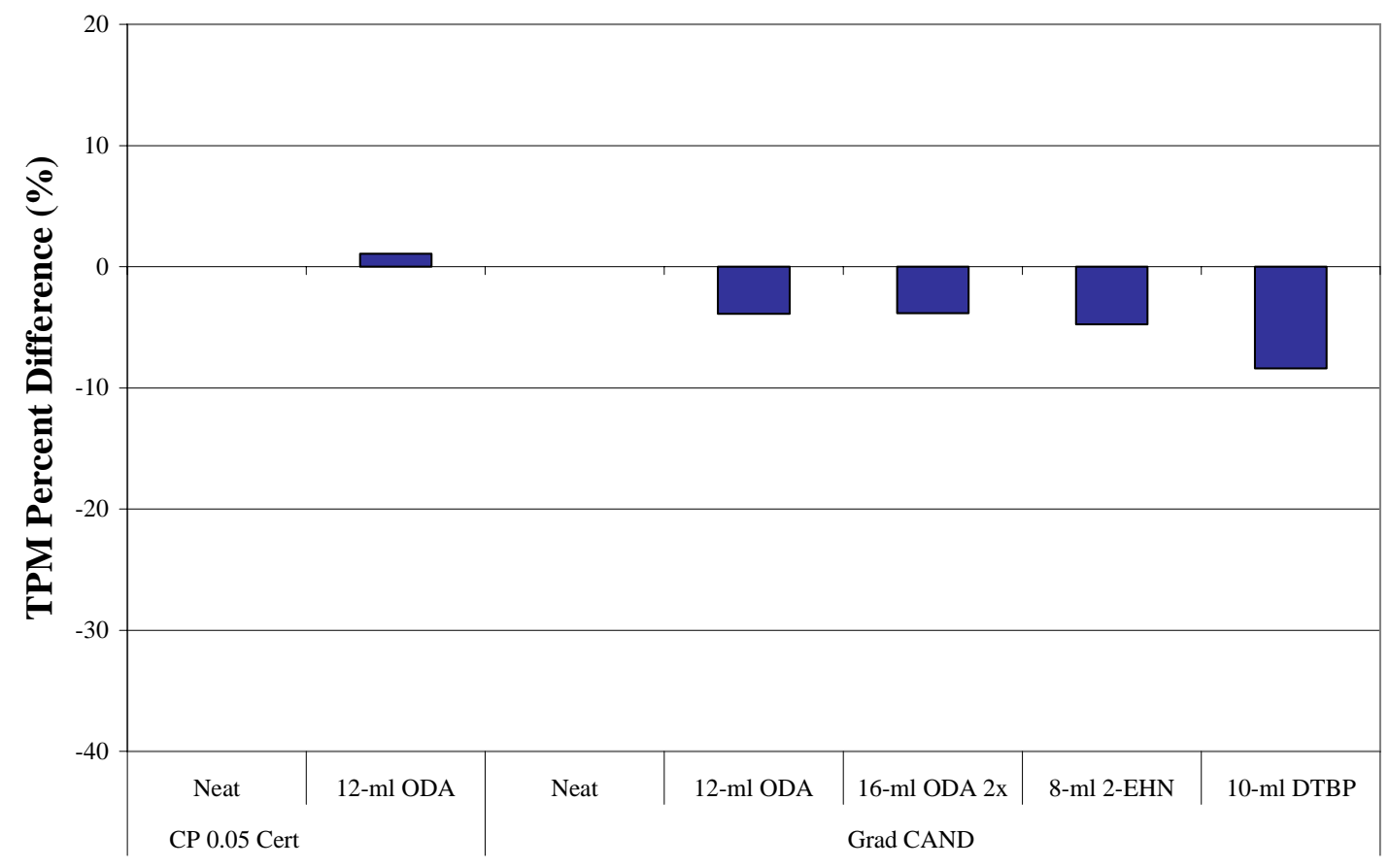

Fuel

Figure 5-12 TPM Percent Difference from Neat Fuels for 1991 DDC S60

\subsection{NOx-PM Trade-off}

One of the most difficult hurdles for engine manufacturers to overcome in reducing the overall NOx and PM emissions to meet current and future standards is the NOx-PM trade-off. This trade-off occurs because when the combustion chamber is cooled with aftertreatment devices, such as cooled EGR, the overall production of NOx is reduced. In return, due to the 
cooler temperatures, the TPM is not able to oxidize; therefore, an increase in TPM is seen. Only the 2004 Cummins ISM 370 showed this trend, as seen in Figure 5-13 and Figure 5-14. Both figures include biodiesels for the 1999 Cummins ISM 370 and the 2004 Cummins ISM 370 which will change the change the NOx-PM trade-off trendline. This correlates well with the use of aftertreatment devices and engine technologies. This figure illustrates the effect of fuel properties on NOx and PM, and it is shown that the fuel properties have more of an affect on NOx and PM than changes in ignition timing for a given engine. This was also shown by John Gibble [23].

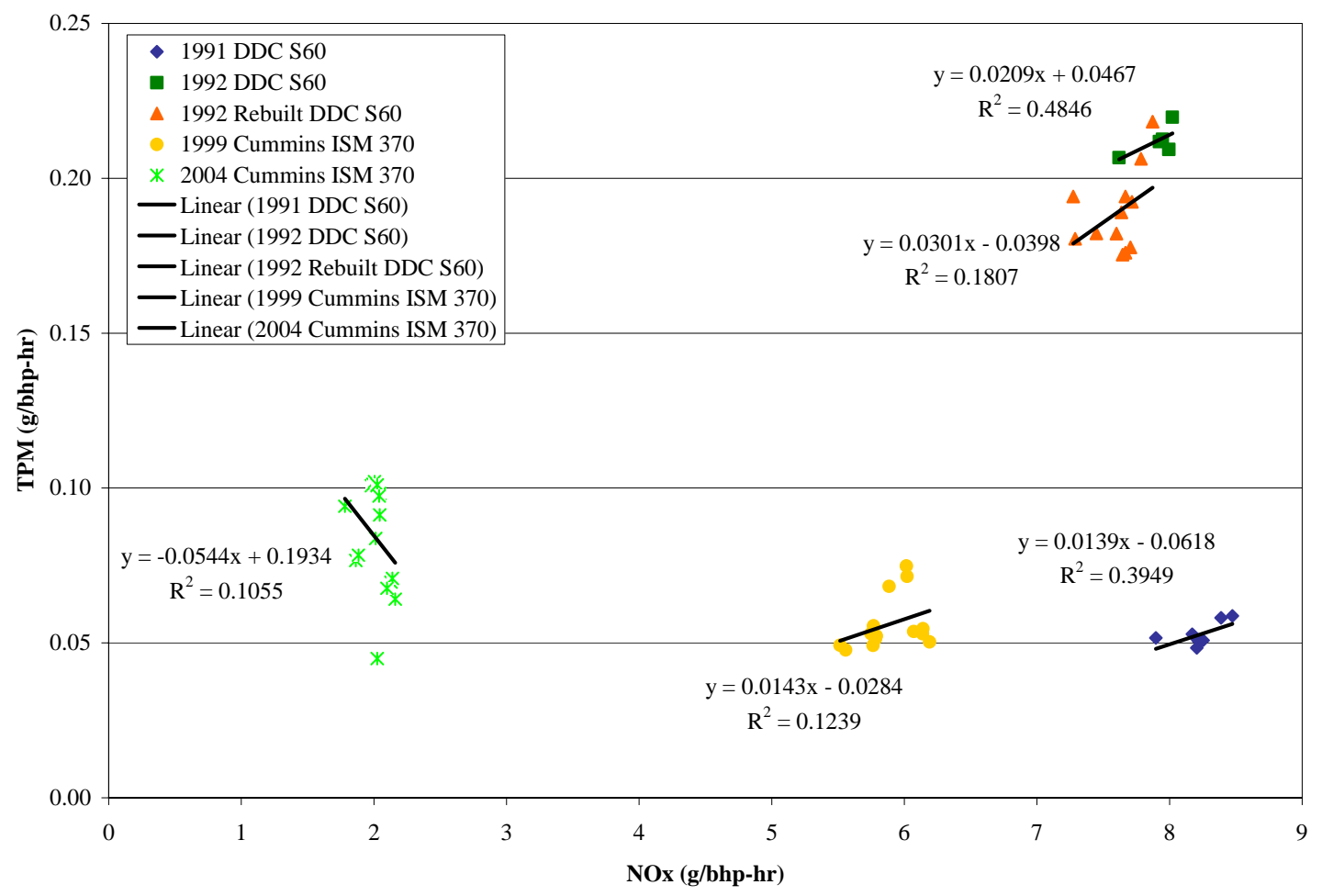

Figure 5-13 NOx-PM Trade-off for SET tests 


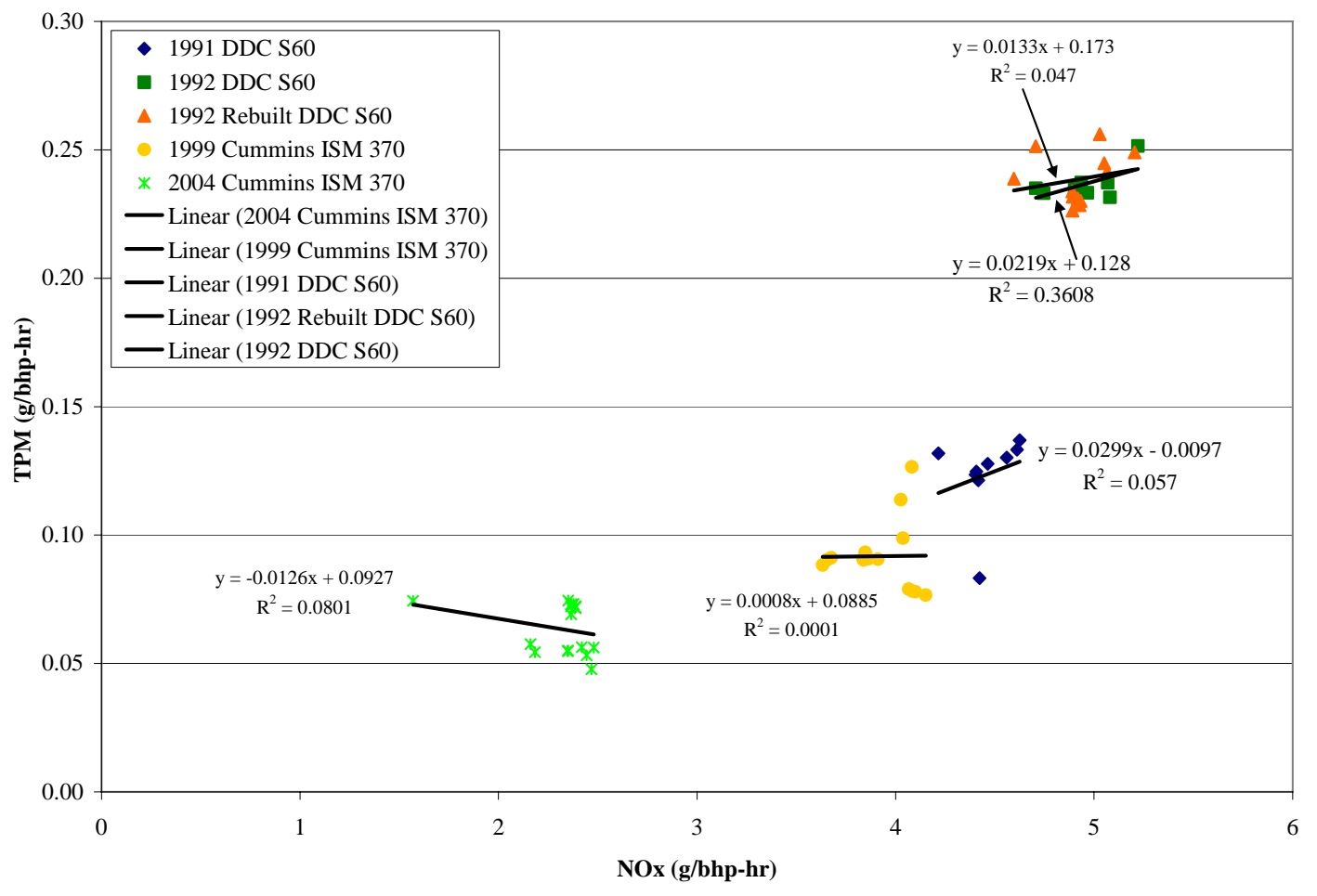

Figure 5-14 NOx-PM Trade-off for FTP tests

\subsection{Work and Fuel Economy}

Figure 5-15 displays the actual work for the fuels tested using the FTP cycle for all five engines. Figure 5-16 is a plot of the brake specific fuel consumption for the same fuels over the FTP for all five engines. The 2004 Cummins ISM 370 has the highest variation out of the five test engines, but all of the variations were less than 3\%. These plots show the work and fuel economy data is repeatable. 


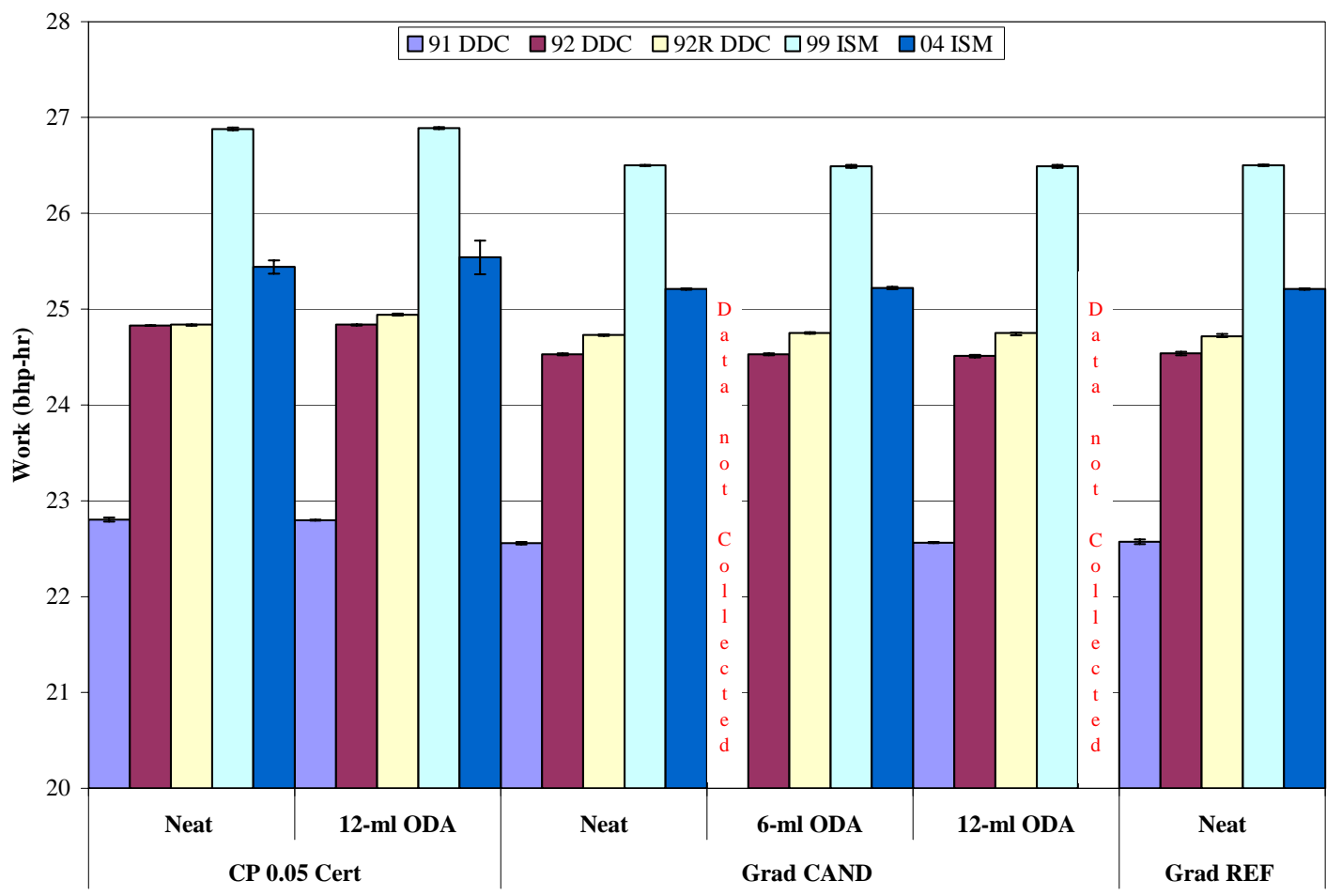

Figure 5-15 Brake Specific Work for FTP Cycle

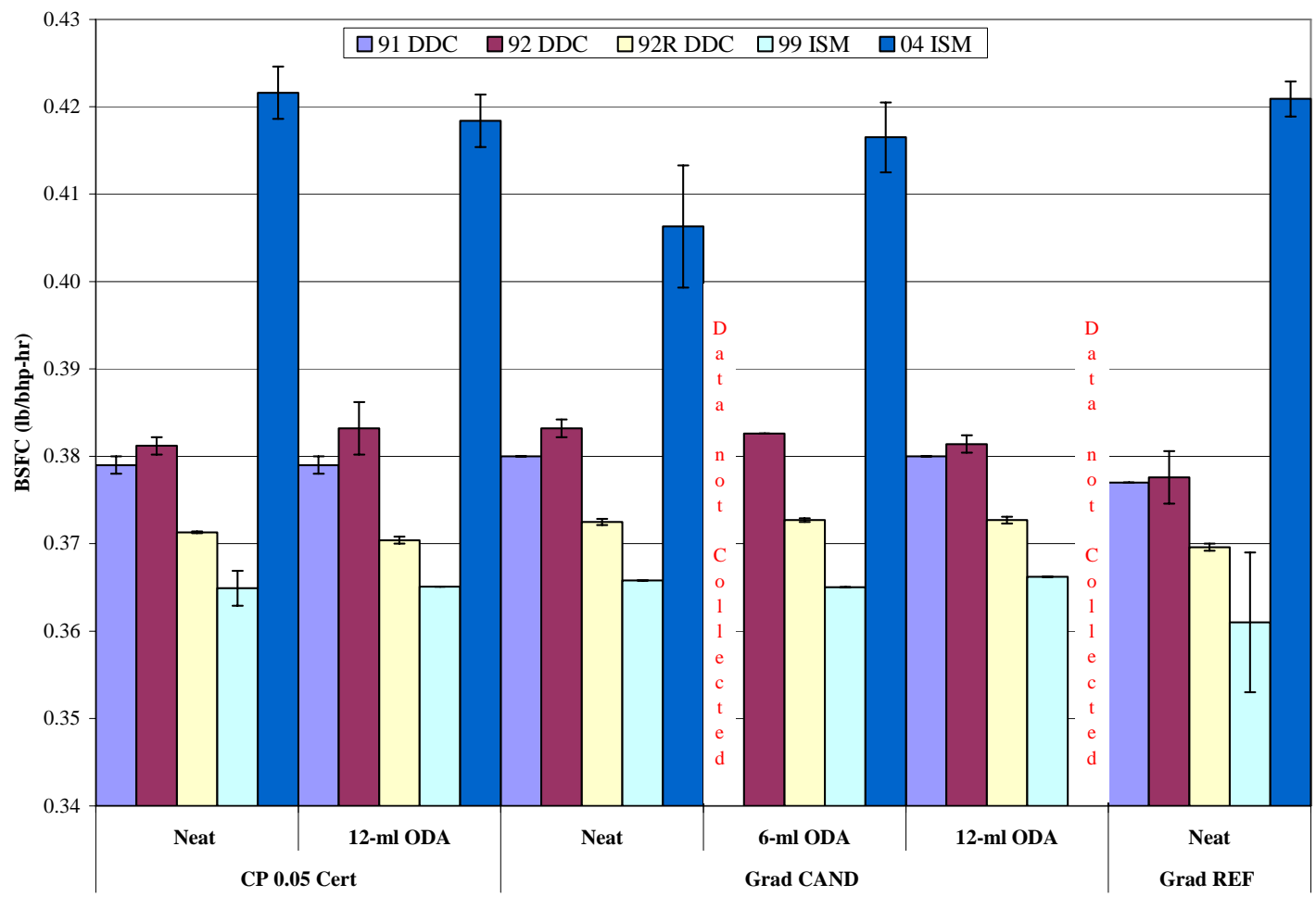

Figure 5-16 Brake Specific Fuel Consumption for FTP Cycle 


\subsection{Summary of Results}

For the 1991 DDC S60, a 7\% reduction was seen in NOx up to about 200 horsepower, but an increase of up to $2 \%$ was seen after this point when the engine was run on the FTP cycle. The $\mathrm{NO}_{2}$ showed an increased production up to about $14 \%$ after approximately 50 horsepower. A similar trend occurred for the 1992 DDC S60 and the 1992 rebuilt DDC S60, except the transition point occurred around 250 horsepower and the increase in $\mathrm{NOx}$ and $\mathrm{NO}_{2}$ after this point was between $1 \%$ and $4 \%$. The 1999 Cummins ISM 370 and the 2004 Cummins ISM 370 engines did not show this trend, which may be due to the engine technologies of higher injection pressure, higher compression ratio, delayed ignition timing, and cooled EGR (on 2004 ISM only) which greatly reduce the NOx production. An increase in $\mathrm{NOx}$ and $\mathrm{NO}_{2}$ production of up to $4 \%$ was seen in the 1999 Cummins ISM 370 after about 150 horsepower, and up to a $6 \%$ increase and after about 100 horsepower in the 2004 Cummins ISM 370. All of this data was for the FTP cycles.

There was a more significant reduction in THC in the older production engines. This reduction was up to $25 \%$, which was seen in the 1992 rebuilt DDC S60. The greatest reduction in the newer technology Cummins engines, up to $25 \%$, was seen with the biodiesels. The petroleum based diesels only showed a reduction up to approximately 5\%. CO showed a reduction in all of the older technology DDC engines of up to approximately $25 \%$. The newer technology Cummins engines showed a similar reduction, but the biodiesels were shown to reduce the $\mathrm{CO}$ emissions up to about $5 \%$ more than the petroleum based diesels. This trend was most prevalent during high power situations.

The SET tests show a similar trend for the older model year engines, where NOx is reduced in the low power modes up to $2 \%$, and an increase is seen in the higher power modes up 
to $2 \%$. The Cummins engines did not show a similar trend, but in fact had an increase in NOx production in the lower power modes between $2 \%$ and $5 \%$. Both Cummins engines showed a greater reduction in TPM than the older technology DDC engines. This reduction was between 20\% and 30\% for the Cummins engines, and between 2\% and 5\% for the Detroit Diesel engines. CO showed a reduction of up to $20 \%$ in the Cummins engines, but was between $10 \%$ and $20 \%$ for the 1991 DDC S60 and the 1992 rebuilt DDC S60. Any reduction below $10 \%$ for CO was considered insignificant based on the repeat SET test data. THC showed a reduction with the treated fuels for all engines, but most of these reductions were found to be insignificant due to the SET test data. The biodiesel fuels showed the great reductions in THC of up to $20 \%$ for the Cummins engines. 


\section{Conclusions and Recommendations}

\subsection{Conclusions}

As the emissions standards continue to become more and more stringent, engine manufacturers and fuel refineries have to improve technologies in order to reduce engine out emissions. The overall emission levels are lower as the model years of the engines become newer, and this is due to the improved engine technologies. The baseline fuels evaluated in this work showed a decreasing emissions trend with newer model years, with the fuel additives showing a greater impact on the older technology engines.

The additives showed a reduction in NOx up to about 250 horsepower with the 1991 and 1992 DDC's, and after this point an increase up to around 2\% was seen. This was most notable in the transient FTP, but a similar trend was seen with the SET test. In the lower power modes of the SET test, the older engines had a $2 \%$ reduction in NOx, but the higher power modes had up to a $2 \%$ increase in NOx.

The two Cummins engines did not show much of a reduction in NOx ( $1 \%$ or less) in the lower power modes of the SET test, and a $1 \%$ to $2 \%$ increase in NOx was seen in the higher power modes. There was up to a 10\% reduction in NOx for the 1999 Cummins ISM 370 at low power, but after about 150 horsepower the additives increase the amount of NOx production. The 2004 Cummins ISM 370 had a 6\% NOx reduction at low power, but the additives increased NOx production between 50 and 100 horsepower.

The data from this study shows that cetane improving additives are beneficial in reducing NOx in legacy engines, but are neutral or slightly increases NOx in newer technology engines. Although the increased NOx production for the newer engines in less than $5 \%$, this is an increase 
that may not allow newer and future technology engines to pass the ever increasingly more stringent emissions standards with conventional cetane improvers.

The biodiesel blends did have an increase in NOx production, but there was a decrease in all of the other regulated emissions. This emissions impact can be seen as being beneficial considering only NOx is being increased and if a cetane improving additive were used the NOx production is only slightly higher than the petroleum based diesels from which the blends were created based on the additive treat rates used in this work. Overall, the use of biodiesel as an alternative fuel seems like an attractive route, but further investigation will need to be complete since none of the older technology engines were tested using biodiesel.

The older technology DDC S60 engines showed an average reduction of 6.5\% for NOx and $\mathrm{NO}_{2}$ during low power operation, but showed an average increase of $2 \%$ while in high power operation, consistent with the NOx data. The other emissions constituents of THC, TPM, and CO have an average reduction of $10 \%, 3 \%$ and $15 \%$, respectively. The Cummins engines showed an average $\mathrm{NOx}$ and $\mathrm{NO}_{2}$ reduction of $5 \%$ for low power operation, but quickly increased NOx production up to 6\% during high power operation. The emissions constituents of THC, TPM and CO show an average reduction of $20 \%, 25 \%$ and $20 \%$, respectively for the newer technology engines.

\subsection{Recommendations}

In order to make additional conclusions about this study, the following suggestions will be made:

- The test matrix in Table 5-1 should be completed so that more conclusions can be drawn about the fuel additives used. 
- The FTP emissions data for this study should be re-analyzed and plotted against percent load in order to see how the emissions constituents vary when fuel additives are used based upon engine loading. This would separate engine speed and load.

- An in-cylinder pressure analysis study should be done for each engine so a microscopic study of the emissions formation can be completed, instead of only a macroscopic study. This is being completed by John Nuszkowski [25].

- The list of engines tested should be broadened to include newer technology engines, especially 2007 and beyond. This would allow more conclusions to be drawn about the effectiveness of fuel additives on newer technology engines.

- A study of the effects of fuel properties on unregulated emissions should be completed using the current test matrix. Although this would be a fairly expensive study, it would be interesting to see the effects of treated fuel on unregulated emissions.

- A study should be done with on-road cycles using the current test matrix to find the difference between on-road cycle emissions and FTP cycle emissions. The main objective would be to identify how accessory loads affect the emissions during on-road cycles. 


\section{References}

1. Code of Federal Regulations, CFR Title 40 Part 86-89, Office of Federal Register National Archives and Records Administration, Washington, DC, 2006.

2. Majewski, W. A. and Khair, M. K., "Diesel Emissions and Their Control,” First Edition, SAE Publications, Warrendale, PA, 2006.

3. Owen, K. and Coley, T., "Automotive Fuels Reference Book," Second Edition, SAE Publications, Warrendale, PA, 1995.

4. Signer, M., Heinze, P., Mercogliano, R., and Stein, H. J., "European Programme on Emissions, Fuels and Engine Technologies (EPEFE) - Heavy Duty Diesel Study,” SAE Paper No. 961074, SAE International, Warrendale, PA, 1996.

5. McCarthy, C., Slodowske, W., Sienicki, E., and Jass, R., "Diesel Fuel Property Effects on Exhaust Emissions from a Heavy Duty Diesel Engine that Meets 1994 Emissions Requirements,” SAE Paper No. 922267, SAE International, Warrendale, PA, 1992.

6. Ruzicka, N., and Liebscher, T., "Possible Exhaust Gas Aftertreatment Concepts for Passenger Car Diesel Engines with Sulfur-free Fuel,” SAE Paper No. 1999-01-1328, SAE International, Warrendale, PA, 1999.

7. Diesel Fuels Technical Review (FTR-2), Chevron Products Company, San Francisco, CA, 1998.

8. Sheehan, J., Dunahay, T., Benemann, J., and Roessler, P., “A Look Back at the U.S. Department of Energy Aquatic Species Program - Biodiesel from Algae,” NREL/TP580-24190, National Renewable Energy Laboratories, Golden, CO, 1998. 
9. Howell, S., "U.S. Biodiesel Standards - An Update of Current Activities," SAE Paper No. 971687, SAE International, Warrendale, PA, 1997.

10. "A Comprehensive Analysis of Biodiesel Impacts on Exhaust Emissions," Draft Technical Report EPA420-P-02-001, U.S. Environmental Protection Agency, Washington, DC, October 2002.

11. Jääskeläinen, H., "Ethanol-Diesel Blends,” DieselNet, Ecopoint Inc., Brampton, ON, Canada, 2006, http://www.dieselnet.com/tech/fuel_ediesel.html.

12. Corkwell, K., Jackson, M. and Daly, D., "Review of Exhaust Emissions of Compression Ignition Engines Operating on E Diesel Blends,” SAE Paper No. 2003-01-3283, SAE International, Warrendale, PA, 2003.

13. Tamanouchi, M., Morihisa, H., Yamada, S., Iida, J, Sasaki, T., and Sue, H., "Effects of Fuel Properties on Exhaust Emissions for Diesel Engines With and Without Oxidation Catalyst and High Pressure Injection,” SAE Paper No. 970758, SAE International, Warrendale, PA, 1997.

14. Ullman, T. L., Mason, R. L., and Montalvo, D. A., "Effects of Fuel Aromatics, Cetane Number, and Cetane Improver on Emissions from a 1991 Prototype Heavy-Duty Diesel Engine,” SAE Paper No. 902171, SAE International, Warrendale, PA, 1990.

15. Mann, N., Kvinge, F., Wilson, G., "Diesel Fuel Effects on Emissions - Towards a Better Understanding,” SAE Paper No. 982486, SAE International, Warrendale, PA, 1998.

16. Sharp, C. A., "The Effect of Biodiesel Fuels on Transient Emissions from Modern Diesel Engines, Part I Regulated Emissions and Performance,” SAE Paper No. 2000-01-1967, SAE International, Warrendale, PA, 2000. 
17. Graboski, M. S., "Transient Emissions from No. 2 Diesel and Biodiesel Blends in a DDC Series 60 Engine,” SAE Paper No. 961166, SAE International, Warrendale, PA, 1996.

18. Alam, M., Song, J., Acharya, R., Boehman, A., and Miller, K., "Combustion and Emissions Performance of Low Sulfur, Ultra Low Sulfur and Biodiesel Blends in a DI Diesel Engine,” SAE Paper No. 2004-01-3024, SAE International, Warrendale, PA, 2004.

19. Lin, L., Shulin, D., Jin, X., Jinxiang, W., Xiaohong, G., "Effects of Combustion Chamber Geometry on In-Cylinder Air Motion and Performance in DI Diesel Engine,” SAE Paper No. 2000-01-0510, SAE International, Warrendale, PA, 2000.

20. Schmitz, G., Oilgschläger, U., Eifler, G., and Lechner, H., “Automated System for Optimized Calibration of Engine Management Systems,” SAE Paper No. 940151, SAE International, Warrendale, PA, 1994.

21. Shih, L., "Comparison of the Effects of Various Fuel Additives on the Diesel Engine Emissions,” SAE Paper No. 982573, SAE International, Warrendale, PA, 1998.

22. Flynn, P. F., “How Chemistry Controls Engine Design,” American Society of Mechanical Engineers, Internal Combustion Engine Division, Vol. 37, Pg. 1-9, Argonne, IL, 2001.

23. Gibble, J. C., "Comparison of Heavy-Duty Engine Emissions Between an On-Road Route and Engine Dynamometer Simulated On-Road Cycle,” M.S. Thesis, Department of Mechanical and Aerospace Engineering, West Virginia University, Morgantown, WV, 2003.

24. Reddy, V. S., "Evaluation of Current and Early Production Electronically Controlled Heavy-Duty Diesel Engine Emissions Based on Fuel Property Differences,” M.S. Thesis, 
Department of Mechanical and Aerospace Engineering, West Virginia University, Morgantown, WV, 2006.

25. Nuszkowski, J. P., “The Effects of Fuel Additives on Diesel Engine Emissions during Steady State and Transient Operation,” Ph.D. Dissertation, Department of Mechanical and Aerospace Engineering, West Virginia University, Morgantown, WV, Projected December 2007.

26. CAFEE Emissions Laboratory Standard Procedures, Calibration Procedures and Scheduled Maintenance Checks, Center for Alternative Fuels, Engines and Emissions, Version 20070305, Revised 3/05/2007.

27. “Eco Physics CLD 844 CM h,” Eco Physics AG, Switzerland, 2006.

28. "Fuel Additive Packages Containing 2-Ethylhexyl Nitrate (2EHN) - Best Practices Manual,” Additives Technical Committee, Europe, 2004.

29. “Material Safety Data Sheet - NOROX DTBP,” Norac Inc., Azusa, CA, 2006.

30. “DI-tert-BUTYL PEROXIDE,” International Programme on Chemical Safety, CAS No. 110-05-4, Switzerland, 1999.

31. Ursic, M. C., "Observations of Variations in Throttle Positions of Heavy-Duty Diesel Engines,” M.S. Thesis, Department of Mechanical and Aerospace Engineering, West Virginia University, Morgantown, WV, Projected December 2007.

32. Warnatz, J., Maas, U., Dibble, R., “Combustion - Physical and Chemical Fundamentals, Modeling and Simulation, Experiments, Pollutant Formation,” Fourth Edition, Springer, Heidelberg, Germany, 2006. 


\section{Appendices}

\subsection{DDC S60 SET Test Results}

Table 8-1 SET TEST Results

\begin{tabular}{|l|c|c|c|c|c|}
\hline \multirow{2}{*}{ Weighted Values } & Grad REF & \multicolumn{4}{c|}{ Grad CAND } \\
\cline { 2 - 6 } & Neat & Neat & 6-ml ODA & 12-ml ODA & 6-ml 2-EHN \\
\hline THC (g/bhp-hr) & 0.0472 & 0.0531 & 0.0515 & 0.0513 & 0.0484 \\
\hline CO (g/bhp-hr) & 2.906 & 3.110 & 3.029 & 3.028 & 3.097 \\
\hline CO2 (g/bhp-hr) & 444.5 & 460.1 & 459.9 & 461.3 & 460.6 \\
\hline NOx (g/bhp-hr) & 7.620 & 8.022 & 7.948 & 7.995 & 7.923 \\
\hline NO2 (g/bhp-hr) & 0.2041 & 0.1950 & 0.2027 & 0.2084 & 0.1904 \\
\hline TPM (g/bhp-hr) & 0.2067 & 0.2197 & 0.2126 & 0.2093 & 0.2119 \\
\hline BSFC (g/bhp-hr) & 146.1 & 148.9 & 147.3 & 147.3 & 148.5 \\
\hline Power (bhp) & 189.3 & 189.2 & 189.3 & 189.1 & 189.1 \\
\hline Work (bhp-hr) & 1.576 & 1.576 & 1.576 & 1.575 & 1.575 \\
\hline
\end{tabular}

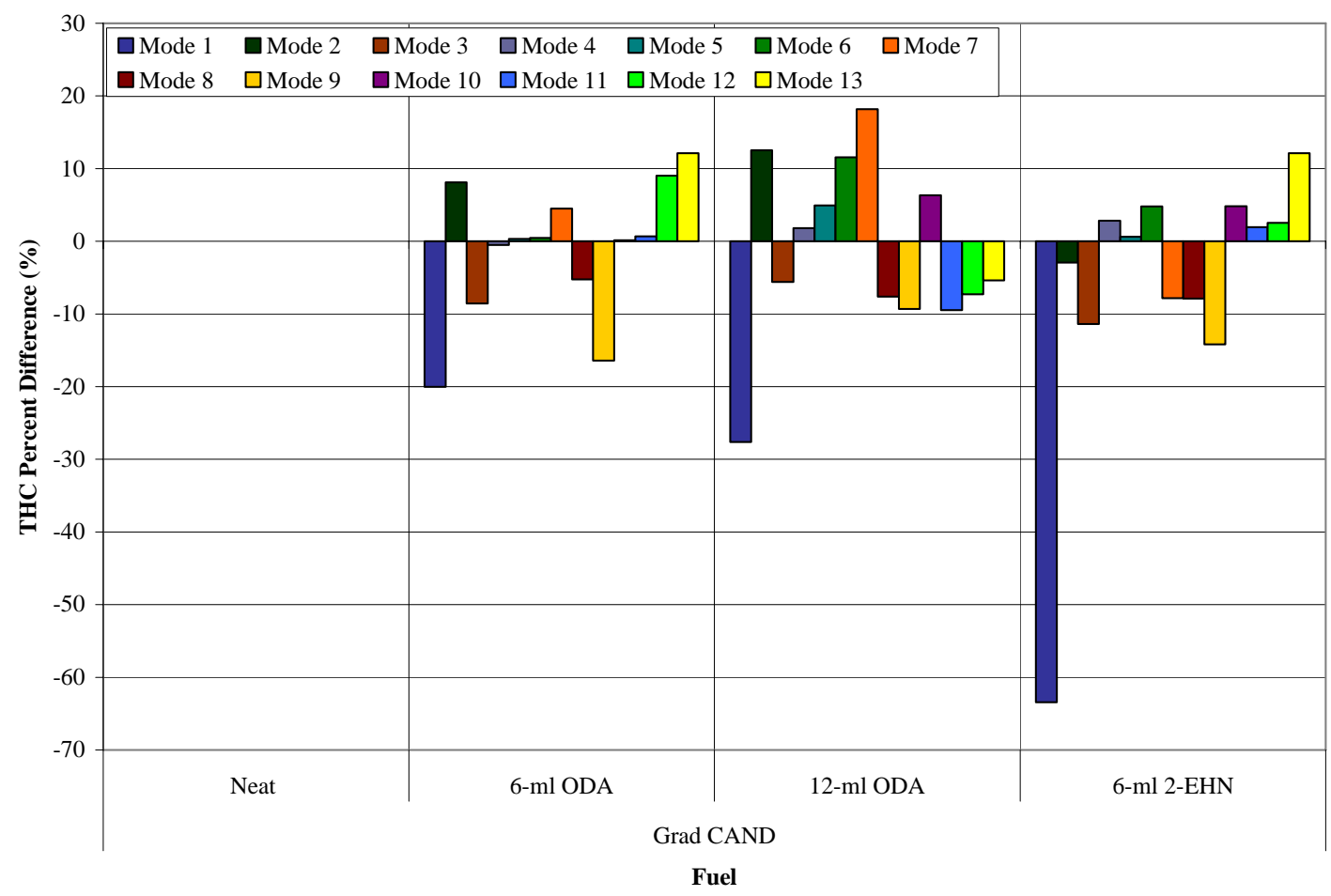

Figure 8-1 THC Percent Difference from Neat Fuel for 1992 DDC S60 


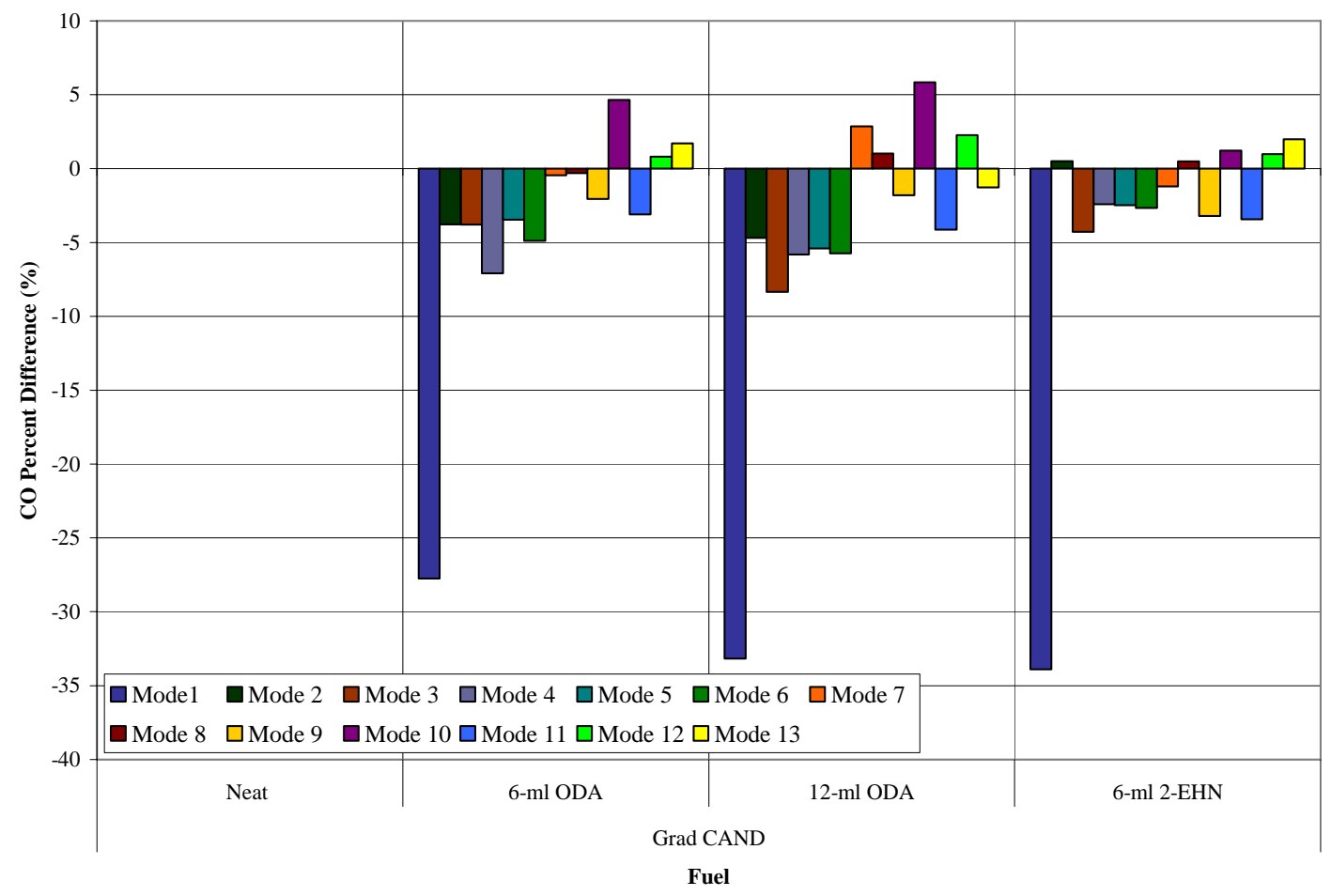

Figure 8-2 CO Percent Difference from Neat Fuel for 1992 DDC S60

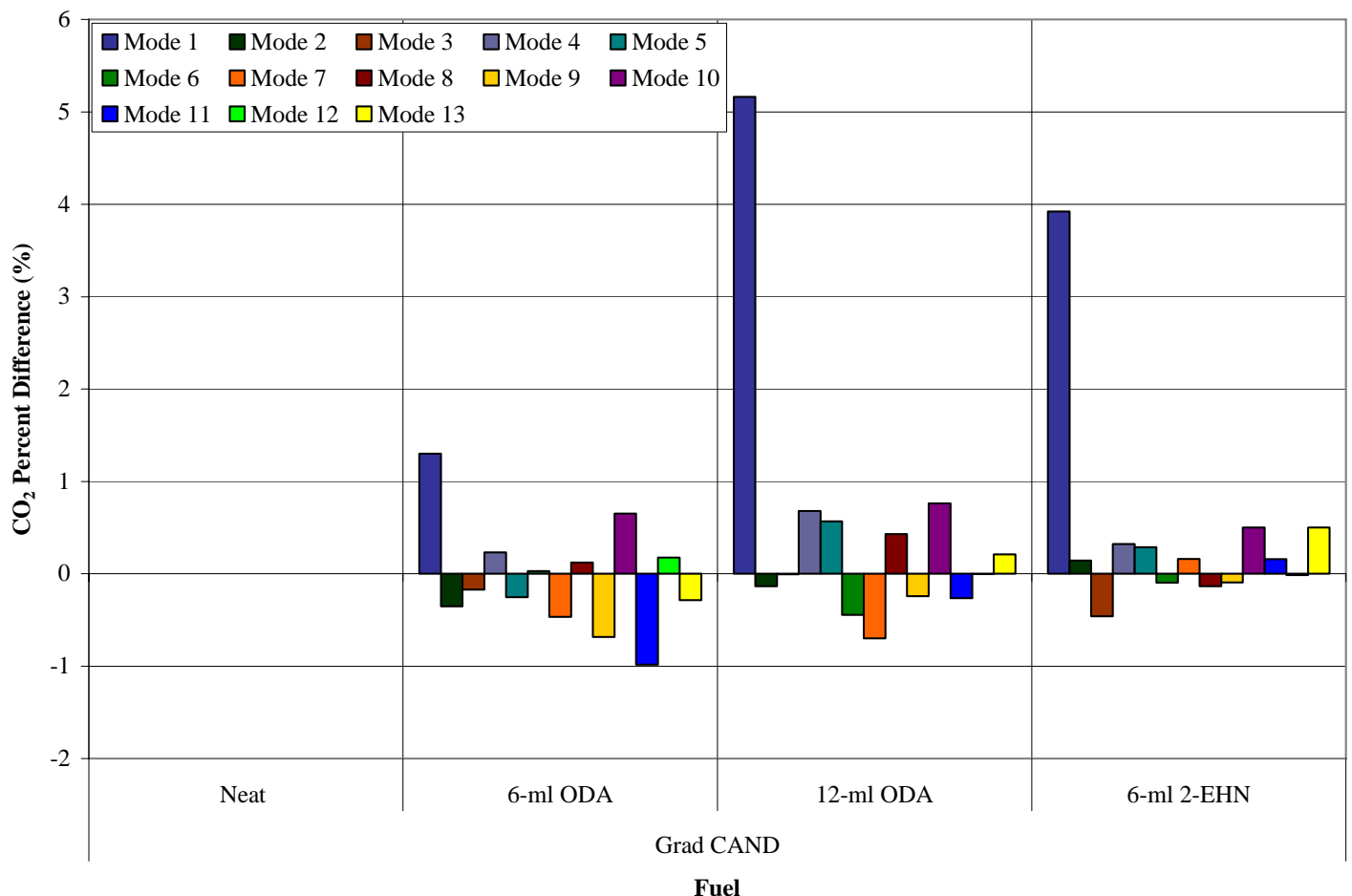

Figure 8-3 $\mathrm{CO}_{2}$ Percent Difference from Neat Fuel for 1992 DDC S60 


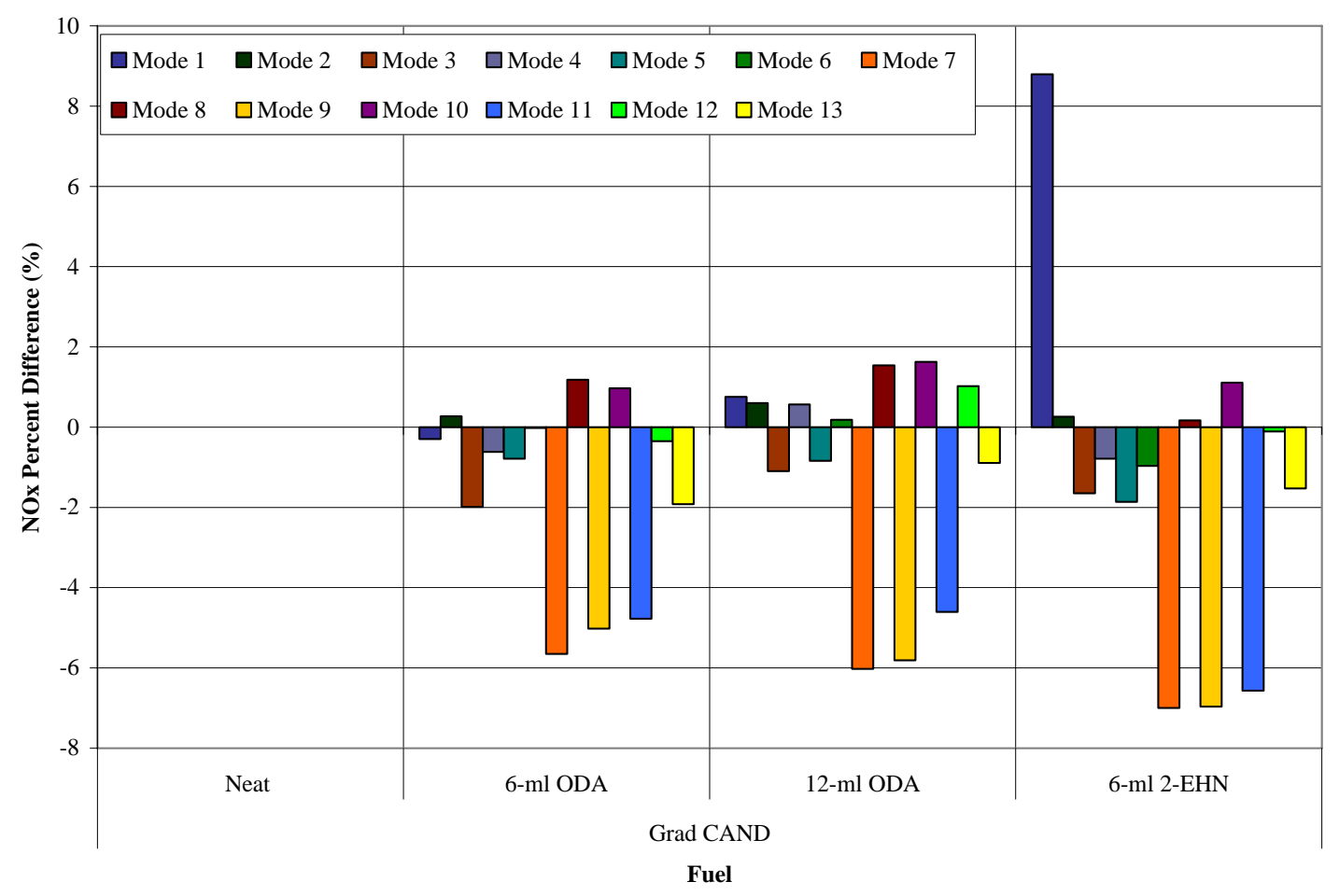

Figure 8-4 NOx Percent Difference from Neat Fuel for 1992 DDC S60

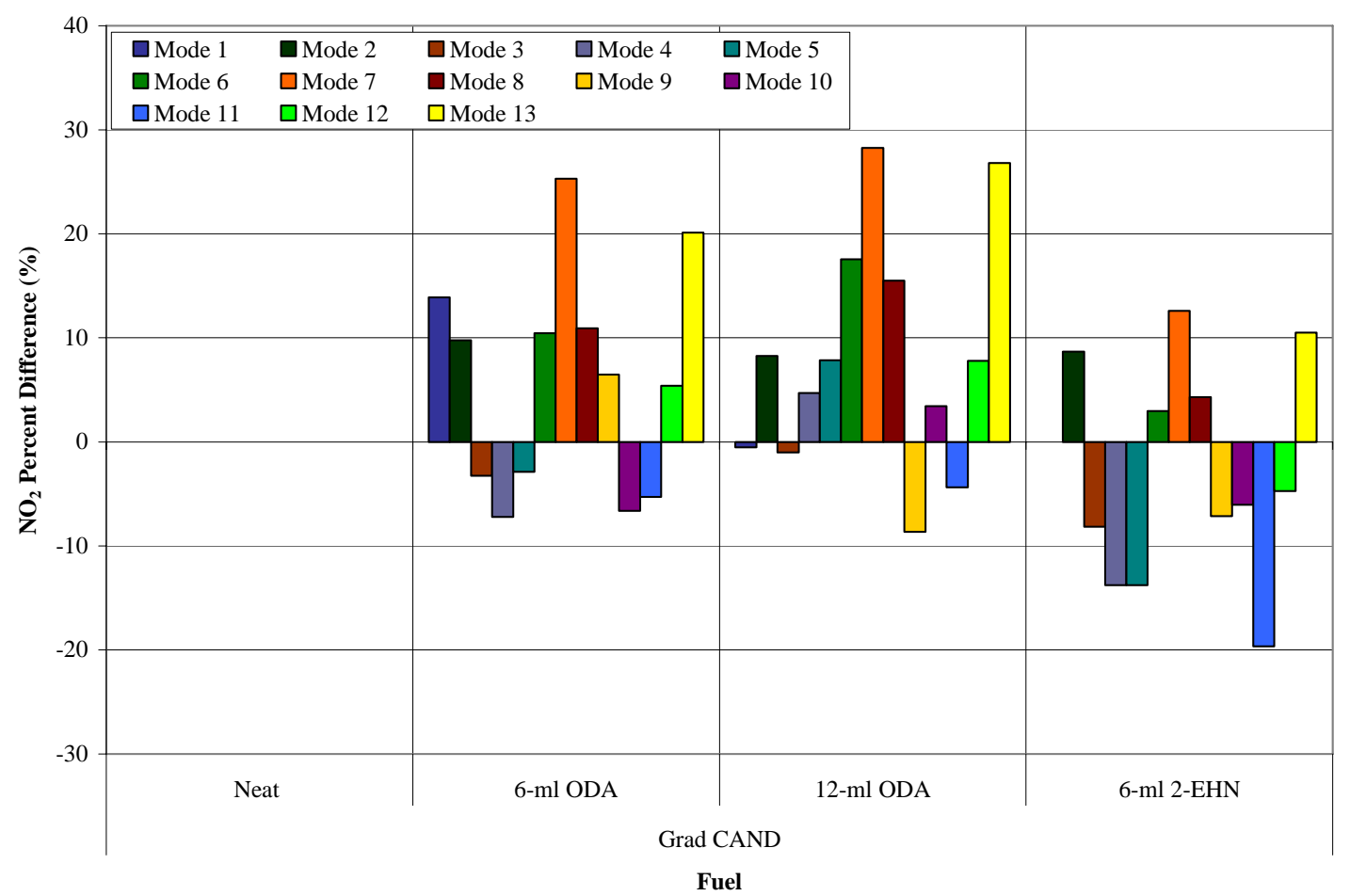

Figure 8-5 $\mathrm{NO}_{2}$ Percent Difference from Neat Fuel for 1992 DDC S60 


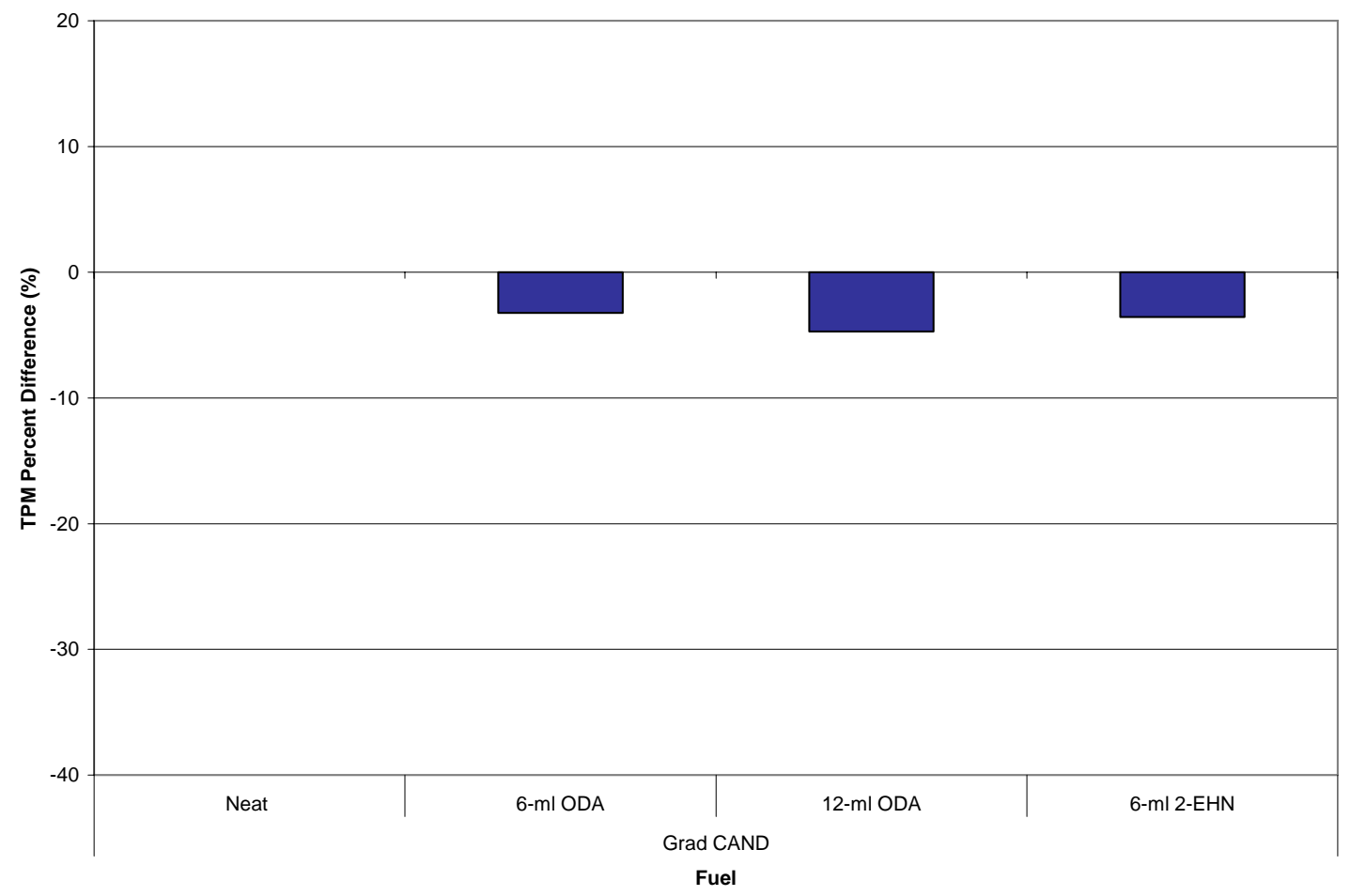

Figure 8-6 TPM Percent Difference from Neat Fuel for 1992 DDC S60

\subsection{DDC S60 FTP Results}

Table 8-2 FTP Results for 1992 DDC S60

\begin{tabular}{|l|c|c|c|c|c|c|c|c|}
\hline & \multicolumn{2}{|c|}{ CP 0.05 Cert } & \multicolumn{2}{|c|}{ Grad REF } & \multicolumn{4}{c|}{ Grad CAND } \\
\cline { 2 - 9 } & Neat & $\begin{array}{c}12-\mathrm{ml} \\
\text { ODA }\end{array}$ & Neat & $\begin{array}{c}10-\mathrm{ml} \\
\text { DTBP }\end{array}$ & Neat & $\begin{array}{c}6-\mathrm{ml} \\
\text { ODA }\end{array}$ & $\begin{array}{c}12-\mathrm{ml} \\
\text { ODA }\end{array}$ & $\begin{array}{c}6-\mathrm{ml} \\
\text { EHN }\end{array}$ \\
\hline THC (g/bhp-hr) & 0.1310 & 0.0987 & 0.0976 & 0.1060 & 0.1327 & 0.1179 & 0.1205 & 0.1155 \\
\hline Standard Deviation & 0.0046 & 0.0038 & 0.0016 & 0.0042 & 0.0044 & 0.0026 & 0.0037 & 0.0034 \\
\hline CO (g/bhp-hr) & 3.267 & 3.006 & 3.175 & 3.234 & 3.195 & 3.026 & 3.118 & 3.064 \\
\hline Standard Deviation & 0.0283 & 0.0038 & 0.0777 & 0.0118 & 0.0323 & 0.0131 & 0.0380 & 0.0418 \\
\hline CO2 (g/bhp-hr) & 535.8 & 528.2 & 531.8 & 532.0 & 538.3 & 539.2 & 539.2 & 539.6 \\
\hline Standard Deviation & 0.5501 & 2.044 & 0.6019 & 1.364 & 0.7448 & 0.7261 & 0.1511 & 0.7577 \\
\hline NOx (g/bhp-hr) & 5.221 & 5.069 & 4.747 & 4.707 & 5.080 & 4.967 & 4.936 & 4.904 \\
\hline Standard Deviation & 0.0036 & 0.0078 & 0.0227 & 0.0201 & 0.0155 & 0.0229 & 0.0289 & 0.0203 \\
\hline NOx 2 (g/bhp-hr) & 5.218 & 5.043 & 4.686 & 4.685 & 5.032 & 4.938 & 4.920 & 4.881 \\
\hline Standard Deviation & 0.0198 & 0.0124 & 0.0174 & 0.0223 & 0.0211 & 0.0268 & 0.0132 & 0.0101 \\
\hline NO (g/bhp-hr) & 0.9576 & 0.8480 & 0.9087 & 0.8345 & 0.8939 & 0.8726 & 0.8290 & 0.7836 \\
\hline Standard Deviation & 0.0236 & 0.0101 & 0.0036 & 0.0156 & 0.0048 & 0.0307 & 0.0426 & 0.0364 \\
\hline TPM (g/bhp-hr) & 0.2515 & 0.2371 & 0.2331 & 0.2350 & 0.2315 & 0.2333 & 0.2373 & 0.2350 \\
\hline Standard Deviation & 0.0052 & 0.0048 & 0.0041 & 0.0039 & 0.0017 & 0.0059 & 0.0047 & 0.0052 \\
\hline BSFC (lb/bhp-hr) & 0.3812 & 0.3832 & 0.3776 & 0.3790 & 0.3832 & 0.3826 & 0.3814 & 0.3830 \\
\hline Standard Deviation & 0.0005 & 0.0034 & 0.0035 & 0.0006 & 0.0008 & 0.0005 & 0.0011 & 0.0003 \\
\hline FC (lb) & 9.465 & 9.519 & 9.265 & 9.287 & 9.400 & 9.387 & 9.350 & 9.381 \\
\hline Standard Deviation & 0.0127 & 0.0878 & 0.0797 & 0.0150 & 0.0225 & 0.0067 & 0.0242 & 0.0065 \\
\hline
\end{tabular}


Table 8-3 Variation Analysis for 1992 DDC S60

\begin{tabular}{|l|c|c|c|}
\hline & Average & $\begin{array}{c}\text { Standard } \\
\text { Deviation }\end{array}$ & $\begin{array}{c}\text { Coefficient of } \\
\text { Variation (\%) }\end{array}$ \\
\hline THC (g/bhp-hr) & 0.1150 & 0.0134 & 11.7 \\
\hline $\mathrm{CO}$ (g/bhp-hr) & 3.136 & 0.0972 & 3.1 \\
\hline $\mathrm{CO} 2$ (g/bhp-hr) & 535.5 & 4.339 & 0.8 \\
\hline $\mathrm{NOx}$ (g/bhp-hr) & 4.954 & 0.1720 & 3.5 \\
\hline $\mathrm{NOx} 2$ (g/bhp-hr) & 4.925 & 0.1804 & 3.7 \\
\hline $\mathrm{NO}_{2}$ (g/bhp-hr) & 0.8660 & 0.0541 & 6.3 \\
\hline $\mathrm{TPM}$ (g/bhp-hr) & 0.2367 & 0.0063 & 2.7 \\
\hline $\mathrm{BSFC}(\mathrm{lb} / \mathrm{bhp}-\mathrm{hr})$ & 0.3814 & 0.0021 & 0.6 \\
\hline FC (lb) & 9.382 & 0.0841 & 0.9 \\
\hline
\end{tabular}

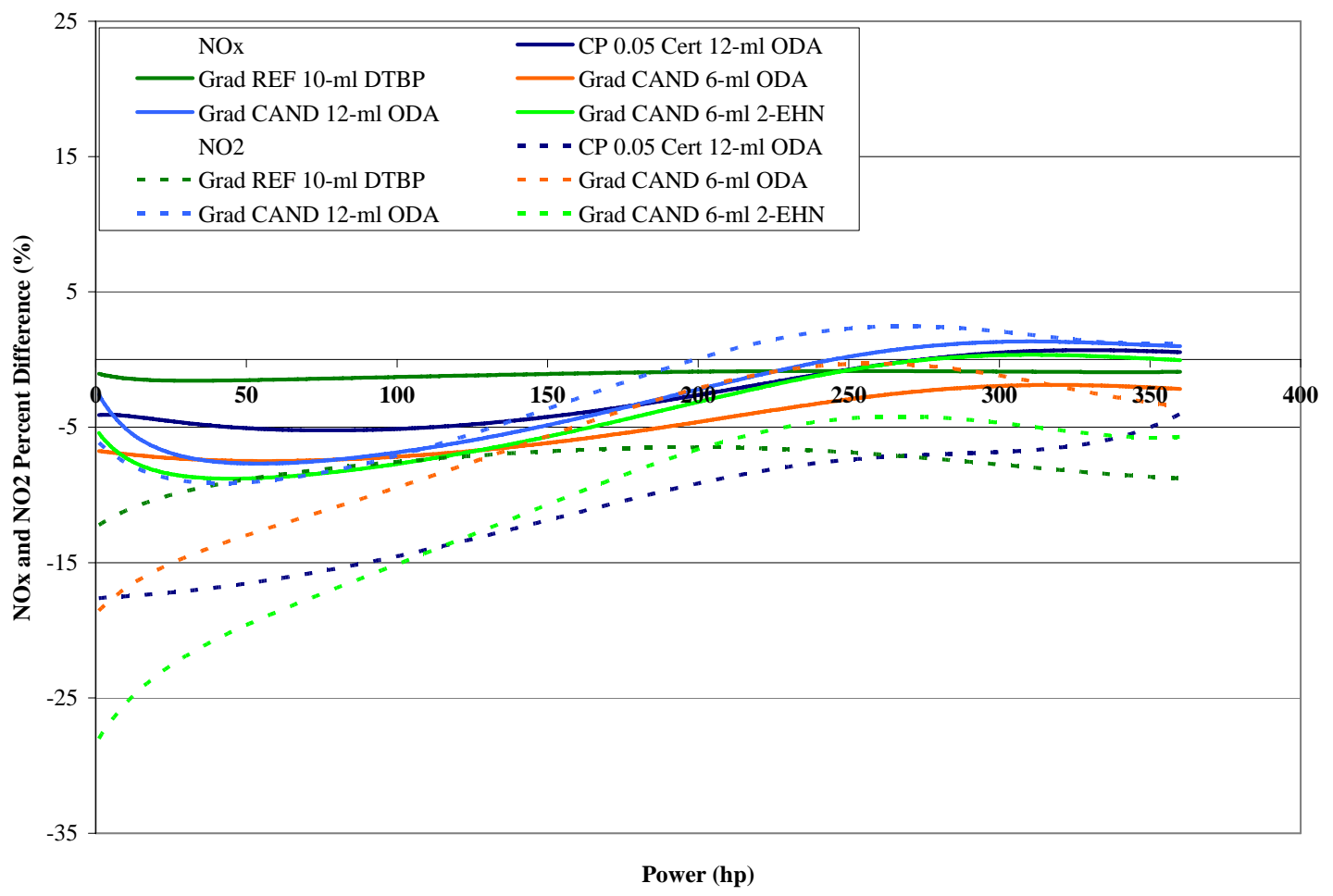

Figure 8-7 NOx and $\mathrm{NO}_{2}$ Percent Difference from Neat Fuels versus Power for 1992 DDC S60 


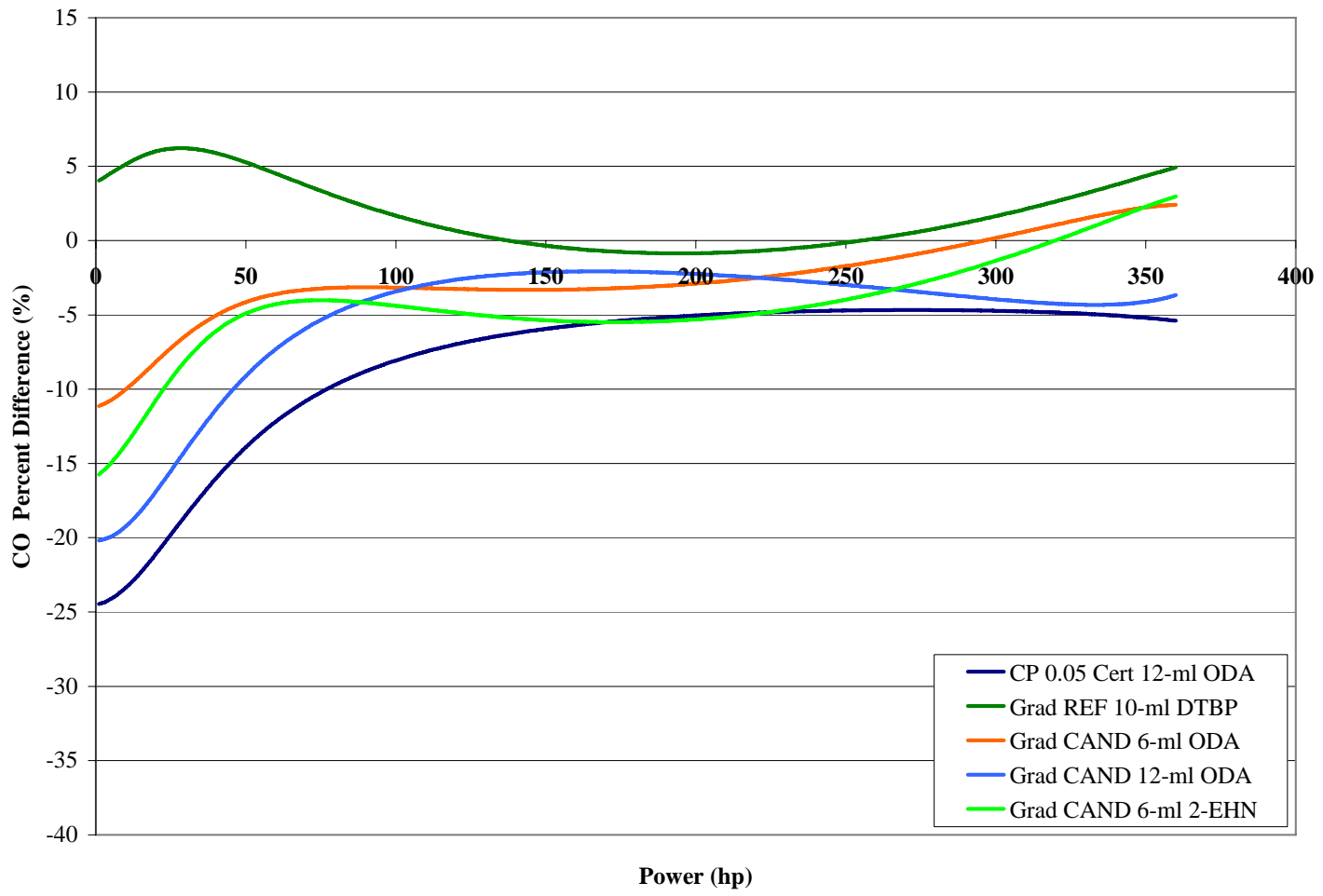

Figure 8-8 CO Percent Difference from Neat Fuels versus Power for 1992 DDC S60

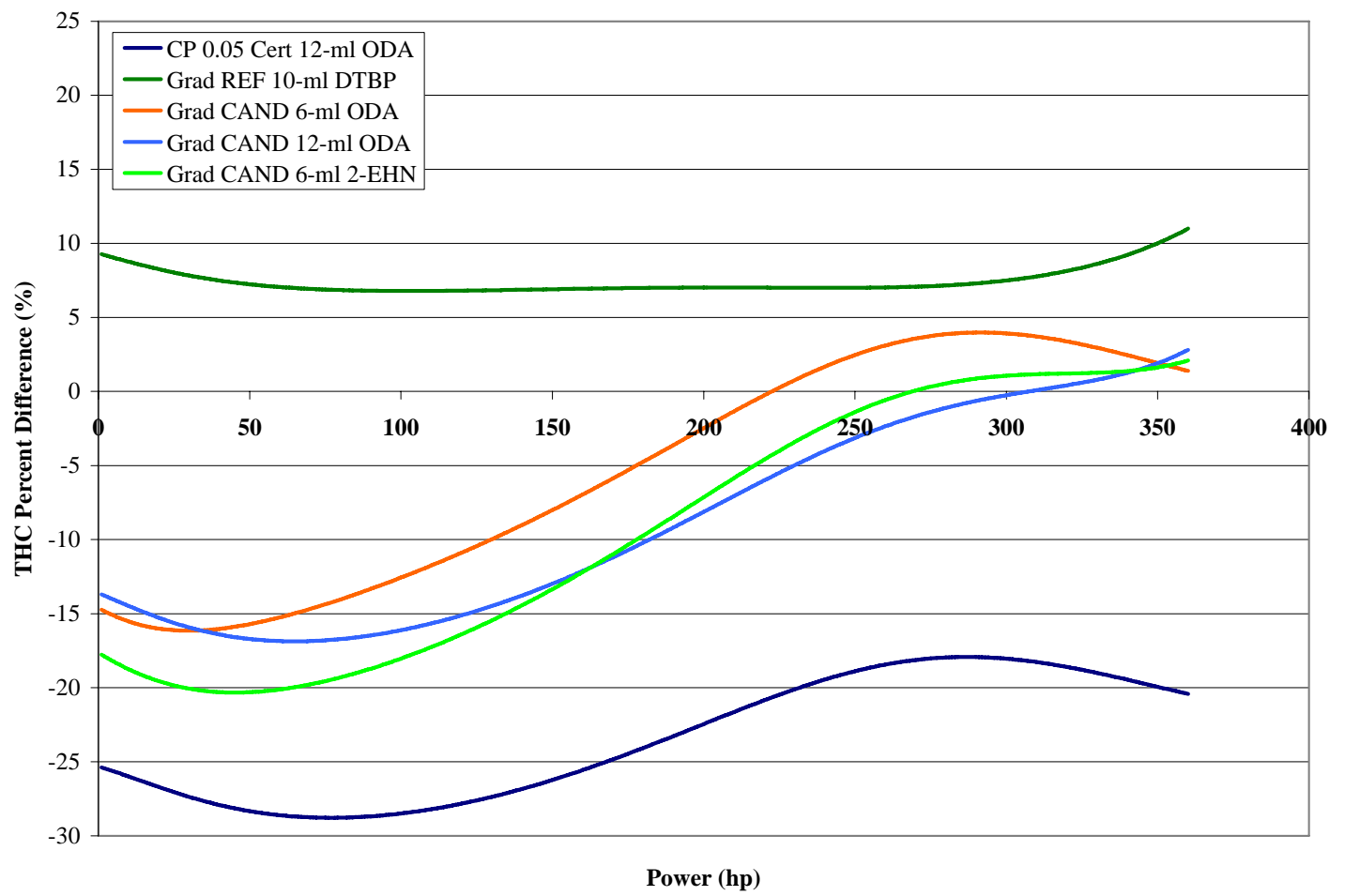

Figure 8-9 THC Percent Difference from Neat Fuels versus Power for 1992 DDC S60 


\subsection{Rebuilt DDC S60 SET Test Results}

Table 8-4 SET Test Results for 1992 Rebuilt DDC S60

\begin{tabular}{|c|c|c|c|c|c|c|c|c|c|c|c|c|}
\hline \multirow[b]{2}{*}{ Weighted Values } & \multicolumn{2}{|c|}{ CP 0.05 Cert } & \multicolumn{2}{|c|}{ Grad REF } & \multicolumn{8}{|c|}{ Grad CAND } \\
\hline & Neat & 12-ml ODA & Neat & $16 \mathrm{ml}$ ODA & Neat 1 & Neat 2 & 6-ml ODA & $\begin{array}{l}12-\mathrm{ml} \\
\text { ODA }\end{array}$ & 16-ml ODA & $\begin{array}{c}16-\mathrm{ml} \text { ODA } \\
2 \mathrm{x}\end{array}$ & $\begin{array}{c}\text { 8-ml } \\
\text { 2-EHN }\end{array}$ & $\begin{array}{l}10-\mathrm{ml} \\
\text { DTBP }\end{array}$ \\
\hline THC (g/bhp-hr) & 0.0428 & 0.0394 & 0.0390 & 0.0364 & 0.0391 & 0.0378 & 0.0323 & 0.0333 & 0.0341 & 0.0341 & 0.0350 & 0.0322 \\
\hline $\mathrm{CO}$ (g/bhp-hr) & 2.835 & 2.727 & 2.746 & 2.688 & 2.780 & 2.577 & 2.488 & 2.535 & 2.463 & 2.459 & 2.560 & 2.532 \\
\hline $\mathrm{CO} 2$ (g/bhp-hr) & 461.3 & 456.6 & 443.9 & 446.2 & 450.9 & 445.7 & 442.8 & 451.8 & 445.3 & 450.8 & 449.7 & 451.9 \\
\hline NOx (g/bhp-hr) & 7.873 & 7.785 & 7.273 & 7.287 & 7.667 & 7.718 & 7.448 & 7.600 & 7.668 & 7.705 & 7.647 & 7.637 \\
\hline NO2 (g/bhp-hr) & 0.207 & 0.186 & 0.197 & 0.192 & 0.198 & 0.194 & 0.192 & 0.190 & 0.191 & 0.191 & 0.199 & 0.198 \\
\hline TPM (g/bhp-hr) & 0.218 & 0.206 & 0.194 & 0.180 & 0.194 & 0.192 & 0.182 & 0.182 & 0.176 & 0.178 & 0.175 & 0.189 \\
\hline BSFC (g/bhp-hr) & 147.0 & 148.9 & 147.1 & 146.9 & 150.5 & 147.5 & 149.5 & 141.2 & 148.7 & 148.6 & 146.6 & 149.2 \\
\hline Power (bhp) & 195.7 & 196.1 & 195.1 & 195.0 & 194.8 & 194.9 & 195.1 & 195.1 & 195.1 & 195.1 & 194.9 & 194.9 \\
\hline Work (bhp-hr) & 1.633 & 1.633 & 1.625 & 1.625 & 1.624 & 1.625 & 1.626 & 1.625 & 1.626 & 1.625 & 1.625 & 1.626 \\
\hline
\end{tabular}

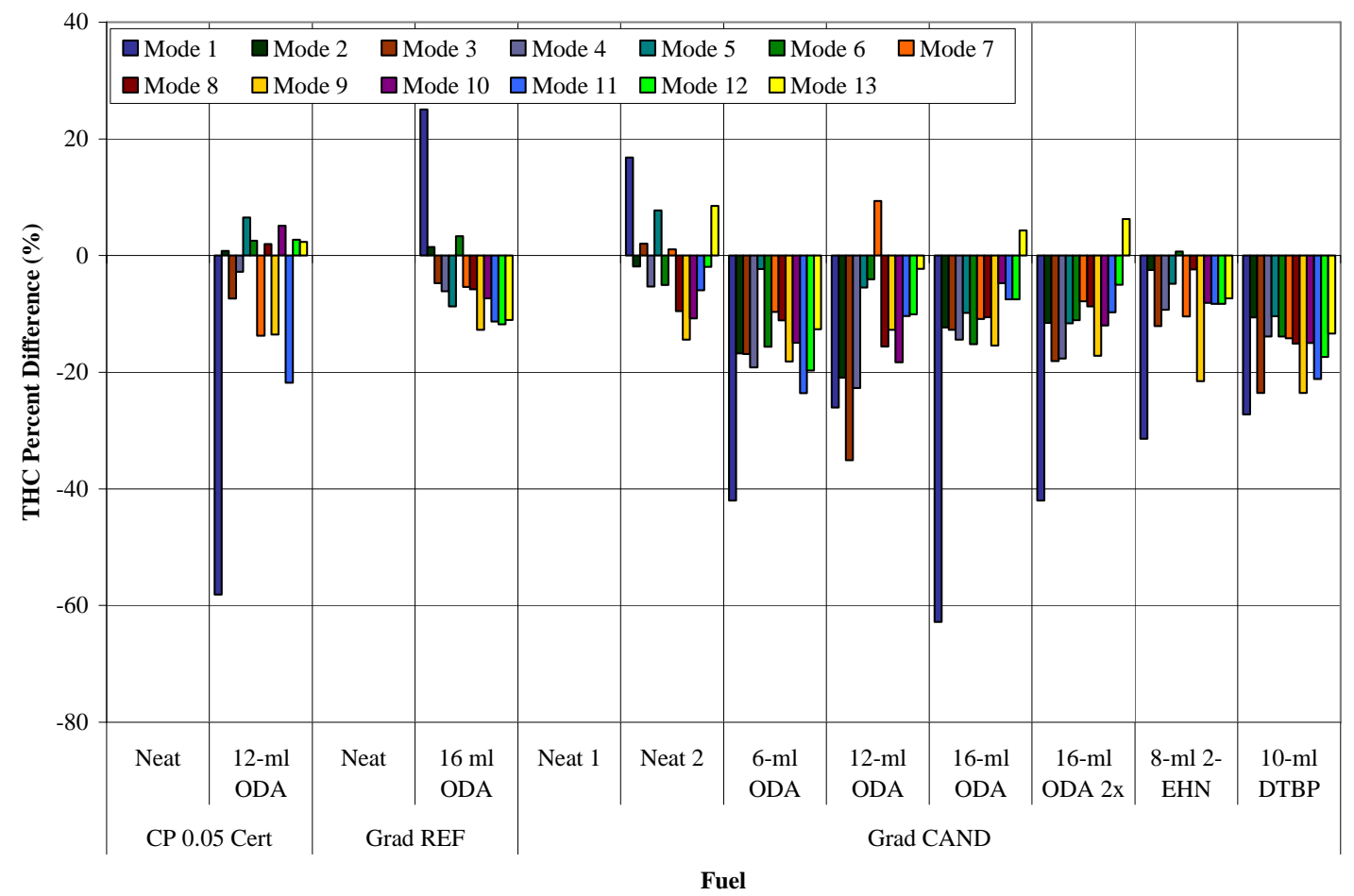

Figure 8-10 THC Percent Difference from Neat Fuels for 1992 Rebuilt DDC S60 


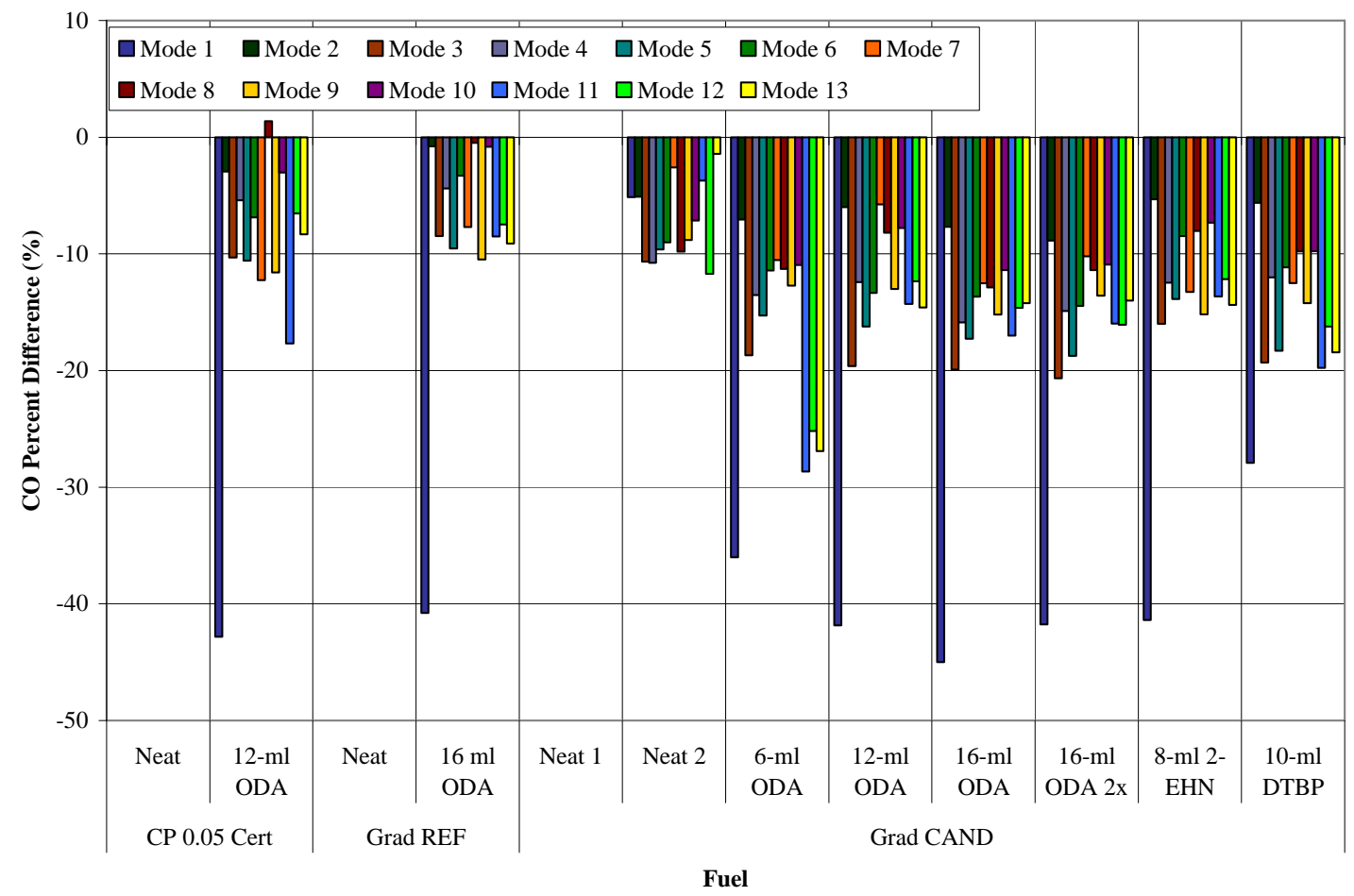

Figure 8-11 CO Percent Difference from Neat Fuels for 1992 Rebuilt DDC S60

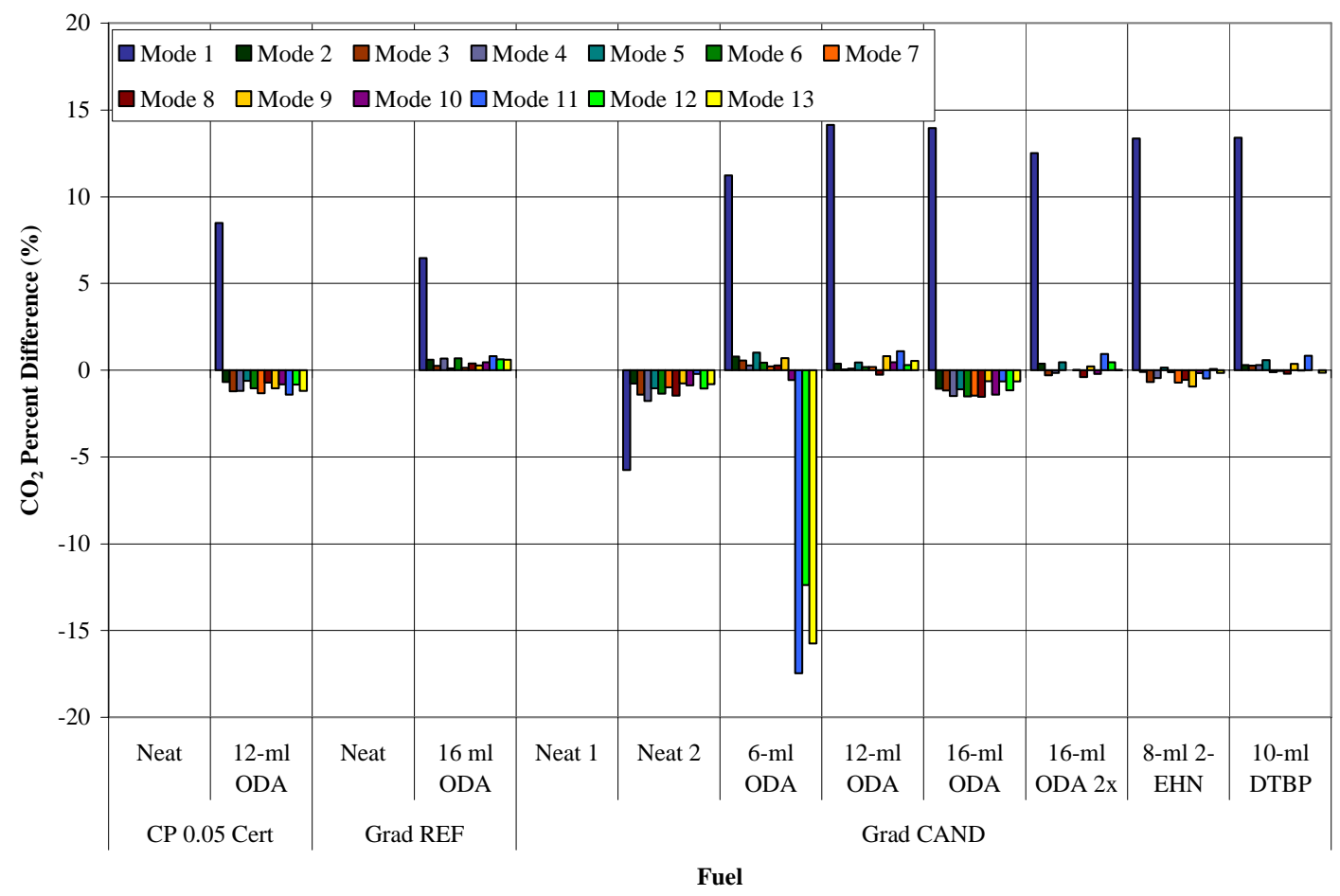

Figure 8-12 $\mathrm{CO}_{2}$ Percent Difference from Neat Fuels for 1992 Rebuilt DDC S60 


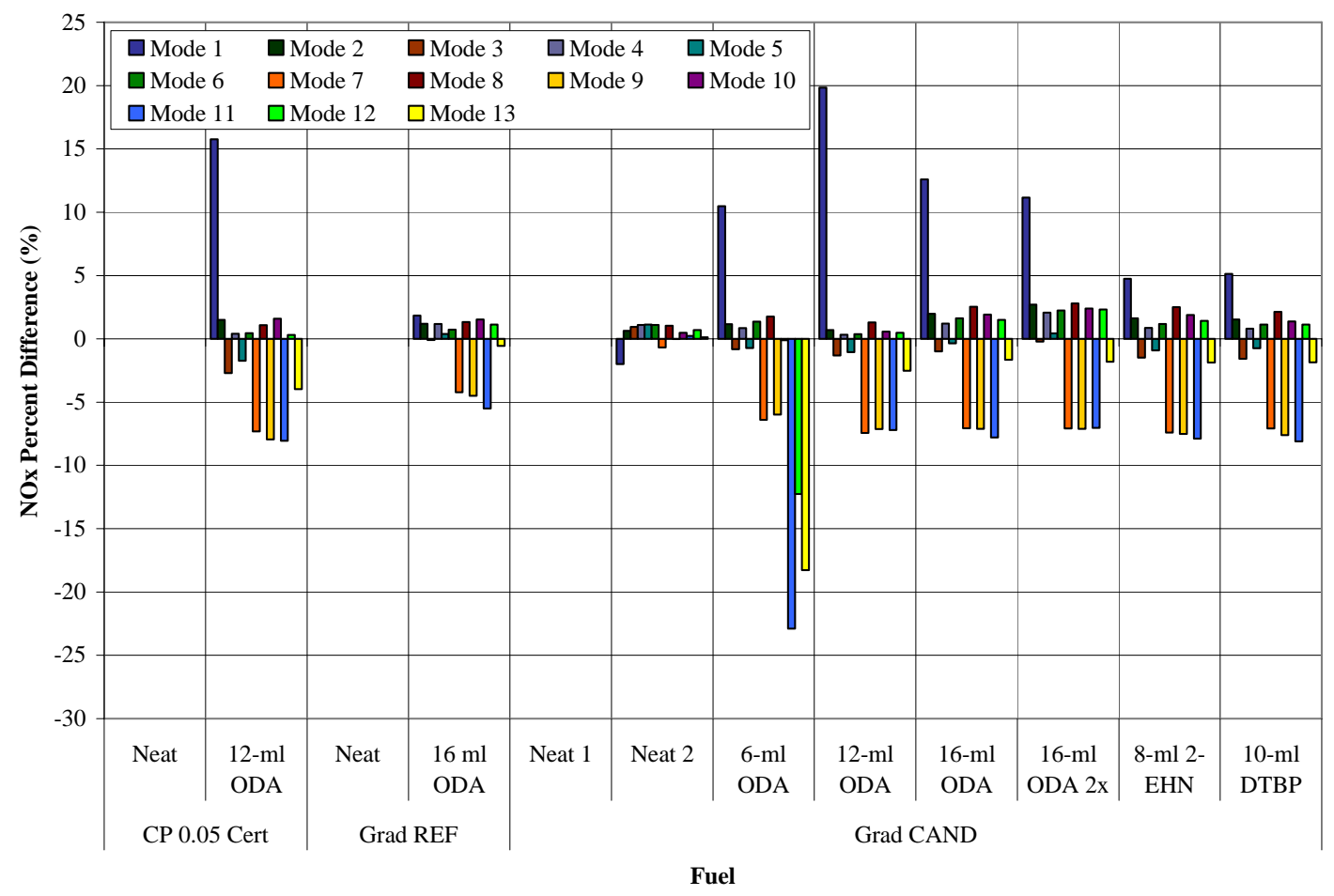

Figure 8-13 NOx Percent Difference from Neat Fuels for 1992 Rebuilt DDC S60

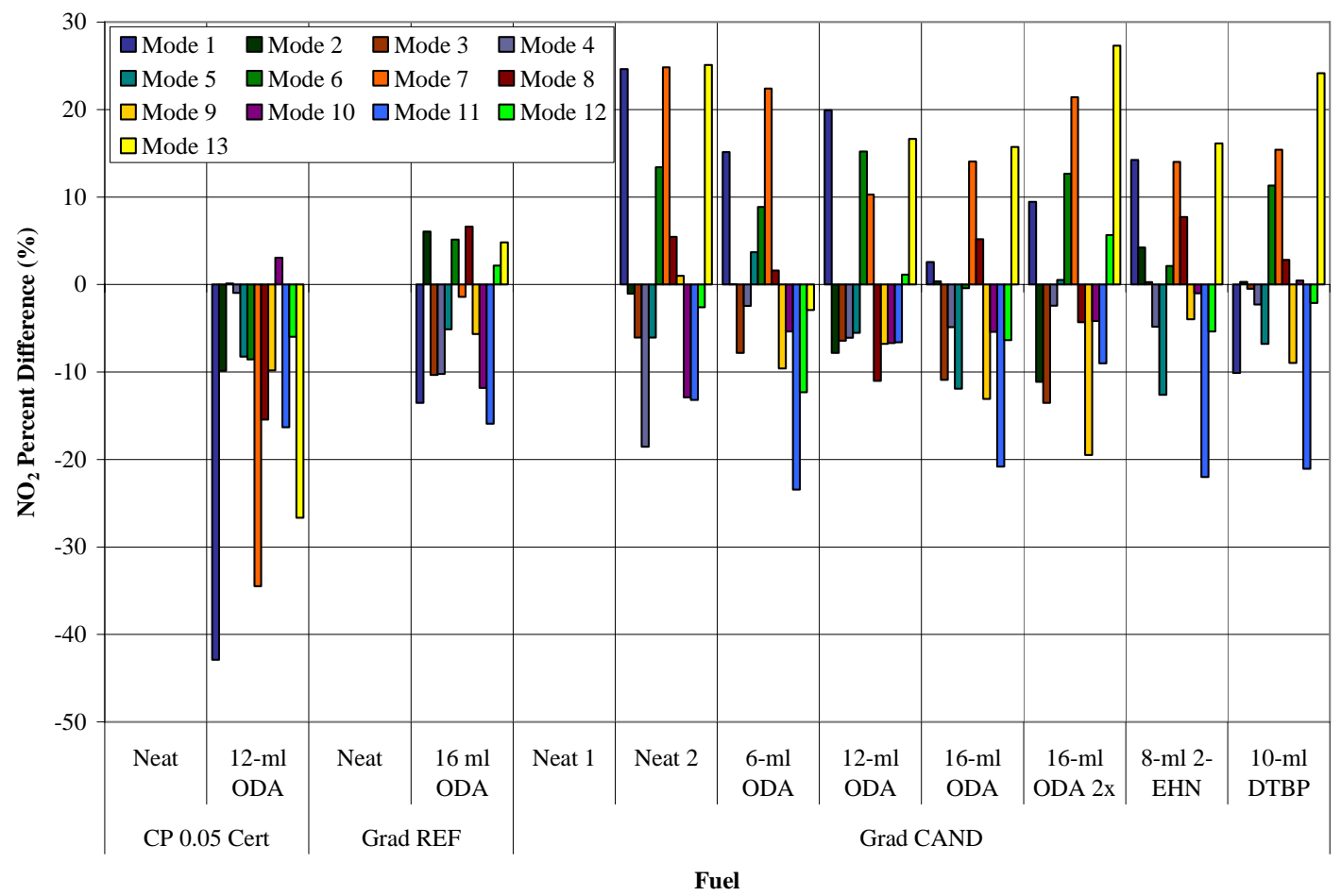

Figure 8-14 $\mathrm{NO}_{2}$ Percent Difference from Neat Fuels for 1992 Rebuilt DDC S60 


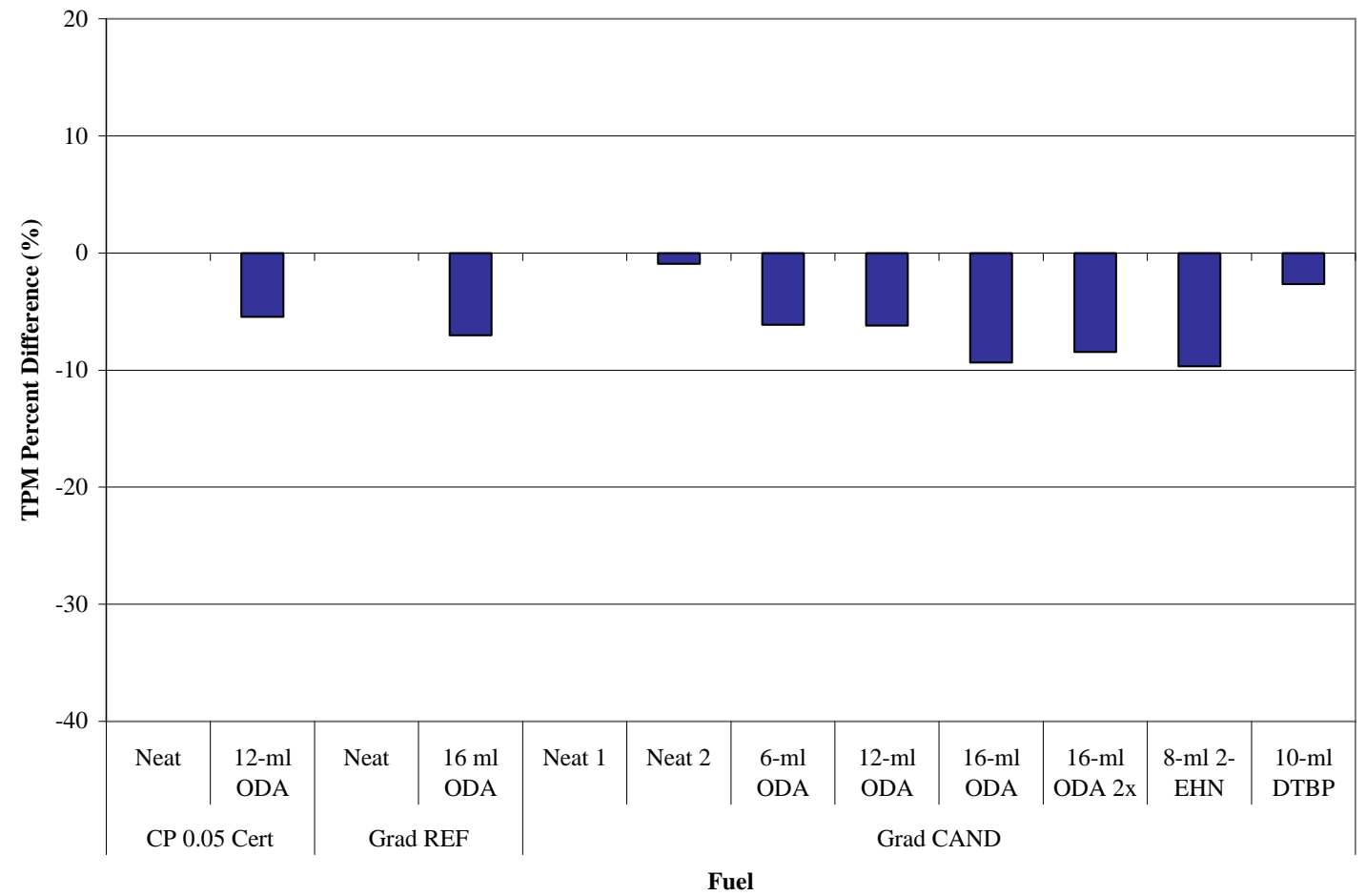

Figure 8-15 TPM Percent Difference from Neat Fuels for 1992 Rebuilt DDC S60 


\subsection{Rebuilt DDC S60 FTP Results}

Table 8-5 FTP Results for 1992 Rebuilt DDC S60

\begin{tabular}{|c|c|c|c|c|c|c|c|c|c|c|c|c|}
\hline & \multicolumn{2}{|c|}{ CP 0.05 Cert } & \multicolumn{2}{|c|}{ Grad REF } & \multicolumn{8}{|c|}{ Grad CAND } \\
\hline & Neat & $\begin{array}{l}\text { 12-ml } \\
\text { ODA }\end{array}$ & Neat & $\begin{array}{l}16 \mathrm{ml} \\
\text { ODA }\end{array}$ & Neat 1 & Neat 2 & $\begin{array}{l}\text { 6-ml } \\
\text { ODA }\end{array}$ & $\begin{array}{l}\text { 12-ml } \\
\text { ODA }\end{array}$ & $\begin{array}{l}\text { 16-ml } \\
\text { ODA }\end{array}$ & $\begin{array}{c}16-\mathrm{ml} \\
\text { ODA } 2 \mathrm{x}\end{array}$ & $\begin{array}{c}8-\mathrm{ml} 2 \\
\text { EHN }\end{array}$ & $\begin{array}{l}10-\mathrm{ml} \\
\text { DTBP }\end{array}$ \\
\hline THC (g/bhp-hr) & 0.1139 & 0.1065 & 0.1135 & 0.0962 & 0.1133 & 0.1060 & 0.0960 & 0.0922 & 0.0990 & 0.0985 & 0.0987 & 0.0912 \\
\hline Standard Deviation & 0.0027 & 0.0012 & 0.0030 & 0.0022 & 0.0017 & 0.0010 & 0.0030 & 0.0012 & 0.0039 & 0.0032 & 0.0026 & 0.0040 \\
\hline CO (g/bhp-hr) & 3.496 & 3.183 & 3.335 & 3.138 & 3.277 & 3.193 & 3.065 & 3.007 & 2.970 & 2.971 & 3.031 & 3.023 \\
\hline Standard Deviation & 0.0180 & 0.0184 & 0.0301 & 0.0296 & 0.0120 & 0.0197 & 0.0125 & 0.0100 & 0.0424 & 0.0105 & 0.0104 & 0.0017 \\
\hline NOx (g/bhp-hr) & 5.205 & 5.028 & 4.706 & 4.596 & 5.052 & 5.067 & 4.932 & 4.891 & 4.918 & 4.928 & 4.890 & 4.892 \\
\hline Standard Deviation & 0.0148 & 0.0066 & 0.0259 & 0.0099 & 0.0275 & 0.0480 & 0.0093 & 0.0218 & 0.0153 & 0.0038 & 0.0055 & 0.0140 \\
\hline NOx 2 (g/bhp-hr) & 5.290 & 5.065 & 4.726 & 4.581 & 5.048 & 5.061 & 4.961 & 4.910 & 4.907 & 4.928 & 4.906 & 4.874 \\
\hline Standard Deviation & 0.0212 & 0.0085 & 0.0313 & 0.0052 & 0.0172 & 0.0255 & 0.0190 & 0.0045 & 0.0110 & 0.0020 & 0.0103 & 0.0067 \\
\hline BSFC (lb/bhp-hr) & 0.3713 & 0.3704 & 0.3696 & 0.3694 & 0.3722 & 0.3729 & 0.3727 & 0.3727 & 0.3721 & 0.3721 & 0.3706 & 0.3727 \\
\hline Standard Deviation & 0.0001 & 0.0005 & 0.0004 & 0.0001 & 0.0001 & 0.0005 & 0.0002 & 0.0004 & 0.0007 & 0.0002 & 0.0021 & 0.0006 \\
\hline $\mathrm{FC}(\mathrm{lb})$ & 9.224 & 9.237 & 9.134 & 9.138 & 9.192 & 9.235 & 9.226 & 9.226 & 9.217 & 9.216 & 9.164 & 9.220 \\
\hline Standard Deviation & 0.0010 & 0.0106 & 0.0073 & 0.0010 & 0.0035 & 0.0101 & 0.0049 & 0.0074 & 0.0150 & 0.0078 & 0.0485 & 0.0116 \\
\hline
\end{tabular}

Table 8-6 Variation Analysis for 1992 Rebuilt DDC S60

\begin{tabular}{|c|c|c|c|}
\hline & Average & $\begin{array}{l}\text { Standard } \\
\text { Deviation }\end{array}$ & $\begin{array}{l}\text { Coefficient of } \\
\text { Variation (\%) }\end{array}$ \\
\hline THC (g/bhp-hr) & 0.1021 & 0.0083 & 8.1 \\
\hline CO (g/bhp-hr) & 3.141 & 0.1636 & 5.2 \\
\hline CO2 (g/bhp-hr) & 522.2 & 4.121 & 0.8 \\
\hline NOx (g/bhp-hr) & 4.925 & 0.1609 & 3.3 \\
\hline NOx 2 (g/bhp-hr) & 4.938 & 0.1776 & 3.6 \\
\hline $\mathrm{NO}_{2}$ (g/bhp-hr) & 0.8836 & 0.0536 & 6.1 \\
\hline TPM (g/bhp-hr) & 0.2386 & 0.0099 & 4.1 \\
\hline BSFC (lb/bhp-hr) & 0.3715 & 0.0013 & 0.3 \\
\hline FC (lb) & 9.202 & 0.0367 & 0.4 \\
\hline
\end{tabular}




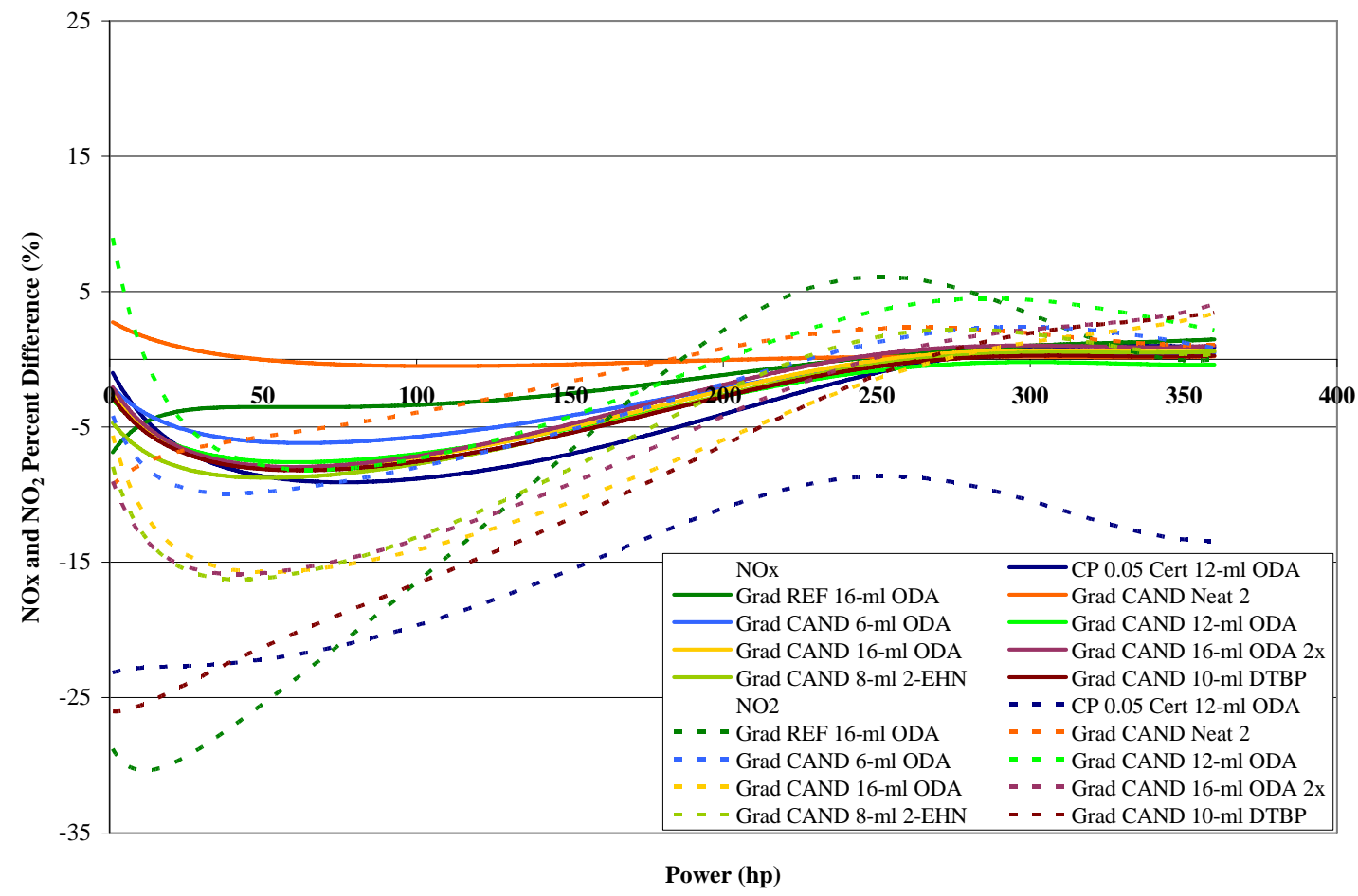

Figure 8-16 NOx and $\mathrm{NO}_{2}$ Percent Difference from Neat Fuels versus Power for 1992 Rebuilt DDC S60

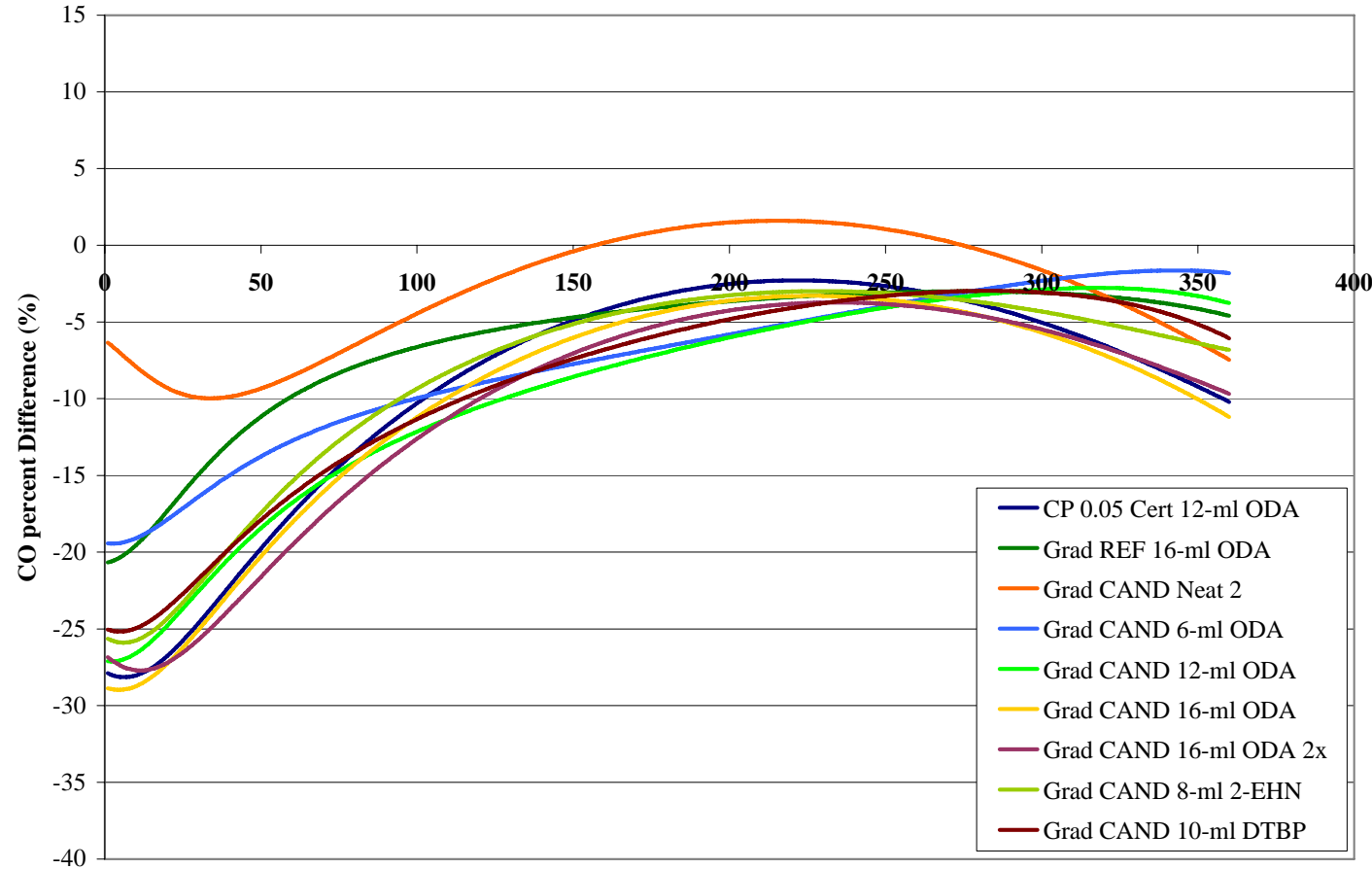

Power (hp)

Figure 8-17 CO Percent Difference from Neat Fuels versus Power for 1992 Rebuilt DDC S60 


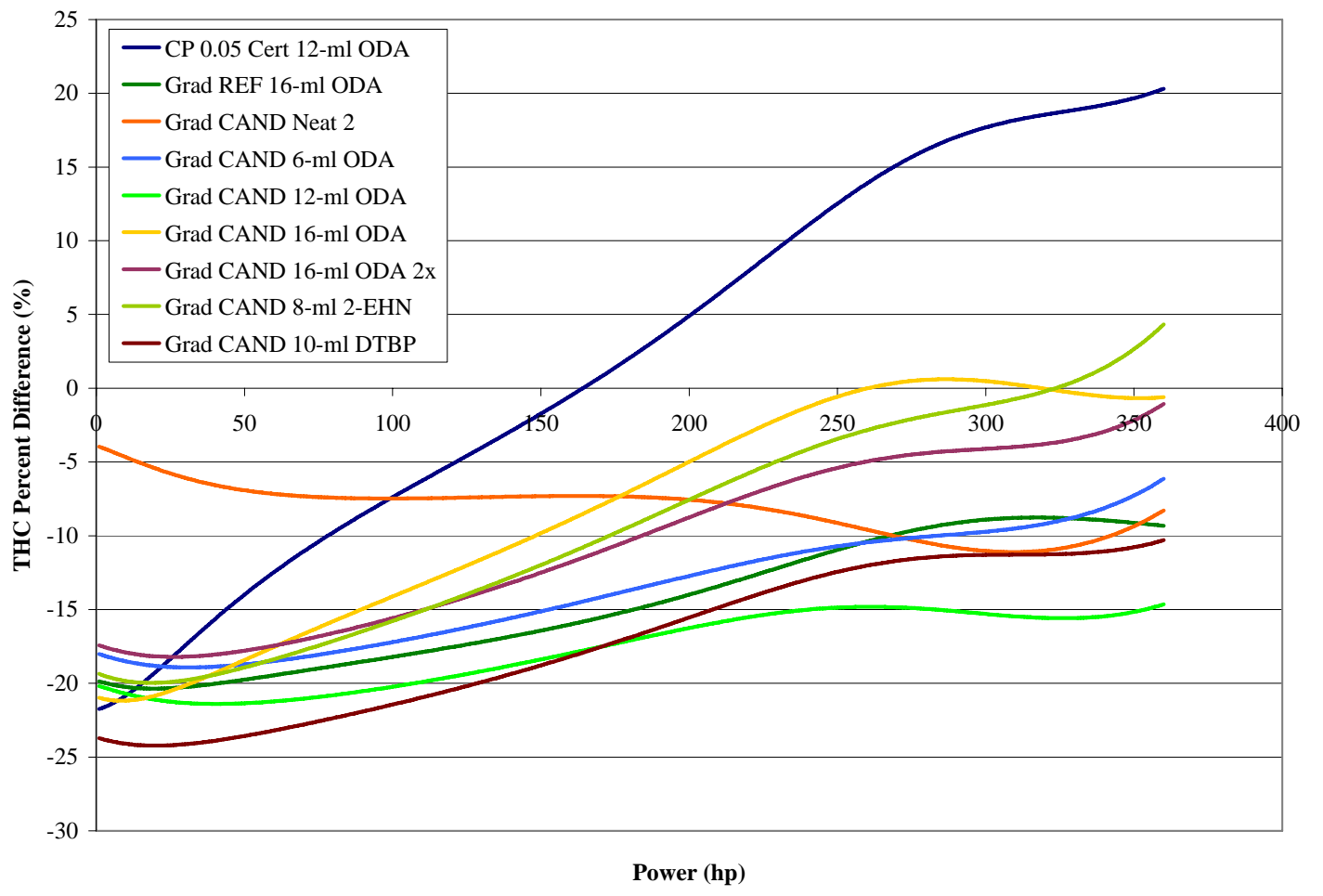

Figure 8-18 THC Percent Difference from Neat Fuels versus Power for 1992 Rebuilt DDC S60 


\subsection{Cummins ISM 370 SET Test Results}

Table 8-7 SET Test Results for 1999 Cummins ISM 370

\begin{tabular}{|c|c|c|c|c|c|c|c|c|c|c|c|c|c|c|}
\hline \multirow[b]{2}{*}{ Weighted Values } & \multicolumn{7}{|c|}{ CP 0.05 Cert } & \multicolumn{2}{|c|}{ Grad REF } & \multicolumn{5}{|c|}{ Grad CAND } \\
\hline & Neat 1 & Neat 2 & 12-ml ODA & B20 A Neat & B20 B Neat & $\begin{array}{c}\text { B20 B 6-ml 2 } \\
\text { EHN }\end{array}$ & $\begin{array}{l}\text { B20 B 10- } \\
\text { ml DTBP }\end{array}$ & Neat 1 & Neat 2 & Neat & 6-ml ODA & 12-ml ODA & $\begin{array}{c}\text { 6-ml } \\
\text { 2-EHN }\end{array}$ & 10-ml DTBP \\
\hline THC (g/bhp-hr) & 0.1423 & 0.1462 & 0.1444 & 0.1146 & 0.1171 & 0.1210 & 0.1216 & 0.1387 & 0.1416 & 0.1468 & 0.1507 & 0.1521 & 0.1487 & 0.1463 \\
\hline $\mathrm{CO}$ (g/bhp-hr) & 0.2247 & 0.2244 & 0.2017 & 0.2070 & 0.2062 & 0.1897 & 0.1917 & 0.2225 & 0.2056 & 0.2208 & 0.2218 & 0.2050 & 0.2080 & 0.2115 \\
\hline CO2 (g/bhp-hr) & 456.5 & 453.1 & 456.1 & 454.7 & 454.7 & 454.3 & 454.2 & 447.6 & 445.1 & 454.5 & 451.8 & 450.8 & 450.6 & 451.7 \\
\hline NOx (g/bhp-hr) & 6.016 & 5.887 & 6.022 & 6.071 & 6.191 & 6.141 & 6.138 & 5.557 & 5.516 & 5.765 & 5.749 & 5.768 & 5.783 & 5.790 \\
\hline NO2 (g/bhp-hr) & 0.1563 & 0.1983 & 0.1408 & 0.0026 & 0.0022 & 0.1219 & 0.1285 & 0.1479 & 0.1390 & 0.1481 & 0.1452 & 0.1528 & 0.1515 & 0.1444 \\
\hline TPM (g/bhp-hr) & 0.0748 & 0.0682 & 0.0714 & 0.0537 & 0.0503 & 0.0546 & 0.0530 & 0.0477 & 0.0493 & 0.0491 & 0.0530 & 0.0555 & 0.0512 & 0.0522 \\
\hline BSFC (g/bhp-hr) & 147.9 & 146.9 & 147.7 & 150.6 & 141.4 & 150.6 & 150.6 & 146.6 & 146.4 & 147.9 & 146.9 & 147.6 & 147.6 & 147.8 \\
\hline Power (bhp) & 198.8 & 198.4 & 198.4 & 197.3 & 197.8 & 197.4 & 197.3 & 197.8 & 197.8 & 197.2 & 197.7 & 197.6 & 197.8 & 197.4 \\
\hline Work (bhp-hr) & 1.657 & 1.654 & 1.653 & 1.644 & 1.648 & 1.645 & 1.645 & 1.648 & 1.649 & 1.643 & 1.648 & 1.647 & 1.648 & 1.645 \\
\hline
\end{tabular}




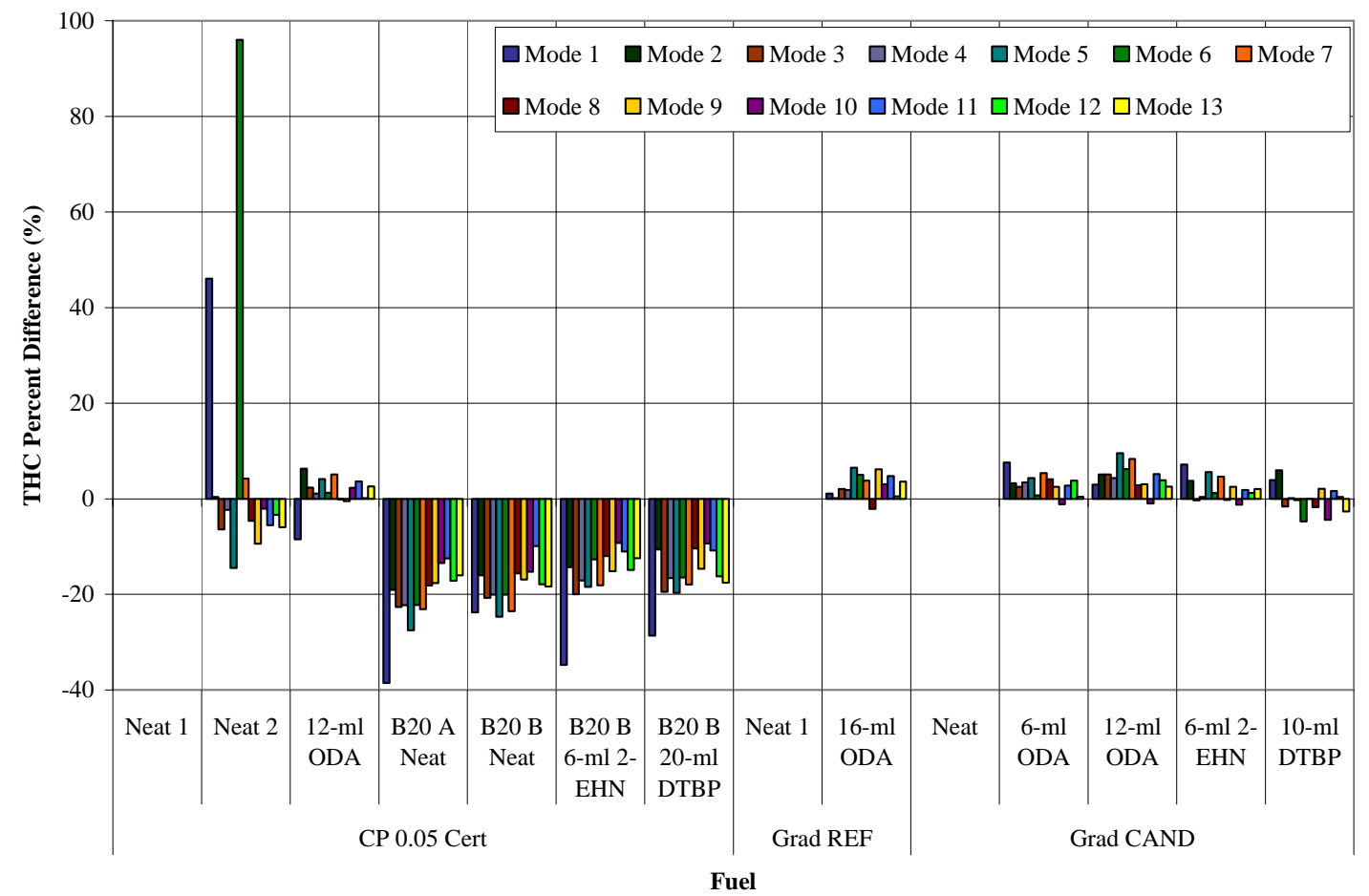

Figure 8-19 THC Percent Difference from Neat Fuels for 1999 Cummins ISM 370

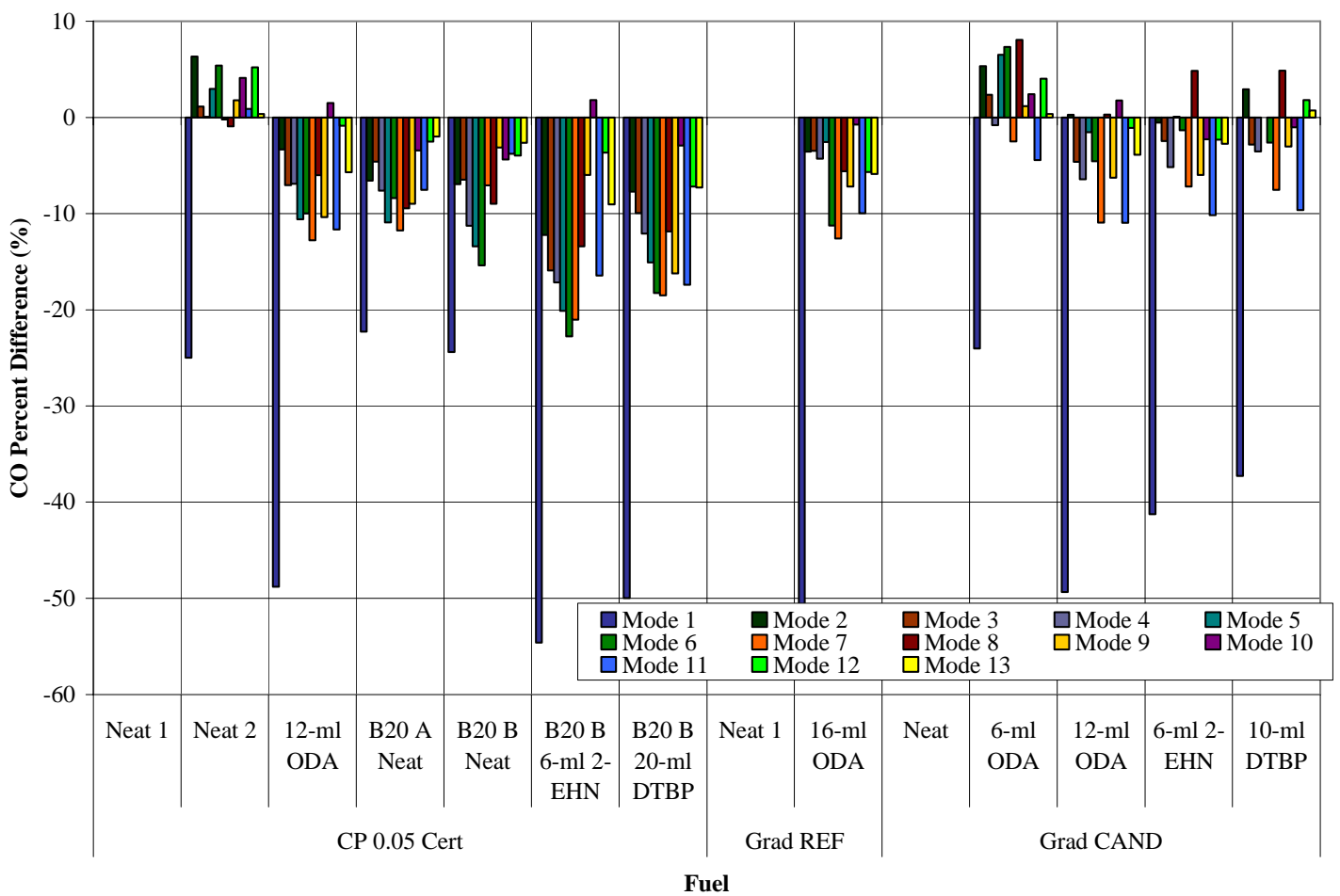

Figure 8-20 CO Percent Difference from Neat Fuels for 1999 Cummins ISM 370 


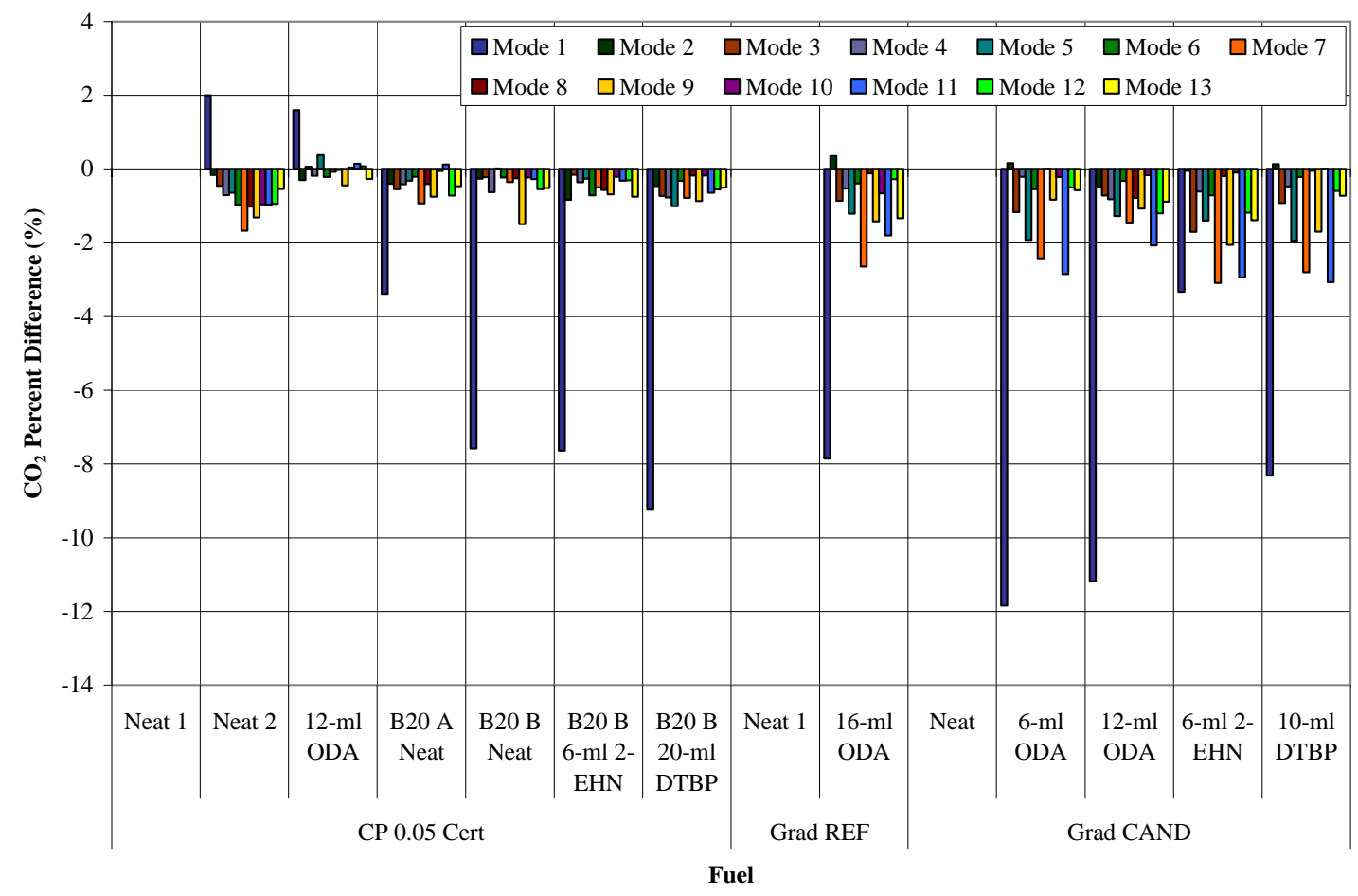

Figure 8-21 $\mathrm{CO}_{2}$ Percent Difference from Neat Fuels for 1999 Cummins ISM 370

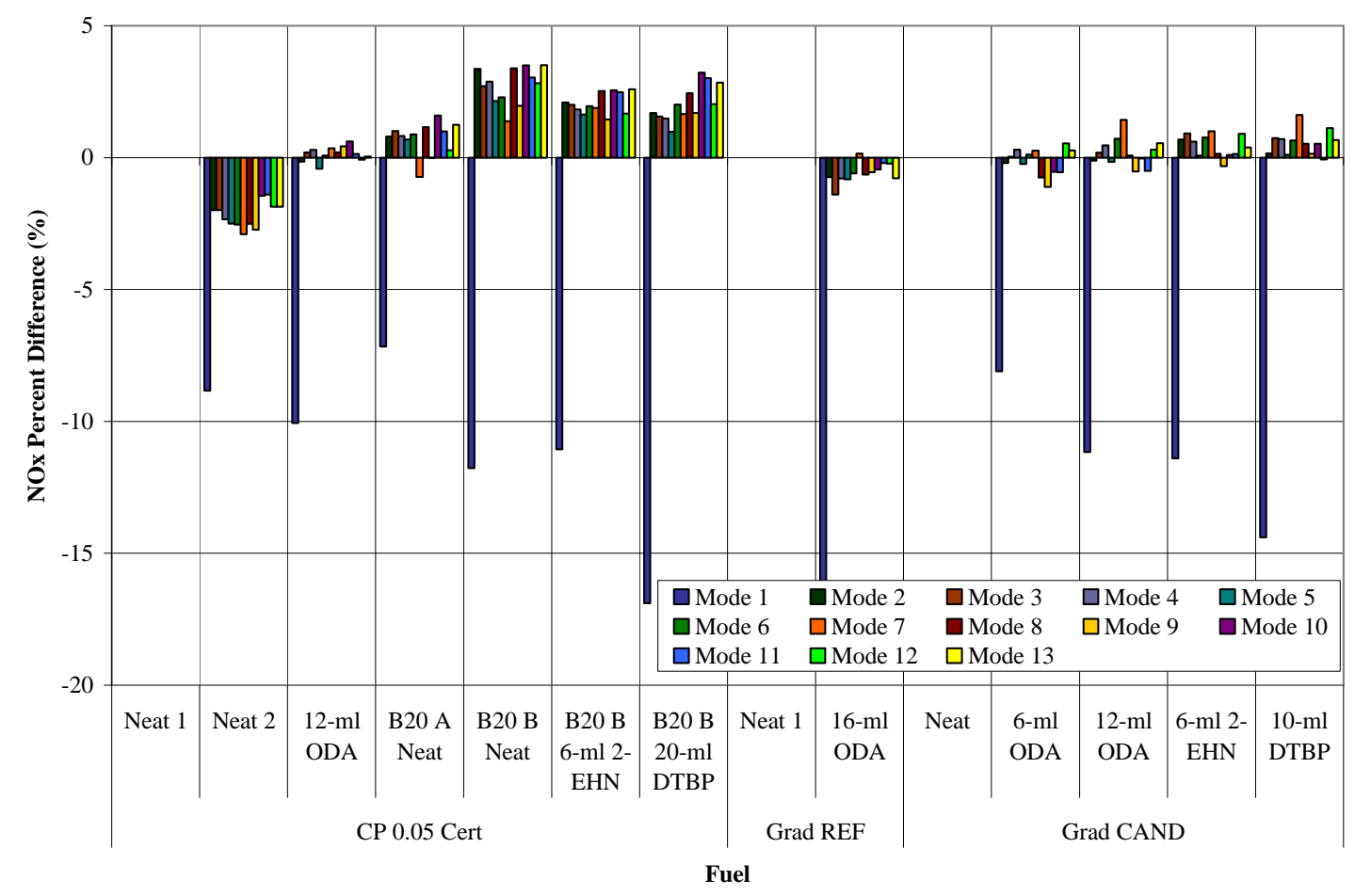

Figure 8-22 NOx Percent Difference from Neat Fuels for 1999 Cummins ISM 370 


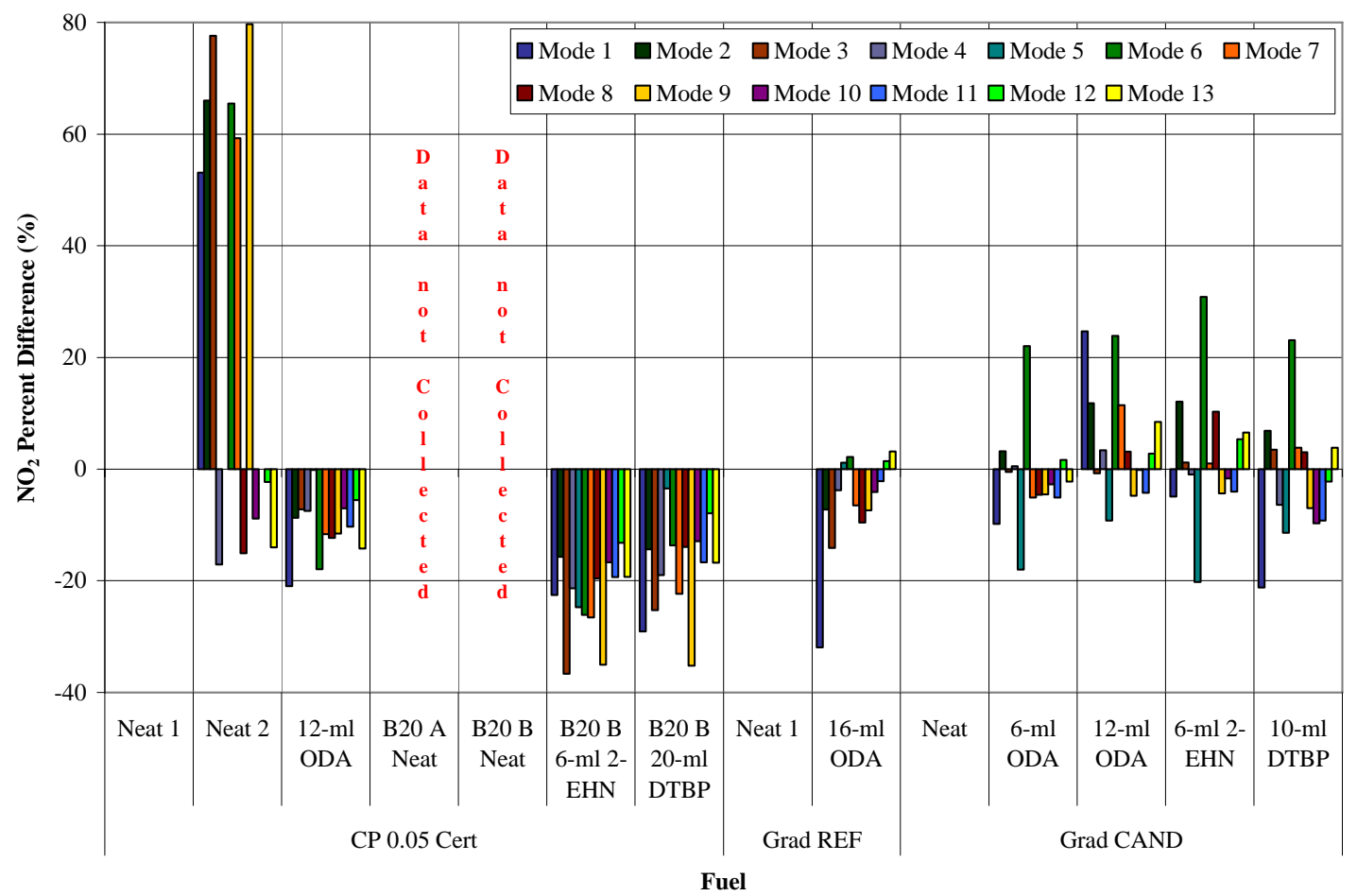

Figure 8-23 $\mathrm{NO}_{2}$ Percent Difference from Neat Fuels for 1999 Cummins ISM 370

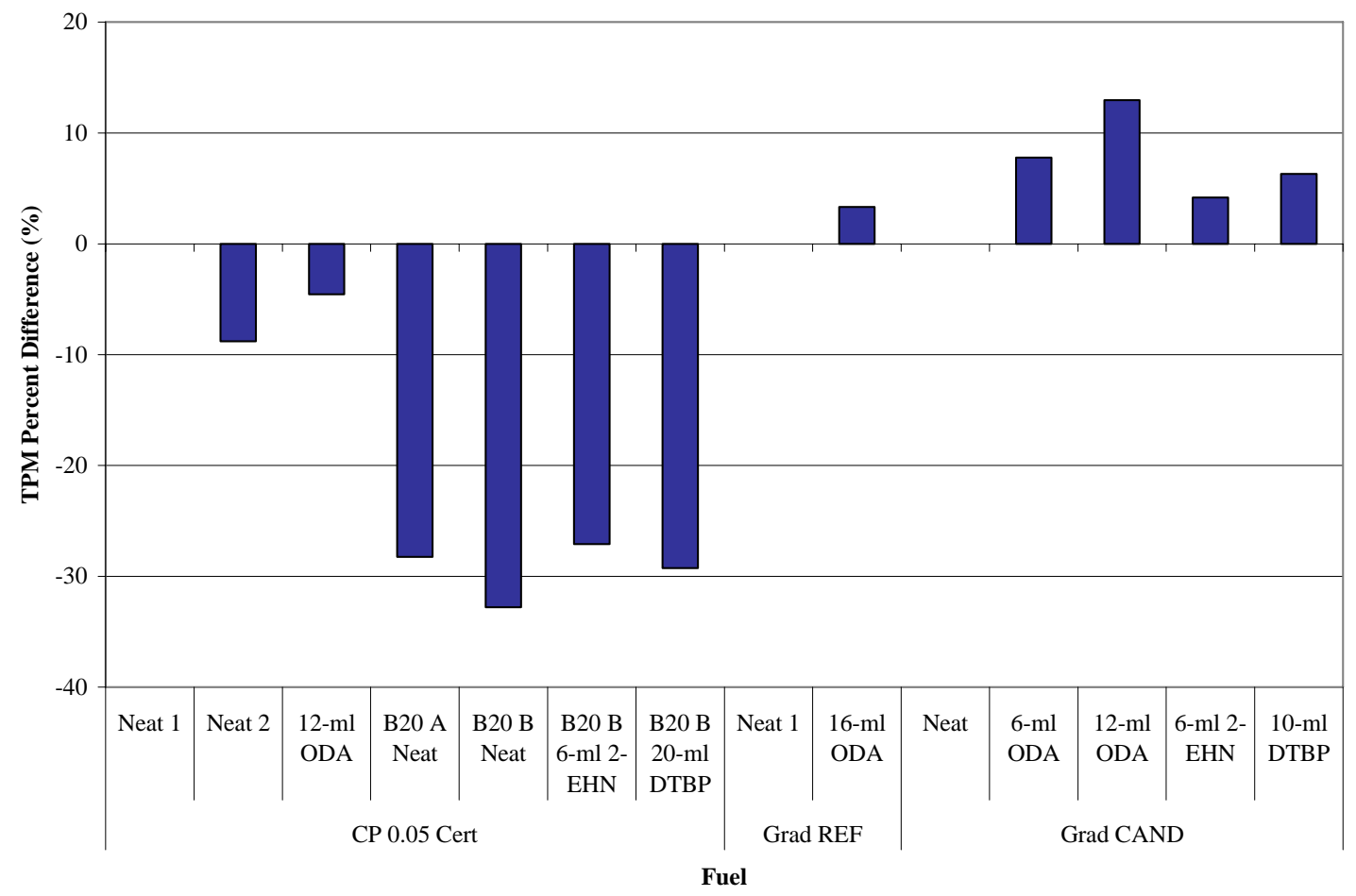

Figure 8-24 TPM Percent Difference from Neat Fuels for 1999 Cummins ISM 370 


\subsection{Cummins ISM 370 FTP Results}

Table 8-8 FTP Results for 1999 Cummins ISM 370

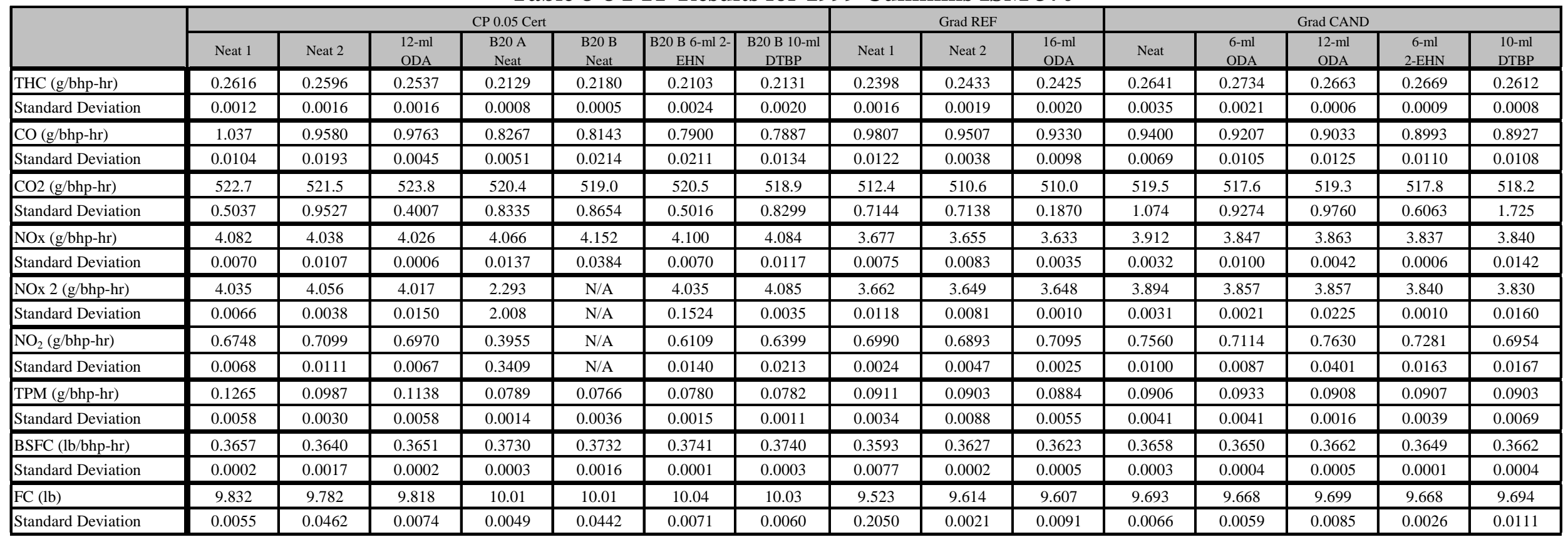


Table 8-9 Variation Analysis for 1999 Cummins ISM 370

\begin{tabular}{|l|c|c|c|}
\hline & Average & $\begin{array}{c}\text { Standard } \\
\text { Deviation }\end{array}$ & $\begin{array}{c}\text { Coefficient of } \\
\text { Variation (\%) }\end{array}$ \\
\hline THC (g/bhp-hr) & 0.2458 & 0.0223 & 9.1 \\
\hline CO (g/bhp-hr) & 0.9074 & 0.0740 & 8.2 \\
\hline CO2 (g/bhp-hr) & 518.1 & 4.106 & 0.8 \\
\hline NOx (g/bhp-hr) & 3.921 & 0.1732 & 4.4 \\
\hline $\mathrm{NOx}^{2}$ (g/bhp-hr) & 3.768 & 0.4511 & 12.0 \\
\hline $\mathrm{NO}_{2}$ (g/bhp-hr) & 0.6771 & 0.0903 & 13.3 \\
\hline TPM (g/bhp-hr) & 0.0918 & 0.0135 & 14.7 \\
\hline BSFC (lb/bhp-hr) & 0.3668 & 0.0046 & 1.3 \\
\hline FC (lb) & 9.779 & 0.1711 & 1.7 \\
\hline
\end{tabular}

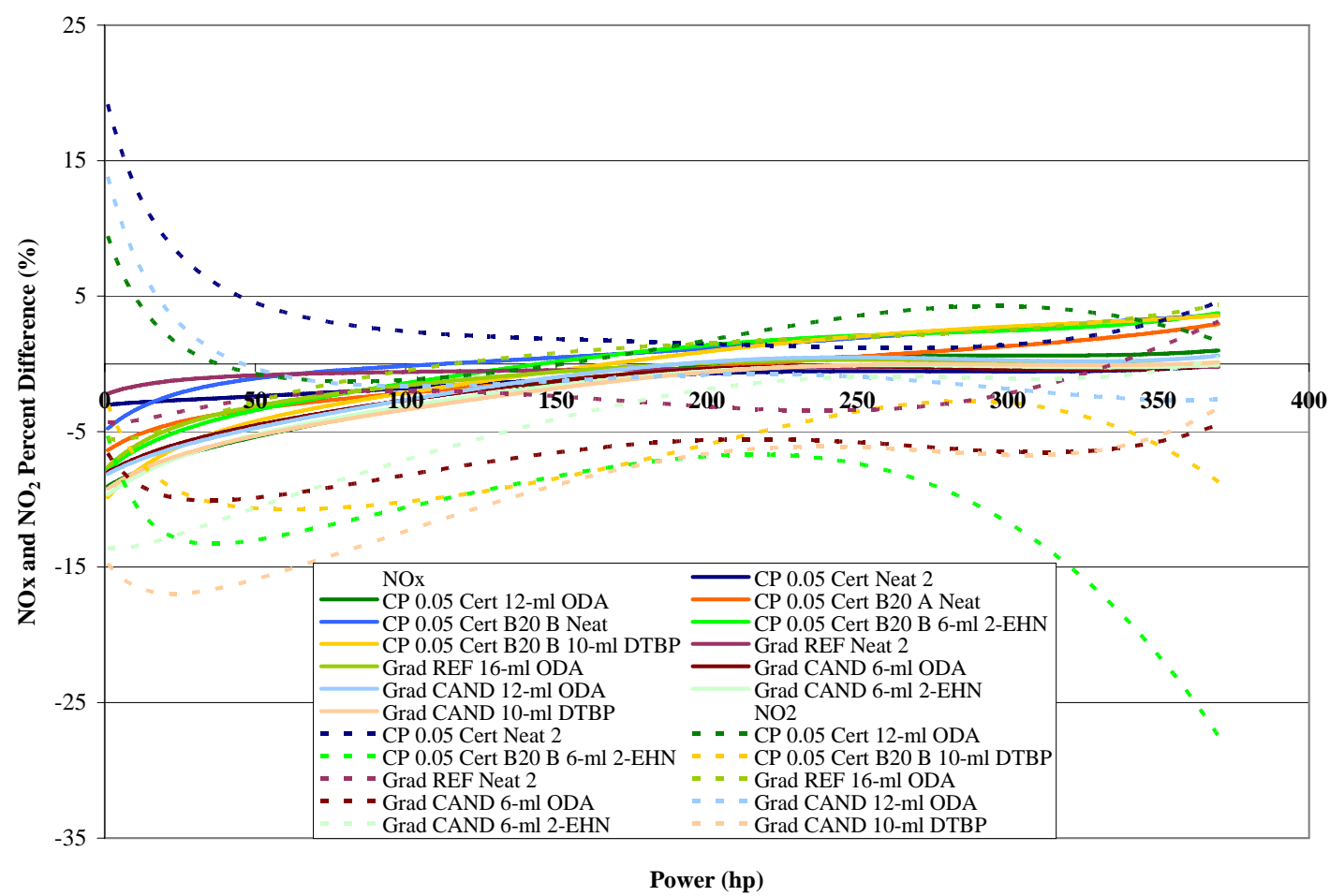

Figure 8-25 NOx and $\mathrm{NO}_{2}$ Percent Difference from Neat Fuels versus Power for 1999 Cummins ISM 370 


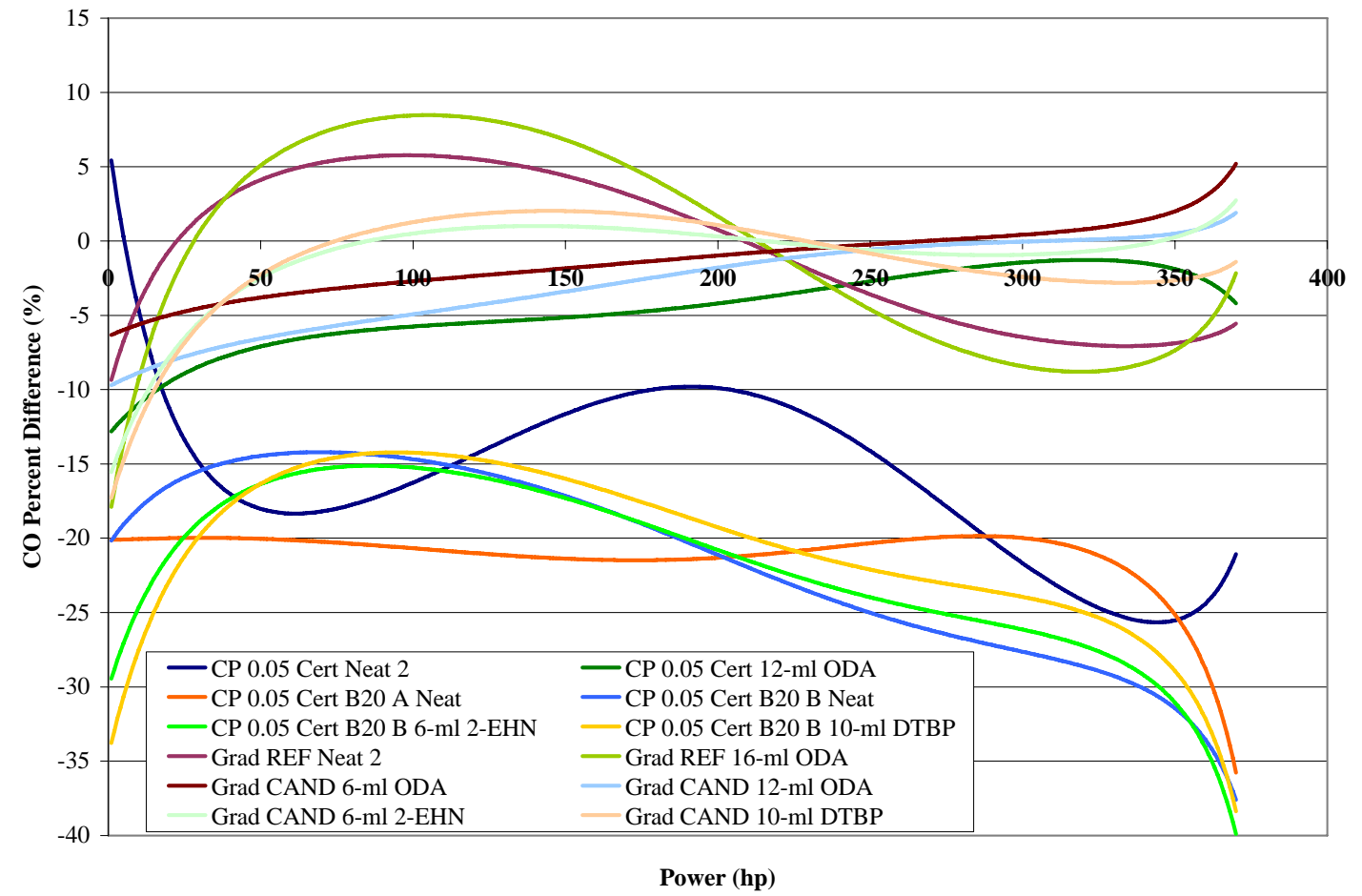

Figure 8-26 CO Percent Difference from Neat Fuels versus Power for 1999 Cummins ISM 370

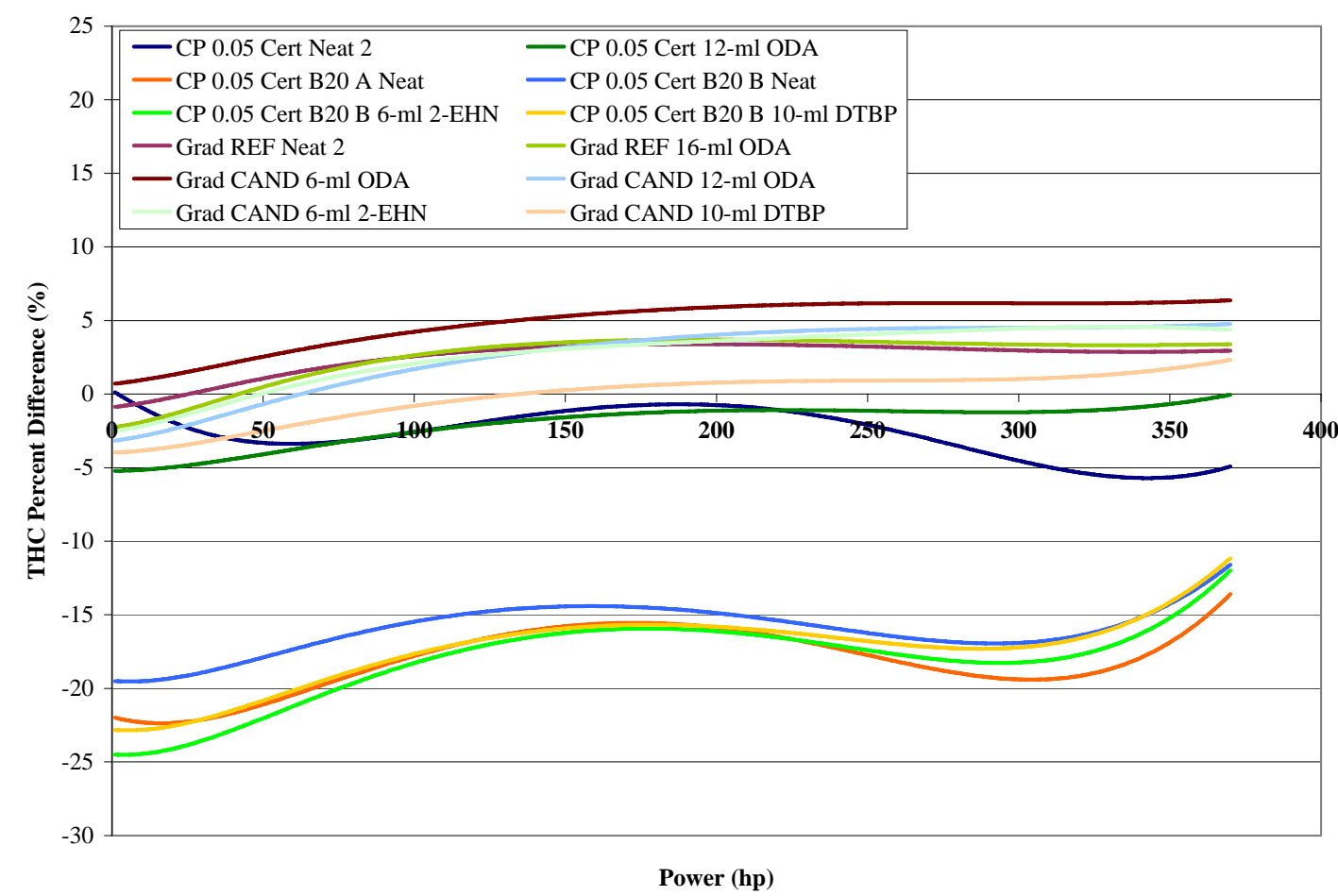

Figure 8-27 THC Percent Difference from Neat Fuels versus Power for 1999 Cummins ISM 370 


\subsection{Cummins ISM 370 SET Test Results}

Table 8-10 SET Test Results for 2004 Cummins ISM 370

\begin{tabular}{|c|c|c|c|c|c|c|c|c|c|c|c|c|c|c|c|c|c|}
\hline \multirow{2}{*}{$\begin{array}{l}\text { Weighted } \\
\text { Values }\end{array}$} & \multicolumn{12}{|c|}{ CP 0.05 Cert } & \multicolumn{3}{|c|}{ Grad REF } & \multicolumn{2}{|c|}{ Grad CAND } \\
\hline & Neat 1 & Neat 2 & 12-ml ODA & 24-ml ODA & $\begin{array}{c}\text { 6-ml 2- } \\
\text { EHN }\end{array}$ & $\begin{array}{l}\text { 12-ml 2- } \\
\text { EHN }\end{array}$ & 15-ml DTBP & B20 A Neat & B20 B Neat & B20 C Neat & $\mid \begin{array}{c}\text { B20 B 10-ml } \\
\text { 2-EHN }\end{array}$ & $\begin{array}{c}55-\mathrm{ml} \\
\text { Nitrogen }\end{array}$ & Neat 1 & Neat 2 & 16-ml ODA & Neat & 6-ml ODA \\
\hline $\begin{array}{c}\text { THC } \\
\text { (g/bhp-hr) }\end{array}$ & 0.1077 & 0.1092 & 0.1078 & 0.1100 & 0.1084 & 0.1129 & 0.1081 & 0.0941 & 0.1000 & 0.0968 & 0.0925 & 0.1135 & 0.1064 & 0.1058 & 0.0973 & 0.1175 & 0.1169 \\
\hline $\begin{array}{c}\text { CO } \\
\text { (g/bhp-hr) }\end{array}$ & 0.4554 & 0.3633 & 0.4226 & 0.4001 & 0.4390 & 0.4076 & 0.3958 & 0.3749 & 0.3746 & 0.3667 & 0.3532 & 0.4377 & 0.5277 & 0.4570 & 0.4478 & 0.3630 & 0.4004 \\
\hline $\begin{array}{c}\mathrm{CO} 2 \\
\text { (g/bhp-hr) }\end{array}$ & 535.4 & 541.6 & 530.1 & 537.1 & 536.1 & 535.9 & 536.4 & 537.8 & 538.7 & 536.6 & 538.2 & 540.6 & 526.9 & 528.7 & 529.2 & 533.3 & 535.0 \\
\hline $\begin{array}{c}\text { NOx } \\
\text { (g/bhp-hr) }\end{array}$ & 1.981 & 2.120 & 1.993 & 2.043 & 2.004 & 2.025 & 2.040 & 2.129 & 2.139 & 2.162 & 2.130 & 2.043 & 1.781 & 1.863 & 1.882 & 2.099 & 2.025 \\
\hline $\begin{array}{c}\text { NO2 } \\
\text { (g/bhp-hr) }\end{array}$ & 0.1463 & 0.1464 & 0.1473 & 0.1517 & 0.1463 & 0.1446 & 0.1366 & 0.1398 & 0.1435 & 0.1426 & 0.1325 & 0.1502 & 0.1618 & 0.1718 & 0.1862 & 0.1558 & 0.1525 \\
\hline $\begin{array}{c}\text { TPM } \\
\text { (g/bhp-hr) }\end{array}$ & 0.1008 & 0.0837 & 0.1013 & 0.0982 & 0.1021 & 0.1010 & 0.0974 & 0.0696 & 0.0708 & 0.0641 & 0.0014 & 0.0913 & 0.0942 & 0.0766 & 0.0783 & 0.0677 & 0.0300 \\
\hline $\begin{array}{c}\text { BSFC } \\
\text { (g/bhp-hr) }\end{array}$ & 171.1 & 169.6 & 170.6 & 172.6 & 172.6 & 171.1 & 169.5 & 175.2 & 174.1 & 171.5 & 181.5 & 171.4 & 173.7 & 171.4 & 171.8 & 172.5 & 172.6 \\
\hline $\begin{array}{c}\text { Power } \\
\text { (bhp) }\end{array}$ & 182.6 & 183.9 & 182.5 & 182.4 & 182.4 & 182.4 & 182.5 & 181.5 & 182.0 & 182.1 & 181.5 & 182.0 & 179.5 & 181.6 & 181.5 & 183.2 & 181.4 \\
\hline $\begin{array}{c}\text { Work } \\
\text { (bhp-hr) }\end{array}$ & 1.522 & 1.533 & 1.521 & 1.520 & 1.520 & 1.520 & 1.520 & 1.513 & 1.517 & 1.518 & 1.512 & 1.517 & 1.496 & 1.514 & 1.513 & 1.527 & 1.512 \\
\hline
\end{tabular}




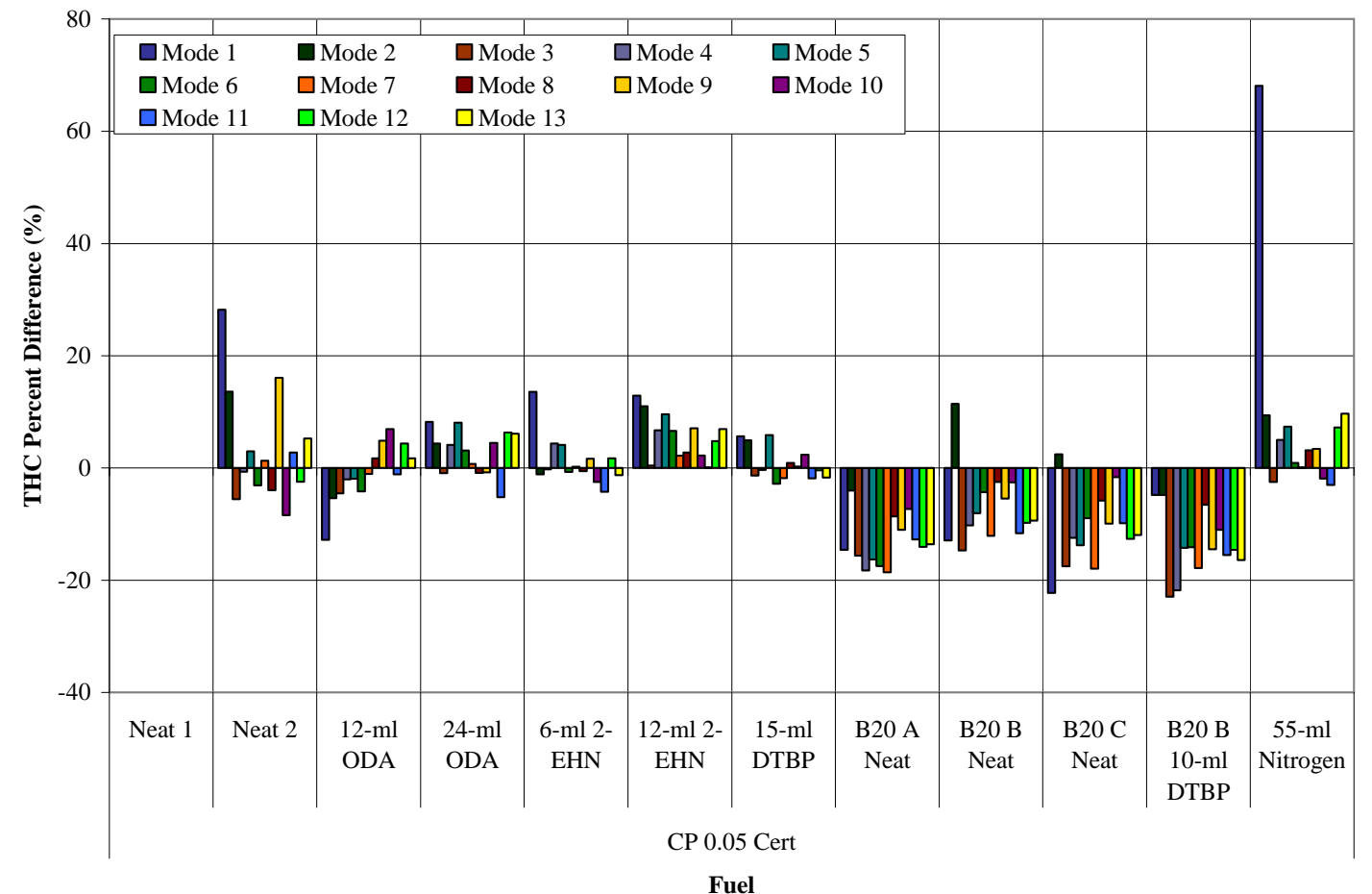

Figure 8-28 THC Percent Difference from Neat Fuel for 2004 Cummins ISM 370

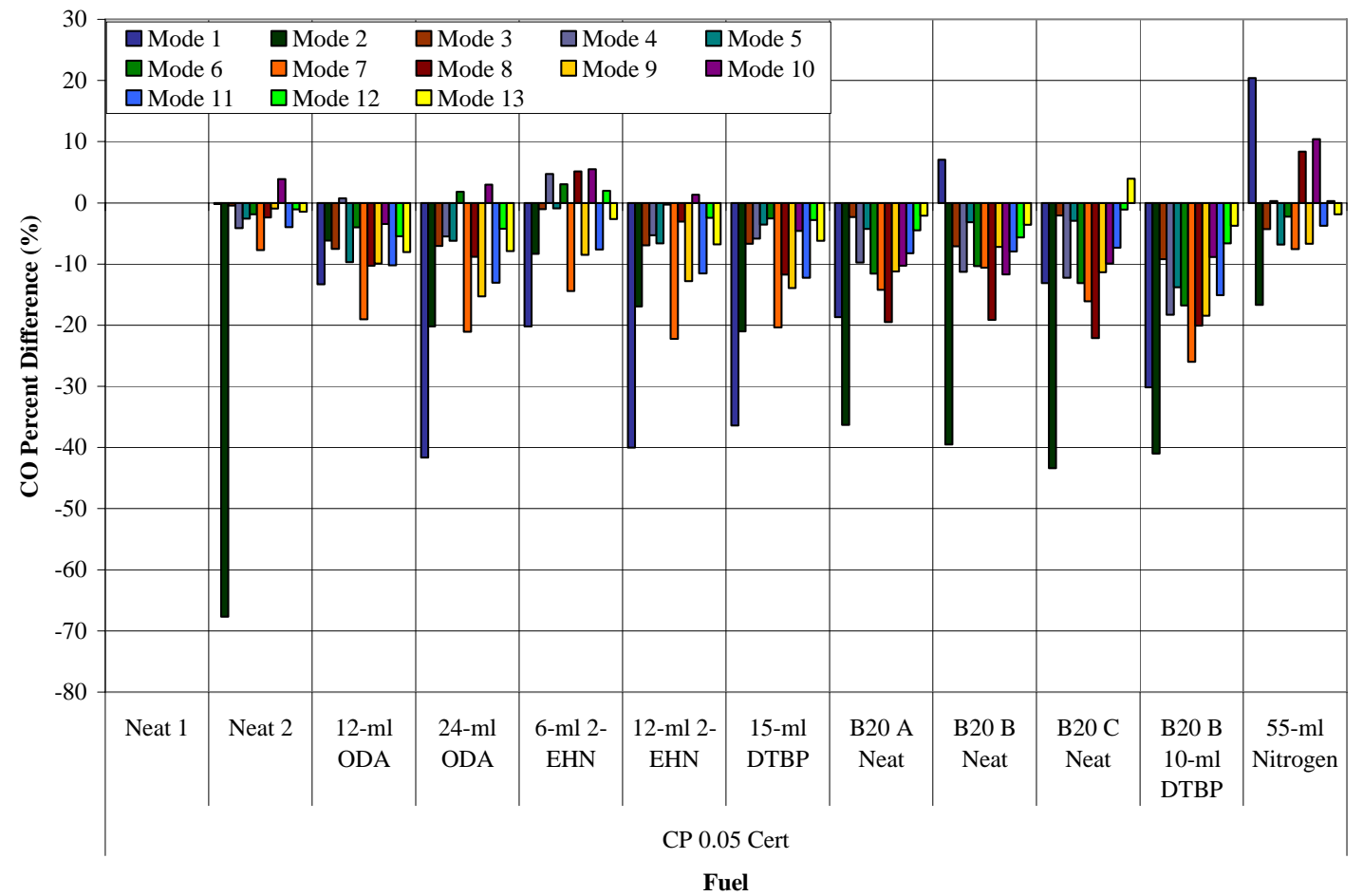

Figure 8-29 CO Percent Difference from Neat Fuel for 2004 Cummins ISM 370 


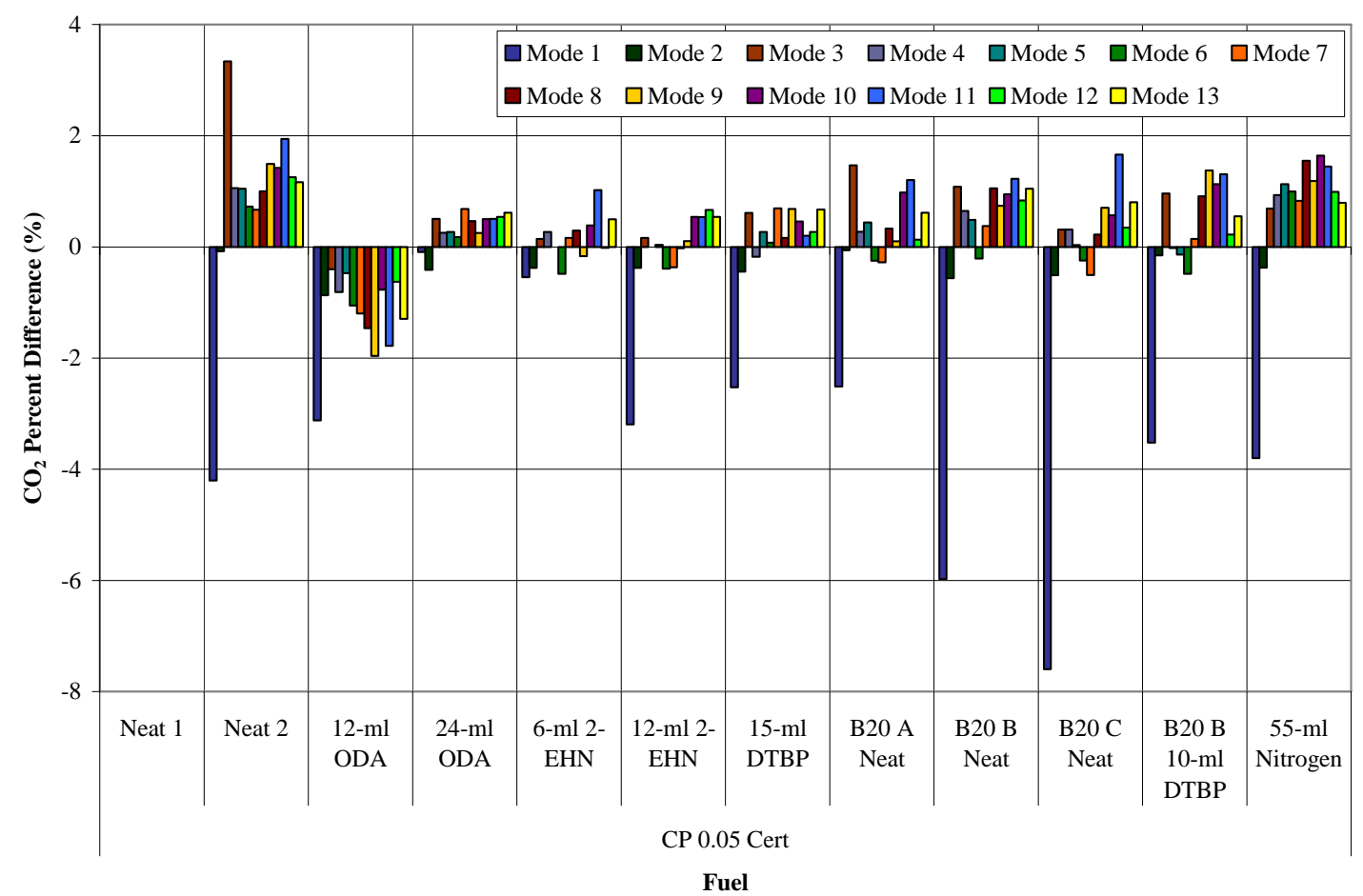

Figure 8-30 $\mathrm{CO}_{2}$ Percent Difference from Neat Fuel for 2004 Cummins ISM 370

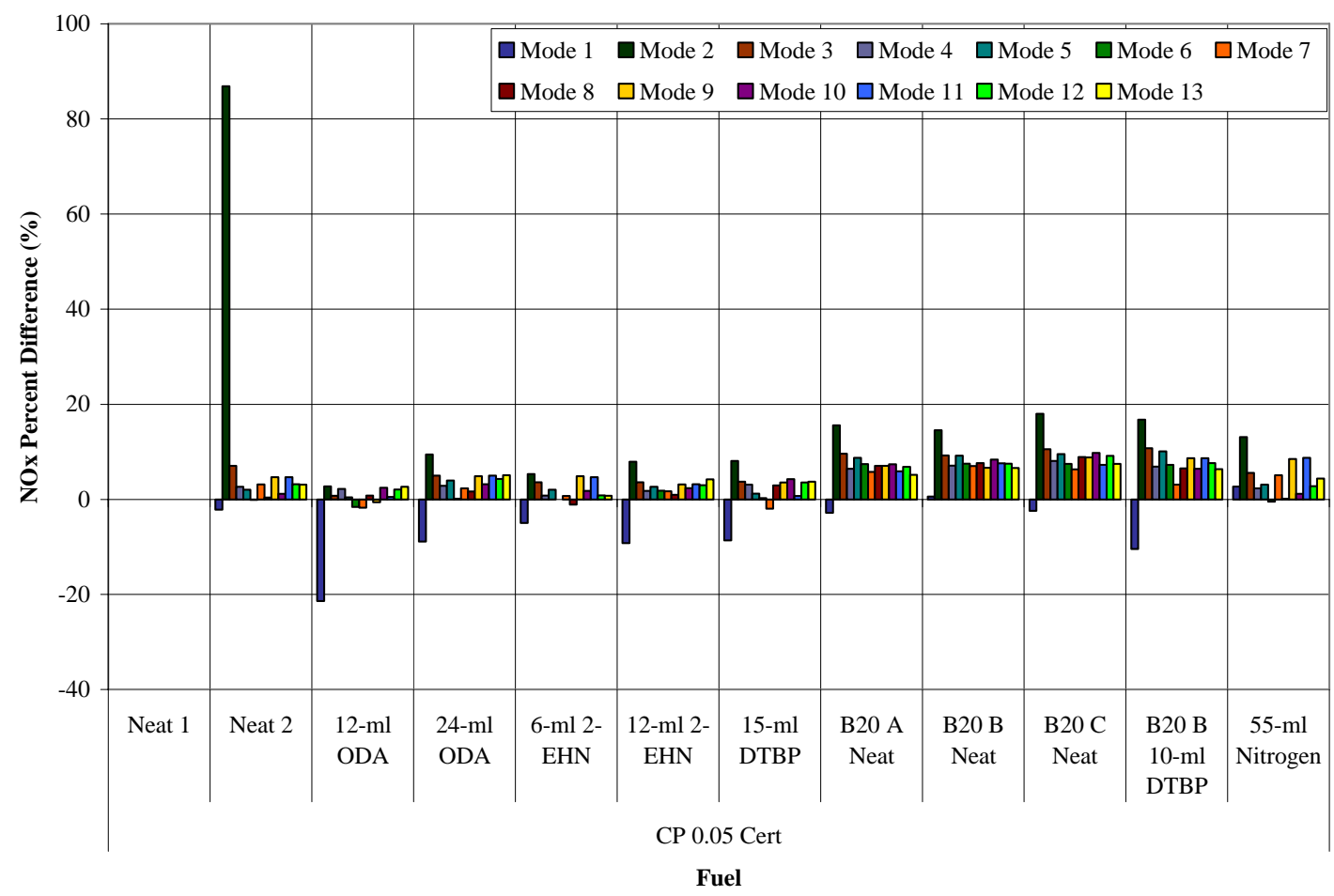

Figure 8-31 NOx Percent Difference from Neat Fuel for 2004 Cummins ISM 370 


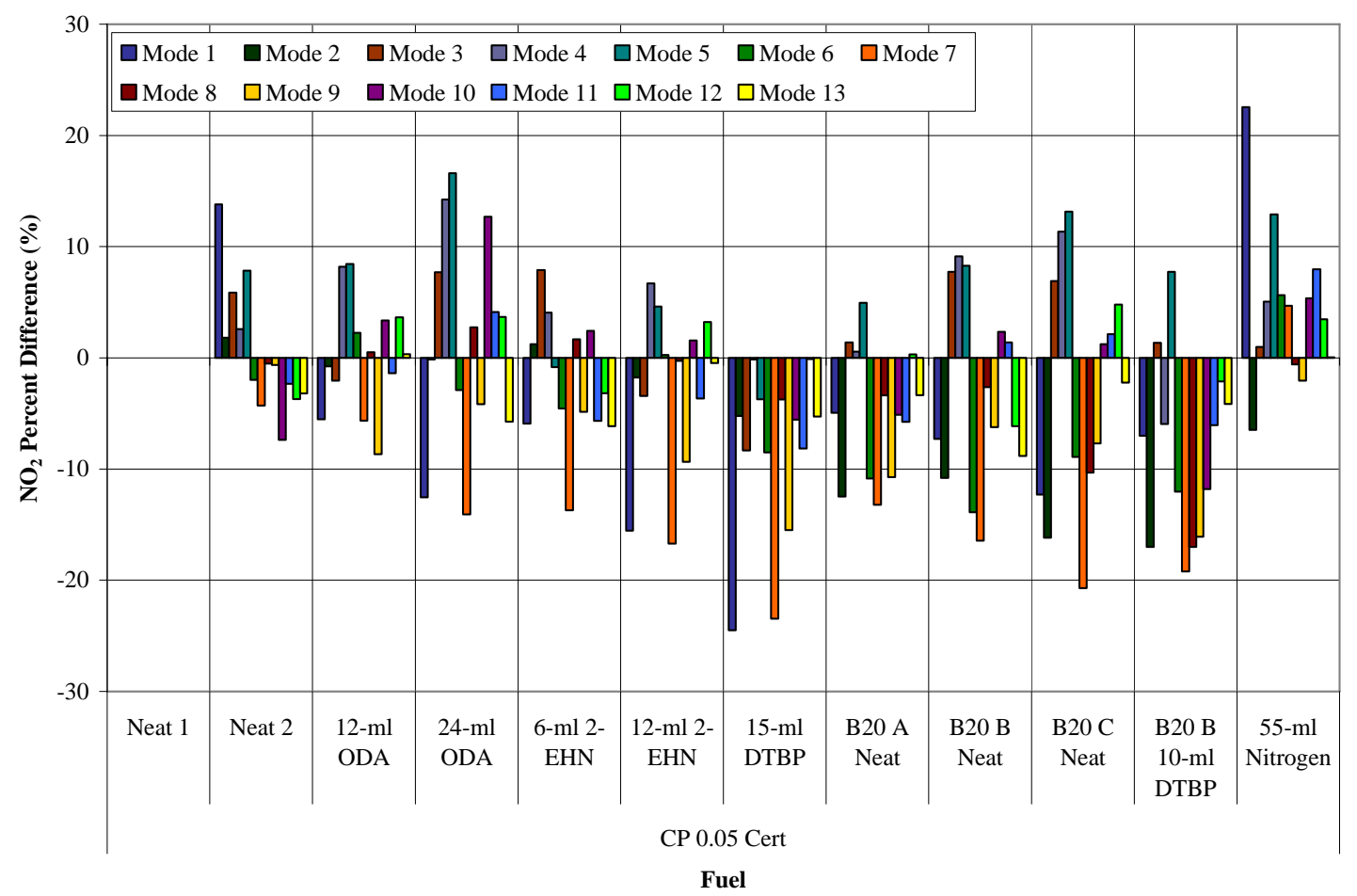

Figure 8-32 $\mathrm{NO}_{2}$ Percent Difference from Neat Fuel for 2004 Cummins ISM 370

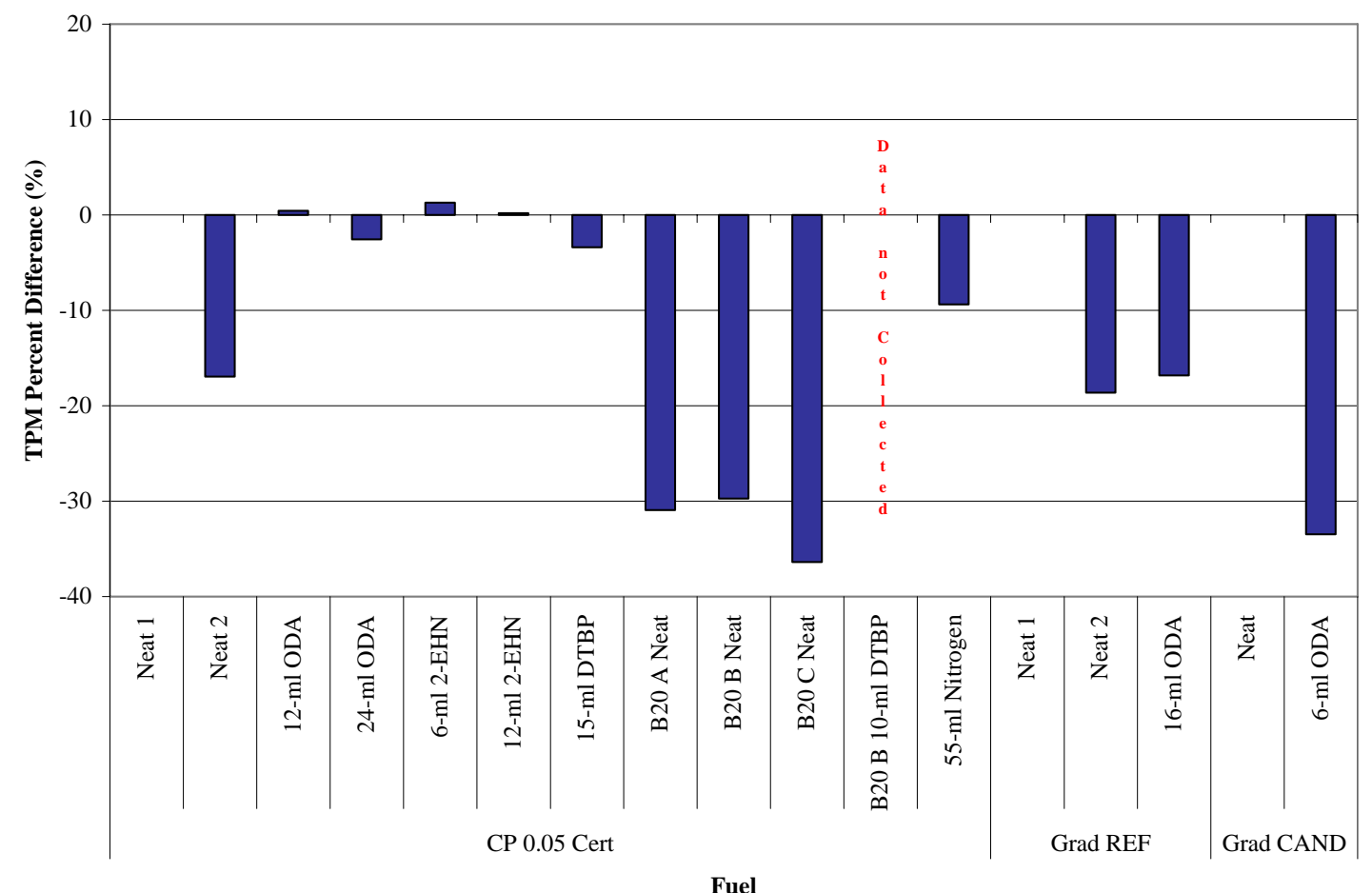

Figure 8-33 TPM Percent Difference from Neat Fuel for 2004 Cummins ISM 370 


\subsection{Cummins ISM 370 FTP Results}

Table 8-11 FTP Results for 2004 Cummins ISM 370

\begin{tabular}{|c|c|c|c|c|c|c|c|c|c|c|c|c|c|c|c|c|}
\hline & \multicolumn{12}{|c|}{ CP 0.05 Cert } & \multicolumn{2}{|c|}{ Grad REF } & \multicolumn{2}{|c|}{ Grad CAND } \\
\hline & Neat 1 & Neat 2 & Neat 3 & 12-ml ODA & 24-ml ODA & $\begin{array}{c}6-\mathrm{ml} \\
\text { 2-EHN }\end{array}$ & $\begin{array}{c}12-\mathrm{ml} \\
2 \text {-EHN }\end{array}$ & $\begin{array}{l}15-\mathrm{ml} \\
\text { DTBP }\end{array}$ & $\begin{array}{c}\text { B20 A } \\
\text { Neat }\end{array}$ & $\begin{array}{c}\text { B20 B } \\
\text { Neat }\end{array}$ & $\begin{array}{l}\text { B20 C } \\
\text { Neat }\end{array}$ & $\begin{array}{c}\text { B20 B 10-ml } \\
\text { DTBP }\end{array}$ & Neat 1 & Neat 2 & Neat & $\begin{array}{l}\text { 6-ml } \\
\text { ODA }\end{array}$ \\
\hline THC (g/bhp-hr) & 0.2001 & 0.2062 & 0.2108 & 0.2035 & 0.2059 & 0.2038 & 0.2044 & 0.1994 & 0.1808 & 0.1856 & 0.1814 & 0.1840 & 0.1954 & 0.1916 & 0.2141 & 0.2167 \\
\hline Standard Deviation & 0.0031 & 0.0020 & 0.0043 & 0.0014 & 0.0005 & 0.0014 & 0.0031 & 0.0010 & 0.0019 & 0.0017 & 0.0012 & 0.0046 & 0.0012 & 0.0029 & 0.0018 & 0.0018 \\
\hline CO (g/bhp-hr) & 0.6167 & 0.5920 & 0.6087 & 0.5710 & 0.5570 & 0.5720 & 0.5433 & 0.5263 & 0.5433 & 0.5490 & 0.5453 & 0.5267 & 0.6147 & 0.5683 & 0.5603 & 0.5580 \\
\hline Standard Deviation & 0.0116 & 0.0066 & 0.0045 & 0.0154 & 0.0044 & 0.0157 & 0.0144 & 0.0086 & 0.0080 & 0.0044 & 0.0021 & 0.0051 & 0.0119 & 0.0065 & 0.0114 & 0.0089 \\
\hline CO2 (g/bhp-hr) & 601.6 & 603.6 & 605.0 & 601.6 & 600.7 & 599.8 & 600.4 & 601.4 & 602.1 & 604.8 & 602.0 & 604.5 & 591.5 & 590.8 & 596.3 & 598.4 \\
\hline Standard Deviation & 0.6056 & 1.143 & 0.8373 & 0.8004 & 1.914 & 0.6953 & 0.4905 & 1.062 & 1.243 & 1.148 & 0.9752 & 0.8576 & 1.213 & 1.064 & 0.8975 & 0.7209 \\
\hline NOx (g/bhp-hr) & 1.569 & 2.366 & 2.378 & 2.352 & 2.387 & 2.366 & 2.385 & 2.365 & 2.443 & 2.480 & 2.468 & 2.420 & 2.161 & 2.183 & 2.349 & 2.350 \\
\hline Standard Deviation & 1.359 & 0.0053 & 0.0127 & 0.0104 & 0.0070 & 0.0121 & 0.0130 & 0.0165 & 0.0111 & 0.0059 & 0.0035 & 0.0318 & 0.0098 & 0.0023 & 0.0030 & 0.0057 \\
\hline NOx 2 (g/bhp-hr) & 2.335 & 2.348 & 2.362 & 2.334 & 2.363 & 2.360 & 2.369 & 2.357 & 2.408 & 2.462 & 2.437 & 2.437 & 2.154 & 2.163 & 2.330 & 2.326 \\
\hline Standard Deviation & 0.0066 & 0.0068 & 0.0189 & 0.0112 & 0.0184 & 0.0127 & 0.0122 & 0.0180 & 0.0074 & 0.0145 & 0.0042 & 0.0047 & 0.0105 & 0.0095 & 0.0029 & 0.0053 \\
\hline $\mathrm{NO}_{2}$ (g/bhp-hr) & 0.7935 & 0.8165 & 0.8597 & 0.7759 & 0.8050 & 0.7940 & 0.7932 & 0.7732 & 0.8028 & 0.8196 & 0.8106 & 0.8109 & 0.0241 & 0.8372 & 0.8486 & 0.8540 \\
\hline Standard Deviation & 0.0066 & 0.0108 & 0.0041 & 0.0040 & 0.0092 & 0.0072 & 0.0093 & 0.0063 & 0.0066 & 0.0029 & 0.0109 & 0.0061 & 0.0077 & 0.0070 & 0.0038 & 0.0087 \\
\hline TPM (g/bhp-hr) & 0.0744 & 0.0691 & 0.0732 & 0.0745 & 0.0719 & 0.0731 & 0.0720 & 0.0721 & 0.0532 & 0.0562 & 0.0478 & 0.0564 & 0.0576 & 0.0544 & 0.0548 & 0.0550 \\
\hline Standard Deviation & 0.0057 & 0.0009 & 0.0004 & 0.0058 & 0.0018 & 0.0004 & 0.0008 & 0.0005 & 0.0013 & 0.0014 & 0.0009 & 0.0027 & 0.0014 & 0.0020 & 0.0016 & 0.0007 \\
\hline BSFC (lb/bhp-hr) & 0.4208 & 0.4219 & 0.4227 & 0.4184 & 0.4130 & 0.4199 & 0.4184 & 0.4160 & 0.4236 & 0.4197 & 0.4296 & 0.4342 & 0.4226 & 0.4191 & 0.4063 & 0.4165 \\
\hline Standard Deviation & 0.0027 & 0.0025 & 0.0023 & 0.0032 & 0.0113 & 0.0024 & 0.0020 & 0.0021 & 0.0064 & 0.0118 & 0.0019 & 0.0037 & 0.0029 & 0.0011 & 0.0068 & 0.0045 \\
\hline $\mathrm{FC}(\mathrm{lb})$ & 10.79 & 10.80 & 10.61 & 10.69 & 10.59 & 10.76 & 10.73 & 10.64 & 10.67 & 10.59 & 10.83 & 10.93 & 10.64 & 10.58 & 10.25 & 10.50 \\
\hline Standard Deviation & 0.0645 & 0.0566 & 0.0630 & 0.0688 & 0.2904 & 0.0613 & 0.0510 & 0.0872 & 0.1615 & 0.2980 & 0.0505 & 0.0894 & 0.0764 & 0.0284 & 0.1722 & 0.1119 \\
\hline
\end{tabular}


Table 8-12 Variation Analysis for 2004 Cummins ISM 370

\begin{tabular}{|l|c|c|c|}
\hline & Average & $\begin{array}{c}\text { Standard } \\
\text { Deviation }\end{array}$ & $\begin{array}{c}\text { Coefficient of } \\
\text { Variation (\%) }\end{array}$ \\
\hline THC (g/bhp-hr) & 0.1990 & 0.0115 & 5.8 \\
\hline $\mathrm{CO}$ (g/bhp-hr) & 0.5658 & 0.0289 & 5.1 \\
\hline $\mathrm{CO} 2$ (g/bhp-hr) & 600.3 & 4.239 & 0.7 \\
\hline $\mathrm{NOx}$ (g/bhp-hr) & 2.314 & 0.2161 & 9.3 \\
\hline $\mathrm{NOx} 2$ (g/bhp-hr) & 2.347 & 0.0842 & 3.6 \\
\hline $\mathrm{NO}_{2}$ (g/bhp-hr) & 0.063 & 0.0096 & 15.2 \\
\hline TPM (g/bhp-hr) & 0.0635 & 0.0096 & 15.2 \\
\hline $\mathrm{BSFC}(\mathrm{lb} / \mathrm{bhp}-\mathrm{hr})$ & 0.4202 & 0.0063 & 1.5 \\
\hline FC (lb) & 10.66 & 0.1566 & 1.5 \\
\hline
\end{tabular}

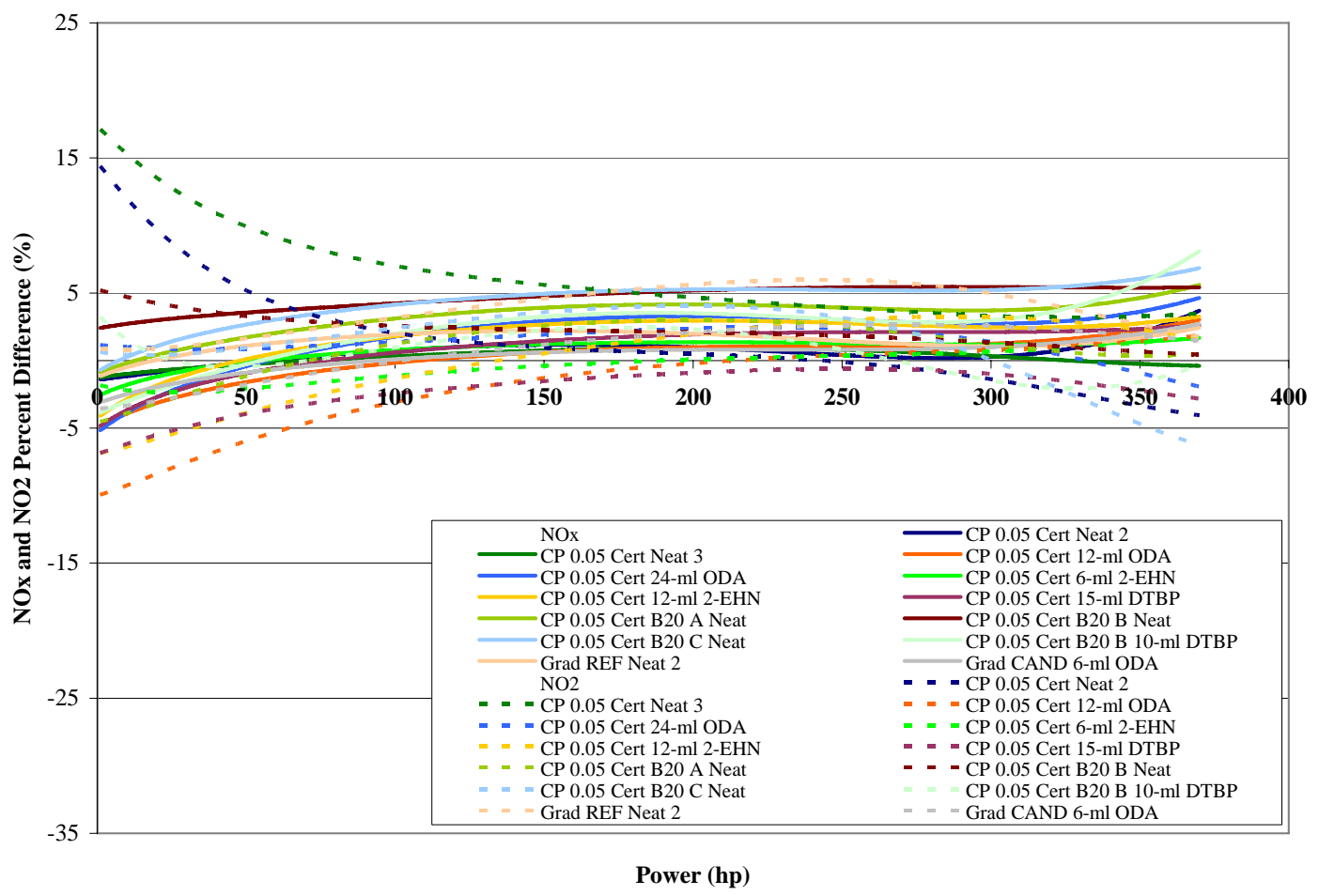

Figure 8-34 NOx and $\mathrm{NO}_{2}$ Percent Difference from Neat Fuels versus Power for 2004 Cummins ISM 370 


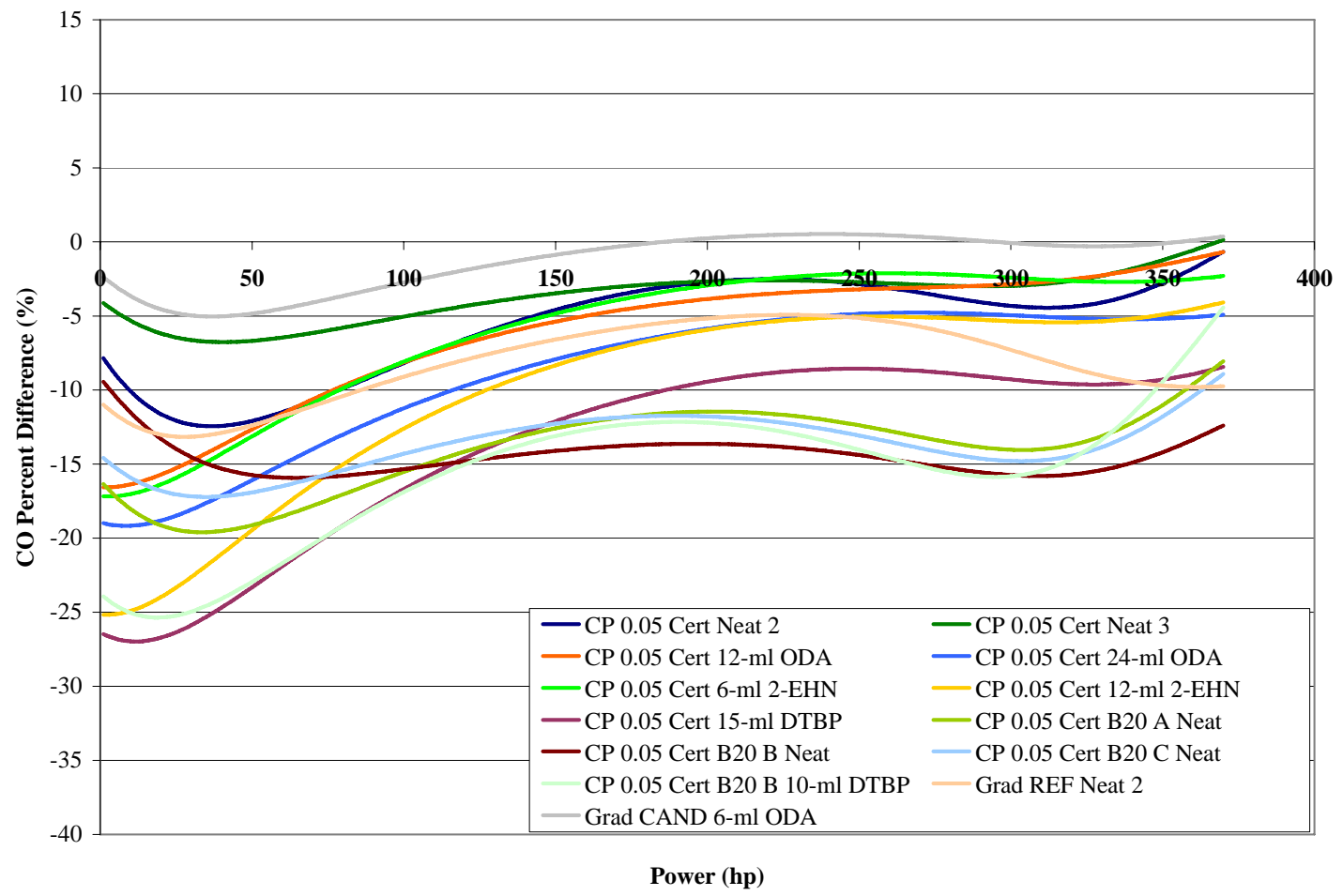

Figure 8-35 CO Percent Difference from Neat Fuels versus Power for 2004 Cummins ISM 370

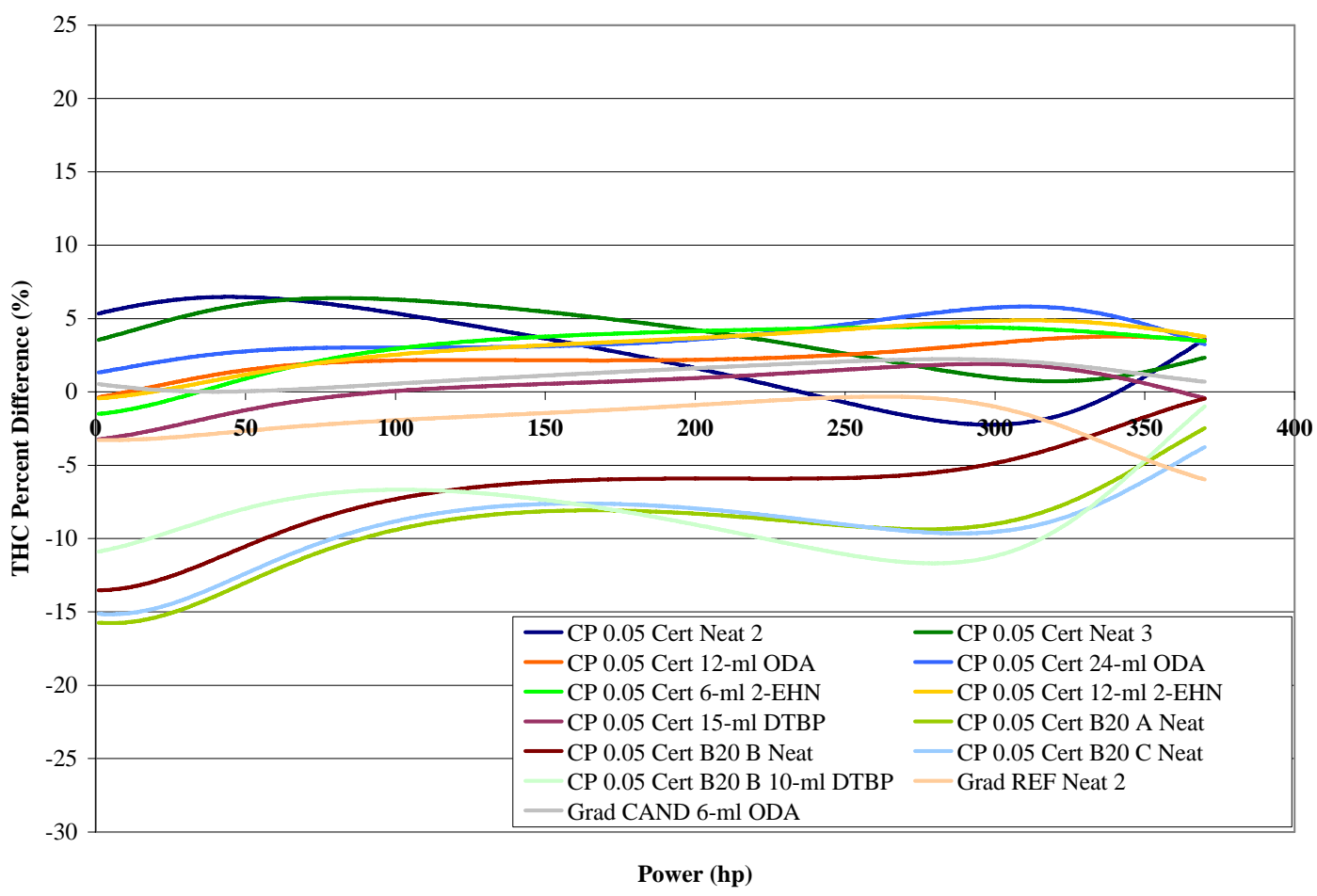

Figure 8-36 THC Percent Difference from Neat Fuels versus Power for 2004 Cummins ISM 370 


\subsection{Summary of FTP Emissions Data for 1991 DDC S60}

Table 8-13 Summary of CP 0.05 Cert Neat 1 Fuel for 1991 DDC S60

\begin{tabular}{|c|c|c|c|c|c|c|c|c|c|c|c|c|}
\hline \multicolumn{4}{|c|}{ Fuel: CP 0.05 Cert Neat } & \multirow{2}{*}{$\begin{array}{l}\text { Work } \\
\text { bhp-hr }\end{array}$} & \multirow{2}{*}{$\begin{array}{c}\text { Fuel Cons } \\
\text { lb }\end{array}$} & \multirow{2}{*}{$\begin{array}{c}\text { bsFC } \\
\text { lb/bhp-hr }\end{array}$} & \multirow{2}{*}{$\begin{array}{l}\text { bsTHC } \\
\text { g/bhp-hr }\end{array}$} & \multirow{2}{*}{$\begin{array}{c}\text { bsCO } \\
\text { g/bhp-hr }\end{array}$} & \multirow{2}{*}{$\begin{array}{l}\text { bsCO2 } \\
\text { g/bhp-hr }\end{array}$} & \multirow{2}{*}{$\begin{array}{l}\text { bsNOx } \\
\text { g/bhp-hr }\end{array}$} & \multirow{2}{*}{$\begin{array}{l}\text { bsNOx2 } \\
\text { g/bhp-hr }\end{array}$} & \multirow{2}{*}{$\begin{array}{l}\text { bsTPM } \\
\text { g/bhp-hr }\end{array}$} \\
\hline Date & Time & Test No. & Start Type & & & & & & & & & \\
\hline $1 / 17 / 07$ & $18: 31$ & E01673-01 & Warm & 22.81 & 8.621 & 0.3779 & 0.0596 & 2.503 & 536.5 & 4.605 & 4.588 & 0.1339 \\
\hline $1 / 17 / 07$ & 19:11 & E01673-02 & Hot & 22.78 & 8.644 & 0.3794 & 0.0649 & 2.514 & 539.4 & 4.621 & 4.600 & 0.1361 \\
\hline $1 / 17 / 07$ & 19:51 & E01673-03 & Hot & 22.81 & 8.627 & 0.3782 & 0.0600 & 2.437 & 537.4 & 4.596 & 4.577 & 0.1329 \\
\hline $1 / 17 / 07$ & $20: 31$ & E01673-04 & Hot & 22.82 & 8.633 & 0.3783 & 0.0611 & 2.407 & 537.6 & 4.620 & 4.586 & 0.1307 \\
\hline \multirow{3}{*}{\multicolumn{4}{|c|}{$\begin{array}{r}\text { Hot Start Average } \\
\text { Hot Start Std Dev } \\
\text { COV }(\%)\end{array}$}} & 22.80 & 8.635 & 0.3786 & 0.0620 & 2.453 & 538.1 & 4.612 & 4.588 & 0.1332 \\
\hline & & & & 0.02 & 0.009 & 0.0007 & 0.0026 & 0.055 & 1.1 & 0.014 & 0.012 & 0.0027 \\
\hline & & & & 0.09 & 0.10 & 0.18 & 4.15 & 2.25 & 0.21 & 0.31 & 0.25 & 2.02 \\
\hline
\end{tabular}

Comments: Throttle 3

Table 8-14 Summary of CP 0.05 Cert 12-ml ODA Fuel for 1991 DDC S60

\begin{tabular}{|c|c|c|c|c|c|c|c|c|c|c|c|c|}
\hline \multicolumn{4}{|c|}{ Fuel: CP 0.05 Cert 12-ml ODA } & Work & Fuel Cons & bsFC & bsTHC & bsCO & bsCO2 & bsNOx & bsNOx2 & bsTPM \\
\hline Date & Time & Test No. & Start Type & bhp-hr & $\mathrm{lb}$ & lb/bhp-hr & g/bhp-hr & g/bhp-hr & g/bhp-hr & g/bhp-hr & g/bhp-hr & g/bhp-hr \\
\hline $1 / 18 / 07$ & $7: 27$ & E01676-01 & Warm & 22.79 & 8.786 & 0.3856 & 0.0618 & 2.524 & 542.7 & 4.608 & 4.598 & 0.2155 \\
\hline $1 / 18 / 07$ & 8:07 & E01676-02 & Hot & 22.79 & 8.659 & 0.3799 & 0.0562 & 2.341 & 535.8 & 4.568 & 4.562 & 0.1305 \\
\hline $1 / 18 / 07$ & $8: 48$ & E01676-03 & Hot & 22.80 & 8.641 & 0.3789 & 0.0559 & 2.341 & 534.8 & 4.550 & 4.548 & 0.1290 \\
\hline $1 / 18 / 07$ & 9:28 & E01676-04 & Hot & 22.80 & 8.631 & 0.3785 & 0.0571 & 2.370 & 534.9 & 4.563 & 4.541 & 0.1310 \\
\hline \multirow{3}{*}{\multicolumn{4}{|c|}{$\begin{array}{r}\text { Hot Start Average } \\
\text { Hot Start Std Dev } \\
\text { COV (\%) }\end{array}$}} & 22.80 & 8.644 & 0.3791 & 0.0564 & 2.351 & 535.2 & 4.560 & 4.550 & 0.130 \\
\hline & & & & 0.01 & 0.014 & 0.0007 & 0.0006 & 0.017 & 0.6 & 0.009 & 0.011 & 0.001 \\
\hline & & & & 0.03 & 0.16 & 0.19 & 1.11 & 0.71 & 0.10 & 0.20 & 0.23 & 0.79 \\
\hline
\end{tabular}

Comments: Throttle 3 
Table 8-15 Summary of Grad REF Neat Fuel for 1991 DDC S60

\begin{tabular}{|c|c|c|c|c|c|c|c|c|c|c|c|c|}
\hline \multicolumn{4}{|c|}{ Fuel: Grad REF Neat } & \multirow{2}{*}{$\begin{array}{l}\text { Work } \\
\text { bhp-hr }\end{array}$} & \multirow{2}{*}{\begin{tabular}{|c} 
Fuel Cons \\
$\mathrm{lb}$ \\
\end{tabular}} & \multirow{2}{*}{$\begin{array}{c}\text { bsFC } \\
\text { lb/bhp-hr }\end{array}$} & \multirow{2}{*}{$\begin{array}{l}\text { bsTHC } \\
\text { g/bhp-hr }\end{array}$} & \multirow{2}{*}{$\begin{array}{c}\text { bsCO } \\
\text { g/bhp-hr }\end{array}$} & \multirow{2}{*}{$\begin{array}{l}\text { bsCO2 } \\
\text { g/bhp-hr }\end{array}$} & \multirow{2}{*}{$\begin{array}{c}\text { bsNOx } \\
\text { g/bhp-hr }\end{array}$} & \multirow{2}{*}{$\begin{array}{l}\text { bsNOx2 } \\
\text { g/bhp-hr }\end{array}$} & \multirow{2}{*}{$\begin{array}{c}\text { bsTPM } \\
\text { g/bhp-hr }\end{array}$} \\
\hline Date & Time & Test No. & Start Type & & & & & & & & & \\
\hline $1 / 18 / 07$ & $13: 56$ & E01680-01 & Warm & 22.56 & 8.519 & 0.3775 & 0.0563 & 2.437 & 529.2 & 4.181 & 4.144 & 0.1287 \\
\hline $1 / 18 / 07$ & $14: 36$ & E01680-02 & Hot & 22.55 & 8.512 & 0.3774 & 0.0581 & 2.439 & 529.3 & 4.224 & 4.189 & 0.1313 \\
\hline $1 / 18 / 07$ & $15: 17$ & E01680-03 & Hot & 22.60 & 8.516 & 0.3768 & 0.0609 & 2.440 & 528.8 & 4.211 & 4.182 & 0.1307 \\
\hline $1 / 18 / 07$ & $15: 57$ & E01680-04 & Hot & 22.57 & 8.514 & 0.3771 & 0.0575 & 2.480 & 528.5 & 4.212 & 4.180 & 0.1335 \\
\hline \multirow{3}{*}{\multicolumn{4}{|c|}{$\begin{array}{r}\text { Hot Start Average } \\
\text { Hot Start Std Dev } \\
\text { COV (\%) }\end{array}$}} & 22.57 & 8.514 & 0.3771 & 0.0588 & 2.453 & 528.8 & 4.216 & 4.184 & 0.1318 \\
\hline & & & & 0.03 & 0.002 & 0.0003 & 0.0018 & 0.023 & 0.4 & 0.007 & 0.005 & 0.0015 \\
\hline & & & & 0.11 & 0.02 & 0.08 & 3.08 & 0.95 & 0.07 & 0.17 & 0.11 & 1.14 \\
\hline
\end{tabular}

Comments: Throttle 3

Table 8-16 Summary of Grad CAND Neat Fuel for 1991 DDC S60

\begin{tabular}{|c|c|c|c|c|c|c|c|c|c|c|c|c|}
\hline \multicolumn{4}{|c|}{ Fuel: Grad CAND Neat } & \multirow{2}{*}{$\begin{array}{l}\text { Work } \\
\text { bhp-hr }\end{array}$} & \multirow{2}{*}{$\begin{array}{c}\text { Fuel Cons } \\
\text { lb } \\
\end{array}$} & \multirow{2}{*}{$\begin{array}{c}\text { bsFC } \\
\text { lb/bhp-hr }\end{array}$} & \multirow{2}{*}{$\begin{array}{l}\text { bsTHC } \\
\text { g/bhp-hr }\end{array}$} & \multirow{2}{*}{$\begin{array}{c}\text { bsCO } \\
\text { g/bhp-hr }\end{array}$} & \multirow{2}{*}{$\begin{array}{l}\text { bsCO2 } \\
\text { g/bhp-hr }\end{array}$} & \multirow{2}{*}{$\begin{array}{l}\text { bsNOx } \\
\text { g/bhp-hr }\end{array}$} & \multirow{2}{*}{$\begin{array}{l}\text { bsNOx2 } \\
\text { g/bhp-hr }\end{array}$} & \multirow{2}{*}{$\begin{array}{l}\text { bsTPM } \\
\text { g/bhp-hr }\end{array}$} \\
\hline Date & Time & Test No. & Start Type & & & & & & & & & \\
\hline $1 / 19 / 07$ & $6: 39$ & E01684-01 & Warm & 22.58 & 8.661 & 0.3836 & 0.0662 & 2.550 & 541.3 & 4.496 & 4.493 & 0.1308 \\
\hline $1 / 19 / 07$ & $7: 19$ & E01684-02 & Hot & 22.57 & 8.588 & 0.3804 & 0.0622 & 2.381 & 538.4 & 4.457 & 4.445 & 0.1288 \\
\hline $1 / 19 / 07$ & $7: 59$ & E01684-03 & Hot & 22.55 & 8.581 & 0.3805 & 0.0594 & 2.374 & 534.6 & 4.478 & 4.465 & 0.1271 \\
\hline $1 / 19 / 07$ & $8: 39$ & E01684-04 & Hot & 22.55 & 8.570 & 0.3801 & 0.0606 & 2.356 & 537.0 & 4.455 & 4.458 & 0.1273 \\
\hline \multirow{3}{*}{\multicolumn{4}{|c|}{$\begin{array}{r}\text { Hot Start Average } \\
\text { Hot Start Std Dev } \\
\text { COV (\%) }\end{array}$}} & 22.56 & 8.580 & 0.3803 & 0.0607 & 2.370 & 536.7 & 4.463 & 4.456 & 0.1277 \\
\hline & & & & 0.01 & 0.009 & 0.0002 & 0.0014 & 0.013 & 1.9 & 0.013 & 0.010 & 0.0010 \\
\hline & & & & 0.05 & 0.11 & 0.05 & 2.31 & 0.54 & 0.36 & 0.29 & 0.23 & 0.75 \\
\hline
\end{tabular}


Table 8-17 Summary of Grad CAND 12-ml ODA Fuel for 1991 DDC S60

\begin{tabular}{|c|c|c|c|c|c|c|c|c|c|c|c|c|}
\hline \multicolumn{4}{|c|}{ Fuel: Grad CAND 12-ml ODA } & \multirow{2}{*}{$\begin{array}{l}\text { Work } \\
\text { bhp-hr }\end{array}$} & \multirow{2}{*}{\begin{tabular}{|c} 
Fuel Cons \\
$\mathrm{lb}$ \\
\end{tabular}} & \multirow{2}{*}{$\begin{array}{c}\text { bsFC } \\
\text { lb/bhp-hr }\end{array}$} & \multirow{2}{*}{$\begin{array}{l}\text { bsTHC } \\
\text { g/bhp-hr }\end{array}$} & \multirow{2}{*}{$\begin{array}{c}\text { bsCO } \\
\text { g/bhp-hr }\end{array}$} & \multirow{2}{*}{$\begin{array}{l}\text { bsCO2 } \\
\text { g/bhp-hr }\end{array}$} & \multirow{2}{*}{$\begin{array}{c}\text { bsNOx } \\
\text { g/bhp-hr }\end{array}$} & \multirow{2}{*}{$\begin{array}{l}\text { bsNOx2 } \\
\text { g/bhp-hr }\end{array}$} & \multirow{2}{*}{$\begin{array}{l}\text { bsTPM } \\
\text { g/bhp-hr }\end{array}$} \\
\hline Date & Time & Test No. & Start Type & & & & & & & & & \\
\hline $1 / 19 / 07$ & $13: 43$ & E01688-01 & Warm & 22.56 & 8.605 & 0.3814 & 0.0596 & 2.341 & 537.0 & 4.429 & 4.417 & 0.1174 \\
\hline $1 / 19 / 07$ & $14: 23$ & E01688-02 & Hot & 22.57 & 8.582 & 0.3803 & 0.0582 & 2.319 & 535.4 & 4.401 & 4.376 & 0.1267 \\
\hline $1 / 19 / 07$ & $15: 03$ & E01688-03 & Hot & 22.56 & 8.573 & 0.3800 & 0.0575 & 2.267 & 546.6 & 4.396 & 4.365 & 0.1244 \\
\hline $1 / 19 / 07$ & $15: 43$ & E01688-04 & Hot & 22.56 & 8.572 & 0.3801 & 0.0589 & 2.260 & 537.7 & 4.426 & 4.393 & 0.1232 \\
\hline \multirow{3}{*}{\multicolumn{4}{|c|}{$\begin{array}{r}\text { Hot Start Average } \\
\text { Hot Start Std Dev } \\
\text { COV (\%) }\end{array}$}} & 22.56 & 8.576 & 0.3801 & 0.0582 & 2.282 & 539.9 & 4.408 & 4.378 & 0.1248 \\
\hline & & & & 0.01 & 0.006 & 0.0002 & 0.0007 & 0.032 & 5.9 & 0.016 & 0.014 & 0.0018 \\
\hline & & & & 0.03 & 0.06 & 0.04 & 1.20 & 1.41 & 1.09 & 0.36 & 0.32 & 1.42 \\
\hline
\end{tabular}

Comments: Throttle 3,Run -02: CO2 post test span: 0.981. Run -03: CO2 post test span: 1.018.

Table 8-18 Summary of Grad CAND 16-ml ODA 2x Fuel for 1991 DDC S60

\begin{tabular}{|c|c|c|c|c|c|c|c|c|c|c|c|c|}
\hline \multicolumn{4}{|c|}{ Fuel: Grad CAND 16-ml ODA 2x } & \multirow{2}{*}{$\begin{array}{l}\text { Work } \\
\text { bhp-hr }\end{array}$} & \multirow{2}{*}{$\begin{array}{c}\text { Fuel Cons } \\
\text { lb } \\
\end{array}$} & \multirow{2}{*}{$\begin{array}{c}\text { bsFC } \\
\text { lb/bhp-hr }\end{array}$} & \multirow{2}{*}{$\begin{array}{l}\text { bsTHC } \\
\text { g/bhp-hr }\end{array}$} & \multirow{2}{*}{$\begin{array}{c}\text { bsCO } \\
\text { g/bhp-hr }\end{array}$} & \multirow{2}{*}{$\begin{array}{c}\text { bsCO2 } \\
\text { g/bhp-hr }\end{array}$} & \multirow{2}{*}{$\begin{array}{c}\text { bsNOx } \\
\text { g/bhp-hr }\end{array}$} & \multirow{2}{*}{$\begin{array}{l}\text { bsNOx2 } \\
\text { g/bhp-hr }\end{array}$} & \multirow{2}{*}{$\begin{array}{l}\text { bsTPM } \\
\text { g/bhp-hr }\end{array}$} \\
\hline Date & Time & \begin{tabular}{|l|} 
Test No. \\
\end{tabular} & Start Type & & & & & & & & & \\
\hline $1 / 20 / 07$ & $7: 28$ & E01692-01 & Warm & 22.59 & 8.604 & 0.3809 & 0.0612 & 2.292 & 533.9 & 4.371 & 4.329 & -0.0023 \\
\hline $1 / 20 / 07$ & $8: 09$ & E01692-02 & Hot & 22.56 & 8.579 & 0.3802 & 0.0595 & 2.239 & 533.9 & 4.399 & 4.345 & 0.1252 \\
\hline $1 / 20 / 07$ & $8: 49$ & E01692-03 & Hot & 22.58 & 8.580 & 0.3799 & 0.0626 & 2.216 & 532.4 & 4.403 & 4.365 & 0.1232 \\
\hline $1 / 20 / 07$ & $9: 29$ & E01692-04 & Hot & 22.58 & 8.572 & 0.3797 & 0.0590 & 2.245 & 532.1 & 4.405 & 4.364 & 0.1224 \\
\hline \multirow{3}{*}{\multicolumn{4}{|c|}{$\begin{array}{r}\text { Hot Start Average } \\
\text { Hot Start Std Dev } \\
\text { COV (\%) }\end{array}$}} & 22.57 & 8.577 & 0.3799 & 0.0604 & 2.233 & 532.8 & 4.402 & 4.358 & 0.1236 \\
\hline & & & & 0.01 & 0.004 & 0.0003 & 0.0020 & 0.015 & 1.0 & 0.003 & 0.011 & 0.0015 \\
\hline & & & & 0.05 & 0.05 & 0.07 & 3.23 & 0.69 & 0.18 & 0.07 & 0.26 & 1.20 \\
\hline
\end{tabular}


Table 8-19 Summary of Grad CAND 8-ml 2-EHN Fuel for 1991 DDC S60

\begin{tabular}{|c|c|c|c|c|c|c|c|c|c|c|c|c|}
\hline \multicolumn{4}{|c|}{ Fuel: Grad CAND 8-ml 2-EHN } & \multirow{2}{*}{$\begin{array}{l}\text { Work } \\
\text { bhp-hr }\end{array}$} & \multirow{2}{*}{\begin{tabular}{|c} 
Fuel Cons \\
$\mathrm{lb}$ \\
\end{tabular}} & \multirow{2}{*}{$\begin{array}{c}\text { bsFC } \\
\text { lb/bhp-hr }\end{array}$} & \multirow{2}{*}{$\begin{array}{l}\text { bsTHC } \\
\text { g/bhp-hr }\end{array}$} & \multirow{2}{*}{$\begin{array}{c}\text { bsCO } \\
\text { g/bhp-hr }\end{array}$} & \multirow{2}{*}{$\begin{array}{l}\text { bsCO2 } \\
\text { g/bhp-hr }\end{array}$} & \multirow{2}{*}{$\begin{array}{c}\text { bsNOx } \\
\text { g/bhp-hr }\end{array}$} & \multirow{2}{*}{$\begin{array}{l}\text { bsNOx2 } \\
\text { g/bhp-hr }\end{array}$} & \multirow{2}{*}{$\begin{array}{c}\text { bsTPM } \\
\text { g/bhp-hr }\end{array}$} \\
\hline Date & Time & Test No. & Start Type & & & & & & & & & \\
\hline $1 / 20 / 07$ & $11: 14$ & E01694-01 & Warm & 22.57 & 8.587 & 0.3804 & 0.0624 & 2.351 & 532.0 & 4.396 & 4.374 & 0.1255 \\
\hline $1 / 20 / 07$ & $11: 54$ & E01694-02 & Hot & 22.58 & 8.582 & 0.3801 & 0.0610 & 2.246 & 531.4 & 4.412 & 4.386 & 0.1243 \\
\hline $1 / 20 / 07$ & $12: 34$ & E01694-03 & Hot & 22.57 & 8.571 & 0.3798 & 0.0596 & 2.245 & 532.3 & 4.432 & 4.411 & 0.0000 \\
\hline $1 / 20 / 07$ & $13: 14$ & E01694-04 & Hot & 22.56 & 8.594 & 0.3810 & 0.0602 & 2.264 & 531.4 & 4.425 & 4.378 & 0.1256 \\
\hline \multirow{3}{*}{\multicolumn{4}{|c|}{$\begin{array}{r}\text { Hot Start Average } \\
\text { Hot Start Std Dev } \\
\text { COV (\%) }\end{array}$}} & 22.57 & 8.582 & 0.3803 & 0.0603 & 2.252 & 531.7 & 4.423 & 4.392 & 0.0833 \\
\hline & & & & 0.01 & 0.012 & 0.0006 & 0.0007 & 0.011 & 0.5 & 0.010 & 0.017 & 0.0721 \\
\hline & & & & 0.04 & 0.13 & 0.16 & 1.17 & 0.47 & 0.09 & 0.23 & 0.39 & 86.61 \\
\hline
\end{tabular}

Comments: Throttle 3

Table 8-20 Summary of Grad CAND 10-ml DTBP Fuel for 1991 DDC S60

\begin{tabular}{|c|c|c|c|c|c|c|c|c|c|c|c|c|}
\hline \multicolumn{4}{|c|}{ Fuel: Grad CAND 10-ml DTBP } & \multirow{2}{*}{$\begin{array}{l}\text { Work } \\
\text { bhp-hr }\end{array}$} & \multirow{2}{*}{$\begin{array}{c}\text { Fuel Cons } \\
\mathrm{lb} \\
\end{array}$} & \multirow{2}{*}{$\begin{array}{c}\text { bsFC } \\
\text { lb/bhp-hr }\end{array}$} & \multirow{2}{*}{$\begin{array}{l}\text { bsTHC } \\
\text { g/bhp-hr }\end{array}$} & \multirow{2}{*}{$\begin{array}{c}\text { bsCO } \\
\text { g/bhp-hr }\end{array}$} & \multirow{2}{*}{$\begin{array}{c}\text { bsCO2 } \\
\text { g/bhp-hr }\end{array}$} & \multirow{2}{*}{$\begin{array}{c}\text { bsNOx } \\
\text { g/bhp-hr }\end{array}$} & \multirow{2}{*}{$\begin{array}{l}\text { bsNOx2 } \\
\text { g/bhp-hr }\end{array}$} & \multirow{2}{*}{$\begin{array}{l}\text { bsTPM } \\
\text { g/bhp-hr }\end{array}$} \\
\hline Date & Time & Test No. & Start Type & & & & & & & & & \\
\hline $1 / 20 / 07$ & $14: 55$ & E01696-01 & Warm & 22.59 & 8.573 & 0.3795 & 0.0640 & 2.291 & 531.4 & 4.389 & 4.358 & 0.1210 \\
\hline $1 / 20 / 07$ & $15: 35$ & E01696-02 & Hot & 22.58 & 8.573 & 0.3798 & 0.0604 & 2.279 & 532.7 & 4.412 & 4.366 & 0.1219 \\
\hline $1 / 20 / 07$ & $16: 15$ & E01696-03 & Hot & 22.56 & 8.578 & 0.3802 & 0.0583 & 2.251 & 533.6 & 4.429 & 4.401 & 0.1196 \\
\hline $1 / 20 / 07$ & $16: 56$ & E01696-04 & Hot & 22.56 & 8.670 & 0.3843 & 0.0579 & 2.280 & 535.3 & 4.411 & 4.397 & 0.1224 \\
\hline \multirow{3}{*}{\multicolumn{4}{|c|}{$\begin{array}{r}\text { Hot Start Average } \\
\text { Hot Start Std Dev } \\
\text { COV (\%) }\end{array}$}} & 22.57 & 8.599 & 0.3810 & 0.0602 & 2.275 & 533.3 & 4.410 & 4.381 & 0.1213 \\
\hline & & & & 0.02 & 0.048 & 0.0023 & 0.0028 & 0.017 & 1.6 & 0.016 & 0.022 & 0.0012 \\
\hline & & & & 0.07 & 0.56 & 0.59 & 4.64 & 0.75 & 0.30 & 0.37 & 0.49 & 1.01 \\
\hline
\end{tabular}


Table 8-21 Summary of CP 0.05 Cert Neat 2 Fuel for 1991 DDC S60

\begin{tabular}{|c|c|c|c|c|c|c|c|c|c|c|c|c|}
\hline \multicolumn{4}{|c|}{ Fuel: CP 0.05 Cert Neat } & \multirow{2}{*}{$\begin{array}{l}\text { Work } \\
\text { bhp-hr }\end{array}$} & \multirow{2}{*}{$\begin{array}{c}\text { Fuel Cons } \\
\text { lb } \\
\end{array}$} & \multirow{2}{*}{$\begin{array}{c}\text { bsFC } \\
\text { lb/bhp-hr }\end{array}$} & \multirow{2}{*}{$\begin{array}{l}\text { bsTHC } \\
\text { g/bhp-hr }\end{array}$} & \multirow{2}{*}{$\begin{array}{c}\text { bsCO } \\
\text { g/bhp-hr }\end{array}$} & \multirow{2}{*}{$\begin{array}{c}\text { bsCO2 } \\
\text { g/bhp-hr }\end{array}$} & \multirow{2}{*}{$\begin{array}{l}\text { bsNOx } \\
\text { g/bhp-hr }\end{array}$} & \multirow{2}{*}{$\begin{array}{l}\text { bsNOx2 } \\
\text { g/bhp-hr }\end{array}$} & \multirow{2}{*}{$\begin{array}{c}\text { bsTPM } \\
\text { g/bhp-hr }\end{array}$} \\
\hline Date & Time & Test No. & Start Type & & & & & & & & & \\
\hline $1 / 21 / 07$ & $7: 31$ & E01699-01 & Warm & 22.78 & 8.687 & 0.3813 & 0.0582 & 2.572 & 532.0 & 4.582 & 4.538 & 0.1395 \\
\hline $1 / 21 / 07$ & $8: 11$ & E01699-02 & Hot & 22.80 & 8.653 & 0.3796 & 0.0597 & 2.542 & 533.8 & 4.617 & 4.584 & 0.1382 \\
\hline $1 / 21 / 07$ & $8: 51$ & E01699-03 & Hot & 22.80 & 8.643 & 0.3791 & 0.0615 & 2.575 & 534.3 & 4.610 & 4.590 & 0.1374 \\
\hline $1 / 21 / 07$ & $9: 31$ & E01699-04 & Hot & 22.80 & 8.663 & 0.3800 & 0.0561 & 2.579 & 533.1 & 4.647 & 4.626 & 0.1354 \\
\hline \multirow{3}{*}{\multicolumn{4}{|c|}{$\begin{array}{r}\text { Hot Start Average } \\
\text { Hot Start Std Dev } \\
\text { COV (\%) }\end{array}$}} & 22.80 & 8.653 & 0.3796 & 0.0591 & 2.565 & 533.7 & 4.625 & 4.600 & 0.1370 \\
\hline & & & & 0.00 & 0.010 & 0.0005 & 0.0027 & 0.020 & 0.6 & 0.020 & 0.023 & 0.0015 \\
\hline & & & & 0.00 & 0.12 & 0.12 & 4.65 & 0.79 & 0.11 & 0.43 & 0.49 & 1.08 \\
\hline
\end{tabular}

Comments: Throttle 3

\subsection{Summary of FTP Emissions Data for 1992 DDC S60}

Table 8-22 Summary of CP 0.05 Cert Neat Fuel for 1992 DDC S60

\begin{tabular}{|c|c|c|c|c|c|c|c|c|c|c|c|c|}
\hline \multicolumn{4}{|c|}{ Fuel: CP 0.05 Cert } & \multirow{2}{*}{$\begin{array}{l}\text { Work } \\
\text { bhp-hr }\end{array}$} & \multirow{2}{*}{$\begin{array}{c}\text { Fuel Cons } \\
\text { lb } \\
\end{array}$} & \multirow{2}{*}{$\begin{array}{c}\text { bsFC } \\
\text { lb/bhp-hr }\end{array}$} & \multirow{2}{*}{$\begin{array}{l}\text { bsTHC } \\
\text { g/bhp-hr }\end{array}$} & \multirow{2}{*}{$\begin{array}{c}\text { bsCO } \\
\text { g/bhp-hr }\end{array}$} & \multirow{2}{*}{$\begin{array}{l}\text { bsCO2 } \\
\text { g/bhp-hr }\end{array}$} & \multirow{2}{*}{$\begin{array}{l}\text { bsNOx } \\
\text { g/bhp-hr }\end{array}$} & \multirow{2}{*}{$\begin{array}{l}\text { bsNOx2 } \\
\text { g/bhp-hr }\end{array}$} & \multirow{2}{*}{$\begin{array}{l}\text { bsTPM } \\
\text { g/bhp-hr }\end{array}$} \\
\hline Date & Time & Test No. & Start Type & & & & & & & & & \\
\hline $1 / 24 / 07$ & $17: 25$ & E01703-05 & Hot & 24.83 & 9.473 & 0.3815 & 0.1271 & 3.243 & 536.2 & 5.222 & 5.239 & 0.2478 \\
\hline $1 / 24 / 07$ & 18:05 & E01703-06 & Hot & 24.83 & 9.450 & 0.3806 & 0.1298 & 3.259 & 535.2 & 5.217 & 5.214 & 0.2491 \\
\hline $1 / 24 / 07$ & $18: 45$ & E01703-07 & Hot & 24.83 & 9.471 & 0.3815 & 0.1360 & 3.298 & 536.1 & 5.224 & 5.200 & 0.2575 \\
\hline \multirow{3}{*}{\multicolumn{4}{|c|}{$\begin{array}{r}\text { Hot Start Average } \\
\text { Hot Start Std Dev } \\
\text { COV (\%) }\end{array}$}} & 24.83 & 9.46 & 0.3812 & 0.1310 & 3.267 & 535.8 & 5.221 & 5.218 & 0.2515 \\
\hline & & & & 0.00 & 0.01 & 0.0005 & 0.00 & 0.028 & 0.6 & 0.00 & 0.02 & 0.0052 \\
\hline & & & & 0.00 & 0.13 & 0.14 & 3.48 & 0.87 & 0.10 & 0.07 & 0.38 & 2.08 \\
\hline
\end{tabular}

Comments: run -01 through -04 ran with air compressor engaged, Throttle 3 
Table 8-23 Summary of CP 0.05 Cert 12-ml ODA Fuel for 1992 DDC S60

\begin{tabular}{|c|c|c|c|c|c|c|c|c|c|c|c|c|}
\hline \multicolumn{4}{|c|}{ Fuel: CP 0.05 Cert 12-ml ODA } & \multirow{2}{*}{$\begin{array}{c}\text { Work } \\
\text { bhp-hr }\end{array}$} & \multirow{2}{*}{$\begin{array}{c}\text { Fuel Cons } \\
\text { lb }\end{array}$} & \multirow{2}{*}{$\begin{array}{c}\text { bsFC } \\
\text { lb/bhp-hr }\end{array}$} & \multirow{2}{*}{$\begin{array}{l}\text { bsTHC } \\
\text { g/bhp-hr }\end{array}$} & \multirow{2}{*}{$\begin{array}{c}\text { bsCO } \\
\text { g/bhp-hr }\end{array}$} & \multirow{2}{*}{$\begin{array}{l}\text { bsCO2 } \\
\text { g/bhp-hr }\end{array}$} & \multirow{2}{*}{$\begin{array}{l}\text { bsNOx } \\
\text { g/bhp-hr }\end{array}$} & \multirow{2}{*}{$\begin{array}{l}\text { bsNOx2 } \\
\text { g/bhp-hr }\end{array}$} & \multirow{2}{*}{$\begin{array}{l}\text { bsTPM } \\
\text { g/bhp-hr }\end{array}$} \\
\hline Date & Time & Test No. & Start Type & & & & & & & & & \\
\hline $1 / 25 / 07$ & $8: 46$ & E01707-01 & Warm & 24.85 & 9.498 & 0.3823 & 0.0929 & 3.066 & 534.3 & 5.068 & 5.052 & 0.2810 \\
\hline $1 / 25 / 07$ & $9: 27$ & E01707-02 & Hot & 24.84 & 9.472 & 0.3812 & 0.1013 & 3.009 & 530.5 & 5.074 & 5.050 & 0.2425 \\
\hline $1 / 25 / 07$ & $10: 07$ & E01707-03 & Hot & 24.85 & 9.620 & 0.3871 & 0.0943 & 3.002 & 527.1 & 5.060 & 5.029 & 0.2335 \\
\hline $1 / 25 / 07$ & $10: 47$ & E01707-04 & Hot & 24.83 & 9.464 & 0.3812 & 0.1004 & 3.008 & 526.9 & 5.073 & 5.051 & 0.2354 \\
\hline \multirow{3}{*}{\multicolumn{4}{|c|}{$\begin{array}{r}\text { Hot Start Average } \\
\text { Hot Start Std Dev } \\
\text { COV (\%) }\end{array}$}} & 24.84 & 9.519 & 0.3832 & 0.0987 & 3.006 & 528.2 & 5.069 & 5.043 & 0.2371 \\
\hline & & & & 0.01 & 0.088 & 0.0034 & 0.0038 & 0.004 & 2.0 & 0.008 & 0.012 & 0.0048 \\
\hline & & & & 0.04 & 0.92 & 0.89 & 3.86 & 0.13 & 0.39 & 0.15 & 0.25 & 2.00 \\
\hline
\end{tabular}

Comments: Throttle 3. Added fuel during soak period before run -03; may have affected fuel consumed.

Table 8-24 Summary of Grad REF Neat Fuel for 1992 DDC S60

\begin{tabular}{|c|c|c|c|c|c|c|c|c|c|c|c|c|}
\hline \multicolumn{4}{|c|}{ Fuel: Grad Ref Neat } & \multirow{2}{*}{$\begin{array}{l}\text { Work } \\
\text { bhp-hr }\end{array}$} & \multirow{2}{*}{$\begin{array}{c}\text { Fuel Cons } \\
\text { lb }\end{array}$} & \multirow{2}{*}{$\begin{array}{c}\text { bsFC } \\
\text { lb/bhp-hr }\end{array}$} & \multirow{2}{*}{$\begin{array}{l}\text { bsTHC } \\
\text { g/bhp-hr }\end{array}$} & \multirow{2}{*}{$\begin{array}{c}\text { bsCO } \\
\text { g/bhp-hr }\end{array}$} & \multirow{2}{*}{$\begin{array}{l}\text { bsCO2 } \\
\text { g/bhp-hr }\end{array}$} & \multirow{2}{*}{$\begin{array}{l}\text { bsNOx } \\
\text { g/bhp-hr }\end{array}$} & \multirow{2}{*}{$\begin{array}{l}\text { bsNOx2 } \\
\text { g/bhp-hr }\end{array}$} & \multirow{2}{*}{$\begin{array}{l}\text { bsTPM } \\
\text { g/bhp-hr }\end{array}$} \\
\hline Date & Time & Test No. & Start Type & & & & & & & & & \\
\hline $1 / 25 / 07$ & $14: 52$ & E01710-01 & Warm & 24.51 & 9.398 & 0.3834 & 0.0989 & 3.231 & 531.6 & 4.714 & 4.673 & 0.2390 \\
\hline $1 / 25 / 07$ & $15: 32$ & E01710-02 & Hot & 24.56 & 9.173 & 0.3736 & 0.0958 & 3.265 & 531.6 & 4.763 & 4.694 & 0.2372 \\
\hline $1 / 25 / 07$ & $16: 12$ & E01710-03 & Hot & 24.53 & 9.308 & 0.3794 & 0.0987 & 3.130 & 531.5 & 4.721 & 4.666 & 0.2329 \\
\hline $1 / 25 / 07$ & $16: 52$ & E01710-04 & Hot & 24.52 & 9.314 & 0.3798 & 0.0984 & 3.131 & 532.5 & 4.757 & 4.698 & 0.2290 \\
\hline \multirow{3}{*}{\multicolumn{4}{|c|}{$\begin{array}{r}\text { Hot Start Average } \\
\text { Hot Start Std Dev } \\
\text { COV (\%) }\end{array}$}} & 24.54 & 9.265 & 0.3776 & 0.0976 & 3.175 & 531.8 & 4.747 & 4.686 & 0.2310 \\
\hline & & & & 0.02 & 0.080 & 0.0035 & 0.0016 & 0.078 & 0.6 & 0.023 & 0.017 & 0.0028 \\
\hline & & & & 0.08 & 0.86 & 0.92 & 1.63 & 2.45 & 0.11 & 0.48 & 0.37 & 1.19 \\
\hline
\end{tabular}

Comments: Throttle 3 
Table 8-25 Summary of Grad CAND Neat Fuel for 1992 DDC S60

\begin{tabular}{|c|c|c|c|c|c|c|c|c|c|c|c|c|}
\hline \multicolumn{4}{|c|}{ Fuel: Grad Cand Neat } & \multirow{2}{*}{$\begin{array}{c}\text { Work } \\
\text { bhp-hr }\end{array}$} & \multirow{2}{*}{$\begin{array}{c}\text { Fuel Cons } \\
\text { lb }\end{array}$} & \multirow{2}{*}{$\begin{array}{c}\text { bsFC } \\
\text { lb/bhp-hr }\end{array}$} & \multirow{2}{*}{$\begin{array}{l}\text { bsTHC } \\
\text { g/bhp-hr }\end{array}$} & \multirow{2}{*}{$\begin{array}{c}\text { bsCO } \\
\text { g/bhp-hr }\end{array}$} & \multirow{2}{*}{$\begin{array}{l}\text { bsCO2 } \\
\text { g/bhp-hr }\end{array}$} & \multirow{2}{*}{$\begin{array}{l}\text { bsNOx } \\
\text { g/bhp-hr }\end{array}$} & \multirow{2}{*}{$\begin{array}{l}\text { bsNOx2 } \\
\text { g/bhp-hr }\end{array}$} & \multirow{2}{*}{$\begin{array}{l}\text { bsTPM } \\
\text { g/bhp-hr }\end{array}$} \\
\hline Date & Time & Test No. & Start Type & & & & & & & & & \\
\hline $1 / 26 / 07$ & $7: 43$ & E01713-01 & Warm & 24.50 & 9.564 & 0.3904 & 0.1252 & 3.366 & 543.4 & 5.092 & 5.048 & 0.2378 \\
\hline $1 / 26 / 07$ & $8: 23$ & E01713-02 & Hot & 24.54 & 9.426 & 0.3841 & 0.1360 & 3.224 & 539.1 & 5.080 & 5.029 & 0.2334 \\
\hline $1 / 26 / 07$ & 9:03 & E01713-03 & Hot & 24.53 & 9.388 & 0.3827 & 0.1277 & 3.200 & 537.6 & 5.064 & 5.012 & 0.2311 \\
\hline $1 / 26 / 07$ & $9: 43$ & E01713-04 & Hot & 24.52 & 9.386 & 0.3828 & 0.1345 & 3.160 & 538.2 & 5.095 & 5.054 & 0.2300 \\
\hline \multirow{3}{*}{\multicolumn{4}{|c|}{$\begin{array}{r}\text { Hot Start Average } \\
\text { Hot Start Std Dev } \\
\text { COV (\%) }\end{array}$}} & 24.53 & 9.400 & 0.3832 & 0.1327 & 3.195 & 538.3 & 5.080 & 5.032 & 0.2315 \\
\hline & & & & 0.01 & 0.023 & 0.0008 & 0.0044 & 0.032 & 0.7 & 0.016 & 0.021 & 0.0017 \\
\hline & & & & 0.04 & 0.24 & 0.20 & 3.33 & 1.01 & 0.14 & 0.31 & 0.42 & 0.75 \\
\hline
\end{tabular}

Comments: Throttle 3

$$
\operatorname{COV}(\%)
$$

Table 8-26 Summary of Grad CAND 12-ml ODA Fuel for 1992 DDC S60

\begin{tabular}{|c|c|c|c|c|c|c|c|c|c|c|c|c|}
\hline \multicolumn{4}{|c|}{ Fuel: Grad Cand 12-ml ODA } & \multirow{2}{*}{$\begin{array}{c}\text { Work } \\
\text { bhp-hr }\end{array}$} & \multirow{2}{*}{$\begin{array}{c}\text { Fuel Cons } \\
\text { lb } \\
\end{array}$} & \multirow{2}{*}{$\begin{array}{c}\text { bsFC } \\
\text { lb/bhp-hr }\end{array}$} & \multirow{2}{*}{$\begin{array}{l}\text { bsTHC } \\
\text { g/bhp-hr }\end{array}$} & \multirow{2}{*}{$\begin{array}{c}\text { bsCO } \\
\text { g/bhp-hr }\end{array}$} & \multirow{2}{*}{$\begin{array}{l}\text { bsCO2 } \\
\text { g/bhp-hr }\end{array}$} & \multirow{2}{*}{$\begin{array}{c}\text { bsNOx } \\
\text { g/bhp-hr }\end{array}$} & \multirow{2}{*}{$\begin{array}{l}\text { bsNOx2 } \\
\text { g/bhp-hr }\end{array}$} & \multirow{2}{*}{$\begin{array}{c}\text { bsTPM } \\
\text { g/bhp-hr }\end{array}$} \\
\hline Date & Time & \begin{tabular}{|l|} 
Test No. \\
\end{tabular} & Start Type & & & & & & & & & \\
\hline $1 / 26 / 07$ & $15: 42$ & E01716-03 & Warm & 24.50 & 9.370 & 0.3824 & 0.1245 & 3.136 & 545.4 & 5.036 & 4.980 & 0.2428 \\
\hline $1 / 26 / 07$ & $16: 22$ & E01716-04 & Hot & 24.54 & 9.391 & 0.3827 & 0.1176 & 3.011 & 538.6 & 4.992 & 4.968 & 0.2269 \\
\hline $1 / 26 / 07$ & $17: 02$ & E01716-05 & Hot & 24.54 & 9.379 & 0.3821 & 0.1207 & 3.030 & 539.1 & 4.947 & 4.928 & 0.2343 \\
\hline $1 / 26 / 07$ & $17: 43$ & E01716-0@ & Hot & 24.52 & 9.390 & 0.3830 & 0.1155 & 3.036 & 540.0 & 4.962 & 4.917 & 0.2386 \\
\hline \multirow{3}{*}{\multicolumn{4}{|c|}{$\begin{array}{r}\text { Hot Start Average } \\
\text { Hot Start Std Dev } \\
\text { COV (\%) }\end{array}$}} & 24.53 & 9.387 & 0.3826 & 0.1179 & 3.026 & 539.2 & 4.967 & 4.938 & 0.2333 \\
\hline & & & & 0.01 & 0.007 & 0.0005 & 0.0026 & 0.013 & 0.7 & 0.023 & 0.027 & 0.0059 \\
\hline & & & & 0.05 & 0.07 & 0.12 & 2.22 & 0.43 & 0.13 & 0.46 & 0.54 & 2.53 \\
\hline
\end{tabular}

Comments: Throttle 3

$$
\operatorname{COV}(\%)
$$


Table 8-27 Summary of Grad CAND 6-ml 2-EHN Fuel for 1992 DDC S60

\begin{tabular}{|c|c|c|c|c|c|c|c|c|c|c|c|c|}
\hline \multicolumn{4}{|c|}{ Fuel: Grad CAND 6-ml 2-EHN } & \multirow{2}{*}{$\begin{array}{c}\text { Work } \\
\text { bhp-hr }\end{array}$} & \multirow{2}{*}{$\begin{array}{c}\text { Fuel Cons } \\
\text { lb }\end{array}$} & \multirow{2}{*}{$\begin{array}{c}\text { bsFC } \\
\text { lb/bhp-hr }\end{array}$} & \multirow{2}{*}{$\begin{array}{l}\text { bsTHC } \\
\text { g/bhp-hr }\end{array}$} & \multirow{2}{*}{$\begin{array}{c}\text { bsCO } \\
\text { g/bhp-hr }\end{array}$} & \multirow{2}{*}{$\begin{array}{l}\text { bsCO2 } \\
\text { g/bhp-hr }\end{array}$} & \multirow{2}{*}{$\begin{array}{l}\text { bsNOx } \\
\text { g/bhp-hr }\end{array}$} & \multirow{2}{*}{$\begin{array}{l}\text { bsNOx2 } \\
\text { g/bhp-hr }\end{array}$} & \multirow{2}{*}{$\begin{array}{l}\text { bsTPM } \\
\text { g/bhp-hr }\end{array}$} \\
\hline Date & Time & Test No. & Start Type & & & & & & & & & \\
\hline $1 / 27 / 07$ & $7: 17$ & E01721-01 & Warm & 24.49 & 9.363 & 0.3824 & 0.1185 & 3.289 & 544.3 & 4.868 & 4.884 & 0.2848 \\
\hline $1 / 27 / 07$ & $7: 57$ & E01721-02 & Hot & 24.49 & 9.387 & 0.3833 & 0.1178 & 3.112 & 540.4 & 4.910 & 4.872 & 0.2408 \\
\hline $1 / 27 / 07$ & $8: 37$ & E01721-03 & Hot & 24.49 & 9.381 & 0.3830 & 0.1172 & 3.036 & 539.6 & 4.920 & 4.892 & 0.2335 \\
\hline $1 / 27 / 07$ & 9:17 & E01721-04 & Hot & 24.49 & 9.374 & 0.3828 & 0.1116 & 3.044 & 538.9 & 4.881 & 4.880 & 0.2307 \\
\hline \multirow{3}{*}{\multicolumn{4}{|c|}{$\begin{array}{r}\text { Hot Start Average } \\
\text { Hot Start Std Dev } \\
\text { COV (\%) }\end{array}$}} & 24.49 & 9.381 & 0.3830 & 0.1155 & 3.064 & 539.6 & 4.904 & 4.881 & 0.2350 \\
\hline & & & & 0.00 & 0.007 & 0.0003 & 0.0034 & 0.042 & 0.8 & 0.020 & 0.010 & 0.0052 \\
\hline & & & & 0.00 & 0.07 & 0.07 & 2.96 & 1.36 & 0.14 & 0.41 & 0.21 & 2.21 \\
\hline
\end{tabular}

Comments: Throttle 3

$$
\operatorname{COV}(\%)
$$

Table 8-28 Summary of Grad REF 10-ml DTBP Fuel for 1992 DDC S60

\begin{tabular}{|c|c|c|c|c|c|c|c|c|c|c|c|c|}
\hline \multicolumn{4}{|c|}{ Fuel: Grad Ref 10-ml DTBP } & \multirow{2}{*}{$\begin{array}{l}\text { Work } \\
\text { bhp-hr }\end{array}$} & \multirow{2}{*}{$\begin{array}{c}\text { Fuel Cons } \\
\text { lb } \\
\end{array}$} & \multirow{2}{*}{$\begin{array}{c}\text { bsFC } \\
\text { lb/bhp-hr }\end{array}$} & \multirow{2}{*}{$\begin{array}{l}\text { bsTHC } \\
\text { g/bhp-hr }\end{array}$} & \multirow{2}{*}{$\begin{array}{c}\text { bsCO } \\
\text { g/bhp-hr }\end{array}$} & \multirow{2}{*}{$\begin{array}{c}\text { bsCO2 } \\
\text { g/bhp-hr }\end{array}$} & \multirow{2}{*}{$\begin{array}{l}\text { bsNOx } \\
\text { g/bhp-hr }\end{array}$} & \multirow{2}{*}{$\begin{array}{l}\text { bsNOx2 } \\
\text { g/bhp-hr }\end{array}$} & \multirow{2}{*}{$\begin{array}{c}\text { bsTPM } \\
\text { g/bhp-hr }\end{array}$} \\
\hline Date & Time & \begin{tabular}{|l|} 
Test No. \\
\end{tabular} & Start Type & & & & & & & & & \\
\hline $1 / 27 / 07$ & $11: 08$ & E01723-01 & Warm & 24.53 & 9.219 & 0.3758 & 0.1112 & 3.342 & 532.5 & 4.660 & 4.647 & 0.2471 \\
\hline $1 / 27 / 07$ & $11: 48$ & E01723-02 & Hot & 24.50 & 9.272 & 0.3784 & 0.1096 & 3.240 & 532.6 & 4.686 & 4.660 & 0.2388 \\
\hline $1 / 27 / 07$ & $12: 28$ & E01723-03 & Hot & 24.51 & 9.302 & 0.3796 & 0.1069 & 3.241 & 533.0 & 4.726 & 4.702 & 0.2352 \\
\hline $1 / 27 / 07$ & $13: 08$ & E01723-04 & Hot & 24.51 & 9.288 & 0.3789 & 0.1014 & 3.220 & 530.4 & 4.710 & 4.694 & 0.2310 \\
\hline \multirow{3}{*}{\multicolumn{4}{|c|}{$\begin{array}{r}\text { Hot Start Average } \\
\text { Hot Start Std Dev } \\
\text { COV (\%) }\end{array}$}} & 24.51 & 9.287 & 0.3790 & 0.1060 & 3.234 & 532.0 & 4.707 & 4.685 & 0.2350 \\
\hline & & & & 0.01 & 0.015 & 0.0006 & 0.0042 & 0.012 & 1.4 & 0.020 & 0.022 & 0.0039 \\
\hline & & & & 0.02 & 0.16 & 0.16 & 3.94 & 0.37 & 0.26 & 0.43 & 0.48 & 1.68 \\
\hline
\end{tabular}

Comments: Throttle 3 


\subsection{Summary of FTP Emissions Data for 1992 Rebuilt DDC S60}

Table 8-29 Summary of CP 0.05 Cert Neat Fuel for 1992 Rebuilt DDC S60

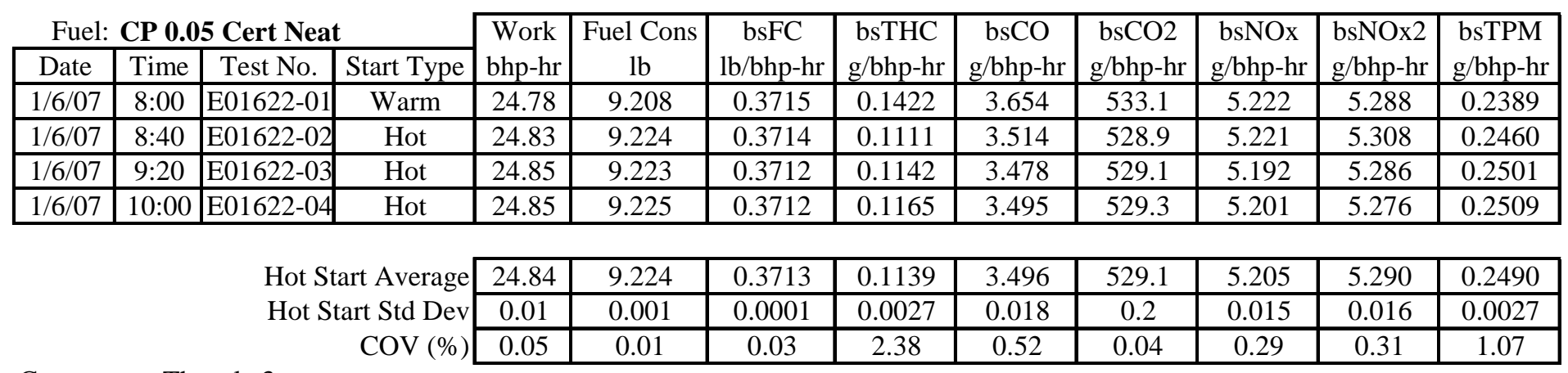

Comments: Throttle 3

Table 8-30 Summary of CP 0.05 Cert 12-ml ODA Fuel for 1992 Rebuilt DDC S60

\begin{tabular}{|c|c|c|c|c|c|c|c|c|c|c|c|c|}
\hline \multicolumn{4}{|c|}{ Fuel: CP 0.05 Cert 12-ml ODA } & \multirow{2}{*}{$\begin{array}{l}\text { Work } \\
\text { bhp-hr }\end{array}$} & \multirow{2}{*}{$\begin{array}{c}\text { Fuel Cons } \\
\mathrm{lb} \\
\end{array}$} & \multirow{2}{*}{$\begin{array}{c}\text { bsFC } \\
\text { lb/bhp-hr }\end{array}$} & \multirow{2}{*}{$\begin{array}{c}\text { bsTHC } \\
\text { g/bhp-hr }\end{array}$} & \multirow{2}{*}{$\begin{array}{c}\text { bsCO } \\
\text { g/bhp-hr }\end{array}$} & \multirow{2}{*}{$\begin{array}{c}\text { bsCO2 } \\
\text { g/bhp-hr }\end{array}$} & \multirow{2}{*}{$\begin{array}{c}\text { bsNOx } \\
\text { g/bhp-hr }\end{array}$} & \multirow{2}{*}{$\begin{array}{l}\text { bsNOx2 } \\
\text { g/bhp-hr }\end{array}$} & \multirow{2}{*}{$\begin{array}{c}\text { bsTPM } \\
\text { g/bhp-hr }\end{array}$} \\
\hline Date & Time & \begin{tabular}{|l|} 
Test No. \\
\end{tabular} & Start Type & & & & & & & & & \\
\hline $1 / 7 / 07$ & $7: 26$ & E01626-01 & Warm & 24.90 & 9.250 & 0.3715 & 0.1679 & 3.386 & 536.0 & 5.053 & 5.077 & 0.3287 \\
\hline $1 / 7 / 07$ & $8: 06$ & E01626-02 & Hot & 24.94 & 9.227 & 0.3699 & 069 & 3.162 & 9.9 & & 63 & 529 \\
\hline $1 / 7 / 07$ & $8: 46$ & E01626-03 & Hot & 24. & & & & & & & & 589 \\
\hline $1 / 7 / 07$ & 9:26 & E01626-04 & Hot & 24.94 & 9.248 & 0.3708 & 0.1052 & 3.196 & 528.3 & 5.027 & 5.074 & 0.2563 \\
\hline \multicolumn{4}{|c|}{$\begin{array}{r}\text { Hot Start Average } \\
\text { Hot Start Std Dev } \\
\text { COV (\%) }\end{array}$} & 0.02 & 0.11 & 0.12 & 1.08 & 0.58 & 0.34 & 0.13 & 0.17 & 1.18 \\
\hline
\end{tabular}

Comments: Throttle 3 
Table 8-31 Summary of Grad REF Neat Fuel for 1992 Rebuilt DDC S60

\begin{tabular}{|c|c|c|c|c|c|c|c|c|c|c|c|c|}
\hline \multicolumn{4}{|c|}{ Fuel: Grad REF Neat } & \multirow{2}{*}{$\begin{array}{l}\text { Work } \\
\text { bhp-hr }\end{array}$} & \multirow{2}{*}{$\begin{array}{c}\text { Fuel Cons } \\
\mathrm{lb} \\
\end{array}$} & \multirow{2}{*}{$\begin{array}{c}\text { bsFC } \\
\text { lb/bhp-hr }\end{array}$} & \multirow{2}{*}{$\begin{array}{l}\text { bsTHC } \\
\text { g/bhp-hr }\end{array}$} & \multirow{2}{*}{$\begin{array}{c}\text { bsCO } \\
\text { g/bhp-hr }\end{array}$} & \multirow{2}{*}{$\begin{array}{c}\text { bsCO2 } \\
\text { g/bhp-hr }\end{array}$} & \multirow{2}{*}{$\begin{array}{l}\text { bsNOx } \\
\text { g/bhp-hr }\end{array}$} & \multirow{2}{*}{$\begin{array}{l}\text { bsNOx2 } \\
\text { g/bhp-hr }\end{array}$} & \multirow{2}{*}{$\begin{array}{l}\text { bsTPM } \\
\text { g/bhp-hr }\end{array}$} \\
\hline Date & Time & Test No. & Start Type & & & & & & & & & \\
\hline $1 / 8 / 07$ & $8: 39$ & E01631-01 & Warm & 24.67 & 9.247 & 0.3748 & 0.1934 & 3.584 & 521.0 & 4.700 & 4.705 & 0.3541 \\
\hline $1 / 8 / 07$ & 9:19 & E01631-02 & Hot & 24.71 & 9.139 & 0.3699 & 0.1172 & 3.377 & 521.0 & 4.738 & 4.762 & 0.2547 \\
\hline $1 / 8 / 07$ & $10: 00$ & E01631-03 & Hot & 24.72 & 9.124 & 0.3691 & 0.1126 & 3.334 & 516.3 & 4.680 & 4.713 & 0.2503 \\
\hline $1 / 8 / 07$ & $10: 40$ & E01631-04 & Hot & 24.72 & 9.134 & 0.3696 & 0.1142 & 3.306 & 515.9 & 4.690 & 4.715 & 0.2503 \\
\hline $1 / 8 / 07$ & $11: 20$ & E01631-05 & Hot & 24.71 & 9.140 & 0.3699 & 0.1100 & 3.324 & 517.6 & 4.714 & 4.712 & 0.2505 \\
\hline \multirow{3}{*}{\multicolumn{4}{|c|}{$\begin{array}{r}\text { Hot Start Average } \\
\text { Hot Start Std Dev } \\
\text { COV (\%) }\end{array}$}} & 24.72 & 9.134 & 0.3696 & 0.1135 & 3.335 & 517.7 & 4.706 & 4.726 & 0.2514 \\
\hline & & & & 0.01 & 0.007 & 0.0004 & 0.0030 & 0.030 & 2.3 & 0.026 & 0.024 & 0.0022 \\
\hline & & & & 0.02 & 0.08 & 0.10 & 2.65 & 0.90 & 0.45 & 0.55 & 0.52 & 0.87 \\
\hline
\end{tabular}

Table 8-32 Summary of Grad REF 16-ml ODA Fuel for 1992 Rebuilt DDC S60

\begin{tabular}{|c|c|c|c|c|c|c|c|c|c|c|c|c|}
\hline \multicolumn{4}{|c|}{ Fuel: Grad REF 16-ml ODA } & \multirow{2}{*}{$\begin{array}{l}\text { Work } \\
\text { bhp-hr }\end{array}$} & \multirow{2}{*}{$\begin{array}{c}\text { Fuel Cons } \\
\text { lb }\end{array}$} & \multirow{2}{*}{$\begin{array}{c}\text { bsFC } \\
\text { lb/bhp-hr }\end{array}$} & \multirow{2}{*}{$\begin{array}{l}\text { bsTHC } \\
\text { g/bhp-hr }\end{array}$} & \multirow{2}{*}{$\begin{array}{c}\text { bsCO } \\
\text { g/bhp-hr }\end{array}$} & \multirow{2}{*}{$\begin{array}{c}\text { bsCO2 } \\
\text { g/bhp-hr }\end{array}$} & \multirow{2}{*}{$\begin{array}{l}\text { bsNOx } \\
\text { g/bhp-hr }\end{array}$} & \multirow{2}{*}{$\begin{array}{l}\text { bsNOx2 } \\
\text { g/bhp-hr }\end{array}$} & \multirow{2}{*}{$\begin{array}{l}\text { bsTPM } \\
\text { g/bhp-hr }\end{array}$} \\
\hline Date & Time & \begin{tabular}{|l|} 
Test No. \\
\end{tabular} & Start Type & & & & & & & & & \\
\hline $1 / 8 / 07$ & $15: 18$ & E01633-01 & Warm & 24.69 & 9.193 & 0.3723 & 0.1294 & 3.301 & 515.2 & 4.581 & 4.573 & 0.2639 \\
\hline $1 / 8 / 07$ & $15: 58$ & E01633-02 & Hot & 24.73 & 9.138 & 0.3695 & 0.0992 & 3.176 & 517.9 & 4.594 & 4.581 & 0.2417 \\
\hline $1 / 8 / 07$ & $16: 38$ & E01633-03 & Hot & 24.74 & 9.139 & 0.3694 & 0.0939 & 3.142 & 517.7 & 4.597 & 4.586 & 0.2372 \\
\hline $1 / 8 / 07$ & $17: 18$ & E01633-04 & Hot & 24.73 & 9.137 & 0.3694 & 0.0962 & 3.129 & 517.4 & 4.585 & 4.579 & 0.2374 \\
\hline $1 / 8 / 07$ & $17: 58$ & E01633-05 & Hot & 24.75 & 9.139 & 0.3693 & 0.0956 & 3.105 & 517.8 & 4.609 & 4.579 & 0.2369 \\
\hline \multirow{2}{*}{\multicolumn{4}{|c|}{$\begin{array}{r}\text { Hot Start Average } \\
\text { Hot Start Std Dev } \\
\text { COV (\%) }\end{array}$}} & 0.01 & 0.001 & 0.0001 & 0.0022 & 0.030 & 0.2 & 0.010 & 0.003 & 0.0023 \\
\hline & & & & 0.04 & 0.01 & 0.02 & 2.30 & 0.94 & 0.04 & 0.22 & 0.07 & 0.95 \\
\hline
\end{tabular}

Comments: 
Table 8-33 Summary of Grad CAND Neat 1 Fuel for 1992 Rebuilt DDC S60

\begin{tabular}{|c|c|c|c|c|c|c|c|c|c|c|c|c|}
\hline \multicolumn{4}{|c|}{ Fuel: Grad CAND Neat } & \multirow{2}{*}{$\begin{array}{l}\text { Work } \\
\text { bhp-hr }\end{array}$} & \multirow{2}{*}{$\begin{array}{c}\text { Fuel Cons } \\
\text { lb }\end{array}$} & \multirow{2}{*}{$\begin{array}{c}\text { bsFC } \\
\text { lb/bhp-hr }\end{array}$} & \multirow{2}{*}{$\begin{array}{l}\text { bsTHC } \\
\text { g/bhp-hr }\end{array}$} & \multirow{2}{*}{$\begin{array}{c}\text { bsCO } \\
\text { g/bhp-hr }\end{array}$} & \multirow{2}{*}{$\begin{array}{l}\text { bsCO2 } \\
\text { g/bhp-hr }\end{array}$} & \multirow{2}{*}{$\begin{array}{l}\text { bsNOx } \\
\text { g/bhp-hr }\end{array}$} & \multirow{2}{*}{$\begin{array}{l}\text { bsNOx2 } \\
\text { g/bhp-hr }\end{array}$} & \multirow{2}{*}{$\begin{array}{l}\text { bsTPM } \\
\text { g/bhp-hr }\end{array}$} \\
\hline Date & Time & \begin{tabular}{|l|} 
Test No. \\
\end{tabular} & Start Type & & & & & & & & & \\
\hline $1 / 9 / 07$ & $7: 25$ & E01635-01 & Warm & 24.65 & 9.259 & 0.3756 & 0.1746 & 3.469 & 529.5 & 5.067 & 5.082 & 0.3084 \\
\hline $1 / 9 / 07$ & $8: 05$ & E01635-02 & Hot & 24.71 & 9.152 & 0.3704 & 0.1156 & 3.269 & 523.5 & 5.022 & 5.033 & 0.2435 \\
\hline $1 / 9 / 07$ & $8: 45$ & E01635-03 & Hot & 24.69 & 9.189 & 0.3722 & 0.1151 & 3.265 & 524.6 & 5.024 & 5.034 & 0.2443 \\
\hline $1 / 9 / 07$ & $9: 25$ & E01635-04 & Hot & 24.70 & 9.196 & 0.3723 & 0.1130 & 3.289 & 521.2 & 5.079 & 5.066 & 0.2447 \\
\hline $1 / 9 / 07$ & $10: 05$ & E01635-05 & Hot & 24.70 & 9.192 & 0.3721 & 0.1117 & 3.277 & 522.7 & 5.052 & 5.043 & 0.2454 \\
\hline \multirow{3}{*}{\multicolumn{4}{|c|}{$\begin{array}{r}\text { Hot Start Average } \\
\text { Hot Start Std Dev } \\
\text { COV (\%) }\end{array}$}} & 24.70 & 9.182 & 0.3718 & 0.1139 & 3.275 & 523.0 & 5.044 & 5.044 & 0.2445 \\
\hline & & & & 0.01 & 0.020 & 0.0009 & 0.0018 & 0.011 & 1.5 & 0.027 & 0.015 & 0.0008 \\
\hline & & & & 0.03 & 0.22 & 0.24 & 1.60 & 0.32 & 0.28 & 0.53 & 0.30 & 0.32 \\
\hline
\end{tabular}

Comments: Hot Start E01635-02 TPM temperature signal noisy.

Table 8-34 Summary of Grad CAND 8-ml 2-EHN Fuel for 1992 Rebuilt DDC S60

\begin{tabular}{|c|c|c|c|c|c|c|c|c|c|c|c|c|}
\hline \multicolumn{4}{|c|}{ Fuel: Grad CAND 8-ml 2-EHN } & \multirow{2}{*}{$\begin{array}{l}\text { Work } \\
\text { bhp-hr }\end{array}$} & \multirow{2}{*}{$\begin{array}{c}\text { Fuel Cons } \\
\text { lb }\end{array}$} & \multirow{2}{*}{$\begin{array}{c}\text { bsFC } \\
\text { lb/bhp-hr }\end{array}$} & \multirow{2}{*}{$\begin{array}{l}\text { bsTHC } \\
\text { g/bhp-hr }\end{array}$} & \multirow{2}{*}{$\begin{array}{c}\text { bsCO } \\
\text { g/bhp-hr }\end{array}$} & \multirow{2}{*}{$\begin{array}{l}\text { bsCO2 } \\
\text { g/bhp-hr }\end{array}$} & \multirow{2}{*}{$\begin{array}{l}\text { bsNOx } \\
\text { g/bhp-hr }\end{array}$} & \multirow{2}{*}{$\begin{array}{l}\text { bsNOx2 } \\
\text { g/bhp-hr }\end{array}$} & \multirow{2}{*}{$\begin{array}{l}\text { bsTPM } \\
\text { g/bhp-hr }\end{array}$} \\
\hline Date & Time & Test No. & Start Type & & & & & & & & & \\
\hline $1 / 9 / 07$ & $14: 37$ & E01638-01 & Warm & 24.69 & 9.253 & 0.3747 & 0.1222 & 3.172 & 523.8 & 4.892 & 4.910 & 0.2479 \\
\hline $1 / 9 / 07$ & $15: 17$ & E01638-02 & Hot & 24.72 & 9.191 & 0.3718 & 0.1011 & 3.037 & 518.1 & 4.885 & 4.906 & 0.2348 \\
\hline $1 / 9 / 07$ & $15: 57$ & E01638-03 & Hot & 24.73 & 9.193 & 0.3718 & 0.0990 & 3.037 & 520.3 & 4.890 & 4.898 & 0.2333 \\
\hline $1 / 9 / 07$ & $16: 37$ & E01638-04 & Hot & 24.74 & 9.108 & 0.3681 & 0.0960 & 3.019 & 521.8 & 4.896 & 4.914 & 0.2334 \\
\hline \multirow{3}{*}{\multicolumn{4}{|c|}{$\begin{array}{r}\text { Hot Start Average } \\
\text { Hot Start Std Dev } \\
\text { COV (\%) }\end{array}$}} & 24.73 & 9.164 & 0.3706 & 0.0987 & 3.031 & 520.1 & 4.890 & 4.906 & 0.2338 \\
\hline & & & & 0.01 & 0.049 & 0.0021 & 0.0026 & 0.010 & 1.8 & 0.006 & 0.008 & 0.0009 \\
\hline & & & & 0.04 & 0.53 & 0.58 & 2.60 & 0.34 & 0.35 & 0.11 & 0.16 & 0.37 \\
\hline
\end{tabular}

Comments: 
Table 8-35 Summary of Grad CAND 16-ml ODA Fuel for 1992 Rebuilt DDC S60

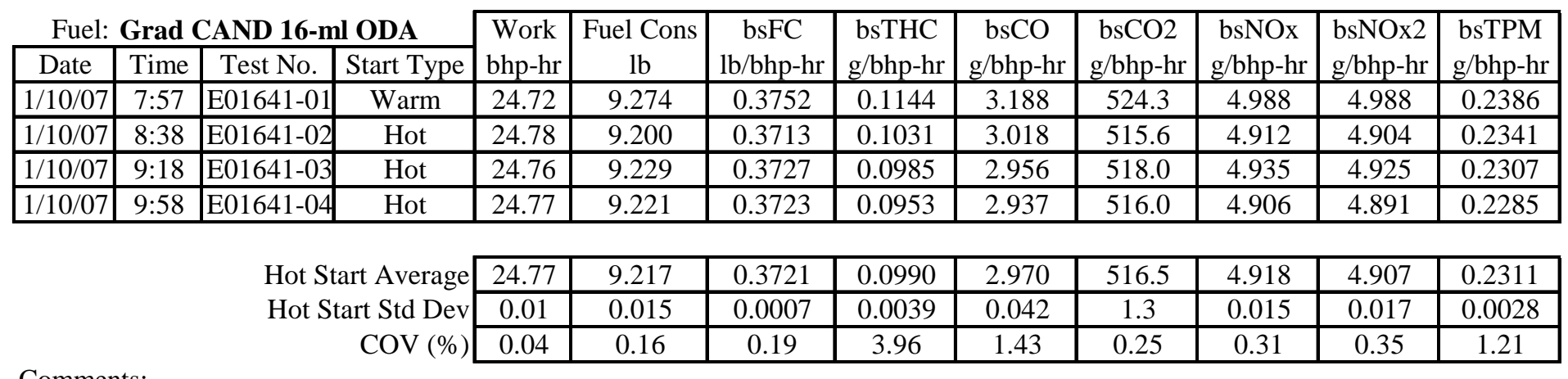

Comments:

Table 8-36 Summary of Grad CAND 16-ml ODA 2x Fuel for 1992 Rebuilt DDC S60

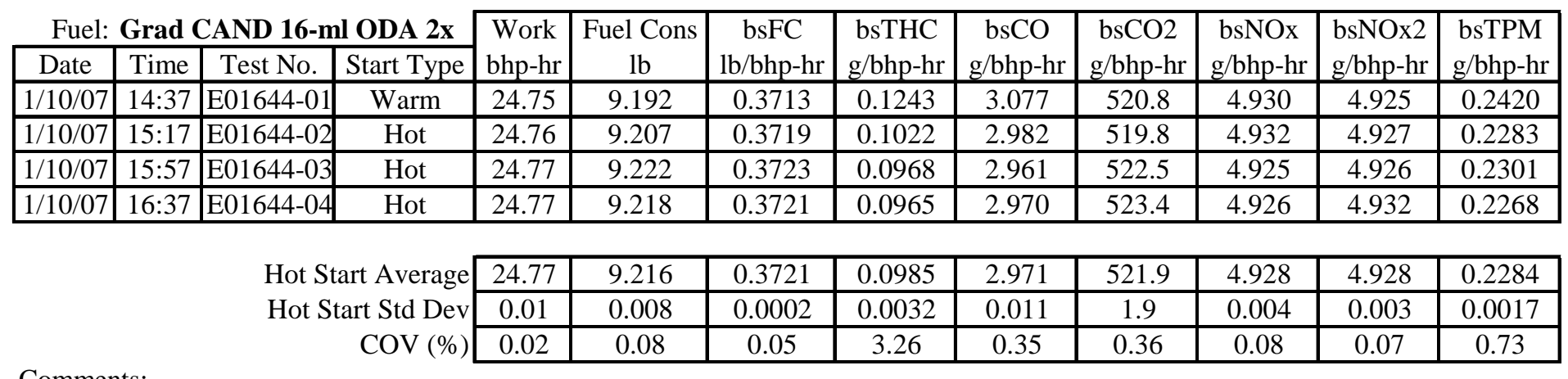


Table 8-37 Summary of Grad CAND Neat 2 Fuel for 1992 Rebuilt DDC S60

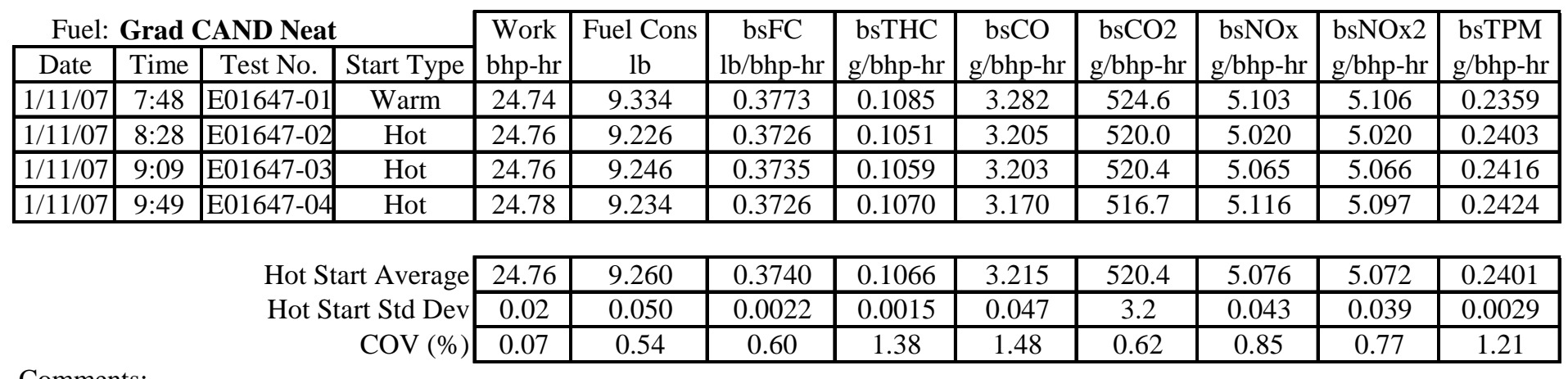

Table 8-38 Summary of Grad CAND 10-ml DTBP Fuel for 1992 Rebuilt DDC S60

\begin{tabular}{|c|c|c|c|c|c|c|c|c|c|c|c|c|}
\hline \multicolumn{4}{|c|}{ Fuel: Grad CAND 10-ml DTBP } & \multirow{2}{*}{$\begin{array}{l}\text { Work } \\
\text { bhp-hr }\end{array}$} & \multirow{2}{*}{$\begin{array}{c}\text { Fuel Cons } \\
\text { lb }\end{array}$} & \multirow{2}{*}{$\begin{array}{c}\text { bsFC } \\
\text { lb/bhp-hr }\end{array}$} & \multirow{2}{*}{$\begin{array}{l}\text { bsTHC } \\
\text { g/bhp-hr }\end{array}$} & \multirow{2}{*}{$\begin{array}{c}\text { bsCO } \\
\text { g/bhp-hr }\end{array}$} & \multirow{2}{*}{$\begin{array}{c}\text { bsCO2 } \\
\text { g/bhp-hr }\end{array}$} & \multirow{2}{*}{$\begin{array}{l}\text { bsNOx } \\
\text { g/bhp-hr }\end{array}$} & \multirow{2}{*}{$\begin{array}{l}\text { bsNOx2 } \\
\text { g/bhp-hr }\end{array}$} & \multirow{2}{*}{$\begin{array}{l}\text { bsTPM } \\
\text { g/bhp-hr }\end{array}$} \\
\hline Date & Time & Test No. & Start Type & & & & & & & & & \\
\hline $1 / 11 / 07$ & $12: 50$ & E01650-01 & Warm & 24.78 & 9.256 & 0.3735 & 0.1062 & 3.070 & 525.5 & 4.909 & 4.890 & 0.2263 \\
\hline $1 / 11 / 07$ & $13: 30$ & E01650-02 & Hot & 24.75 & 9.208 & 0.3721 & 0.0956 & 3.025 & 522.3 & 4.881 & 4.856 & 0.2332 \\
\hline $1 / 11 / 07$ & $14: 10$ & E01650-03 & Hot & 24.75 & 9.222 & 0.3727 & 0.0902 & 3.022 & 523.9 & 4.888 & 383 & 0.2306 \\
\hline $1 / 11 / 07$ & $14: 50$ & E01650-04 & Hot & 24.74 & 9.231 & 0.3732 & 0.0879 & 3.022 & 523.6 & 4.908 & 4.884 & 0.2315 \\
\hline \multicolumn{4}{|c|}{$\begin{array}{r}\text { Hot Start Average } \\
\text { Hot Start Std Dev } \\
\text { COV }(\%)\end{array}$} & 0.02 & 0.13 & 0.15 & 4.33 & 0.06 & 0.16 & 0.29 & 0.33 & 0.58 \\
\hline
\end{tabular}


Table 8-39 Summary of Grad CAND 6-ml ODA Fuel for 1992 Rebuilt DDC S60

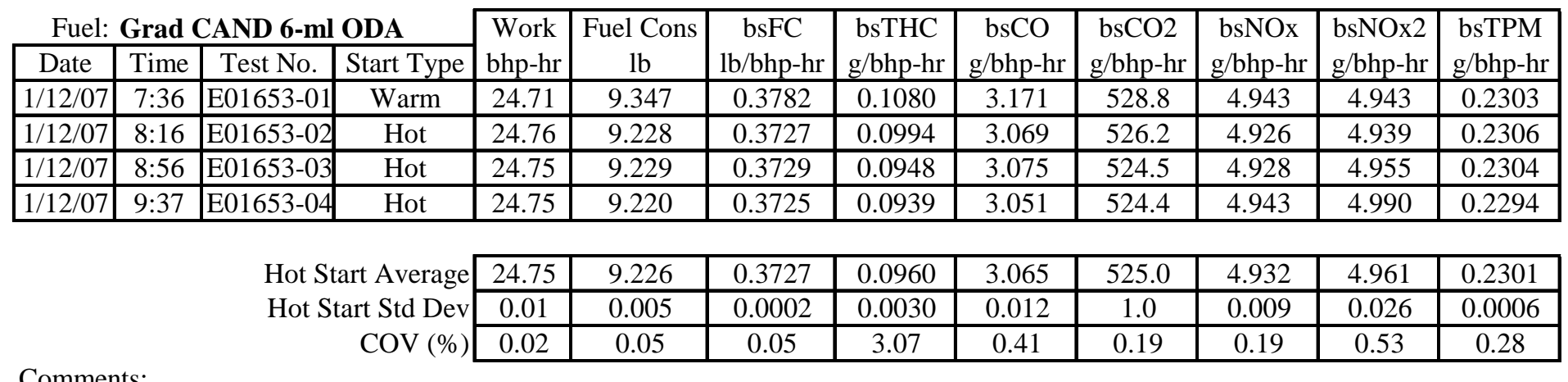

Table 8-40 Summary of Grad CAND 12-ml ODA Fuel for 1992 Rebuilt DDC S60

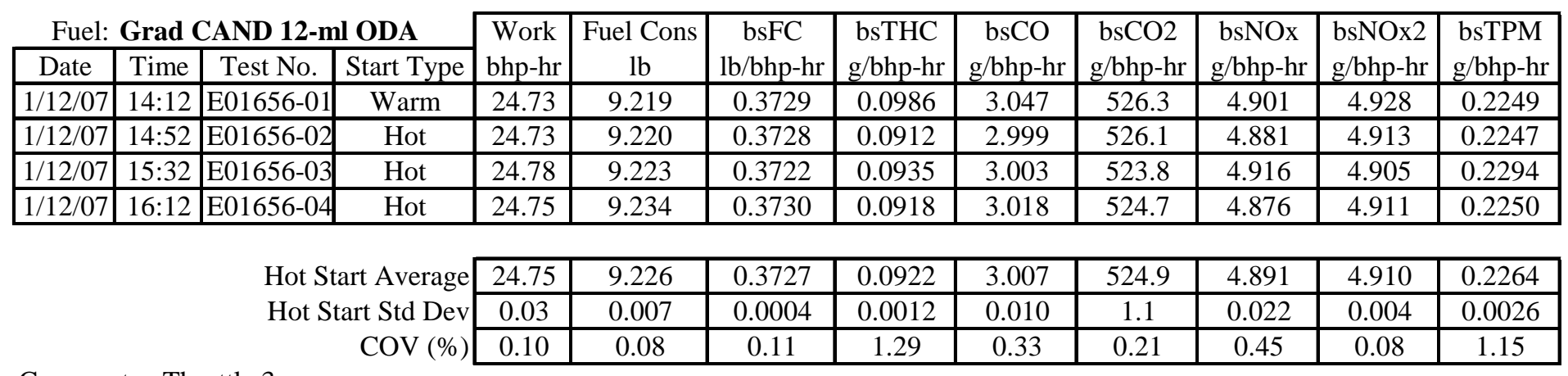

Comments: Throttle 3 


\subsection{Summary of FTP Emissions Data for 1999 Cummins ISM 370}

Table 8-41 Summary of CP 0.05 Cert Neat 1 Fuel for 1999 Cummins ISM 370

\begin{tabular}{|c|c|c|c|c|c|c|c|c|c|c|c|c|}
\hline \multicolumn{4}{|c|}{ Fuel: CP 0.05 Cert Neat } & \multirow{2}{*}{$\begin{array}{l}\text { Work } \\
\text { bhp-hr }\end{array}$} & \multirow{2}{*}{$\begin{array}{c}\text { Fuel Cons } \\
\mathrm{lb} \\
\end{array}$} & \multirow{2}{*}{$\begin{array}{c}\text { bsFC } \\
\text { lb/bhp-hr }\end{array}$} & \multirow{2}{*}{$\begin{array}{l}\text { bsTHC } \\
\text { g/bhp-hr }\end{array}$} & \multirow{2}{*}{$\begin{array}{c}\text { bsCO } \\
\text { g/bhp-hr }\end{array}$} & \multirow{2}{*}{$\begin{array}{c}\text { bsCO2 } \\
\text { g/bhp-hr }\end{array}$} & \multirow{2}{*}{$\begin{array}{l}\text { bsNOx } \\
\text { g/bhp-hr }\end{array}$} & \multirow{2}{*}{$\begin{array}{l}\text { bsNOx2 } \\
\text { g/bhp-hr }\end{array}$} & \multirow{2}{*}{$\begin{array}{c}\text { bsTPM } \\
\text { g/bhp-hr }\end{array}$} \\
\hline Date & Time & Test No. & Start Type & & & & & & & & & \\
\hline $2 / 7 / 07$ & $15: 30$ & E01729-01 & Hot & 26.88 & 9.836 & 0.3659 & 0.2626 & 1.049 & 522.3 & 4.089 & 4.041 & 0.1307 \\
\hline $2 / 7 / 07$ & $16: 10$ & E01729-02 & Hot & 26.90 & 9.835 & 0.3656 & 0.2620 & 1.034 & 522.6 & 4.075 & 4.028 & 0.1290 \\
\hline \multicolumn{4}{|c|}{$\begin{array}{r}\text { Hot Start Average } \\
\text { Hot Start Std Dev } \\
\text { COV (\%) }\end{array}$} & 26.89 & 9.832 & 0.3657 & 0.2616 & 1.037 & 522.7 & 4.082 & 4.035 & 0.1265 \\
\hline
\end{tabular}

Comments: Throttle 1

Table 8-42 Summary of CP 0.05 Cert 12-ml ODA Fuel for 1999 Cummins ISM 370

\begin{tabular}{|c|c|c|c|c|c|c|c|c|c|c|c|c|}
\hline \multicolumn{4}{|c|}{ Fuel: CP 0.05 Cert 12-ml ODA } & \multirow{2}{*}{$\begin{array}{l}\text { Work } \\
\text { bhp-hr }\end{array}$} & \multirow{2}{*}{$\begin{array}{c}\text { Fuel Cons } \\
\text { lb }\end{array}$} & \multirow{2}{*}{$\begin{array}{c}\text { bsFC } \\
\text { lb/bhp-hr }\end{array}$} & \multirow{2}{*}{$\begin{array}{l}\text { bsTHC } \\
\text { g/bhp-hr }\end{array}$} & \multirow{2}{*}{$\begin{array}{c}\text { bsCO } \\
\text { g/bhp-hr }\end{array}$} & \multirow{2}{*}{$\begin{array}{c}\text { bsCO2 } \\
\text { g/bhp-hr }\end{array}$} & \multirow{2}{*}{$\begin{array}{c}\text { bsNOx } \\
\text { g/bhp-hr }\end{array}$} & \multirow{2}{*}{$\begin{array}{l}\text { bsNOx2 } \\
\text { g/bhp-hr }\end{array}$} & \multirow{2}{*}{$\begin{array}{l}\text { bsTPM } \\
\text { g/bhp-hr }\end{array}$} \\
\hline Date & Time & Test No. & Start Type & & & & & & & & & \\
\hline $2 / 8 / 07$ & $9: 57$ & E01732-01 & Hot & 26.90 & 9.824 & 0.3652 & 0.2538 & 0.981 & 524.0 & 4.026 & 4.021 & 0.1164 \\
\hline $2 / 8 / 07$ & $10: 37$ & E01732-02 & Hot & 26.89 & 9.821 & 0.3652 & 0.2521 & 0.972 & 524.0 & 4.027 & 4.029 & 0.1179 \\
\hline \multicolumn{4}{|c|}{$\begin{array}{r}\text { Hot Start Average } \\
\text { Hot Start Std Dev } \\
\text { COV (\%) }\end{array}$} & 26.89 & 9.818 & 0.3651 & 0.2537 & 0.976 & 523.8 & 4.026 & 4.017 & 0.1138 \\
\hline
\end{tabular}

Comments: Throttle 1 
Table 8-43 Summary of Grad REF Neat Fuel for 1999 Cummins ISM 370

\begin{tabular}{|c|c|c|c|c|c|c|c|c|c|c|c|c|}
\hline \multicolumn{4}{|c|}{ Fuel: Grad REF Neat } & \multirow{2}{*}{$\begin{array}{l}\text { Work } \\
\text { bhp-hr }\end{array}$} & \multirow{2}{*}{$\begin{array}{c}\text { Fuel Cons } \\
\text { lb } \\
\end{array}$} & \multirow{2}{*}{$\begin{array}{c}\text { bsFC } \\
\text { lb/bhp-hr }\end{array}$} & \multirow{2}{*}{$\begin{array}{l}\text { bsTHC } \\
\text { g/bhp-hr }\end{array}$} & \multirow{2}{*}{$\begin{array}{c}\text { bsCO } \\
\text { g/bhp-hr }\end{array}$} & \multirow{2}{*}{$\begin{array}{c}\text { bsCO2 } \\
\text { g/bhp-hr }\end{array}$} & \multirow{2}{*}{$\begin{array}{l}\text { bsNOx } \\
\text { g/bhp-hr }\end{array}$} & \multirow{2}{*}{$\begin{array}{l}\text { bsNOx2 } \\
\text { g/bhp-hr }\end{array}$} & \multirow{2}{*}{$\begin{array}{l}\text { bsTPM } \\
\text { g/bhp-hr }\end{array}$} \\
\hline Date & Time & Test No. & Start Type & & & & & & & & & \\
\hline $2 / 8 / 07$ & $13: 51$ & E01735-01 & Warm & 26.51 & 9.637 & 0.3635 & 0.2414 & 1.007 & 512.2 & 3.676 & 3.649 & 0.0904 \\
\hline $2 / 8 / 07$ & $14: 31$ & E01735-02 & Hot & 26.51 & 9.640 & 0.3636 & 0.2394 & 0.970 & 511.8 & 3.677 & 3.652 & 0.0922 \\
\hline 2/8/07 & $15: 51$ & E01735-04 & Hot & 26.49 & 9.642 & 0.3639 & 0.2384 & 0.994 & 513.2 & 3.684 & 3.675 & 0.0874 \\
\hline \multirow{2}{*}{\multicolumn{4}{|c|}{$\begin{array}{r}\text { Hot Start Average } \\
\text { Hot Start Std Dev } \\
\text { COV (\%) }\end{array}$}} & 0.01 & $\frac{0.025}{0.205}$ & $\frac{0.0300}{0.0077}$ & 0.00 & $\frac{0.901}{0.012}$ & 0.7 & & & \\
\hline & & & & 0.04 & 2.15 & 2.15 & 0.68 & 1.25 & 0.14 & 0.20 & 0.32 & 5.04 \\
\hline
\end{tabular}

Comments: Throttle 1

Table 8-44 Summary of Grad CAND Neat Fuel for 1999 Cummins ISM 370

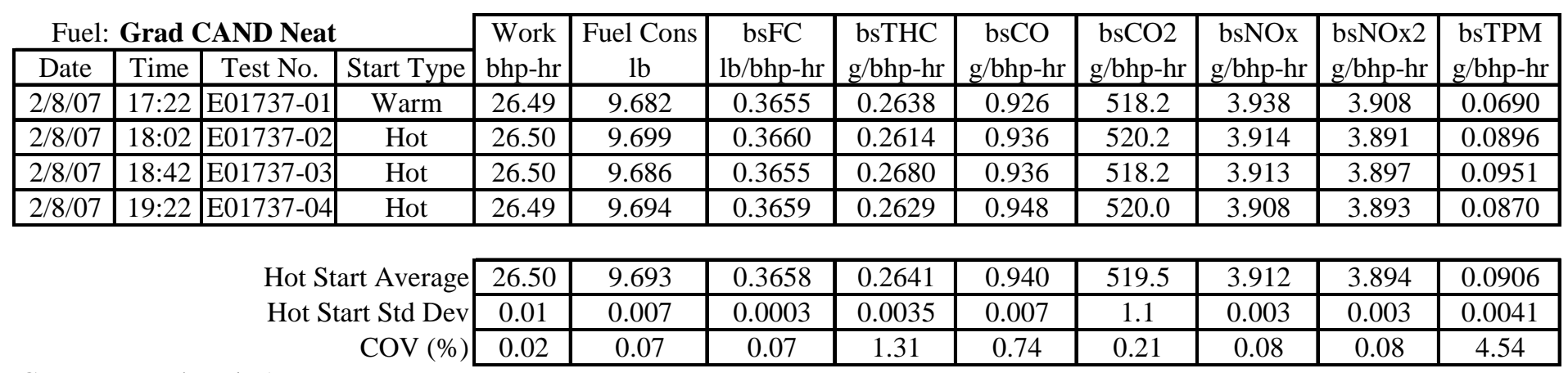

Comments: Throttle 1 
Table 8-45 Summary of Grad CAND 12-ml ODA Fuel for 1999 Cummins ISM 370

\begin{tabular}{|c|c|c|c|c|c|c|c|c|c|c|c|c|}
\hline \multicolumn{4}{|c|}{ Fuel: Grad CAND 12-ml ODA } & \multirow{2}{*}{$\begin{array}{l}\text { Work } \\
\text { bhp-hr }\end{array}$} & \multirow{2}{*}{$\begin{array}{c}\text { Fuel Cons } \\
\text { lb }\end{array}$} & \multirow{2}{*}{$\begin{array}{c}\text { bsFC } \\
\text { lb/bhp-hr }\end{array}$} & \multirow{2}{*}{$\begin{array}{l}\text { bsTHC } \\
\text { g/bhp-hr }\end{array}$} & \multirow{2}{*}{$\begin{array}{c}\text { bsCO } \\
\text { g/bhp-hr }\end{array}$} & \multirow{2}{*}{$\begin{array}{l}\text { bsCO2 } \\
\text { g/bhp-hr }\end{array}$} & \multirow{2}{*}{$\begin{array}{l}\text { bsNOx } \\
\text { g/bhp-hr }\end{array}$} & \multirow{2}{*}{$\begin{array}{l}\text { bsNOx2 } \\
\text { g/bhp-hr }\end{array}$} & \multirow{2}{*}{$\begin{array}{l}\text { bsTPM } \\
\text { g/bhp-hr }\end{array}$} \\
\hline Date & Time & Test No. & Start Type & & & & & & & & & \\
\hline $2 / 9 / 07$ & $8: 41$ & E01739-01 & Warm & 26.46 & 9.746 & 0.3684 & 0.2669 & 0.908 & 520.6 & 3.878 & 3.858 & 0.0879 \\
\hline $2 / 9 / 07$ & 10:01 & E01739-03 & Hot & 26.47 & 9.700 & 0.3665 & 0.2668 & 0.891 & 518.8 & 3.866 & 3.873 & 0.0916 \\
\hline $2 / 9 / 07$ & $11: 22$ & E01739-05 & Hot & 26.50 & 9.690 & 0.3657 & 0.2656 & 0.916 & 518.7 & 3.858 & 3.831 & 0.0890 \\
\hline \multirow{2}{*}{\multicolumn{4}{|c|}{$\begin{array}{r}\text { Hot Start Average } \\
\text { Hot Start Std Dev } \\
\text { COV (\%) }\end{array}$}} & 0.02 & 0.009 & 0.0005 & 0.0006 & 0.013 & 1.0 & 0.004 & 0.023 & 0.0016 \\
\hline & & & & 0.06 & 0.09 & 0.13 & 0.24 & 1.38 & 0.19 & 0.11 & 0.58 & 1.73 \\
\hline
\end{tabular}

Comments: Throttle 1, Run -02 performed with throttle 3.

Table 8-46 Summary of Grad CAND 6-ml ODA Fuel for 1999 Cummins ISM 370

\begin{tabular}{|c|c|c|c|c|c|c|c|c|c|c|c|c|}
\hline \multicolumn{4}{|c|}{ Fuel: Grad CAND 6-ml ODA } & \multirow{2}{*}{$\begin{array}{l}\text { Work } \\
\text { bhp-hr }\end{array}$} & \multirow{2}{*}{$\begin{array}{c}\text { Fuel Cons } \\
\mathrm{lb} \\
\end{array}$} & \multirow{2}{*}{$\begin{array}{c}\text { bsFC } \\
\text { lb/bhp-hr }\end{array}$} & \multirow{2}{*}{$\begin{array}{l}\text { bsTHC } \\
\text { g/bhp-hr }\end{array}$} & \multirow{2}{*}{$\begin{array}{c}\text { bsCO } \\
\text { g/bhp-hr }\end{array}$} & \multirow{2}{*}{$\begin{array}{l}\text { bsCO2 } \\
\text { g/bhp-hr }\end{array}$} & \multirow{2}{*}{$\begin{array}{l}\text { bsNOx } \\
\text { g/bhp-hr }\end{array}$} & \multirow{2}{*}{$\begin{array}{l}\text { bsNOx2 } \\
\text { g/bhp-hr }\end{array}$} & \multirow{2}{*}{$\begin{array}{l}\text { bsTPM } \\
\text { g/bhp-hr }\end{array}$} \\
\hline Date & Time & Test No. & Start Type & & & & & & & & & \\
\hline $2 / 9 / 07$ & $13: 18$ & E01741-01 & Warm & 26.50 & 9.901 & 0.3736 & 0.2765 & 0.904 & 517.4 & 3.850 & 3.873 & 0.0834 \\
\hline $2 / 9 / 07$ & $13: 58$ & E01741-02 & Hot & 26.49 & 9.672 & 0.3651 & 0.2758 & 0.921 & 516.7 & 3.837 & 3.855 & 0.0980 \\
\hline $2 / 9 / 07$ & $15: 18$ & E01741-04 & Hot & 26.47 & 9.670 & 0.3653 & 0.2725 & 0.931 & 517.5 & 3.847 & 3.858 & 0.0915 \\
\hline \multirow{2}{*}{\multicolumn{4}{|c|}{$\begin{array}{r}\text { Hot Start Average } \\
\text { Hot Start Std Dev } \\
\text { COV (\%) }\end{array}$}} & $\frac{20.45}{0.02}$ & 0.006 & 0.0004 & 0.0021 & $\begin{array}{l}0.021 \\
0.011\end{array}$ & 0.9 & $\frac{0.04 \%}{0.010}$ & $\begin{array}{l}3.05 / \\
0.002\end{array}$ & $\frac{0.0933}{0.0041}$ \\
\hline & & & & 0.06 & 0.06 & 0.10 & 0.78 & 1.14 & 0.18 & 0.26 & 0.05 & 4.36 \\
\hline
\end{tabular}

Comments: Throttle 1 
Table 8-47 Summary of Grad CAND 6-ml 2-EHN Fuel for 1999 Cummins ISM 370

\begin{tabular}{|c|c|c|c|c|c|c|c|c|c|c|c|c|}
\hline \multicolumn{4}{|c|}{ Fuel: Grad CAND 6-ml 2-EHN } & \multirow{2}{*}{$\begin{array}{l}\text { Work } \\
\text { bhp-hr }\end{array}$} & \multirow{2}{*}{$\begin{array}{c}\text { Fuel Cons } \\
\text { lb } \\
\end{array}$} & \multirow{2}{*}{$\begin{array}{c}\text { bsFC } \\
\text { lb/bhp-hr }\end{array}$} & \multirow{2}{*}{$\begin{array}{l}\text { bsTHC } \\
\text { g/bhp-hr }\end{array}$} & \multirow{2}{*}{$\begin{array}{c}\text { bsCO } \\
\text { g/bhp-hr }\end{array}$} & \multirow{2}{*}{$\begin{array}{c}\text { bsCO2 } \\
\text { g/bhp-hr }\end{array}$} & \multirow{2}{*}{$\begin{array}{c}\text { bsNOx } \\
\text { g/bhp-hr }\end{array}$} & \multirow{2}{*}{$\begin{array}{l}\text { bsNOx2 } \\
\text { g/bhp-hr }\end{array}$} & \multirow{2}{*}{$\begin{array}{l}\text { bsTPM } \\
\text { g/bhp-hr }\end{array}$} \\
\hline Date & Time & Test No. & Start Type & & & & & & & & & \\
\hline $2 / 9 / 07$ & $16: 55$ & E01743-01 & Warm & 26.47 & 9.706 & 0.3666 & 0.2701 & 0.902 & 518.3 & 3.843 & 3.844 & 0.0768 \\
\hline $2 / 9 / 07$ & $17: 35$ & E01743-02 & Hot & 26.50 & 9.671 & 0.3650 & 0.2659 & 0.892 & 518.5 & 3.837 & 3.839 & 0.0862 \\
\hline $2 / 9 / 07$ & $18: 15$ & E01743-03 & Hot & 26.48 & 9.667 & 0.3650 & 0.2676 & 0.894 & 517.4 & 3.837 & 3.840 & 0.0932 \\
\hline $2 / 9 / 07$ & $18: 56$ & E01743-04 & Hot & 26.50 & 9.666 & 0.3648 & 0.2671 & 0.912 & 517.4 & 3.836 & 3.841 & 0.0928 \\
\hline \multirow{3}{*}{\multicolumn{4}{|c|}{$\begin{array}{r}\text { Hot Start Average } \\
\text { Hot Start Std Dev } \\
\text { COV }(\%)\end{array}$}} & 26.49 & 9.668 & 0.3649 & 0.2669 & 0.899 & 517.8 & 3.837 & 3.840 & 0.0907 \\
\hline & & & & 0.01 & 0.003 & 0.0001 & 0.0009 & 0.011 & 0.6 & 0.001 & 0.001 & 0.0039 \\
\hline & & & & 0.04 & 0.03 & 0.03 & 0.33 & 1.22 & 0.12 & 0.02 & 0.03 & 4.31 \\
\hline
\end{tabular}

Comments: Throttle 1

Table 8-48 Summary of Grad CAND 10-ml DTBP Fuel for 1999 Cummins ISM 370

\begin{tabular}{|c|c|c|c|c|c|c|c|c|c|c|c|c|}
\hline \multicolumn{4}{|c|}{ Fuel: Grad CAND 10-ml DTBP } & \multirow{2}{*}{$\begin{array}{l}\text { Work } \\
\text { bhp-hr }\end{array}$} & \multirow{2}{*}{$\begin{array}{c}\text { Fuel Cons } \\
\text { lb }\end{array}$} & \multirow{2}{*}{$\begin{array}{c}\text { bsFC } \\
\text { lb/bhp-hr }\end{array}$} & \multirow{2}{*}{$\begin{array}{l}\text { bsTHC } \\
\text { g/bhp-hr }\end{array}$} & \multirow{2}{*}{$\begin{array}{c}\text { bsCO } \\
\text { g/bhp-hr }\end{array}$} & \multirow{2}{*}{$\begin{array}{l}\text { bsCO2 } \\
\text { g/bhp-hr }\end{array}$} & \multirow{2}{*}{$\begin{array}{l}\text { bsNOx } \\
\text { g/bhp-hr }\end{array}$} & \multirow{2}{*}{$\begin{array}{l}\text { bsNOx2 } \\
\text { g/bhp-hr }\end{array}$} & \multirow{2}{*}{$\begin{array}{l}\text { bsTPM } \\
\text { g/bhp-hr }\end{array}$} \\
\hline Date & Time & Test No. & Start Type & & & & & & & & & \\
\hline $2 / 11 / 07$ & $7: 21$ & E01745-01 & Warm & 26.49 & 9.822 & 0.3708 & 0.2611 & 0.915 & 525.2 & 3.943 & 3.961 & 0.0875 \\
\hline $2 / 11 / 07$ & 8:01 & E01745-02 & Hot & 26.48 & 9.706 & 0.3666 & 0.2617 & 0.905 & 520.1 & 3.856 & 3.845 & 0.0851 \\
\hline $2 / 11 / 07$ & $8: 42$ & E01745-03 & Hot & 26.48 & 9.693 & 0.3661 & 0.2603 & 0.885 & 518.0 & 3.832 & 3.813 & 0.0982 \\
\hline $2 / 11 / 07$ & 9:22 & E01745-04 & Hot & 26.48 & 9.684 & 0.3658 & 0.2616 & 0.888 & 516.6 & 3.831 & 3.831 & 0.0877 \\
\hline \multirow{3}{*}{\multicolumn{4}{|c|}{$\begin{array}{r}\text { Hot Start Average } \\
\text { Hot Start Std Dev } \\
\text { COV }(\%)\end{array}$}} & 26.48 & 9.694 & 0.3662 & 0.2612 & 0.893 & 518.2 & 3.840 & 3.830 & 0.0903 \\
\hline & & & & 0.00 & 0.011 & 0.0004 & 0.0008 & 0.011 & 1.7 & 0.014 & 0.016 & 0.0069 \\
\hline & & & & 0.00 & 0.11 & 0.11 & 0.30 & 1.21 & 0.33 & 0.37 & 0.42 & 7.67 \\
\hline
\end{tabular}

Comments: Throttle 1 
Table 8-49 Summary of Grad CAND 16-ml ODA Fuel for 1999 Cummins ISM 370

\begin{tabular}{|c|c|c|c|c|c|c|c|c|c|c|c|c|}
\hline \multicolumn{4}{|c|}{ Fuel: Grad REF 16-ml ODA } & \multirow{2}{*}{$\begin{array}{l}\text { Work } \\
\text { bhp-hr }\end{array}$} & \multirow{2}{*}{$\begin{array}{c}\text { Fuel Cons } \\
\text { lb } \\
\end{array}$} & \multirow{2}{*}{$\begin{array}{c}\text { bsFC } \\
\text { lb/bhp-hr }\end{array}$} & \multirow{2}{*}{$\begin{array}{l}\text { bsTHC } \\
\text { g/bhp-hr }\end{array}$} & \multirow{2}{*}{$\begin{array}{c}\text { bsCO } \\
\text { g/bhp-hr }\end{array}$} & \multirow{2}{*}{$\begin{array}{c}\text { bsCO2 } \\
\text { g/bhp-hr }\end{array}$} & \multirow{2}{*}{$\begin{array}{l}\text { bsNOx } \\
\text { g/bhp-hr }\end{array}$} & \multirow{2}{*}{$\begin{array}{l}\text { bsNOx2 } \\
\text { g/bhp-hr }\end{array}$} & \multirow{2}{*}{$\begin{array}{c}\text { bsTPM } \\
\text { g/bhp-hr }\end{array}$} \\
\hline Date & Time & Test No. & Start Type & & & & & & & & & \\
\hline $2 / 11 / 07$ & $11: 10$ & E01747-01 & Warm & 26.51 & 9.658 & 0.3643 & 0.2633 & 0.921 & 509.3 & 3.648 & 3.653 & 0.0818 \\
\hline $2 / 11 / 07$ & $11: 50$ & E01747-02 & Hot & 26.51 & 9.615 & 0.3627 & 0.2444 & 0.941 & 510.1 & 3.633 & 3.647 & 0.0860 \\
\hline $2 / 11 / 07$ & $13: 10$ & E01747-04 & Hot & 26.52 & 9.608 & 0.3623 & 0.2405 & 0.922 & 509.8 & 3.629 & 3.648 & 0.0947 \\
\hline \multicolumn{4}{|c|}{$\begin{array}{r}\text { Hot Start Average } \\
\text { Hot Start Std Dev } \\
\text { COV (\%) }\end{array}$} & 0.02 & 0.09 & 0.12 & 0.80 & 1.06 & 0.04 & 0.10 & 0.03 & 6.26 \\
\hline
\end{tabular}

Comments: Throttle 1

Table 8-50 Summary of Grad REF Neat Fuel for 1999 Cummins ISM 370

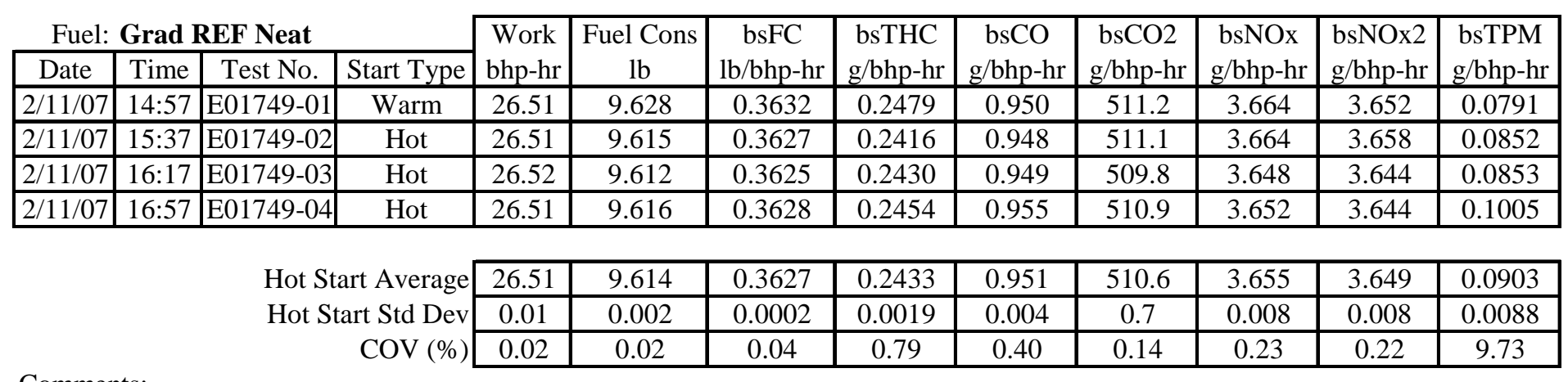


Table 8-51 Summary of CP 0.05 Cert Neat 2 Fuel for 1999 Cummins ISM 370

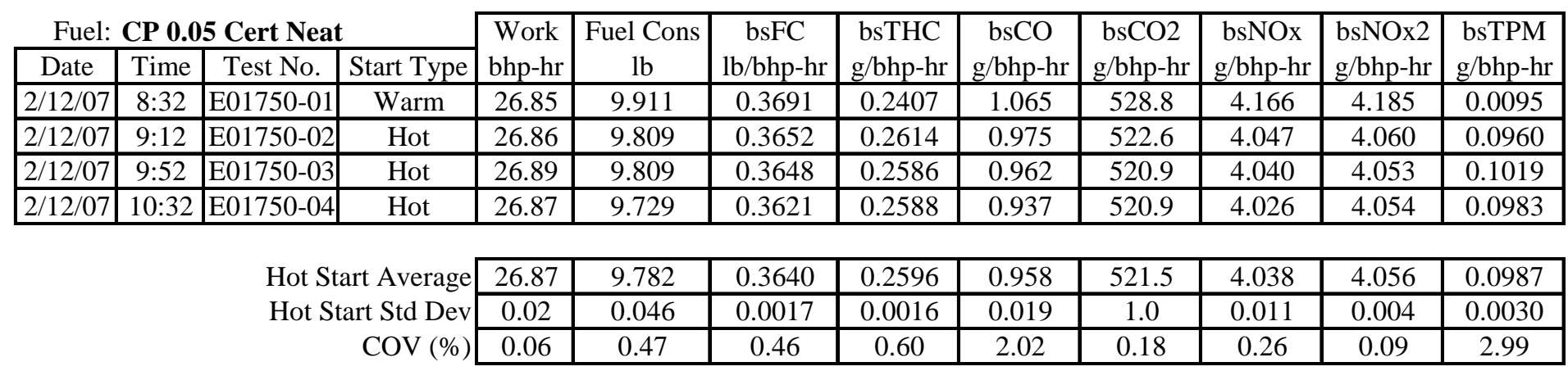

Comments: Throttle 1. No TPM/TEOM data for warm start.

Table 8-52 Summary of CP 0.05 Cert B20 A Neat Fuel for 1999 Cummins ISM 370

\begin{tabular}{|c|c|c|c|c|c|c|c|c|c|c|c|c|}
\hline \multicolumn{4}{|c|}{ Fuel: CP 0.05 Cert B20 A Neat } & \multirow{2}{*}{$\begin{array}{l}\text { Work } \\
\text { bhp-hr }\end{array}$} & \multirow{2}{*}{$\begin{array}{c}\text { Fuel Cons } \\
\text { lb }\end{array}$} & \multirow{2}{*}{$\begin{array}{c}\text { bsFC } \\
\text { lb/bhp-hr }\end{array}$} & \multirow{2}{*}{$\begin{array}{l}\text { bsTHC } \\
\text { g/bhp-hr }\end{array}$} & \multirow{2}{*}{$\begin{array}{c}\text { bsCO } \\
\text { g/bhp-hr }\end{array}$} & \multirow{2}{*}{$\begin{array}{l}\text { bsCO2 } \\
\text { g/bhp-hr }\end{array}$} & \multirow{2}{*}{$\begin{array}{l}\text { bsNOx } \\
\text { g/bhp-hr }\end{array}$} & \multirow{2}{*}{$\begin{array}{l}\text { bsNOx2 } \\
\text { g/bhp-hr }\end{array}$} & \multirow{2}{*}{$\begin{array}{l}\text { bsTPM } \\
\text { g/bhp-hr }\end{array}$} \\
\hline Date & Time & \begin{tabular}{|l|} 
Test No. \\
\end{tabular} & Start Type & & & & & & & & & \\
\hline $2 / 12 / 07$ & $12: 22$ & \begin{tabular}{|l|} 
E01752-01 \\
\end{tabular} & Warm & 26.81 & 10.037 & 0.3744 & 0.2223 & 0.841 & 520.4 & 4.076 & 3.453 & 0.0717 \\
\hline $2 / 12 / 07$ & $13: 02$ & E01752-02 & Hot & 26.82 & 10.012 & & 37 & & & & 02 & 773 \\
\hline $2 / 12 / 07$ & $13: 42$ & E01752-03 & Hot & 26.83 & 10.004 & 0.3729 & 0.2129 & 0.831 & 520.7 & 4.060 & 729 & 0.0797 \\
\hline $2 / 12 / 07$ & $14: 25$ & E01752-05 & Hot & 26.83 & 10.003 & 0.3728 & 0.2121 & 0.828 & 521.0 & 4.057 & 3.151 & 0.0798 \\
\hline \multicolumn{4}{|c|}{$\begin{array}{r}\text { Hot Start Average } \\
\text { Hot Start Std Dev } \\
\text { COV (\%) }\end{array}$} & 0.02 & 0.05 & 0.09 & 0.38 & 0.62 & 0.16 & 0.34 & 87.59 & 1.79 \\
\hline
\end{tabular}

Comments: NOx2 sample pump not functioning properly during any of the runs--data invalid. Run -04 started 90 sec late. 
Table 8-53 Summary of CP 0.05 Cert B20 B Neat Fuel for 1999 Cummins ISM 370

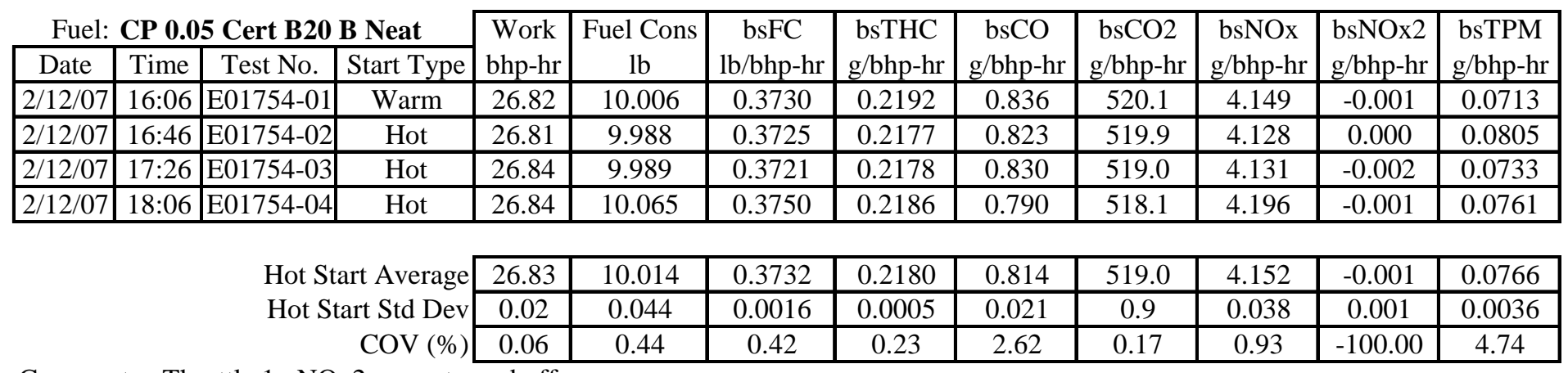

Comments: Throttle 1. NOx2 pump turned off.

Table 8-54 Summary of CP 0.05 Cert B20 B 6-ml 2-EHN Fuel for 1999 Cummins ISM 370

\begin{tabular}{|c|c|c|c|c|c|c|c|c|c|c|c|c|}
\hline \multicolumn{4}{|c|}{ Fuel: CP 0.05 Cert B20 B 6-ml 2-EHN } & \multirow{2}{*}{$\begin{array}{l}\text { Work } \\
\text { bhp-hr }\end{array}$} & \multirow{2}{*}{$\begin{array}{c}\text { Fuel Cons } \\
\text { lb }\end{array}$} & \multirow{2}{*}{$\begin{array}{c}\text { bsFC } \\
\text { lb/bhp-hr }\end{array}$} & \multirow{2}{*}{$\begin{array}{l}\text { bsTHC } \\
\text { g/bhp-hr }\end{array}$} & \multirow{2}{*}{$\begin{array}{c}\text { bsCO } \\
\text { g/bhp-hr }\end{array}$} & \multirow{2}{*}{$\begin{array}{l}\text { bsCO2 } \\
\text { g/bhp-hr }\end{array}$} & \multirow{2}{*}{$\begin{array}{l}\text { bsNOx } \\
\text { g/bhp-hr }\end{array}$} & \multirow{2}{*}{$\begin{array}{l}\text { bsNOx2 } \\
\text { g/bhp-hr }\end{array}$} & \multirow{2}{*}{$\begin{array}{l}\text { bsTPM } \\
\text { g/bhp-hr }\end{array}$} \\
\hline Date & Time & Test No. & Start Type & & & & & & & & & \\
\hline $2 / 13 / 07$ & $7: 38$ & E01756-01 & Warm & 26.81 & 10.156 & 0.3788 & 0.2158 & 0.853 & 526.3 & 4.271 & 3.939 & 0.0811 \\
\hline $2 / 13 / 07$ & $8: 18$ & E01756-02 & Hot & 26.86 & 10.046 & 0.3741 & 0.2075 & 0.812 & 520.3 & 4.092 & 3.859 & 0.0796 \\
\hline $2 / 13 / 07$ & $8: 58$ & E01756-03 & Hot & 26.83 & 10.041 & 0.3742 & 0.2114 & 0.788 & 521.1 & 4.103 & 4.124 & 0.0765 \\
\hline 2/13/07 & 9:39 & E01756-04 & Hot & 26.82 & 10.032 & 0.3740 & 0.2119 & 0.770 & 520.1 & 4.105 & 4.122 & 0.0778 \\
\hline & & & Sall he & 26.84 & 10.040 & 0.3741 & 0.2103 & 0.790 & 520.5 & 4.100 & 4.035 & 0.0780 \\
\hline & & & Start Std Des & 0.02 & 0.007 & 0.0001 & 0.0024 & 0.021 & 0.5 & 0.007 & 0.152 & 0.0015 \\
\hline & & & $\mathrm{COV}(\mathrm{C}$ & 0.08 & 0.07 & 0.03 & 1.15 & 2.67 & 0.10 & 0.17 & 3.78 & 1.96 \\
\hline
\end{tabular}

Comments: Throttle 1. NOx2 on auto range for first two runs. NOx2 heated probe out of temperature range for 200 sec on run -04. 
Table 8-55 Summary of CP 0.05 Cert B20 10-ml DTBP Fuel for 1999 Cummins ISM 370

\begin{tabular}{|c|c|c|c|c|c|c|c|c|c|c|c|c|}
\hline Fuel: & CP 0.0 & 5 Cert B20 & 10-ml DTBP & \multirow{2}{*}{$\begin{array}{l}\text { Work } \\
\text { bhp-hr }\end{array}$} & \multirow{2}{*}{$\begin{array}{c}\text { Fuel Cons } \\
\text { lb }\end{array}$} & \multirow{2}{*}{$\begin{array}{c}\text { bsFC } \\
\text { lb/bhp-hr }\end{array}$} & \multirow{2}{*}{$\begin{array}{l}\text { bsTHC } \\
\text { g/bhp-hr }\end{array}$} & \multirow{2}{*}{$\begin{array}{c}\text { bsCO } \\
\text { g/bhp-hr }\end{array}$} & \multirow{2}{*}{$\begin{array}{l}\text { bsCO2 } \\
\text { g/bhp-hr }\end{array}$} & \multirow{2}{*}{$\begin{array}{l}\text { bsNOx } \\
\text { g/bhp-hr }\end{array}$} & \multirow{2}{*}{$\begin{array}{l}\text { bsNOx2 } \\
\text { g/bhp-hr }\end{array}$} & \multirow{2}{*}{$\begin{array}{l}\text { bsTPM } \\
\text { g/bhp-hr }\end{array}$} \\
\hline Date & Time & Test No. & Start Type & & & & & & & & & \\
\hline $2 / 13 / 07$ & $11: 29$ & E01758-01 & Warm & 26.80 & 10.042 & 0.3747 & 0.2177 & 0.796 & 521.9 & 4.087 & 4.098 & 0.0713 \\
\hline $2 / 13 / 07$ & $12: 09$ & E01758-02 & Hot & 26.82 & 10.029 & 0.3740 & 0.2153 & 0.804 & 519.9 & 4.097 & 4.085 & 0.0773 \\
\hline $2 / 13 / 07$ & $12: 49$ & E01758-03 & Hot & 26.82 & 10.035 & 0.3742 & 0.2125 & 0.779 & 518.7 & 4.082 & 4.082 & 0.0780 \\
\hline 2/13/07 & $13: 30$ & E01758-04 & Hot & 26.82 & 10.023 & 0.3737 & 0.2114 & 0.783 & 518.2 & 4.074 & 4.089 & 0.0794 \\
\hline \multirow{3}{*}{\multicolumn{4}{|c|}{$\begin{array}{r}\text { Hot Start Average } \\
\text { Hot Start Std Dev } \\
\text { COV (\%) }\end{array}$}} & 26.82 & 10.029 & 0.3740 & 0.2131 & 0.789 & 518.9 & 4.084 & 4.085 & 0.0782 \\
\hline & & & & 0.00 & 0.006 & 0.0003 & 0.0020 & 0.013 & 0.8 & 0.012 & 0.004 & 0.0011 \\
\hline & & & & 0.00 & 0.06 & 0.07 & 0.94 & 1.70 & 0.16 & 0.29 & 0.09 & 1.39 \\
\hline
\end{tabular}

Comments: Throttle 1

$$
\operatorname{COV}(\%)
$$

\subsection{Summary of FTP Emissions Data for 2004 Cummins ISM 370}

\section{Table 8-56 Summary of Grad REF Neat Fuel for 2004 Cummins ISM 370}

\begin{tabular}{|c|c|c|c|c|c|c|c|c|c|c|c|c|}
\hline \multicolumn{4}{|c|}{ Fuel: Grad Ref Neat } & \multirow{2}{*}{$\begin{array}{l}\text { Work } \\
\text { bhp-hr }\end{array}$} & \multirow{2}{*}{$\begin{array}{c}\text { Fuel Cons } \\
\text { lb }\end{array}$} & \multirow{2}{*}{$\begin{array}{c}\text { bsFC } \\
\text { lb/bhp-hr }\end{array}$} & \multirow{2}{*}{$\begin{array}{l}\text { bsTHC } \\
\text { g/bhp-hr }\end{array}$} & \multirow{2}{*}{$\begin{array}{c}\text { bsCO } \\
\text { g/bhp-hr }\end{array}$} & \multirow{2}{*}{$\begin{array}{c}\text { bsCO2 } \\
\text { g/bhp-hr }\end{array}$} & \multirow{2}{*}{$\begin{array}{l}\text { bsNOx } \\
\text { g/bhp-hr }\end{array}$} & \multirow{2}{*}{$\begin{array}{l}\text { bsNOx2 } \\
\text { g/bhp-hr }\end{array}$} & \multirow{2}{*}{$\begin{array}{l}\text { bsTPM } \\
\text { g/bhp-hr }\end{array}$} \\
\hline Date & Time & Test No. & Start Type & & & & & & & & & \\
\hline $2 / 20 / 07$ & $14: 37$ & E01762-01 & Warm & 25.17 & 10.672 & 0.4240 & 0.1885 & 0.635 & 598.0 & 2.168 & 2.136 & 0.0956 \\
\hline $2 / 20 / 07$ & $15: 17$ & E01762-02 & Hot & 25.18 & 10.585 & 0.4205 & 0.1941 & 0.623 & 592.2 & 2.153 & 2.144 & 0.0590 \\
\hline $2 / 20 / 07$ & $15: 58$ & E01762-03 & Hot & 25.19 & 10.728 & 0.4259 & 0.1958 & 0.620 & 592.2 & 2.158 & 2.154 & 0.0575 \\
\hline $2 / 20 / 07$ & $16: 38$ & E01762-04 & Hot & 25.18 & 10.610 & 0.4213 & 0.1964 & 0.601 & 590.1 & 2.172 & 2.165 & 0.0562 \\
\hline \multirow{3}{*}{\multicolumn{4}{|c|}{$\begin{array}{r}\text { Hot Start Average } \\
\text { Hot Start Std Dev } \\
\text { COV (\%) }\end{array}$}} & 25.18 & 10.64 & 0.42 & 0.20 & 0.61 & 591.48 & 2.161 & 2.154 & 0.06 \\
\hline & & & & 0.01 & 0.08 & 0.00 & 0.00 & 0.01 & 1.21 & 0.01 & 0.01 & 0.00 \\
\hline & & & & 0.02 & 0.72 & 0.69 & 0.61 & 1.94 & 0.21 & 0.46 & 0.49 & 2.39 \\
\hline
\end{tabular}

Comments: Throttle 1

$$
\text { COV }(\%)
$$

$0.02 \quad 0.72$ 
Table 8-57 Summary of CP 0.05 Cert Neat 1 Fuel for 2004 Cummins ISM 370

\begin{tabular}{|c|c|c|c|c|c|c|c|c|c|c|c|c|}
\hline \multicolumn{4}{|c|}{ Fuel: CP 0.05 Cert Neat 1} & \multirow{2}{*}{$\begin{array}{l}\text { Work } \\
\text { bhp-hr }\end{array}$} & \multirow{2}{*}{$\begin{array}{c}\text { Fuel Cons } \\
\mathrm{lb} \\
\end{array}$} & \multirow{2}{*}{$\begin{array}{c}\text { bsFC } \\
\text { lb/bhp-hr }\end{array}$} & \multirow{2}{*}{$\begin{array}{l}\text { bsTHC } \\
\text { g/bhp-hr }\end{array}$} & \multirow{2}{*}{$\begin{array}{c}\text { bsCO } \\
\text { g/bhp-hr }\end{array}$} & \multirow{2}{*}{$\begin{array}{c}\text { bsCO2 } \\
\text { g/bhp-hr }\end{array}$} & \multirow{2}{*}{$\begin{array}{l}\text { bsNOx } \\
\text { g/bhp-hr }\end{array}$} & \multirow{2}{*}{$\begin{array}{l}\text { bsNOx2 } \\
\text { g/bhp-hr }\end{array}$} & \multirow{2}{*}{$\begin{array}{l}\text { bsTPM } \\
\text { g/bhp-hr }\end{array}$} \\
\hline Date & Time & Test No. & Start Type & & & & & & & & & \\
\hline $2 / 21 / 07$ & 9:02 & E01765-01 & Warm & 25.61 & 10.745 & 0.4195 & 0.1962 & 0.636 & 603.6 & 2.360 & 2.345 & 0.0742 \\
\hline $2 / 21 / 07$ & 9:43 & E01765-02 & Hot & 25.63 & 10.853 & 0.4235 & 0.1966 & 0.630 & 601.7 & 2.360 & 2.341 & 0.0703 \\
\hline $2 / 21 / 07$ & $10: 23$ & E01765-03 & Hot & 25.64 & 10.724 & 0.4182 & 0.2011 & 0.611 & 600.9 & 2.348 & 2.328 & 0.0809 \\
\hline $2 / 21 / 07$ & 11:04 & E01765-04 & Hot & 25.65 & 10.788 & 0.4206 & 0.2026 & 0.609 & 602.1 & 0.000 & 2.336 & 0.0720 \\
\hline \multirow{3}{*}{\multicolumn{4}{|c|}{$\begin{array}{r}\text { Hot Start Average } \\
\text { Hot Start Std Dev } \\
\text { COV (\%) }\end{array}$}} & 25.64 & 10.79 & 0.42 & 0.20 & 0.62 & 601.59 & 1.569 & 2.335 & 0.07 \\
\hline & & & & 0.01 & 0.06 & 0.00 & 0.00 & 0.01 & 0.61 & 1.36 & 0.01 & 0.01 \\
\hline & & & & 0.04 & 0.60 & 0.63 & 1.56 & 1.88 & 0.10 & 86.60 & 0.28 & 7.66 \\
\hline
\end{tabular}

Comments: Throttle 1. RUN ON CP 0.05 CERT MAP.

Table 8-58 Summary of CP 0.05 Cert 12-ml ODA Fuel for 2004 Cummins ISM 370

\begin{tabular}{|c|c|c|c|c|c|c|c|c|c|c|c|c|}
\hline \multicolumn{4}{|c|}{ Fuel: CP 0.05 Cert 12-ml ODA } & \multirow{2}{*}{$\begin{array}{l}\text { Work } \\
\text { bhp-hr }\end{array}$} & \multirow{2}{*}{\begin{tabular}{|c} 
Fuel Cons \\
lb
\end{tabular}} & \multirow{2}{*}{$\begin{array}{c}\text { bsFC } \\
\text { lb/bhp-hr }\end{array}$} & \multirow{2}{*}{$\begin{array}{l}\text { bsTHC } \\
\text { g/bhp-hr }\end{array}$} & \multirow{2}{*}{$\begin{array}{c}\text { bsCO } \\
\text { g/bhp-hr }\end{array}$} & \multirow{2}{*}{$\begin{array}{l}\text { bsCO2 } \\
\text { g/bhp-hr }\end{array}$} & \multirow{2}{*}{$\begin{array}{l}\text { bsNOx } \\
\text { g/bhp-hr }\end{array}$} & \multirow{2}{*}{$\begin{array}{l}\text { bsNOx2 } \\
\text { g/bhp-hr }\end{array}$} & \multirow{2}{*}{$\begin{array}{l}\text { bsTPM } \\
\text { g/bhp-hr }\end{array}$} \\
\hline Date & Time & Test No. & Start Type & & & & & & & & & \\
\hline $2 / 21 / 07$ & $14: 55$ & E01768-01 & Warm & 25.65 & 10.602 & 0.4134 & 0.2002 & 0.581 & 602.5 & 2.357 & 2.335 & 0.0699 \\
\hline $2 / 21 / 07$ & $15: 35$ & E01768-02 & Hot & 25.64 & 10.634 & 0.4147 & 0.2019 & 0.584 & 602.5 & 2.355 & 2.338 & 0.0702 \\
\hline $2 / 21 / 07$ & $16: 15$ & E01768-03 & Hot & 25.34 & 10.663 & 0.4208 & 0.2043 & 0.554 & 601.2 & 2.340 & 2.321 & 0.0811 \\
\hline $2 / 21 / 07$ & $16: 56$ & E01768-04 & Hot & 25.65 & 10.765 & 0.4196 & 0.2044 & 0.575 & 601.1 & 2.360 & 2.342 & 0.0723 \\
\hline \multirow{3}{*}{\multicolumn{4}{|c|}{$\begin{array}{r}\text { Hot Start Average } \\
\text { Hot Start Std Dev } \\
\text { COV (\%) }\end{array}$}} & 25.54 & 10.69 & 0.42 & 0.20 & 0.57 & 601.61 & 2.352 & 2.334 & 0.07 \\
\hline & & & & 0.18 & 0.07 & 0.00 & 0.00 & 0.02 & 0.80 & 0.01 & 0.01 & 0.01 \\
\hline & & & & 0.69 & 0.64 & 0.77 & 0.70 & 2.70 & 0.13 & 0.44 & 0.48 & 7.77 \\
\hline
\end{tabular}

Comments: Throttle 1, RUN ON CP 0.05 CERT MAP. 
Table 8-59 Summary of CP 0.05 Cert 6-ml 2-EHN Fuel for 2004 Cummins ISM 370

\begin{tabular}{|c|c|c|c|c|c|c|c|c|c|c|c|c|}
\hline \multicolumn{4}{|c|}{ Fuel: CP 0.05 Cert 6-ml 2-EHN } & \multirow{2}{*}{$\begin{array}{l}\text { Work } \\
\text { bhp-hr }\end{array}$} & \multirow{2}{*}{\begin{tabular}{|c} 
Fuel Cons \\
lb
\end{tabular}} & \multirow{2}{*}{$\begin{array}{c}\text { bsFC } \\
\text { lb/bhp-hr }\end{array}$} & \multirow{2}{*}{$\begin{array}{l}\text { bsTHC } \\
\text { g/bhp-hr }\end{array}$} & \multirow{2}{*}{$\begin{array}{c}\text { bsCO } \\
\text { g/bhp-hr }\end{array}$} & \multirow{2}{*}{$\begin{array}{c}\text { bsCO2 } \\
\text { g/bhp-hr }\end{array}$} & \multirow{2}{*}{$\begin{array}{l}\text { bsNOx } \\
\text { g/bhp-hr }\end{array}$} & \multirow{2}{*}{$\begin{array}{l}\text { bsNOx2 } \\
\text { g/bhp-hr }\end{array}$} & \multirow{2}{*}{$\begin{array}{l}\text { bsTPM } \\
\text { g/bhp-hr }\end{array}$} \\
\hline Date & Time & Test No. & Start Type & & & & & & & & & \\
\hline $2 / 22 / 07$ & $7: 32$ & E01771-01 & Warm & 25.62 & 10.603 & 0.4139 & 0.2044 & 0.610 & 608.2 & 2.465 & 2.446 & 0.0872 \\
\hline $2 / 22 / 07$ & $8: 12$ & E01771-02 & Hot & 25.64 & 10.828 & 0.4224 & 0.2031 & 0.565 & 600.5 & 2.353 & 2.345 & 0.0729 \\
\hline $2 / 22 / 07$ & $8: 53$ & E01771-03 & Hot & 25.63 & 10.706 & 0.4177 & 0.2029 & 0.561 & 599.2 & 2.377 & 2.368 & 0.0729 \\
\hline $2 / 22 / 07$ & $9: 33$ & E01771-04 & Hot & 25.64 & 10.756 & 0.4195 & 0.2055 & 0.590 & 599.5 & 2.368 & 2.366 & 0.0735 \\
\hline \multirow{3}{*}{\multicolumn{4}{|c|}{$\begin{array}{r}\text { Hot Start Average } \\
\text { Hot Start Std Dev } \\
\text { COV (\%) }\end{array}$}} & 25.64 & 10.76 & 0.42 & 0.20 & 0.57 & 599.76 & 2.366 & 2.360 & 0.07 \\
\hline & & & & 0.01 & 0.06 & 0.00 & 0.00 & 0.02 & 0.70 & 0.01 & 0.01 & 0.00 \\
\hline & & & & 0.02 & 0.57 & 0.56 & 0.71 & 2.75 & 0.12 & 0.51 & 0.54 & 0.50 \\
\hline
\end{tabular}

Comments: Throttle 1, RUN ON CP 0.05 CERT MAP.

\section{Table 8-60 Summary of CP 0.05 Cert 12-ml 2-EHN Fuel for 2004 Cummins ISM 370}

\begin{tabular}{|c|c|c|c|c|c|c|c|c|c|c|c|c|}
\hline \multicolumn{4}{|c|}{ Fuel: CP 0.05 Cert 12-ml 2-EHN } & \multirow{2}{*}{$\begin{array}{c}\text { Work } \\
\text { bhp-hr }\end{array}$} & \multirow{2}{*}{\begin{tabular}{|c} 
Fuel Cons \\
lb
\end{tabular}} & \multirow{2}{*}{$\begin{array}{c}\text { bsFC } \\
\text { lb/bhp-hr }\end{array}$} & \multirow{2}{*}{$\begin{array}{l}\text { bsTHC } \\
\text { g/bhp-hr }\end{array}$} & \multirow{2}{*}{$\begin{array}{c}\text { bsCO } \\
\text { g/bhp-hr }\end{array}$} & \multirow{2}{*}{$\begin{array}{l}\text { bsCO2 } \\
\text { g/bhp-hr }\end{array}$} & \multirow{2}{*}{$\begin{array}{l}\text { bsNOx } \\
\text { g/bhp-hr }\end{array}$} & \multirow{2}{*}{$\begin{array}{l}\text { bsNOx2 } \\
\text { g/bhp-hr }\end{array}$} & \multirow{2}{*}{$\begin{array}{l}\text { bsTPM } \\
\text { g/bhp-hr }\end{array}$} \\
\hline Date & Time & Test No. & Start Type & & & & & & & & & \\
\hline $2 / 22 / 07$ & $11: 40$ & E01773-01 & Warm & 25.64 & 10.856 & 0.4235 & 0.2045 & 0.550 & 600.5 & 2.365 & 2.350 & 0.0705 \\
\hline $2 / 22 / 07$ & $12: 20$ & E01773-02 & Hot & 25.64 & 10.726 & 0.4184 & 0.2053 & 0.535 & 600.7 & 2.370 & 2.355 & 0.0711 \\
\hline $2 / 22 / 07$ & $13: 01$ & E01773-03 & Hot & 25.64 & 10.777 & 0.4203 & 0.2070 & 0.560 & 600.7 & 2.392 & 2.377 & 0.0720 \\
\hline $2 / 22 / 07$ & $13: 41$ & E01773-04 & Hot & 25.64 & 10.675 & 0.4164 & 0.2010 & 0.535 & 599.8 & 2.393 & 2.375 & 0.0727 \\
\hline \multirow{3}{*}{\multicolumn{4}{|c|}{$\begin{array}{r}\text { Hot Start Average } \\
\text { Hot Start Std Dev } \\
\text { COV (\%) }\end{array}$}} & 25.64 & 10.73 & 0.42 & 0.20 & 0.54 & 600.37 & 2.385 & 2.369 & 0.07 \\
\hline & & & & 0.00 & 0.05 & 0.00 & 0.00 & 0.01 & 0.49 & 0.01 & 0.01 & 0.00 \\
\hline & & & & 0.00 & 0.48 & 0.47 & 1.51 & 2.66 & 0.08 & 0.55 & 0.51 & 1.11 \\
\hline
\end{tabular}

Comments: Throttle 1, RUN ON CP 0.05 CERT MAP. 
Table 8-61 Summary of CP 0.05 Cert 24-ml ODA Fuel for 2004 Cummins ISM 370

\begin{tabular}{|c|c|c|c|c|c|c|c|c|c|c|c|c|}
\hline \multicolumn{4}{|c|}{ Fuel: CP 0.05 Cert 24-ml ODA } & \multirow{2}{*}{$\begin{array}{l}\text { Work } \\
\text { bhp-hr }\end{array}$} & \multirow{2}{*}{\begin{tabular}{|c} 
Fuel Cons \\
lb
\end{tabular}} & \multirow{2}{*}{$\begin{array}{c}\text { bsFC } \\
\text { lb/bhp-hr }\end{array}$} & \multirow{2}{*}{$\begin{array}{l}\text { bsTHC } \\
\text { g/bhp-hr }\end{array}$} & \multirow{2}{*}{$\begin{array}{c}\text { bsCO } \\
\text { g/bhp-hr }\end{array}$} & \multirow{2}{*}{$\begin{array}{l}\text { bsCO2 } \\
\text { g/bhp-hr }\end{array}$} & \multirow{2}{*}{$\begin{array}{l}\text { bsNOx } \\
\text { g/bhp-hr }\end{array}$} & \multirow{2}{*}{$\begin{array}{l}\text { bsNOx2 } \\
\text { g/bhp-hr }\end{array}$} & \multirow{2}{*}{$\begin{array}{l}\text { bsTPM } \\
\text { g/bhp-hr }\end{array}$} \\
\hline Date & Time & Test No. & Start Type & & & & & & & & & \\
\hline $2 / 22 / 07$ & $15: 22$ & E01775-01 & Warm & 25.65 & 10.785 & 0.4205 & 0.2083 & 0.566 & 601.7 & 2.375 & 2.355 & 0.0702 \\
\hline $2 / 22 / 07$ & $16: 03$ & E01775-02 & Hot & 25.64 & 10.790 & 0.4207 & 0.2061 & 0.555 & 601.2 & 2.379 & 2.371 & 0.0705 \\
\hline $2 / 22 / 07$ & $16: 43$ & E01775-03 & Hot & 25.65 & 10.261 & 0.4000 & 0.2054 & 0.562 & 602.3 & 2.392 & 2.376 & 0.0712 \\
\hline $2 / 22 / 07$ & $17: 23$ & E01775-04 & Hot & 25.65 & 10.733 & 0.4184 & 0.2063 & 0.554 & 598.6 & 2.390 & 2.342 & 0.0739 \\
\hline \multirow{3}{*}{\multicolumn{4}{|c|}{$\begin{array}{r}\text { Hot Start Average } \\
\text { Hot Start Std Dev } \\
\text { COV (\%) }\end{array}$}} & 25.65 & 10.59 & 0.41 & 0.21 & 0.56 & 600.68 & 2.387 & 2.363 & 0.07 \\
\hline & & & & 0.01 & 0.29 & 0.01 & 0.00 & 0.00 & 1.91 & 0.01 & 0.02 & 0.00 \\
\hline & & & & 0.02 & 2.74 & 2.75 & 0.23 & 0.78 & 0.32 & 0.29 & 0.78 & 2.51 \\
\hline
\end{tabular}

Comments: Throttle 1, Fuel consumed $<$ Fuel recovered on run -03. RUN ON CP 0.05 CERT MAP.

Table 8-62 Summary of CP 0.05 Cert 15-ml DTBP Fuel for 2004 Cummins ISM 370

\begin{tabular}{|c|c|c|c|c|c|c|c|c|c|c|c|c|}
\hline \multicolumn{4}{|c|}{ Fuel: CP Cert 15-ml DTBP } & \multirow{2}{*}{$\begin{array}{l}\text { Work } \\
\text { bhp-hr }\end{array}$} & \multirow{2}{*}{\begin{tabular}{|c} 
Fuel Cons \\
lb \\
\end{tabular}} & \multirow{2}{*}{$\begin{array}{c}\text { bsFC } \\
\text { lb/bhp-hr }\end{array}$} & \multirow{2}{*}{$\begin{array}{l}\text { bsTHC } \\
\text { g/bhp-hr }\end{array}$} & \multirow{2}{*}{$\begin{array}{c}\text { bsCO } \\
\text { g/bhp-hr }\end{array}$} & \multirow{2}{*}{$\begin{array}{c}\text { bsCO2 } \\
\text { g/bhp-hr }\end{array}$} & \multirow{2}{*}{$\begin{array}{c}\text { bsNOx } \\
\text { g/bhp-hr }\end{array}$} & \multirow{2}{*}{$\begin{array}{l}\text { bsNOx2 } \\
\text { g/bhp-hr }\end{array}$} & \multirow{2}{*}{$\begin{array}{l}\text { bsTPM } \\
\text { g/bhp-hr }\end{array}$} \\
\hline Date & Time & \begin{tabular}{|l|} 
Test No. \\
\end{tabular} & Start Type & & & & & & & & & \\
\hline $2 / 23 / 07$ & $7: 20$ & E01777-01 & Warm & 25.69 & 10.766 & 0.4190 & 0.2058 & 0.606 & 608.8 & 2.565 & 2.569 & 0.0790 \\
\hline $2 / 23 / 07$ & $8: 00$ & E01777-02 & Hot & 25.68 & 10.735 & 0.4180 & 0.2005 & 0.534 & 602.6 & 2.381 & 2.377 & 0.0719 \\
\hline $2 / 23 / 07$ & $8: 40$ & E01777-03 & Hot & 25.39 & 10.561 & 0.4160 & 0.1990 & 0.517 & 601.0 & 2.348 & 2.343 & 0.0718 \\
\hline $2 / 23 / 07$ & $9: 21$ & E01777-04 & Hot & 25.70 & 10.637 & 0.4139 & 0.1987 & 0.528 & 600.6 & 2.366 & 2.350 & 0.0728 \\
\hline \multirow{3}{*}{\multicolumn{4}{|c|}{$\begin{array}{r}\text { Hot Start Average } \\
\text { Hot Start Std Dev } \\
\text { COV (\%) }\end{array}$}} & 25.59 & 10.64 & 0.42 & 0.20 & 0.53 & 601.43 & 2.365 & 2.357 & 0.07 \\
\hline & & & & 0.17 & 0.09 & 0.00 & 0.00 & 0.01 & 1.06 & 0.02 & 0.02 & 0.00 \\
\hline & & & & 0.68 & 0.82 & 0.49 & 0.48 & 1.64 & 0.18 & 0.70 & 0.76 & 0.75 \\
\hline
\end{tabular}

Comments: Throttle 1, RUN ON CP 0.05 CERT MAP. 
Table 8-63 Summary of Grad CAND Neat Fuel for 2004 Cummins ISM 370

\begin{tabular}{|c|c|c|c|c|c|c|c|c|c|c|c|c|}
\hline \multicolumn{4}{|c|}{ Fuel: Grad CAND Neat } & \multirow{2}{*}{$\begin{array}{l}\text { Work } \\
\text { bhp-hr }\end{array}$} & \multirow{2}{*}{\begin{tabular}{|c} 
Fuel Cons \\
lb
\end{tabular}} & \multirow{2}{*}{$\begin{array}{c}\text { bsFC } \\
\text { lb/bhp-hr }\end{array}$} & \multirow{2}{*}{$\begin{array}{l}\text { bsTHC } \\
\text { g/bhp-hr }\end{array}$} & \multirow{2}{*}{$\begin{array}{c}\text { bsCO } \\
\text { g/bhp-hr }\end{array}$} & \multirow{2}{*}{$\begin{array}{l}\text { bsCO2 } \\
\text { g/bhp-hr }\end{array}$} & \multirow{2}{*}{$\begin{array}{l}\text { bsNOx } \\
\text { g/bhp-hr }\end{array}$} & \multirow{2}{*}{$\begin{array}{l}\text { bsNOx2 } \\
\text { g/bhp-hr }\end{array}$} & \multirow{2}{*}{$\begin{array}{l}\text { bsTPM } \\
\text { g/bhp-hr }\end{array}$} \\
\hline Date & Time & Test No. & Start Type & & & & & & & & & \\
\hline $2 / 23 / 07$ & $11: 26$ & E01779-01 & Warm & 25.22 & 10.350 & 0.4104 & 0.2168 & 0.560 & 597.6 & 2.342 & 2.327 & 0.0000 \\
\hline $2 / 23 / 07$ & $12: 06$ & E01779-02 & Hot & 25.21 & 10.264 & 0.4071 & 0.2120 & 0.551 & 595.4 & 2.352 & 2.332 & 0.0533 \\
\hline $2 / 23 / 07$ & $12: 47$ & E01779-03 & Hot & 25.22 & 10.408 & 0.4127 & 0.2148 & 0.557 & 596.2 & 2.346 & 2.332 & 0.0565 \\
\hline $2 / 23 / 07$ & $13: 27$ & E01779-04 & Hot & 25.21 & 10.065 & 0.3992 & 0.2154 & 0.573 & 597.2 & 2.349 & 2.327 & 0.0547 \\
\hline \multirow{3}{*}{\multicolumn{4}{|c|}{$\begin{array}{r}\text { Hot Start Average } \\
\text { Hot Start Std Dev } \\
\text { COV (\%) }\end{array}$}} & 25.21 & 10.25 & 0.41 & 0.21 & 0.56 & 596.25 & 2.349 & 2.330 & 0.05 \\
\hline & & & & 0.01 & 0.17 & 0.01 & 0.00 & 0.01 & 0.90 & 0.00 & 0.00 & 0.00 \\
\hline & & & & 0.02 & 1.68 & 1.67 & 0.85 & 2.03 & 0.15 & 0.13 & 0.12 & 2.90 \\
\hline
\end{tabular}

Comments: Throttle 1. No TPM for warm start. RUN ON REFERENCE FUEL MAP.

\section{Table 8-64 Summary of Grad CAND 6-ml ODA Fuel for 2004 Cummins ISM 370}

\begin{tabular}{|c|c|c|c|c|c|c|c|c|c|c|c|c|}
\hline \multicolumn{4}{|c|}{ Fuel: Grad CAND 6-ml ODA } & \multirow{2}{*}{$\begin{array}{l}\text { Work } \\
\text { bhp-hr }\end{array}$} & \multirow{2}{*}{\begin{tabular}{|c} 
Fuel Cons \\
lb
\end{tabular}} & \multirow{2}{*}{$\begin{array}{c}\text { bsFC } \\
\text { lb/bhp-hr }\end{array}$} & \multirow{2}{*}{$\begin{array}{l}\text { bsTHC } \\
\text { g/bhp-hr }\end{array}$} & \multirow{2}{*}{$\begin{array}{c}\text { bsCO } \\
\text { g/bhp-hr }\end{array}$} & \multirow{2}{*}{$\begin{array}{l}\text { bsCO2 } \\
\text { g/bhp-hr }\end{array}$} & \multirow{2}{*}{$\begin{array}{l}\text { bsNOx } \\
\text { g/bhp-hr }\end{array}$} & \multirow{2}{*}{$\begin{array}{l}\text { bsNOx2 } \\
\text { g/bhp-hr }\end{array}$} & \multirow{2}{*}{$\begin{array}{l}\text { bsTPM } \\
\text { g/bhp-hr }\end{array}$} \\
\hline Date & Time & Test No. & Start Type & & & & & & & & & \\
\hline $2 / 23 / 07$ & $15: 11$ & E01781-01 & Warm & 25.22 & 10.622 & 0.4212 & 0.2162 & 0.560 & 598.6 & 2.346 & 2.327 & 0.0530 \\
\hline $2 / 23 / 07$ & $15: 51$ & E01781-02 & Hot & 25.21 & 10.399 & 0.4125 & 0.2147 & 0.551 & 597.6 & 2.344 & 2.320 & 0.0548 \\
\hline $2 / 23 / 07$ & $16: 31$ & E01781-03 & Hot & 25.21 & 10.621 & 0.4213 & 0.2171 & 0.568 & 598.9 & 2.352 & 2.328 & 0.0544 \\
\hline $2 / 23 / 07$ & $17: 12$ & E01781-04 & Hot & 25.23 & 10.485 & 0.4156 & 0.2183 & 0.555 & 598.6 & 2.355 & 2.330 & 0.0558 \\
\hline \multirow{3}{*}{\multicolumn{4}{|c|}{$\begin{array}{r}\text { Hot Start Average } \\
\text { Hot Start Std Dev } \\
\text { COV (\%) }\end{array}$}} & 25.22 & 10.50 & 0.42 & 0.22 & 0.56 & 598.37 & 2.350 & 2.326 & 0.05 \\
\hline & & & & 0.01 & 0.11 & 0.00 & 0.00 & 0.01 & 0.72 & 0.01 & 0.01 & 0.00 \\
\hline & & & & 0.05 & 1.07 & 1.07 & 0.85 & 1.59 & 0.12 & 0.24 & 0.23 & 1.26 \\
\hline
\end{tabular}

Comments: Throttle 1, RUN ON REFERENCE FUEL MAP. 
Table 8-65 Summary of CP 0.05 Cert B20 B Neat Fuel for 2004 Cummins ISM 370

\begin{tabular}{|c|c|c|c|c|c|c|c|c|c|c|c|c|}
\hline \multicolumn{4}{|c|}{ Fuel: CP 0.05 Cert B20 B Neat } & \multirow{2}{*}{$\begin{array}{l}\text { Work } \\
\text { bhp-hr }\end{array}$} & \multirow{2}{*}{$\begin{array}{c}\text { Fuel Cons } \\
\text { lb }\end{array}$} & \multirow{2}{*}{$\begin{array}{c}\text { bsFC } \\
\text { lb/bhp-hr }\end{array}$} & \multirow{2}{*}{$\begin{array}{l}\text { bsTHC } \\
\text { g/bhp-hr }\end{array}$} & \multirow{2}{*}{$\begin{array}{c}\text { bsCO } \\
\text { g/bhp-hr }\end{array}$} & \multirow{2}{*}{$\begin{array}{l}\text { bsCO2 } \\
\text { g/bhp-hr }\end{array}$} & \multirow{2}{*}{$\begin{array}{l}\text { bsNOx } \\
\text { g/bhp-hr }\end{array}$} & \multirow{2}{*}{$\begin{array}{l}\text { bsNOx2 } \\
\text { g/bhp-hr }\end{array}$} & \multirow{2}{*}{$\begin{array}{l}\text { bsTPM } \\
\text { g/bhp-hr }\end{array}$} \\
\hline Date & Time & Test No. & Start Type & & & & & & & & & \\
\hline $2 / 24 / 07$ & $7: 20$ & E01783-01 & Warm & 25.22 & 10.940 & 0.4338 & 0.1773 & 0.542 & 611.1 & 2.492 & 2.476 & 0.0623 \\
\hline $2 / 24 / 07$ & $8: 00$ & E01783-02 & Hot & 25.22 & 10.249 & 0.4063 & 0.1837 & 0.554 & 605.8 & 2.487 & 2.476 & 0.0549 \\
\hline $2 / 24 / 07$ & $8: 40$ & E01783-03 & Hot & 25.23 & 10.704 & 0.4242 & 0.1870 & 0.547 & 605.1 & 2.476 & 2.462 & 0.0560 \\
\hline $2 / 24 / 07$ & 9:21 & E01783-04 & Hot & 25.23 & 10.810 & 0.4285 & 0.1861 & 0.546 & 603.5 & 2.478 & 2.447 & 0.0577 \\
\hline \multirow{3}{*}{\multicolumn{4}{|c|}{$\begin{array}{r}\text { Hot Start Average } \\
\text { Hot Start Std Dev } \\
\text { COV (\%) }\end{array}$}} & 25.23 & 10.59 & 0.42 & 0.19 & 0.55 & 604.80 & 2.480 & 2.462 & 0.06 \\
\hline & & & & 0.01 & 0.30 & 0.01 & 0.00 & 0.00 & 1.15 & 0.01 & 0.01 & 0.00 \\
\hline & & & & 0.02 & 2.82 & 2.81 & 0.92 & 0.79 & 0.19 & 0.24 & 0.59 & 2.51 \\
\hline
\end{tabular}

Comments: Throttle 1, NOx filter temperature controller replaced during warm start. RUN ON REFERENCE FUEL MAP.

Table 8-66 Summary of CP 0.05 Cert B20 A Neat Fuel for 2004 Cummins ISM 370

\begin{tabular}{|c|c|c|c|c|c|c|c|c|c|c|c|c|}
\hline \multicolumn{4}{|c|}{ Fuel: CP Cert B20 A Neat } & \multirow{2}{*}{$\begin{array}{c}\text { Work } \\
\text { bhp-hr }\end{array}$} & \multirow{2}{*}{$\begin{array}{c}\text { Fuel Cons } \\
\text { lb } \\
\end{array}$} & \multirow{2}{*}{$\begin{array}{c}\text { bsFC } \\
\text { lb/bhp-hr }\end{array}$} & \multirow{2}{*}{$\begin{array}{c}\text { bsTHC } \\
\text { g/bhp-hr }\end{array}$} & \multirow{2}{*}{$\begin{array}{c}\text { bsCO } \\
\text { g/bhp-hr }\end{array}$} & \multirow{2}{*}{$\begin{array}{c}\text { bsCO2 } \\
\text { g/bhp-hr }\end{array}$} & \multirow{2}{*}{$\begin{array}{c}\text { bsNOx } \\
\text { g/bhp-hr }\end{array}$} & \multirow{2}{*}{$\begin{array}{l}\text { bsNOx2 } \\
\text { g/bhp-hr }\end{array}$} & \multirow{2}{*}{$\begin{array}{l}\text { bsTPM } \\
\text { g/bhp-hr }\end{array}$} \\
\hline Date & Time & \begin{tabular}{|l|} 
Test No. \\
\end{tabular} & Start Type & & & & & & & & & \\
\hline $2 / 24 / 07$ & $11: 15$ & E01785-01 & Warm & 25.25 & 10.630 & 0.4210 & 0.1770 & 0.519 & 602.9 & 2.437 & 2.421 & 0.0475 \\
\hline $2 / 24 / 07$ & $11: 55$ & E01785-02 & Hot & 25.20 & 10.563 & 0.4192 & 0.1811 & 0.535 & 602.0 & 2.433 & 2.405 & 0.0517 \\
\hline $2 / 24 / 07$ & $12: 35$ & E01785-03 & Hot & 25.20 & 10.599 & 0.4206 & 0.1788 & 0.544 & 600.9 & 2.455 & 2.416 & 0.0536 \\
\hline $2 / 24 / 07$ & $13: 16$ & E01785-04 & Hot & 25.20 & 10.859 & 0.4309 & 0.1825 & 0.551 & 603.4 & 2.442 & 2.402 & 0.0542 \\
\hline \multirow{3}{*}{\multicolumn{4}{|c|}{$\begin{array}{r}\text { Hot Start Average } \\
\text { Hot Start Std Dev } \\
\text { COV (\%) }\end{array}$}} & 25.20 & 10.67 & 0.42 & 0.18 & 0.54 & 602.09 & 2.443 & 2.408 & 0.05 \\
\hline & & & & 0.00 & 0.16 & 0.01 & 0.00 & 0.01 & 1.24 & 0.01 & 0.01 & 0.00 \\
\hline & & & & 0.00 & 1.51 & 1.51 & 1.03 & 1.48 & 0.21 & 0.45 & 0.31 & 2.46 \\
\hline
\end{tabular}

Comments: Throttle 1. RUN ON REFERENCE FUEL MAP. 
Table 8-67 Summary of CP 0.05 Cert B20 C Neat Fuel for 2004 Cummins ISM 370

\begin{tabular}{|c|c|c|c|c|c|c|c|c|c|c|c|c|}
\hline \multicolumn{4}{|c|}{ Fuel: CP Cert B20 C Neat } & \multirow{2}{*}{$\begin{array}{l}\text { Work } \\
\text { bhp-hr }\end{array}$} & \multirow{2}{*}{$\begin{array}{c}\text { Fuel Cons } \\
\text { lb }\end{array}$} & \multirow{2}{*}{$\begin{array}{c}\text { bsFC } \\
\text { lb/bhp-hr }\end{array}$} & \multirow{2}{*}{$\begin{array}{l}\text { bsTHC } \\
\text { g/bhp-hr }\end{array}$} & \multirow{2}{*}{$\begin{array}{c}\text { bsCO } \\
\text { g/bhp-hr }\end{array}$} & \multirow{2}{*}{$\begin{array}{l}\text { bsCO2 } \\
\text { g/bhp-hr }\end{array}$} & \multirow{2}{*}{$\begin{array}{l}\text { bsNOx } \\
\text { g/bhp-hr }\end{array}$} & \multirow{2}{*}{$\begin{array}{l}\text { bsNOx2 } \\
\text { g/bhp-hr }\end{array}$} & \multirow{2}{*}{$\begin{array}{l}\text { bsTPM } \\
\text { g/bhp-hr }\end{array}$} \\
\hline Date & Time & Test No. & Start Type & & & & & & & & & \\
\hline $2 / 24 / 07$ & $14: 53$ & E01787-01 & Warm & 24.91 & 10.580 & 0.4247 & 0.1829 & 0.553 & 604.0 & 2.450 & 2.419 & 0.0444 \\
\hline $2 / 24 / 07$ & $15: 33$ & E01787-02 & Hot & 25.20 & 10.858 & 0.4308 & 0.1810 & 0.543 & 603.0 & 2.471 & 2.434 & 0.0469 \\
\hline $2 / 24 / 07$ & $16: 14$ & E01787-03 & Hot & 25.20 & 10.769 & 0.4274 & 0.1804 & 0.547 & 601.8 & 2.468 & 2.436 & 0.0478 \\
\hline $2 / 24 / 07$ & $16: 54$ & E01787-04 & Hot & 25.21 & 10.855 & 0.4306 & 0.1827 & 0.546 & 601.1 & 2.464 & 2.442 & 0.0487 \\
\hline \multirow{3}{*}{\multicolumn{4}{|c|}{$\begin{array}{r}\text { Hot Start Average } \\
\text { Hot Start Std Dev } \\
\text { COV (\%) }\end{array}$}} & 25.20 & 10.83 & 0.43 & 0.18 & 0.55 & 601.98 & 2.468 & 2.437 & 0.05 \\
\hline & & & & 0.01 & 0.05 & 0.00 & 0.00 & 0.00 & 0.98 & 0.00 & 0.00 & 0.00 \\
\hline & & & & 0.02 & 0.47 & 0.44 & 0.66 & 0.38 & 0.16 & 0.14 & 0.17 & 1.84 \\
\hline
\end{tabular}

Comments: RUN ON REFERENCE FUEL MAP.

Table 8-68 Summary of CP 0.05 Cert B20 B 10-ml DTBP Fuel for 2004 Cummins ISM 370

\begin{tabular}{|c|c|c|c|c|c|c|c|c|c|c|c|c|}
\hline \multicolumn{4}{|c|}{ Fuel: CP Cert B20 B 10-ml DTBP } & \multirow{2}{*}{$\begin{array}{l}\text { Work } \\
\text { bhp-hr }\end{array}$} & \multirow{2}{*}{$\begin{array}{c}\text { Fuel Cons } \\
\text { lb }\end{array}$} & \multirow{2}{*}{$\begin{array}{c}\text { bsFC } \\
\text { lb/bhp-hr }\end{array}$} & \multirow{2}{*}{$\begin{array}{l}\text { bsTHC } \\
\text { g/bhp-hr }\end{array}$} & \multirow{2}{*}{$\begin{array}{c}\text { bsCO } \\
\text { g/bhp-hr }\end{array}$} & \multirow{2}{*}{$\begin{array}{l}\text { bsCO2 } \\
\text { g/bhp-hr }\end{array}$} & \multirow{2}{*}{$\begin{array}{l}\text { bsNOx } \\
\text { g/bhp-hr }\end{array}$} & \multirow{2}{*}{$\begin{array}{l}\text { bsNOx2 } \\
\text { g/bhp-hr }\end{array}$} & \multirow{2}{*}{$\begin{array}{l}\text { bsTPM } \\
\text { g/bhp-hr }\end{array}$} \\
\hline Date & Time & Test No. & Start Type & & & & & & & & & \\
\hline $2 / 26 / 07$ & $8: 47$ & E01789-01 & Warm & 25.04 & 11.316 & 0.4518 & 0.1928 & 0.532 & 609.9 & 2.430 & 2.428 & 0.0453 \\
\hline $2 / 26 / 07$ & $9: 27$ & E01789-02 & Hot & 25.16 & 11.030 & 0.4384 & 0.1893 & 0.528 & 605.0 & 2.440 & 2.441 & 0.0533 \\
\hline $2 / 26 / 07$ & $10: 08$ & E01789-03 & Hot & 25.16 & 10.888 & 0.4327 & 0.1815 & 0.531 & 605.1 & 2.383 & 2.432 & 0.0574 \\
\hline $2 / 26 / 07$ & $10: 48$ & E01789-04 & Hot & 25.17 & 10.865 & 0.4316 & 0.1813 & 0.521 & 603.5 & 2.436 & 2.439 & 0.0584 \\
\hline \multirow{3}{*}{\multicolumn{4}{|c|}{$\begin{array}{r}\text { Hot Start Average } \\
\text { Hot Start Std Dev } \\
\text { COV (\%) }\end{array}$}} & 25.16 & 10.93 & 0.43 & 0.18 & 0.53 & 604.54 & 2.420 & 2.437 & 0.06 \\
\hline & & & & 0.01 & 0.09 & 0.00 & 0.00 & 0.01 & 0.86 & 0.03 & 0.00 & 0.00 \\
\hline & & & & 0.02 & 0.82 & 0.84 & 2.48 & 0.97 & 0.14 & 1.31 & 0.19 & 4.78 \\
\hline
\end{tabular}

Comments: Throttle 1, Run -03: Nox spanned -1.92\% full scale . RUN ON REFERENCE FUEL MAP. 
Table 8-69 Summary of CP 0.05 Cert Neat 2 Fuel for 2004 Cummins ISM 370

\begin{tabular}{|c|c|c|c|c|c|c|c|c|c|c|c|c|}
\hline \multicolumn{4}{|c|}{ Fuel: CP 0.05 Cert Neat 2} & \multirow{2}{*}{$\begin{array}{l}\text { Work } \\
\text { bhp-hr }\end{array}$} & \multirow{2}{*}{$\begin{array}{c}\text { Fuel Cons } \\
\mathrm{lb} \\
\end{array}$} & \multirow{2}{*}{$\begin{array}{c}\text { bsFC } \\
\text { lb/bhp-hr }\end{array}$} & \multirow{2}{*}{$\begin{array}{l}\text { bsTHC } \\
\text { g/bhp-hr }\end{array}$} & \multirow{2}{*}{$\begin{array}{c}\text { bsCO } \\
\text { g/bhp-hr }\end{array}$} & \multirow{2}{*}{$\begin{array}{c}\text { bsCO2 } \\
\text { g/bhp-hr }\end{array}$} & \multirow{2}{*}{$\begin{array}{l}\text { bsNOx } \\
\text { g/bhp-hr }\end{array}$} & \multirow{2}{*}{$\begin{array}{l}\text { bsNOx2 } \\
\text { g/bhp-hr }\end{array}$} & \multirow{2}{*}{$\begin{array}{l}\text { bsTPM } \\
\text { g/bhp-hr }\end{array}$} \\
\hline Date & Time & Test No. & Start Type & & & & & & & & & \\
\hline $2 / 26 / 07$ & $12: 42$ & E01791-01 & Warm & 25.61 & 10.905 & 0.4258 & 0.2197 & 0.565 & 599.6 & 2.379 & 2.368 & 0.0636 \\
\hline $2 / 26 / 07$ & $13: 21$ & E01791-02 & Hot & 25.61 & 10.746 & 0.4197 & 0.2078 & 0.591 & 602.3 & 2.372 & 2.356 & 0.0683 \\
\hline $2 / 26 / 07$ & $14: 02$ & E01791-03 & Hot & 25.58 & 10.859 & 0.4246 & 0.2069 & 0.599 & 604.5 & 2.364 & 2.343 & 0.0692 \\
\hline $2 / 26 / 07$ & $14: 42$ & E01791-04 & Hot & 25.62 & 10.796 & 0.4214 & 0.2039 & 0.586 & 603.9 & 2.362 & 2.346 & 0.0700 \\
\hline \multirow{3}{*}{\multicolumn{4}{|c|}{$\begin{array}{r}\text { Hot Start Average } \\
\text { Hot Start Std Dev } \\
\text { COV (\%) }\end{array}$}} & 25.60 & 10.80 & 0.42 & 0.21 & 0.59 & 603.56 & 2.366 & 2.348 & 0.07 \\
\hline & & & & 0.02 & 0.06 & 0.00 & 0.00 & 0.01 & 1.14 & 0.01 & 0.01 & 0.00 \\
\hline & & & & 0.08 & 0.52 & 0.59 & 0.99 & 1.11 & 0.19 & 0.22 & 0.29 & 1.23 \\
\hline
\end{tabular}

Comments: Throttle 1. RUN ON CP 0.05 CERT MAP.

Table 8-70 Summary of CP 0.05 Cert Neat 3 Fuel for 2004 Cummins ISM 370

\begin{tabular}{|c|c|c|c|c|c|c|c|c|c|c|c|c|}
\hline \multicolumn{4}{|c|}{ Fuel: CP 0.05 Cert Neat 3} & Work & Fuel Cons & bsFC & bsTHC & bsCO & bsCO2 & bsNOx & bsNOx2 & bsTPM \\
\hline Date & Time & Test No. & Start Type & bhp-hr & $\mathrm{lb}$ & lb/bhp-hr & g/bhp-hr & g/bhp-hr & g/bhp-hr & g/bhp-hr & g/bhp-hr & g/bhp-hr \\
\hline $2 / 26 / 07$ & $15: 22$ & E01792-01 & Hot & 25.20 & 10.583 & 0.4201 & 0.2060 & 0.604 & 604.6 & 2.386 & 2.377 & 0.0727 \\
\hline $2 / 26 / 07$ & $16: 03$ & E01792-02 & Hot & 24.90 & 10.565 & 0.4242 & 0.2143 & 0.613 & 604.4 & 2.363 & 2.341 & 0.0734 \\
\hline $2 / 26 / 07$ & $16: 43$ & E01792-03 & Hot & 25.20 & 10.682 & 0.4238 & 0.2122 & 0.609 & 606.0 & 2.384 & 2.369 & 0.0735 \\
\hline
\end{tabular}

\begin{tabular}{|c|c|c|c|c|c|c|c|c|c|}
\hline Hot Start Average & 25.10 & 10.61 & 0.42 & 0.21 & 0.61 & 605.02 & 2.378 & 2.362 & 0.07 \\
\hline Hot Start Std Dev & 0.17 & 0.06 & 0.00 & 0.00 & 0.00 & 0.84 & 0.01 & 0.02 & 0.00 \\
\hline $\operatorname{COV}(\%)$ & 0.69 & 0.59 & 0.53 & 2.05 & 0.74 & 0.14 & 0.54 & 0.80 & 0.61 \\
\hline
\end{tabular}

Comments: Throttle 1. RUN ON REFERENCE FUEL MAP. 


\section{Table 8-71 Summary of Grad REF Neat 2 Fuel for 2004 Cummins ISM 370}

\begin{tabular}{|c|c|c|c|c|c|c|c|c|c|c|c|c|}
\hline \multicolumn{4}{|c|}{ Fuel: Grad REF Neat 2} & \multirow{2}{*}{$\begin{array}{l}\text { Work } \\
\text { bhp-hr }\end{array}$} & \multirow{2}{*}{$\begin{array}{c}\text { Fuel Cons } \\
\mathrm{lb}\end{array}$} & \multirow{2}{*}{$\begin{array}{l}\text { bsFC } \\
\text { lb/bhp-hr }\end{array}$} & \multirow{2}{*}{$\begin{array}{l}\text { bsTHC } \\
\text { g/bhp-hr }\end{array}$} & \multirow{2}{*}{$\begin{array}{l}\text { bsCO } \\
\text { g/bhp-hr }\end{array}$} & \multirow{2}{*}{$\begin{array}{l}\mathrm{bsCO} 2 \\
\text { g/bhp-hr }\end{array}$} & \multirow{2}{*}{$\begin{array}{l}\text { bsNOx } \\
\text { g/bhp-hr }\end{array}$} & \multirow{2}{*}{$\begin{array}{l}\text { bsNOx2 } \\
\text { g/bhp-hr }\end{array}$} & \multirow{2}{*}{$\begin{array}{l}\text { bsTPM } \\
\text { g/bhp-hr }\end{array}$} \\
\hline Date & Time & Test No. & Start Type & & & & & & & & & \\
\hline $2 / 28 / 07$ & $7: 31$ & E01799-01 & Warm & 25.25 & 10.389 & 0.4115 & 0.1858 & 0.588 & 598.6 & 2.221 & 2.209 & 0.0582 \\
\hline $2 / 28 / 07$ & $8: 11$ & E01799-02 & Hot & 25.25 & 10.588 & 0.4194 & 0.1892 & 0.575 & 592.0 & 2.186 & 2.172 & 0.0522 \\
\hline $2 / 28 / 07$ & $8: 52$ & E01799-03 & Hot & 25.24 & 10.546 & 0.4178 & 0.1907 & 0.562 & 590.0 & 2.182 & 2.153 & 0.0560 \\
\hline 2/28/07 & 9:32 & E01799-04 & Hot & 25.24 & 10.600 & 0.4200 & 0.1948 & 0.568 & 590.5 & 2.182 & 2.164 & 0.0549 \\
\hline \multicolumn{4}{|c|}{ Hot Start Average } & 25.24 & 10.578 & 0.4191 & 0.1916 & 0.568 & 590.8 & 2.183 & 2.163 & 0.0544 \\
\hline \multirow{2}{*}{\multicolumn{4}{|c|}{$\begin{array}{r}\text { Hot Start Std Dev } \\
\text { COV (\%) }\end{array}$}} & 0.01 & 0.028 & 0.0011 & 0.0029 & 0.007 & 1.1 & 0.002 & 0.010 & 0.0020 \\
\hline & & & & 0.02 & 0.27 & 0.27 & 1.51 & 1.14 & 0.18 & 0.11 & 0.44 & 3.62 \\
\hline
\end{tabular}

Comments: Throttle 1, with EGR. 


\subsection{Summary of Multiple SET Test Emissions Data for 1992 DDC S60}

Table 8-72 Summary of Multiple SET Test Data for 1992 Rebuilt DDC S60

\begin{tabular}{|c|c|c|c|c|c|c|c|c|c|c|c|c|c|c|c|c|c|c|}
\hline & \multicolumn{6}{|c|}{ Grad REF } & \multicolumn{12}{|c|}{ Grad CAND } \\
\hline & 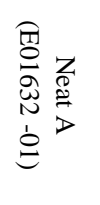 & 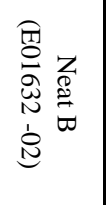 & 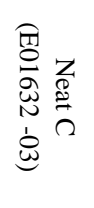 & 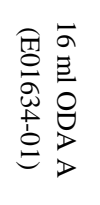 & 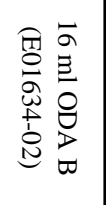 & 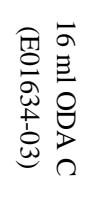 & 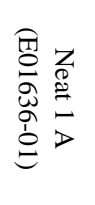 & 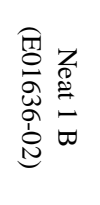 & 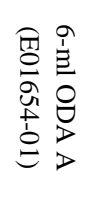 & 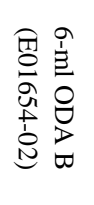 & 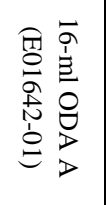 & 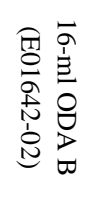 & 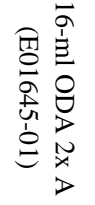 & 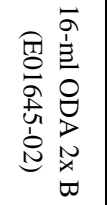 & 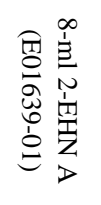 & 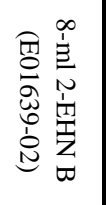 & 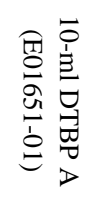 & 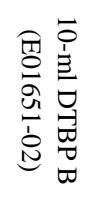 \\
\hline THC (g/bhp-hr) & 0.0409 & 0.0389 & 0.0371 & 0.0361 & 0.0363 & 0.0367 & 0.0403 & 0.0380 & 0.0343 & 0.0304 & 0.0346 & 0.0336 & 0.0343 & 0.0338 & 0.0350 & 0.0350 & 0.0324 & 0.0321 \\
\hline CO (g/bhp-hr) & 2.728 & 2.783 & 2.726 & 2.632 & 2.710 & 2.721 & 2.763 & 2.797 & 2.489 & 2.487 & 2.464 & 2.462 & 2.470 & 2.448 & 2.547 & 2.572 & 2.558 & 2.505 \\
\hline CO2 (g/bhp-hr) & 446.1 & 446.8 & 438.7 & 446.9 & 445.5 & 446.4 & 450.1 & 451.6 & 454.3 & 431.3 & 446.4 & 444.2 & 451.2 & 450.4 & 449.7 & 449.6 & 451.0 & 452.8 \\
\hline NOx (g/bhp-hr) & 7.265 & 7.246 & 7.308 & 7.280 & 7.304 & 7.278 & 7.662 & 7.671 & 7.659 & 7.237 & 7.679 & 7.656 & 7.710 & 7.701 & 7.644 & 7.649 & 7.664 & 7.610 \\
\hline NO2 (g/bhp-hr) & 0.1829 & 0.2021 & 0.2059 & 0.1776 & 0.1947 & 0.2026 & 0.1904 & 0.2057 & 0.1973 & 0.1870 & 0.1889 & 0.1939 & 0.1837 & 0.1981 & 0.1960 & 0.2016 & 0.1909 & 0.2043 \\
\hline TPM (g/bhp-hr) & 0.1990 & 0.1926 & 0.1909 & 0.1769 & 0.1788 & 0.1857 & 0.1997 & 0.1886 & 0.1792 & 0.1852 & 0.1743 & 0.1776 & 0.1737 & 0.1817 & 0.1753 & 0.1754 & 0.1781 & 0.1999 \\
\hline BSFC (g/bhp-hr) & 146.0 & 147.7 & 147.5 & 144.8 & 147.4 & 148.4 & 148.8 & 152.3 & 147.6 & 151.5 & 147.1 & 150.4 & 147.0 & 150.2 & 147.4 & 145.7 & 147.5 & 150.9 \\
\hline Power (bhp) & 195.0 & 195.2 & 195.0 & 195.1 & 195.0 & 194.8 & 194.8 & 194.8 & 195.0 & 195.1 & 195.0 & 195.2 & 195.1 & 195.1 & 195.0 & 194.8 & 194.9 & 194.9 \\
\hline Work (bhp-hr) & 1.624 & 1.626 & 1.626 & 1.625 & 1.625 & 1.625 & 1.624 & 1.624 & 1.626 & 1.626 & 1.626 & 1.625 & 1.625 & 1.626 & 1.625 & 1.625 & 1.626 & 1.625 \\
\hline
\end{tabular}

Note - The multiple test weighted emissions values in this table were averaged to find the values in Table 5-7. 